\title{
WestVirginiaUniversity
}

THE RESEARCH REPOSITORY @ WVU

Graduate Theses, Dissertations, and Problem Reports

2003

\section{Modeling of product variability in fluidized bed coating equipment}

\author{
Ku Zilati Ku Shaari \\ West Virginia University
}

Follow this and additional works at: https://researchrepository.wvu.edu/etd

\section{Recommended Citation}

Ku Shaari, Ku Zilati, "Modeling of product variability in fluidized bed coating equipment" (2003). Graduate Theses, Dissertations, and Problem Reports. 1892.

https://researchrepository.wvu.edu/etd/1892

This Thesis is protected by copyright and/or related rights. It has been brought to you by the The Research Repository @WVU with permission from the rights-holder(s). You are free to use this Thesis in any way that is permitted by the copyright and related rights legislation that applies to your use. For other uses you must obtain permission from the rights-holder(s) directly, unless additional rights are indicated by a Creative Commons license in the record and/ or on the work itself. This Thesis has been accepted for inclusion in WVU Graduate Theses, Dissertations, and Problem Reports collection by an authorized administrator of The Research Repository @ WVU. For more information, please contact researchrepository@mail.wvu.edu. 


\title{
Modeling of Product Variability in Fluidized Bed Coating Equipment
}

\author{
Ku Zilati Ku Shaari \\ Thesis Submitted to the \\ College of Engineering and Mineral Resources \\ at West Virginia University \\ in partial fulfillment of the requirements \\ for the degree of \\ Master of Science \\ in \\ Chemical Engineering \\ Richard Turton, Ph.D., Chair \\ Eugene V. Cilento, Ph.D. \\ Charter D. Stinespring, Ph.D. \\ Department of Chemical Engineering \\ Morgantown, West Virginia \\ 2003
}

Keywords: Monte Carlo Simulation, Wurster Fluidized Bed, Fluidization, Particle Coating, Coating Variation. 


\section{ABSTRACT \\ Modeling of Product Variability in Fluidized Bed Coating Equipment}

\section{Ku Zilati Ku Shaari}

Particle coating in fluidized bed equipment is common practice for improving the properties of solid products, particularly in the pharmaceutical, food and agricultural industries. In this thesis, the application of particle coating to pharmaceutical products utilizing the Wurster-column coating process is addressed. This technique is extensively used in the pharmaceutical industry for precision drug coating and modified release coating of tablets and pellets.

The simulation of particle movement in fluidized beds has been successfully developed using Monte Carlo simulation. Raw velocity and voidage data for each region of a semicircular fluidized bed, obtained by Subramanian (2001), are used in the simulation. The average velocities in the $\mathrm{x}$ - and $\mathrm{y}$-directions, the average voidage, and the standard deviations of the velocities in each region were calculated and used as input data for the model. Random numbers generated from a unit normal distribution were used to determine the starting position of the particle as well as the movement of the particles within the bed. The simulation results show that the pattern of particle movement is similar to the velocity profile of the original data and voidage profile agrees with the original data.

A simple experiment in an empty (without particles) fluidizing bed shows that the spray material moves vertically through the draft tube and out of the top of the bed. In addition, the spray material was found to vary radially from the spray nozzle and form a non-symmetric spray distribution. The simulation results, which are verified with pulse test experiments, show that the spray distribution and the spray shape at the bottom of the bed varied with different bed conditions, particularly with and without the presence of a particle deflector. Comparison of simulated results with pulse test experiments showed that the distribution of spray material and shape of the spray play important roles in the prediction of the mass coating distributions per-tablet-per-pass through the spray zone. 


\section{ACKNOWLEDGEMENTS}

I would like to express my deep gratitude to my supervisor Dr. Richard Turton whose help, stimulating suggestions and encouragement helped me through this research. His valuable instruction, dynamic thinking, and broad and profound knowledge were a great help in my accomplishment.

My sincere thanks to my advisory committee members, Dr Eugene V. Cilento and Dr. Charter Stinespring for their helpful comments and suggestions

My special thanks goes to my parents KuShaari and Badariah and my mother inlaw for their unconditional love, encouragement and spiritual support. And I wish to thank to the Malaysian Government for sponsoring my master study at WVU.

Finally I would like to dedicate this thesis to my beloved husband Mokhtar and our kids Amanda and Faris whose enduring love and encouragement enabled me to complete this work. This work would never have been possible without their patience. 


\section{TABLES OF CONTENTS}

ABSTRACTS

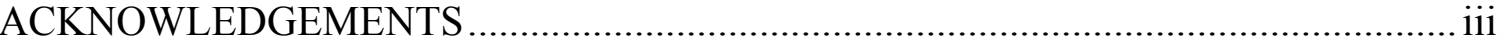

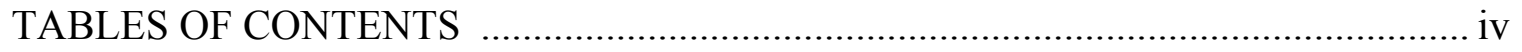

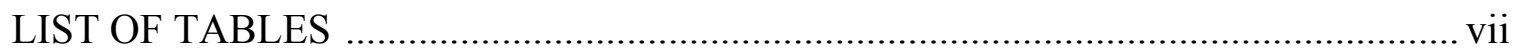

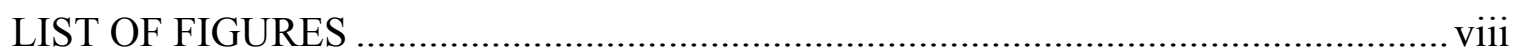

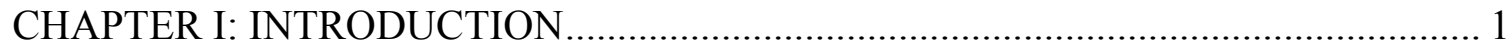

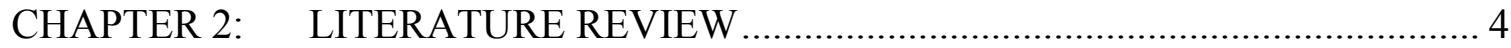

2.1 Background on Particle Coating In the Pharmaceutical Industry ...................... 4

2.2 Particle behavior in Fluidized Bed Coating Equipment .................................. 5

2.3 Study of Particle Coating in Fluidized Bed Equipment.................................... 9

2.4 Prediction and Model of Particle Coating Processes ..................................... 14

CHAPTER 3: $\quad$ EXPERIMENTAL PROCEDURES …................................................ 20

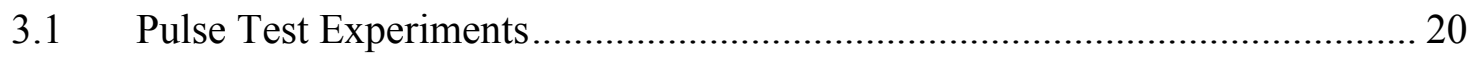

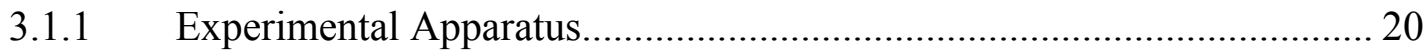

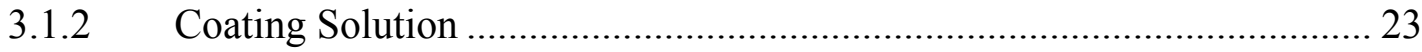

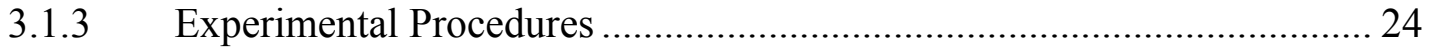

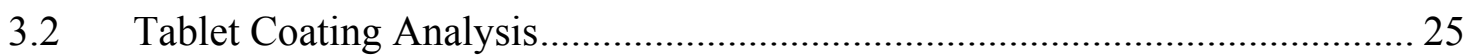

CHAPTER 4: MODEL DEVELOPMENT AND CALCULATION METHODS ...... 26

4.1 Starting Location for Tablet Movement …................................................... 30 


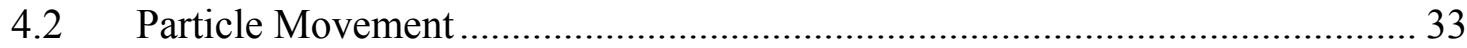

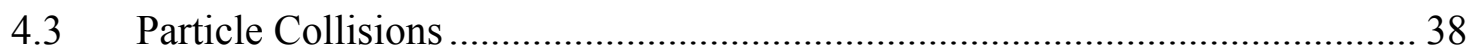

4.4 Modeling the Spray and Coating of Particles ............................................. 40

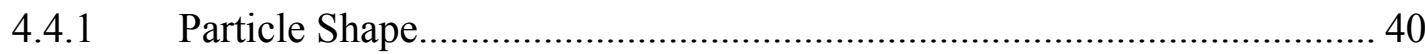

4.4.2 Spray Shape and Evaluation of Coating Coverage ............................... 42

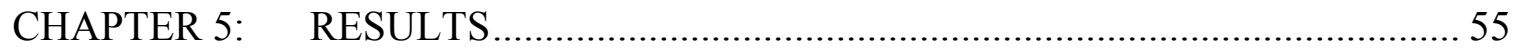

5.1 Experimental Results From Pulse Tests ................................................... 55

5.1.1 Results for Experiments without a Particle Deflector (No-Deflector

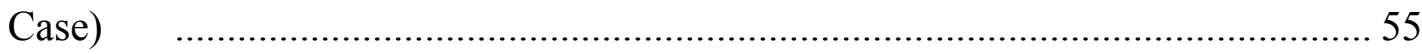

5.1.2 Results for Experiments with the "Optimized" Particle Deflector

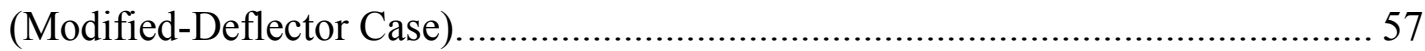

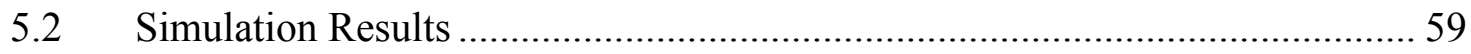

5.2.1 Validation the of Particle Movement Model ......................................... 59

5.2.2 Validation of Particle Coating Model with Uniform Velocity and

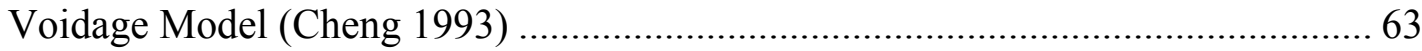

5.2.3 Validation of Particle Coating Model with Experimental Data................ 70

5.2.4 The Effect of Spray Shape and Discretization Method on the Predicted

Coating Distribution

5.2.5 The Effect of Spray Shape on the Coating Uniformity Predicted by the

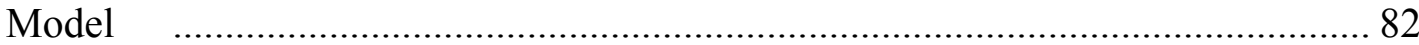

5.2.6 The Effect of Spray Distribution to the Coating Uniformity Predicted by the Model

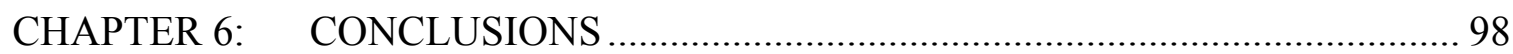

CHAPTER 7: $\quad$ RECOMMENDATIONS FOR FUTURE WORK ............................. 102 
Appendix I: $\quad$ Calculation of Particle Circulation Time......................................... 110

Appendix II: $\quad$ Scanning Spectra of Blue Dye \#1 and Red Dye \#3 in Water............. 112

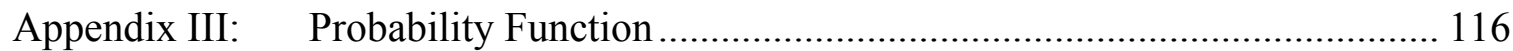

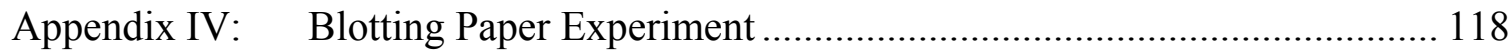

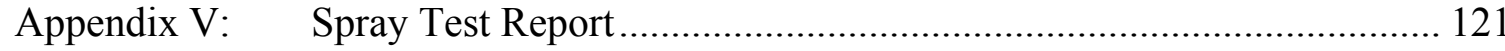

Appendix VI: $\quad$ Subramanian's Experimental Data................................................... 124

Appendix VII: Sample Calculation for the Uniform Voidage/Velocity Data ............ 125

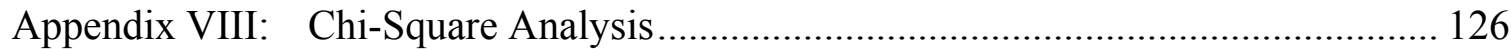

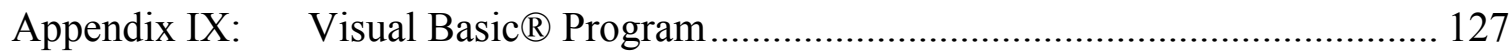




\section{LIST OF TABLES}

Table 3.1: $\quad$ Physical properties of tablets used in the experiment............................. 23

Table 3.2: Formulations for the solutions used in the pulse test experiment............. 24

Table 5.1: $\quad$ Summary of No-Deflector pulse test experimental results...................... 56

Table 5.2: $\quad$ Summary of Modified-Deflector pulse test experimental results............. 58

Table 5.3: List of equations used in Coating Model and Cheng's model................... 66

Table A-1.1: Measurement of time taken for the particle to move $20 \mathrm{~cm}$ distance from the top to the bottom of the bed in the annulus region................................. 110

Table A-2.1: Data for calibration of the spectrophotometer for Blue Dye \#1............ 114

Table A-2.2: Data for calibration of the spectrophotometer for Red Dye \#3. ............. 115

Table A-3.1: Probability function of the volumetric flow rate for No-Deflector.......... 116

Table A-3.2: Probability function of the volumetric flow rate for Modified-Deflector116

Table A-6.1: Experimental matrix for the velocity and voidage profile study

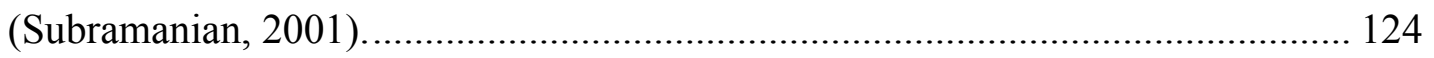

Table A-8.1: Chi-square analysis between experimental pulse test data and simulation results for No-Deflector case using Case I spray distribution. 126 


\section{LIST OF FIGURES}

Figure 1.1: Schematic diagram of a semi-circular fluidized bed coating equipment. Solid arrows indicate the direction of particle movement. 2

Figure 2.1: Wurster fluidized bed coater illustrates the gap height and deflector (Subramanian, 2001) 6

Figure 2.2: Comparison of the radial voidage profiles with Spray (S) and Without Spray (WS) in the draft tube at different axial locations, z (Gap Height, $\mathrm{Hg}=10$ mm) (Saadevandi, 1996). 11

Figure 2.3: Comparison of the radial voidage profiles with Spray (S) and Without Spray (WS) in the draft tube at different axial locations, z (Gap Height, $\mathrm{Hg}=5 \mathrm{~mm}$ ) (Saadevandi, 1996). 12

Figure 2.4: Details of the tumbling fluidized bed coating chamber (Abe, 1998)....... 16

Figure 2.5: $\quad$ Schematic diagram of a spray model (Cheng, 1993). 19

Figure 3. 1: Schematic diagram of the draft tube region of the semi-circular column of fluidized bed illustrated in Figure 1.1. 21

Figure 3. 2: Schematic diagram shows a fluidized bed with no particle deflector and with modified deflector.

Figure 4.1: A photograph of the front view of semi-circular fluidized bed spouted region (Subramanian, 2001).

Figure 4.2: A schematic diagram of front view of semi-circular fluidized bed spouted region.

Figure 4.3: A schematic diagram of the top view of semicircular fluidized bed 29 
Figure 4.4: A sample of a cumulative probability function used to determine the starting point of a particle for the simulation. 32

Figure 4.5: (a) $R N$, random numbers of unit normal distribution calculated from Equation (4.12). (b) $R N D$, uniform distribution of computer generated random numbers. 36

Figure 4.6: Graph shows the cumulative distribution of 10,000 data points generated from random numbers $R N$ (using Equation 4.12).

Figure 4.7: A comparison between the unit normal variable (z-value) generated from Equation (4.12) and the true unit normal distribution, $\mathrm{N}(0,1)$. 37

Figure 4.8: Image of tablets in fluidized bed - spouted region, (Subramanian, 2000). Arrows show possible directions of particle movement. 38

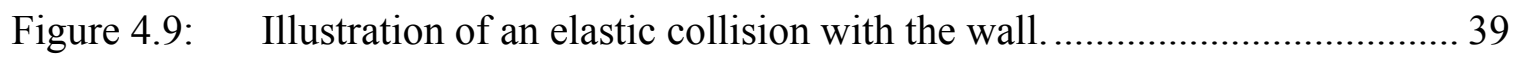

Figure 4.10: The shape of pharmaceutical tablet used in the experiment (Subramanian, 2000). 41

Figure 4.11: Figure illustrates the minimum (A) and maximum (B) surface areas that tablets expose to the spray. 41

Figure 4.12: A schematic diagram illustrates a solid cone spray zone. 43

Figure 4.13: A schematic diagram illustrates the discretization of a particle's projected surface area assuming a solid cone spray shape. 44

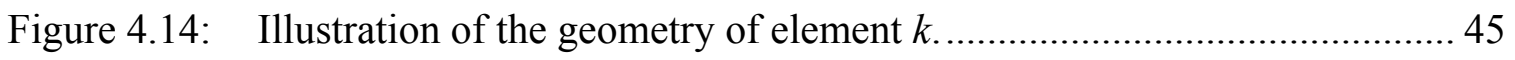

Figure 4.15: A schematic diagram of a spherical cap in the spray zone 47

Figure 4.16: A schematic diagram shows the effect of particle position in the spray zone on the fraction of spray material received by the particle. 48 
Figure 4.17: A schematic diagram illustrates the flow direction of spray material when running in a fluidized bed (with fluidizing air) without the particles. Arrows show the flow direction of the spray material along the draft tube. 50

Figure 4.18: A schematic diagram of the shape of a uniform, upward moving spray. . 50

Figure 4.19: A schematic diagram illustrates the discretization of the particle projected surface area with the uniform, upward spray shape assumption. 51

Figure 4.20: A schematic diagram illustrates a cylindrical volume of element, $k$........ 52

Figure 4.21: A schematic diagram illustrates a spray distribution as a function of radial position in the spouted region. The details of this spray distribution are given in Section 5.2.6. 54

Figure 5.1: The results of the pulse test experiments for No-Deflector case. 57

Figure 5.2: The results of the pulse test experiments for the Modified-Deflector case. . 58

Figure 5.3: Simulation of particle movement using experiment Run 2 data 60

Figure 5.4: Voidage map in the draft-tube at different axial locations for experiment Run 2 (Subramanian, 2001). 61

Figure 5.5: Particle velocity map in the draft-tube at different axial locations, for experiment Run 2 (Subramanian, 2001). 62

Figure 5.6: Illustration of the assumptions used Cheng's Model................................ 64

Figure 5.7: A schematic diagram illustrates the technique of discretizing the projected surface area in Cheng's Model. 64

Figure 5.8: A schematic diagram illustrates the technique for discretizing the projected surface area in the coating model used to compare Cheng's Model 65 
Figure 5.9: Effect of voidage on coefficient of variation of coating per particle for Cheng's Model and the coating model from this work.

Figure 5.10: The effect of insert (draft tube) diameter and particle size on the coefficient of variation of coating per particle. 68

Figure 5.11: The effect of number of discretized sections on the predicted value from simulation.

Figure 5.12: Sample output of the simulation using uniform velocity (only in the ydirection) and voidage. Input data taken from experimental Run 6. 71

Figure 5.13: Sample output of the simulation using uniform velocity (only in the ydirection) and voidage. Input data taken from experiment Run 8 .

Figure 5.14: Sample output of simulation using uniform velocity (only in the ydirection) and experimental voidage data from experimental Run 6. 73

Figure 5.15: Sample output of simulation using uniform velocity (only in the ydirection) and experimental voidage data from experimental Run 8. 74

Figure 5.16: Sample output of the simulation with all input data taken from experimental Run 6. The profile of the velocity used in this simulation is shown in Figure 5.18 75

Figure 5.17: Sample output of the simulation with all input data taken from experimental Run 8. The profile of the velocity used in this simulation is shown in Figure 5.19 76

Figure 5.18: Particle velocity map in the draft-tube at different axial location for experiment Run 6 (Subramanian, 2001). 
Figure 5.19: Particle velocity map in the draft-tube at different axial location for

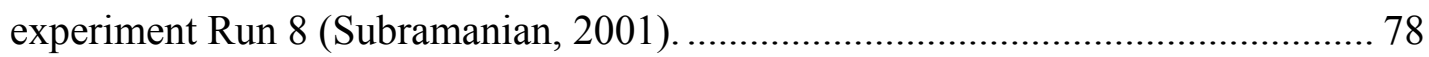

Figure 5.20: The relationship between the particle starting points and the distance from the spray nozzle for No-Deflector case. 80

Figure 5.21: Coating distribution for No-Deflector case (discretized with respect to the spray nozzle) compared with experimental pulse test distribution 80

Figure 5.22: Direction of spray used in subsequent coating simulations. 81

Figure 5.23: Illustration of the solid cone spray shape used in the model 83

Figure 5.24: Illustration of the rectangular spray shape used in the model..... 83

Figure 5.25: Coating distribution for No-Deflector case simulated with uniform input data, uniform spray density, but different spray shapes compared with experimental results. 84

Figure 5.26: The output of simulation for the No-Deflector case simulated with uniform input data and solid cone and rectangular spray shapes. 85

Figure 5.27: Rectangular spray shape without a top boundary having vertical direction of spray material. 86

Figure 5.28: Overall spray distribution for 30 psi atomizing air. The darker bars indicate the region in the draft tube. 88

Figure 5.29: Coating distribution for No-Deflector case simulated using overall spray distribution compared with the experimental pulse test distribution. 89

Figure 5.30: Coating distribution for Modified-Deflector case simulated using overall spray distribution compared with the experimental pulse test distribution

Figure 5.31: Spray distribution of Case I for 30 psi atomizing air 90 
Figure 5.32: Coating distribution for No-Deflector case simulated using Case I spray distribution compared with the experimental pulse test distribution. 91

Figure 5.33: Coating distribution for Modified-Deflector case simulated using Case I spray distribution compared with the experimental pulse test distribution. 92

Figure 5.34: Spray distribution of Case II for 30 psi atomizing air. 93

Figure 5.35: Coating distribution for No-Deflector case simulated using Case II spray distribution compared with the experimental pulse test distribution.

Figure 5.36: Coating distribution for Modified-Deflector case simulated using Case II spray distribution compared with the experimental pulse test distribution. 95

Figure 5.37: The rectangular spray shape having 45 degree angle at the bottom of the spray zone. 95

Figure 5.38: Coating distribution for Modified-Deflector case simulated using Case II spray distribution having $45^{\circ}$ angle at the bottom of the spray zone, compared with the experimental pulse test distribution. 96

Figure 5.39: Coating distribution for No-Deflector case simulated using Case II spray distribution having $45^{\circ}$ angle at the bottom of the spray zone. 97

Figure A-2.1: Spectra of Blue Dye \#1 in water.

Figure A-2.2: Spectra of Red Dye \#3 in water. 113

Figure A-2.3: Calibration curve for spectrophotometer of Blue Dye \#1

Figure A-2.4: Calibration curve for spectrophotometer of Red Dye \#3. 115

Figure A-3.1: Probability function of No-Deflector case. 117

Figure A-3.2: Probability function of Modified-Deflector case.

Figure A-4.1: Schematic diagram shows blotting paper on the draft tube wall. 118 
Figure A-4.2: Schematic diagram illustrates the trace of spray material on the blotting paper . 120

Figure A-4.3: The arrows indicate the flow direction of the spray material in the vacinity of the spray zone during the bed was fluidized............................................... 120

Figure A-5.1: The spray distribution for 30 psi atomizing air pressure...................... 122

Figure A-5.2: The spray distribution for 40 psi atomizing air pressure.. ................... 123

Figure A-5.3: The spray distribution for 50 psi atomizing air pressure..................... 123 


\section{CHAPTER I： INTRODUCTION}

The fluidized bed technique, originally developed as a method for contacting coarse particles with gas, consists of a jet of gas forced vertically upwards through the bed of solid particles. As the gas travels through the particle bed, it imparts unique properties to the bed. For example, the bed behaves in many ways like a liquid. As gas flow increases, the solids remain fluidized and the mixing within the bed becomes more vigorous. At some gas velocity, the solids become entrained and a net upward movements of the bed solids, occurs.

Figure 1.1 illustrates a typical fluidized bed coating apparatus. The operation of the bed starts with injecting a gas at the required flow rate through the gas plenum at the bottom of the bed. This gas passes through the distributor plate before entering the bottom of the bed, which is filled with solid particles. As mentioned earlier, the jet of gas causes the particles to move up until they reach the expanded section at the top of the bed (fountain region). At this point the particles decelerate and fall back into the annular region.

Once steady state is achieved, the coating solution together with atomizing air is injected through the spray nozzle, which creates a spray zone within the bed. As the particles pass through the spray zone, they receive coating material. The amount of coating material received by a single particle in a given time is a function of the amount of coating received per-pass and the number of passes through the spray nozzle (Mann and Cosby, 1973).

Particle coating in fluidized bed equipment is common practice for improving the properties of material, particularly in the pharmaceutical, food and agricultural industries. 


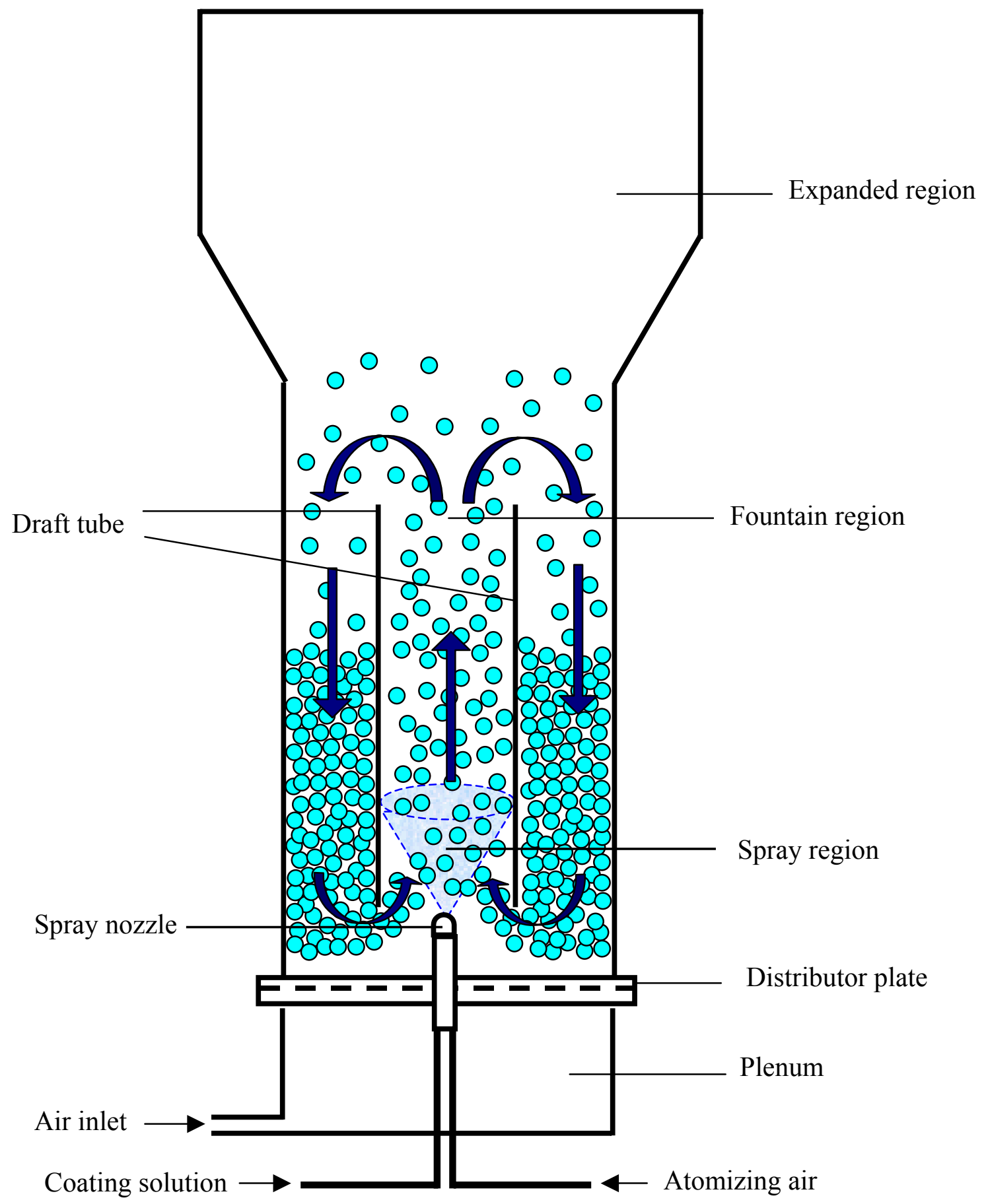

Figure 1.1: Schematic diagram of a semi-circular fluidized bed coating equipment, solid arrows indicate the direction of particle movement. 
Many techniques have been developed by researchers to achieve high quality coating. In the Pharmaceutical Industry, batch fluidized bed processing has been used for the past 30 years (Britannica, 2001). The technology was originally developed specifically for rapid drying. Since then, fluidized bed processing has become routine for other applications, such as agglomeration, granulation, drying of solutions and suspensions on to inert bed particles, air-suspension coating, rotary pelletization and solution layering, and other mechanical functions such as solids blending, comminution, and aerosol collection from a gas stream (Britannica, 2001).

In this study, the application of particle coating on pharmaceutical products utilizing the Wurster-column coating process is investigated. This coating technique is extensively used in the Pharmaceutical Industry for precision drug coating and modified release coating of tablets and pellets. In such applications, the reduction or minimization of the variation of coating level between individual particles is very important. Based on the experimental data obtained for velocity and voidage in the draft tube region of a semicircular fluidized bed coater, a simulation model is developed to describe the particle coating behavior of Wurster fluidized bed coating equipment. The experimental results are used to validate the results of simulations and key parameters affecting the distribution of coating mass on individual particle is investigated in this work. 


\section{CHAPTER 2: LITERATURE REVIEW}

\subsection{Background on Particle Coating In the Pharmaceutical Industry}

The particle coating process in the Pharmaceutical Industry has been practiced over many decades and is perhaps one of the oldest pharmaceutical processes still in existence (Porter, 1985). The purpose of coating particles is not solely to mask unpleasant taste or smell, but developments in pharmaceutical technology have demonstrated several other purposes such as controlling the release of the drug from the tablet, facilitating handling and production, and improving tablet appearance and protecting the drug from its surrounding environment to improve its stability (Britannica, 2001).

It has been reported that the earliest attempt to coat tablets required the handling of a single tablet (Porter, 1985). Such pills were mounted on tiny forceps before they were dipped in a coating solution several times until the desired coating was achieved. Surprisingly, this technique did not give uniform results. Even in the 1950's, several patents for applying tablet coating by dipping methods were introduced (Singiser et al, 1966). However, this technique was not being extensively used and publicized. In 1856 , the first sugar-coated pills were introduced by Warner, a Philadelphia pharmacist (Porter, 1985). Using the same technique as in the candy industry, pharmaceutical pan-coating processes were then developed. Due to several problems encountered in sugar coating processes, such as poor mixing characteristics and poor drying efficiency, a film coating technique was developed to overcome these problems. However, the disadvantage of the film coating technique was the use of a solvent system that always employed flammable 
and toxic materials. This then led to the development of fluidized bed coating equipment, which can be used for both solvent- and aqueous-based coating formulations.

The first fluidized bed coating equipment was based on a Wurster (U.S. Patent, $2,648,609)$ fluidized bed with a single spray gun located at the center and bottom of the bed (Figure 1.1). The particles to be coated are fluidized by air entering the bed through the distributor plate at a given flow rate, which is sufficient to make the particles move up the central column. At the point where the air velocity decreases, known as the fountain region, the particles drop back to the bottom of the bed through the packed bed annular region. These particles will receive coating material every time they pass through the spouted region. However, the amount of coating material received by each particle depends on several factors, which will be explained later.

\subsection{Particle behavior in Fluidized Bed Coating Equipment}

The Wurster fluidized bed coater consists of a concentric cylindrical partition known as a draft tube, inserted in a cylindrical column at a certain height (gap) from the bottom of the bed (Figure 2.1). Subramanian (2001) found that the variation in gap height has a significant effect on the particle velocity and the voidage of the bed. The bottom of the bed is supported by a distributor plate, which allows gas to pass through it. The air velocity passing through the draft tube, which is known as the spouted region, is known to be higher than the air velocity passing through annulus region (Shelukar et al, 2000). The particles that move with the air in the spouted region will receive coating from a spray nozzle located at the center, and bottom of the bed. In the presence of the moving air, the coated particles will dry as they move up to the fountain region. As the 
air moves out of the draft tube, its velocity is reduced which in turn causes the particles to fall back into the bed through the annulus region. By means of a pneumatic effect caused by the moving air, the particles in the annular region will be dragged into the spouted region again. This process continues repeatedly until the desired amount of coating material is deposited on the particles. Due to the excellent heat and mass transfer occurring in fluidized beds, uniform layers of coating are formed in relatively short processing times (Kucharski and Kmiec, 1983).

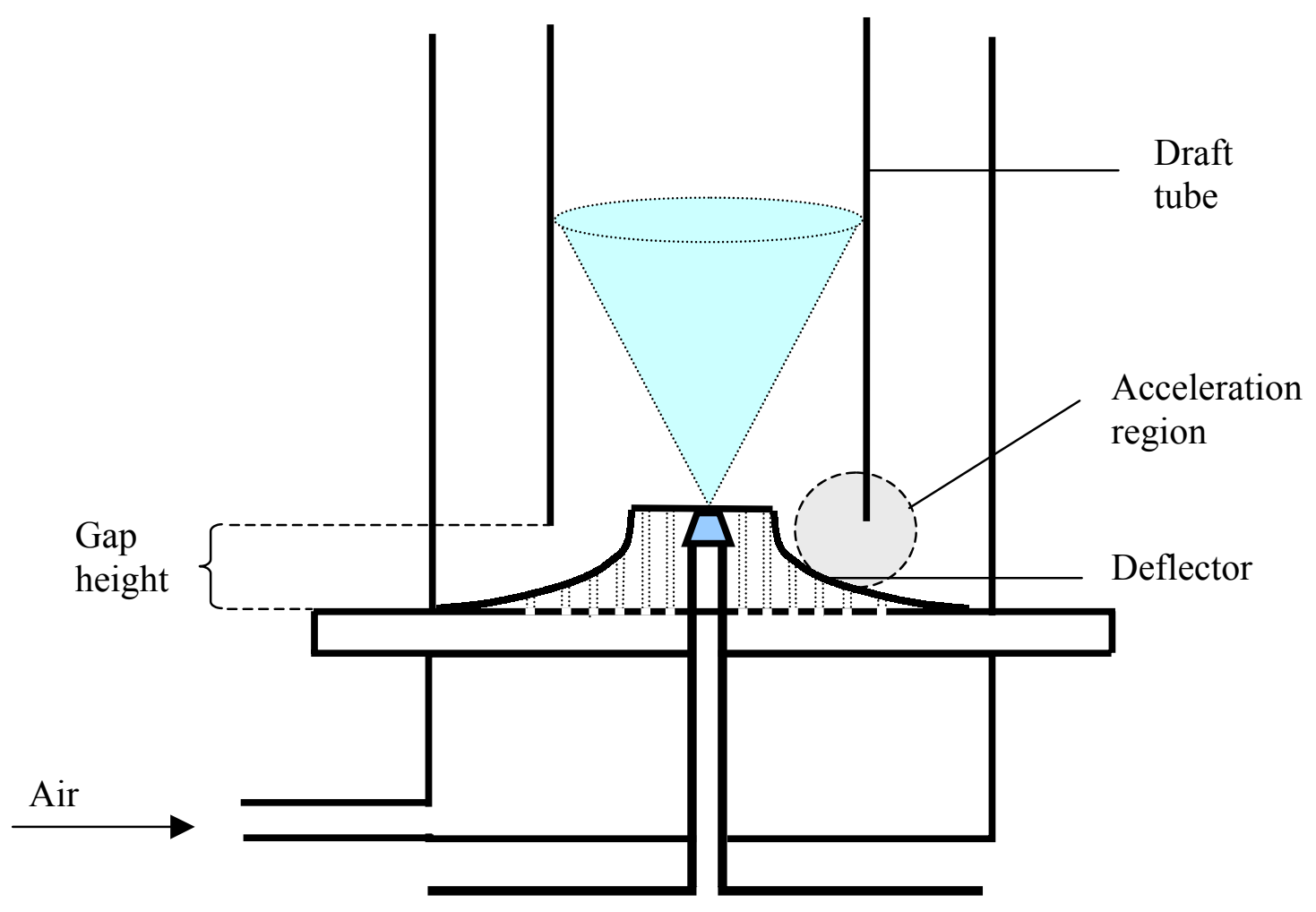

Figure 2.1: Wurster fluidized bed coater illustrates the gap height and deflector (Subramanian, 2001). 
In order to explain the particle coating behavior in a fluidized bed, it is important to understand the hydrodynamics of the particle movement through the bed. To do this, different techniques and equipment have been utilized. These include photography and video imaging techniques (Subramanian, 2001), high-speed photography (Toomey and Johnson, 1953), cinematic motion pictures (Massilla and Westwater, 1959), radioactive tracking techniques (Van Velzen et al, 1974), magnetic tracers (Cheng and Turton, 1994, and Mann et al, 1973), data processing technique for noisy signal (Xu, 1997), and fiber optic equipment (He, 1994a and He 1994b).

Mann and Crosby (1973) studied the effect of the number of cycles distribution in fluidized bed coating equipment using a magnetic tracer technique. They found that as the operating time becomes large, the number of cycles distribution (NCD) becomes normally distributed with the mean and variance only functions of the mean and variance of the cycle time distribution (CTD).

Van Velzen et al. (1974) found that the average particle velocity in a fluidized bed is a function of gas flow rate, gas inlet geometry, axial elevation, bed height, and column diameter. Their results also showed that the solid circulation rate is proportional to the gas flow rate, and a function of column and gas inlet geometry, density of the fluidizing gas, and particle diameter.

In 1969, Lefroy and Davidson found that a half cylinder spouted bed behaves similarly to a cylindrical bed with the same operating parameters and equipment dimensions. Their study also gave an approximate picture of the behavior of a spouted bed at maximum spouted bed depth. 
He et al (1994a) considered three regions (spouted, fountain and annulus -similar to Figure 1.1) of the spouted bed to study the voidage and velocity profiles in both semicircular and circular spouted beds. They observed that the velocity profile in both types of beds were similar, even though the local velocity in the semi-circular bed was thirty percent lower than in the circular bed. In both cases, the voidage in the fountain region varied widely and in the annulus region, the voidage was slightly lower than in a loosely packed bed. The fact that the velocities and voidage profiles of a half cylindrical and a cylindrical fluidized bed behaved similarly was also supported by Saadevandi (1996) in his experiments.

Cheng (1993) found that moving the position of the spray nozzle up into the draft tube region improves the coating uniformity. This is because the spray zone is not in the particle acceleration region (Figure 2.1), which is defined as the area where particles are dragged from the annulus region to the spouted region. She also studied the effect of the gap height and air velocity on the particle circulation rate. The results showed the spacing between the distributor plate and draft tube and the draft tube diameter were the major factors controlling the circulation rate. Xu (1994) also conducted similar studies and concluded that the vertical gap between the distributor plate and the draft tube gave a more significant effect on circulation rate than did the two gas feed rates into inner and outer regions of the draft tube. Shelukar (2000) explained that the gap height has a significant effect on the average circulation time and the circulation time distribution. The average circulation time and the circulation time distribution decrease with increasing gap height because higher gap heights reduce the formation of dead/slow zones in the annulus. 
Subramanian (2000) concluded that at the higher gap height, particles entered the draft tube without excessive restriction resulting in a denser bed as well the tendency for the particles to accelerate to a higher axial height. He also found that the velocity profile for higher gap heights is more symmetrical. In addition, he studied the effect of different deflectors located at the base on the draft tube, in the particle acceleration region, around the spray nozzle. He found that the existence of a deflector (shown in Figure 2.1) improves the particle distribution in the spray zone, resulting in better coating uniformity. The particle velocities at the wall also were much lower than those at the center, which is due to the particle-particle collision near the walls and particle-wall collisions.

\subsection{Study of Particle Coating in Fluidized Bed Equipment}

There are basically four modes of particle coating in fluidized bed equipment:

1) Top spray using conventional spray fluid-bed granulator

2) Bottom spray using a Wurster column

3) Tangential spray using a rotor granulator

4) Tumbler fluidized bed

The most common coating technique used in the Pharmaceutical Industry is Wurster column coating. The particle coating uniformity in Wurster column coating is determined by two factors, namely the coating-per-pass distribution and the circulation time distribution (Mann and Crosby, 1973, and Mann et al 1974).

In 1983, Weiss and Meisen studied the quality of coated urea as a function of bed temperature $\left(48-86^{\circ} \mathrm{C}\right)$, sulfur (coating material) flow rate $(34-260 \mathrm{~g} / \mathrm{min})$, atomizing air 
flow rate $\left(0.402-0.785 \mathrm{~m}^{3} / \mathrm{hr}\right)$, and bed depth $(0.28-0.47 \mathrm{~m})$. From these parameters, bed temperature was found to have a great effect on the product quality, which was defined by the standard 7-day dissolution technique, developed by TVA (Tennessee Valley Authority). The product quality was also found to be proportional to sulfur flow rate and inversely proportional to the atomizing air flow rate.

Iley (1991) focused on how to establish the influence of particle size and porosity on the encapsulation of inorganic particles, coated with polymer latex in a fluidized bed with a draft tube. His experimental results showed that, smaller particles receive more coating material. This is because of the high specific surface area of smaller particles, the coating layer being thinner compared to larger particles. He also found that porous particles gave poor coating quality due to the coating material being sucked into the pores as a result of capillary action. He recommended that for better particle film coating, the core particle should be spherical, of high density and low porosity.

In 2000, Sudsakorn and Turton evaluated the effect of particle size on the uniformity of coating received during a batch fluidized bed coating process. However, their findings were in contrast to what was concluded by Iley, i.e. the amount of coating material (blue dye) deposited on a given size of particles was proportional to the particle diameter to the power of 3.4. Furthermore, the particle size was also found to have a significant effect on the variance of blue dye content but the dependence was slightly lower, which was to the power in the range of $2.8-3.1$. The possible reasons for these phenomena are either that large particles circulate more often or that large particles receive more coating when they pass through the spray zone. 
Saadevandi (1996) investigated the effect of liquid spraying on particle velocities and voidage profiles. By visual observation through the flat transparent front face of the half cylindrical fluidized bed, he found that at the specific conditions of atomization, there were no significant effects from the liquid droplets on fluidized particles as compared to the conditions of within spray. Figure 2.2 and 2.3 show the voidage of the bed at different radial positions from the spray nozzle for the cases of a fluidizing bed with and without spray, measured at high and low gap height respectively. This phenomenon was found to be similar for the velocity profile.

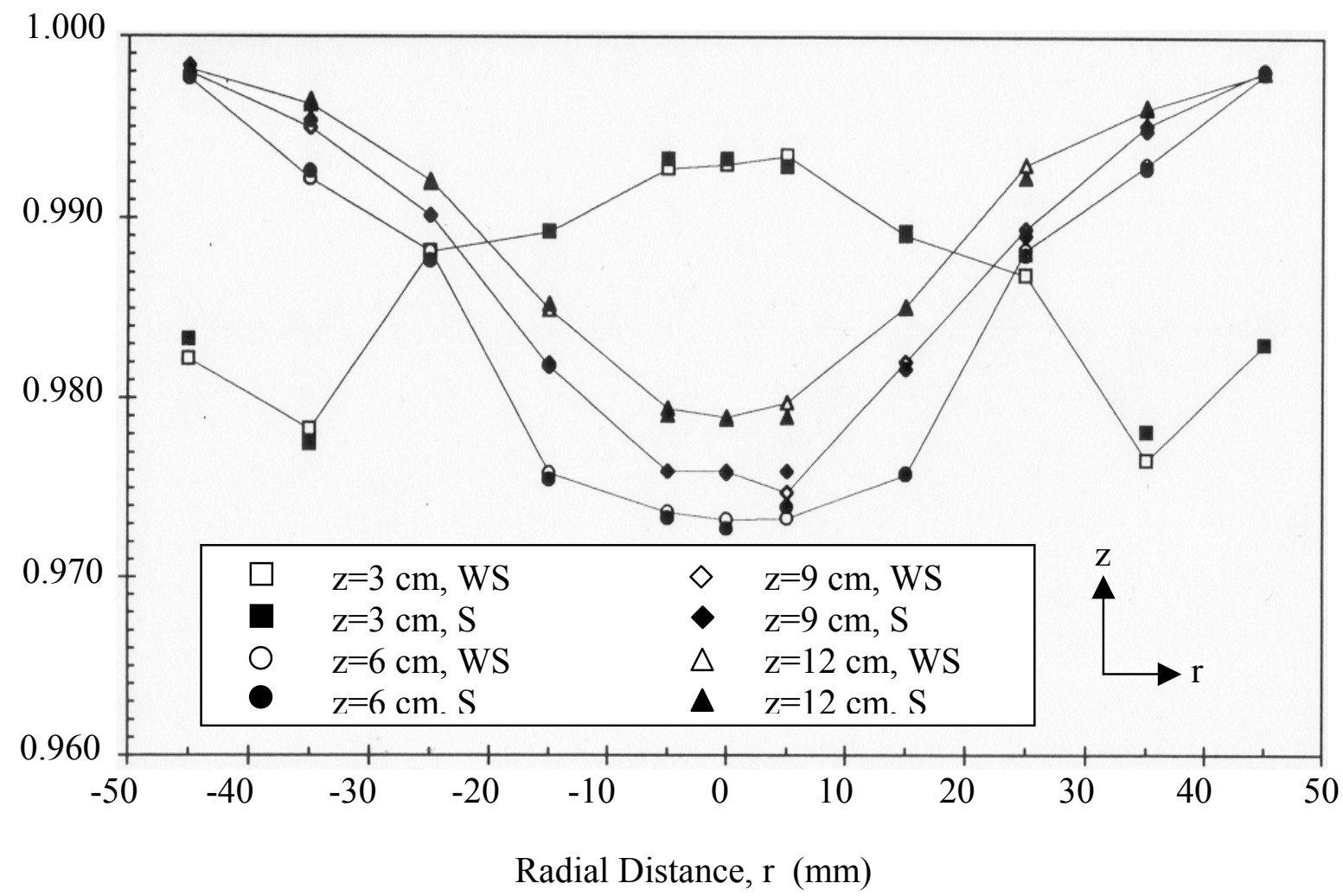

Figure 2.2: Comparison of the radial voidage profiles with Spray (S) and Without Spray (WS) in the draft tube at different axial locations, z (Gap Height, $\mathrm{Hg}=10 \mathrm{~mm}$ ) (Saadevandi, 1996). 


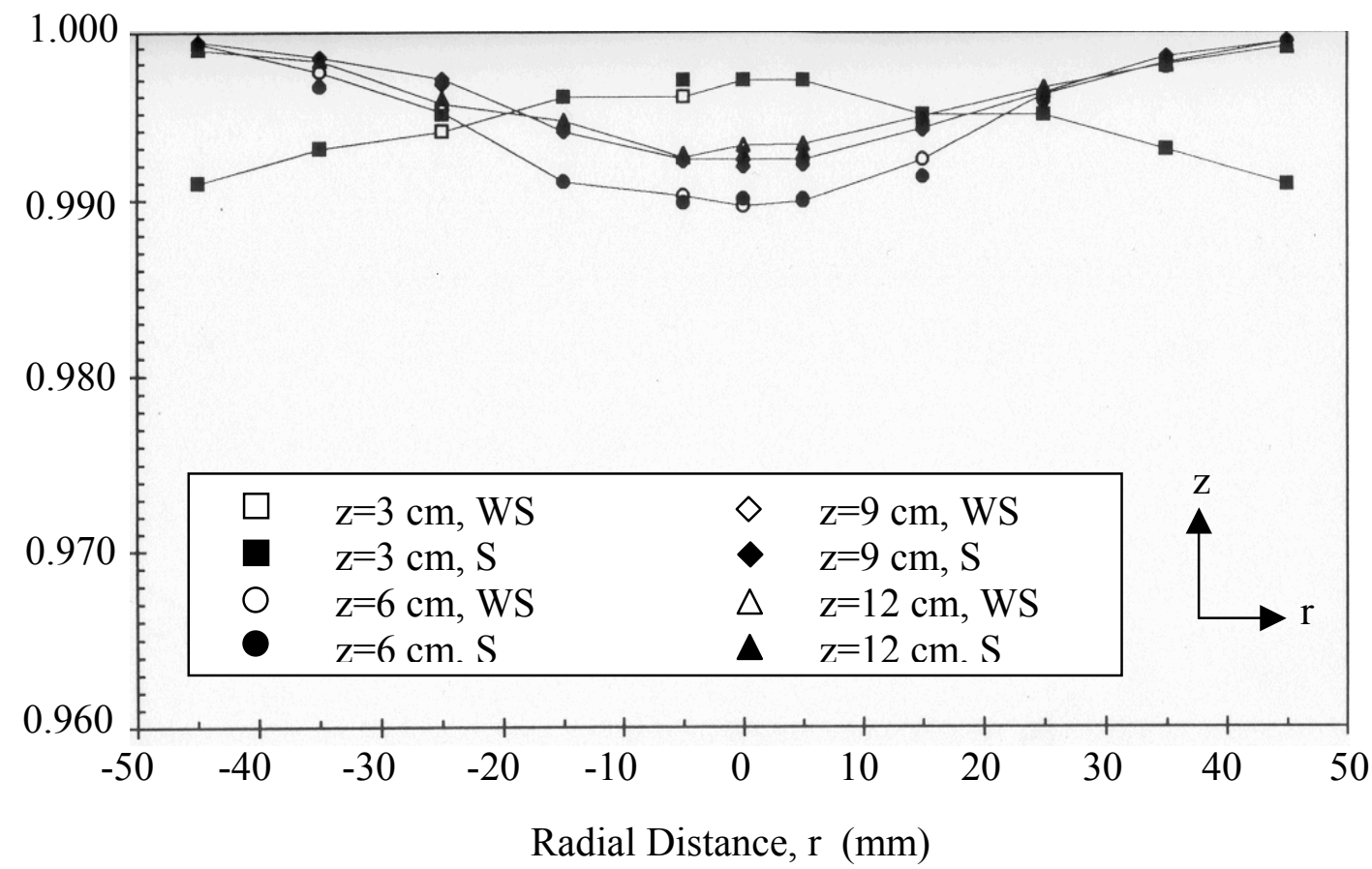

Figure 2.3: Comparison of the radial voidage profiles with Spray (S) and Without Spray (WS) in the draft tube at different axial locations, z (Gap Height, $\mathrm{Hg}=5 \mathrm{~mm}$ ) (Saadevandi, 1996).

Oliveira (1997) studied the effect of spouting gas flow rate, temperature, and coating suspension feed flow rate on the process of coating spherical porous alumina with a suspension of sucrose and talc in water. He found that the particle mass increases with the coating time and the final product is uniform in shape and has a log-normal particle mass distribution. The rate of increase in the particle mass varied significantly with the flow rate of the spouting gas and with the feed mass flow rate of the coating suspension. 
Saleh et al (1999) investigated the influence of fluidization gas velocity, atomizing air and liquid flow rates, liquid concentration, initial bed mass, and particle size on the mechanism of growth of sand particles in a batch fluidized bed coater. An aqueous solution of $\mathrm{NaCl}$ was used as the coating material and sprayed into the bed using a pneumatic atomizer. Even though this study was not involved with a pharmaceutical product, the result is significant as it showed that, for a given particle size, the fluidizing air velocity was the most important factor affecting the coating kinetics and stability. The deposition quality of coating material was found to be affected by the spray droplet size. A decrease in droplet size results in an increase in the atomizing air flow rate permitted for homogenous coating of the solid surface.

Shelukar et al (2000) studied the particle coating uniformity in a Wurster coating process by measuring the coating-per-particle-per-pass distribution with a magnetictracer and measuring coating-per-pass using a dye tracing technique. Their results showed that the coating-per-pass distribution contributes significantly, more than $75 \%$, to the total-coating uniformity. They also found that the coating-per-pass increased with an increase in partition gap (gap height) as well as with an increase in air flow rate. They concluded that the wide coating-per-pass distribution, which was confirmed by highspeed video-imaging, was due to variation in the proximity of the tablets to the nozzle while passing through the spray zone, non-uniform tablet flow patterns into the spray region, and tablet-to-tablet sheltering. 


\subsection{Prediction and Model of Particle Coating Processes}

By understanding the particle behavior in fluidized bed equipment, a computer model may be developed to predict the amount of coating received by a particle-per-pass through the spray zone. Choi and Meisen (1995) developed two mathematical models, describing the operation of shallow spouted beds in which droplets of sulfur (the coating material) are injected co-axially with the spouting air under three different conditions; steady state, transient and continuous. Their models also predict the distribution of the coating material on the bed particles as well as the product quality (determined by 7-day dissolution).

In the first model, particles were assumed to be perfectly mixed and of equal size and all of the spray droplets were assumed to be uniformly distributed throughout the bed. In the second model, they assumed that the fluidized bed has three different regions namely the spout, annulus, and fountain. The key assumptions in this model are that: the particles in the spout and annulus are in plug flow; the particles in the fountain are perfectly mixed; particle segregation due to the changing size and density are negligible and the changes in sulfur (coating material) properties due to solidification and allotropic transformations are insignificant. From these two models, Choi and Meisen concluded that the product quality was primarily dependent on the average sulfur content. Furthermore, the product quality can be increased, by operating several fluidized bed coaters in series.

Maronga and Wnukowski (1997) used the random surface renewal concept to develop population balance equations for the coated particles. The model was then used to estimate the effect of stagnant regions, size of bed, and unequal rate of transfer 
between domains on the coating distribution. They concluded that the existence of stagnant regions within the bed widen the coating distribution. A narrow coating distribution can be achieved by increasing the rate of transfer to the active spray domain (spray zone), relative to the rate of transfer to the non-active domain (non-spray zone). They also observed that the bigger the bed dimension, the wider the coating distribution. This was explained by the fact that a bigger bed dimension contributed to a larger nonactive domain. A vigorous mixing of the bed, which promoted the increase in rate of transfer both in active and non-active domains were found to cause a narrow coating distribution. They concluded that the combination of bed size, rate of spraying, and rates of transfer between active and non-active domains was useful to obtain a required coating distribution of particles.

Abe et al (1998) studied how the amount of coating material received by each individual seed particle varies with operating condition in a tumbler-fluidized bed. Even though the process of a tumbling fluidized bed is slightly different from the Wurster fluidized bed, the principle mechanisms for the amount of coating material deposited on to the particles should be similar. In a tumbling fluidized bed, a rotary disk located at the bottom of the bed rotates at a certain speed to provide a centrifugal force that drives the particles to the outer region of the disk. In the vicinity close to the column wall, the particles were lifted by the fluidizing air, which came out through a net mesh (Figure 2.4). As the velocity decreased, the particles descended onto the center of the rotary disk. The repeated sequence of this process provides a perfect mixing region around the outer region of the disk, where a spray nozzle was located. By changing the operating condition in the bed, they found that the coefficient of variation of the coating mass 
distribution, $c v$, decreased with increasing coating time and seed particle size as well as decreasing holdup. It was suggested that, under these operating conditions, a high mixing rate of particles was achieved. They also found that the effect of the rotational speed of the disk, on the $c v$ is not significant.
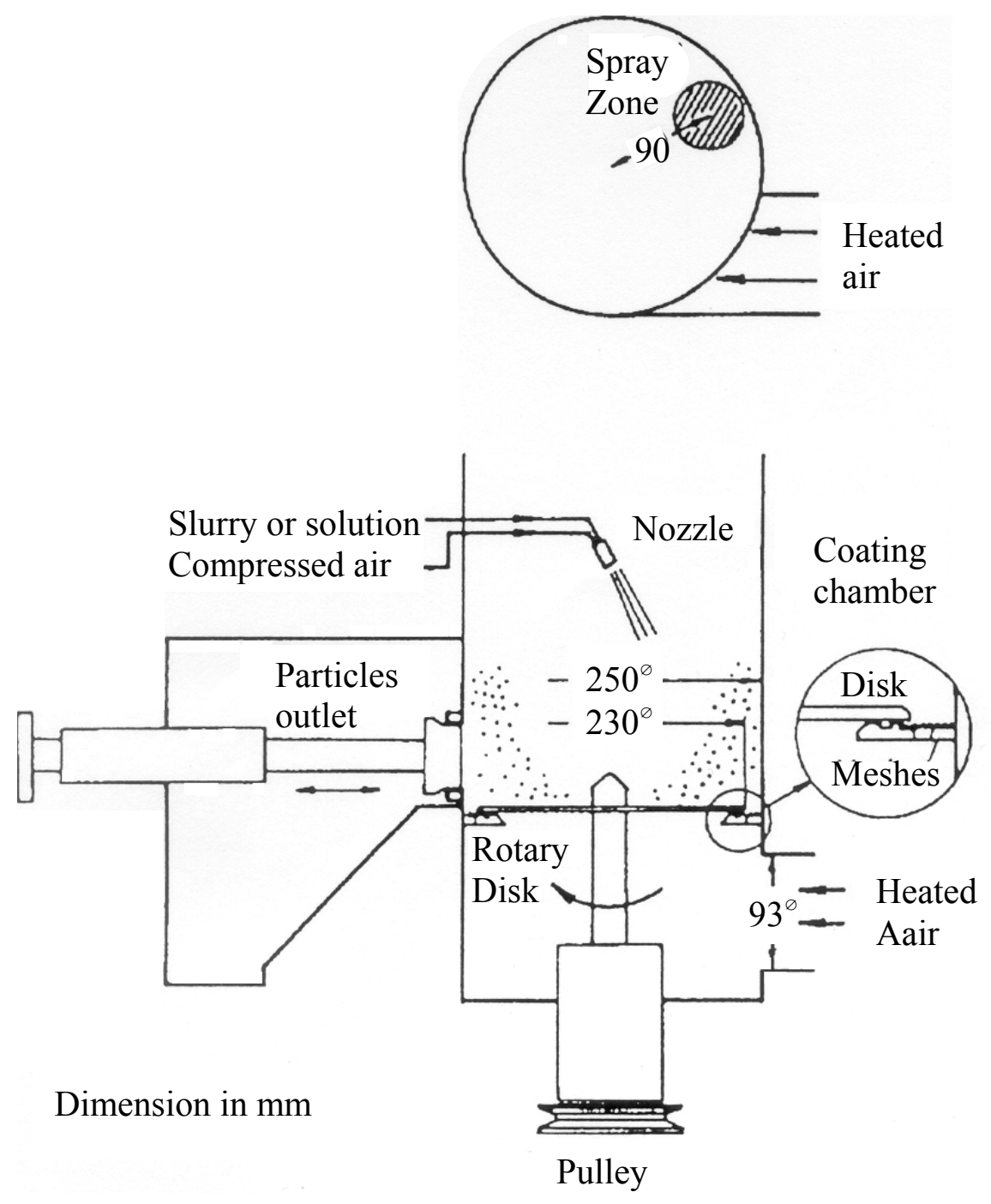

Figure 2.4: Details of the tumbling fluidized bed coating chamber (Abe, 1998). 
Nakamura et al (1998) predicted the effect of the above operating conditions by using Monte Carlo simulations. By estimating the average diameter of the spray droplets using Nukiyama Tanazawa's (Nukiyama, 1929) equation, and assuming that a particle is coated by a spray droplet, they determined the number of cycles in one second by the following equation:

$$
t_{r}=\left(n_{p} / n_{s}\right)\left(N_{s} / N_{p}\right)
$$

where $t_{r}$ is the number of cycle per second, $n_{p}$ is the number of spray droplets per second in the actual tumbling fluidized bed, $n_{s}$ is the average number of coated particles in one cycle in the simulation, $N_{p}$ is the total number of core particles in the practical tumbling fluidized bed, and $N_{s}$ is the total number of core particles in the simulation. Even though the values of simulation results were not directly compared with the values of experimental results, the results from the simulations showed the same phenomena and trends as observed by Abe et al (1998) in their experiments.

Terashita et al (2000) developed a numerical simulation using the discrete element method, to simulate a small particle coater. This coater is an improved version of a Wurster coating equipment. This improvement included conically expanding the lower part of the draft tube and supplying a side air jetting mechanism. As a result, particle stagnation zones outside the draft tube in the coater were reduced compared to the Wurster coater. The results that they obtained confirmed that the small-particle coater designed on the basis of simulation results was useful for small-particle coating operations. 
Cheng and Turton (2000) developed a model explaining the particle-particle variation in the coating mass distribution in terms of the hindering or sheltering effect that particles close to the source of the spray have, on particles farther away. The assumptions made by Cheng and Turton (2000) in their model are:

- The spray zone is a hollow cone (Figure 2.5).

- Particles enter the draft tube in the region of $r_{0}$ to $R$ (see Figure 2.5).

- All the coating drops that are not deposited onto particles by direct impingement are assumed to be lost from the system.

- The flow field of the spray follows straight radially directed steam tubes.

- Particles are distributed uniformly throughout the spray zone with uniform voidage and move vertically upward with a constant velocity.

First, a simple model was developed considering particles passing the spray zone would either receive a certain amount of spray material or no coating at all. From this assumption, they found that only a few percent of particles received coating in any given pass through the spray zone. Then, a more complicated model was developed to explain the coating variation by taking into account the effect of particle hindering in the spray zone. Even though the model was not able to predict the variation under different operating conditions, the result was strong enough to suggest that the sheltering of particles in the spray zone by other particles was the main contribution for the particle-toparticle coating variation within fluidized bed.

Due to the fact that it is important to have uniform coating in the Pharmaceutical Industry, a lot of work has been done to study the particle behavior in the vicinity of the fluidized bed especially in the spray region. The result of the literature survey shows that 
there are significant number of parameters that play an important role in determining the uniformity of fluidized bed coating. Based on this understanding, a particle coating model was developed in this study by using the experimental data of particle velocity and voidage as the input data, to simulate the amount of spray material impinged onto the particle when passing through the spray zone. The coating variations from the simulation results are then compared with those from the experiments.

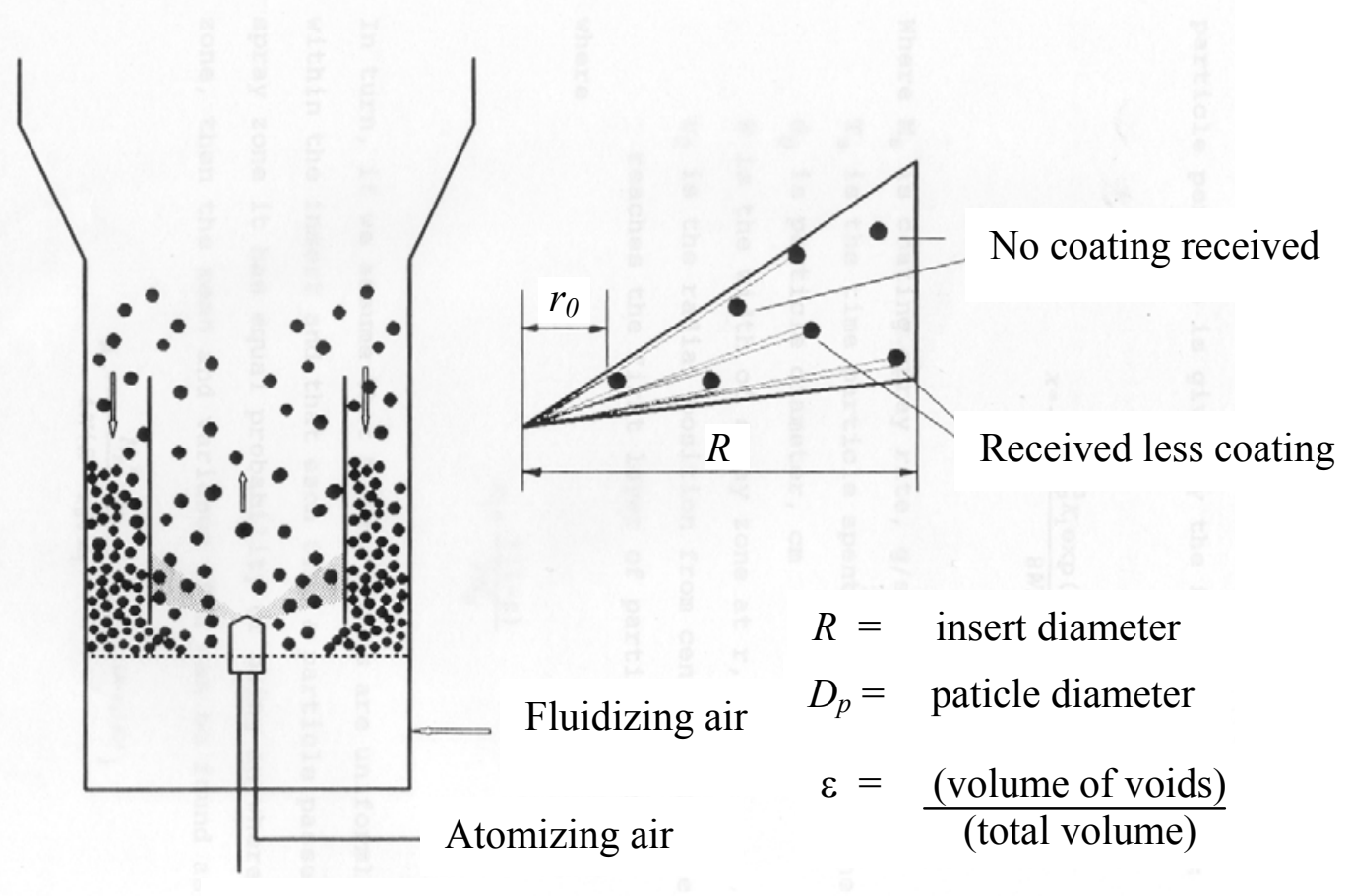

Coating solution

Figure 2.5: Schematic diagram of a Cheng's spray model (Cheng, 1993). 


\section{CHAPTER 3: $\quad$ EXPERIMENTAL PROCEDURES}

\subsection{Pulse Test Experiments}

A particle coating process in a fluidized bed is one of the most efficient techniques used to coat pharmaceutical tablets. Some tablets are formulated to release drug (or the active ingredient) over a long period of time and these sustained release products, require a uniform coating. The objective of the experiments in this study is to analyze the amount of spray material received by a particle when it passes once through the spray zone. These experiments were performed at two fluidized bed conditions; namely with and without a particle deflector. In order to capture the amount of coating material received by the particles, when passing through the spray zone, a pulse of dye was injected into the coating solution for a period of time equal to the duration taken by the particles to make one circulation in the fluidized bed. This time is referred to as the particle circulation time. This experimental process is referred to as a pulse test experiment.

\subsubsection{Experimental Apparatus}

The equipment used in this experiment was the same fluidized bed used by Subramanian for measuring velocity and voidage, which was a semi-circular Wurster fluidized bed coater (Figure 1.1). The dimension of the draft tube region and inner bed are given in Figure 3.1. 


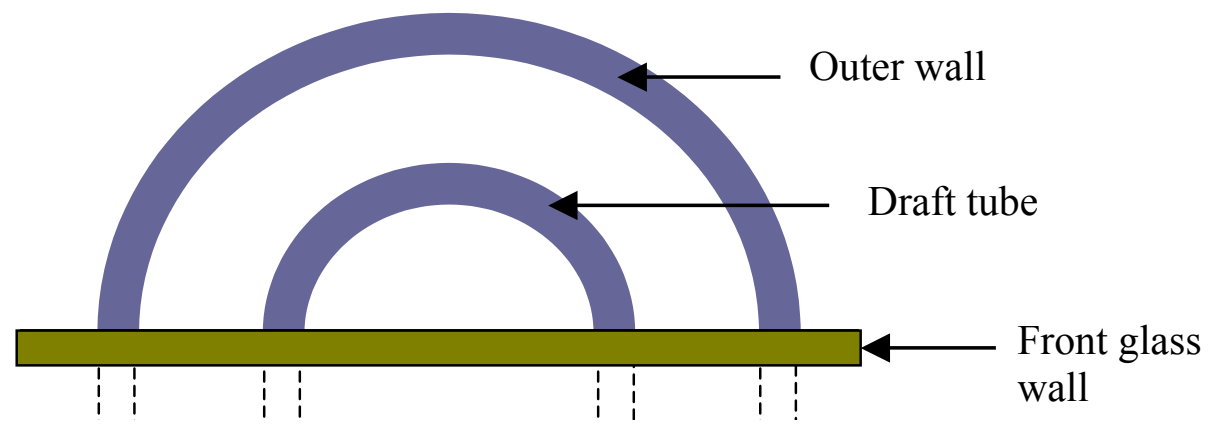

$\underline{\text { Top View }}$

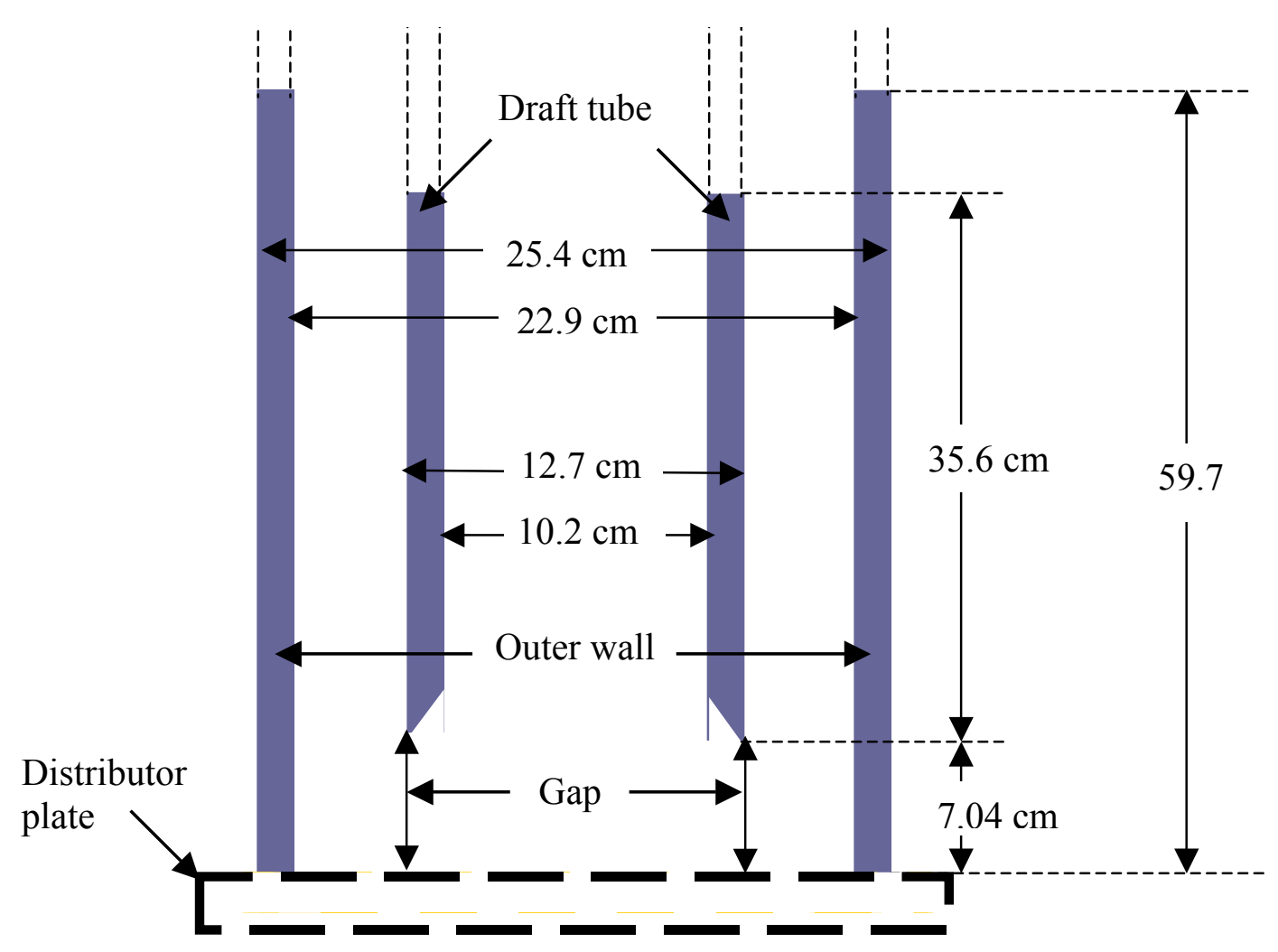

$\underline{\text { Front view }}$

Figure 3.1: Schematic diagram of the draft tube region of the semi-circular column of fluidized bed illustrated in Figure 1.1. 
The pulse test experiment was performed at two different conditions; one without a particle deflector and one with a modified deflector. In the Modified Deflector run, a deflector was fitted on the distributor plate and around the spray nozzle, as shown in Figure 3.2.

A coating solution was pumped into a semi-circular 2-fluid nozzle using a Master Flex micro-processor peristaltic pump (manufactured by Cole Parmer Instrument Company, Chicago, IL).

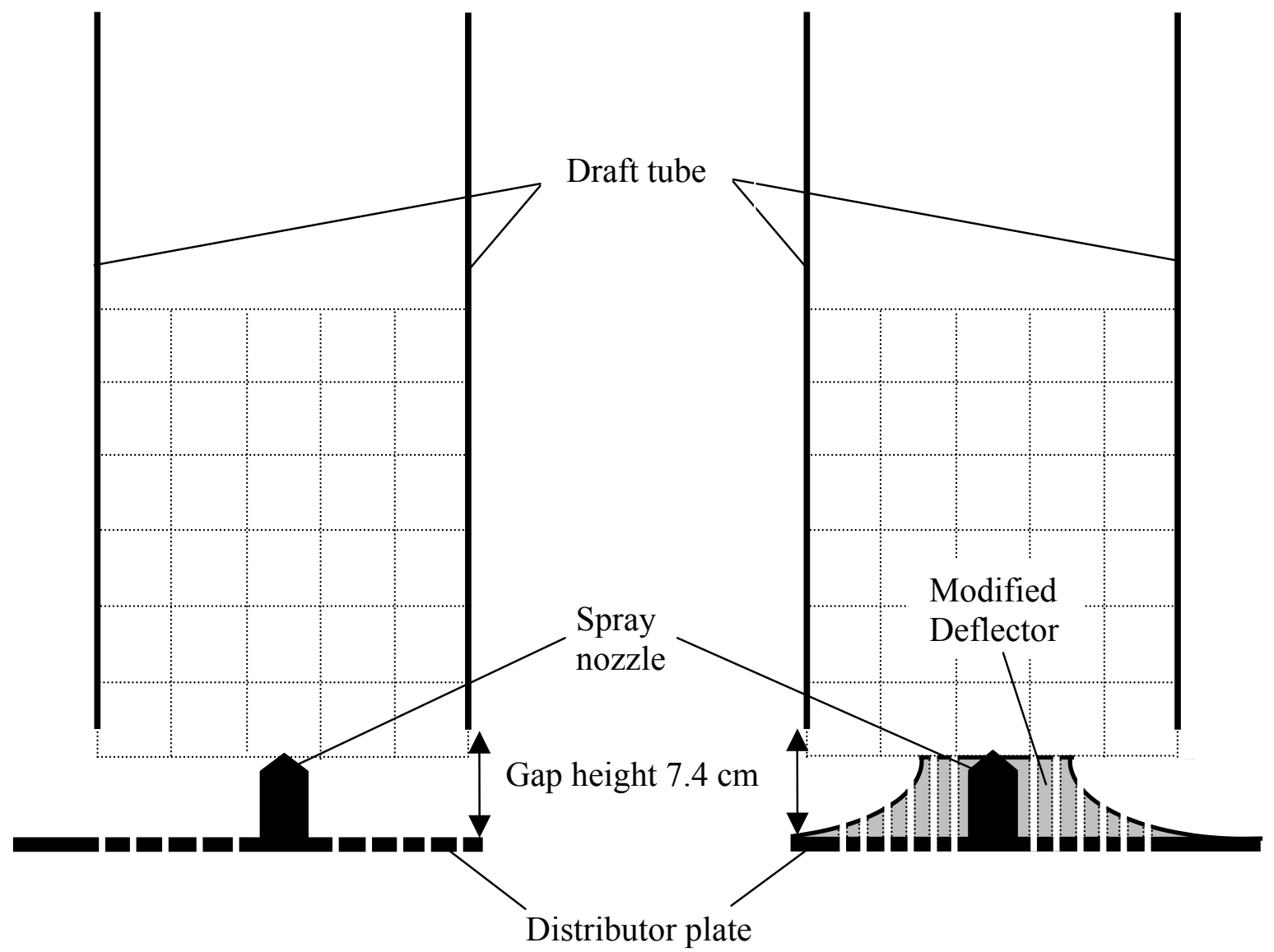

Figure 3.2: Schematic diagram shows a fluidized bed with no particle deflector and with the modified deflector. 
The particles used in this experiment were the same type of pharmaceutical tablets used by Subramanian, with physical properties listed in Table 3.1.

Table 3.1: Physical properties of tablets used in the experiment.

\begin{tabular}{|l|l|}
\hline Physical property & Value \\
\hline Diameter $(\mathrm{mm})$ & 8.05 \\
\hline Thickness $(\mathrm{mm})$ & 4.2 \\
\hline Average volume $\left(\mathrm{cm}^{3}\right)$ & 0.170 \\
\hline Average weight $(\mathrm{g})$ & 0.205 \\
\hline Average density $\left(\mathrm{kg} / \mathrm{m}^{3}\right)$ & 1.215 \\
\hline
\end{tabular}

The tablets were provided by Merck \& Company (West Pont, PA), made of Avicel® PH101 compressed with Magnesium sterate, and pan coated with an aqueous solution of Hydroxy Propyl Methyl Cellulose (HPMC) and Hydroxy Propyl Cellulose.

\subsubsection{Coating Solution}

There were two coating solutions used in this experiment namely a pre-pulse solution and a blue dye solution. The pre-pulse solution was used to coat the tablets before the pulse of blue dye solution was injected. This was done to simulate similar tablet surface conditions as in the actual coating operation. The formulations for these solutions are given in Table 3.2. 
Table 3.2: Formulations for the solutions used in the pulse test experiment.

\begin{tabular}{|l|}
\hline Pre-pulse solution \\
$15 \mathrm{~mL}$ water \\
$135 \mathrm{~mL}$ Aquacoat ${ }^{\circledR}$ (Ethyl cellulose aqueous dispersion with $30 \%$ solids) \\
\hline Blue dye solution \\
$50 \mathrm{~mL}$ water \\
$45 \mathrm{~mL}$ Aquacoat ${ }^{\circledR}$ (Ethyl cellulose aqueous dispersion with $30 \%$ solids) \\
$5 \mathrm{~g}$ blue dye (FD\&C blue dye \#1) \\
\hline Each solution was stirred with a magnetic stirrer until they were used. \\
\hline
\end{tabular}

\subsubsection{Experimental Procedures}

For both No-Deflector and Modified-Deflector experimental runs, the operating conditions are similar to Subramanian's experiment Run 5 and Run 6 respectively. Refer to Appendix VII for Subramanian's experimental matrix.

3.6 kilograms of pharmaceutical tablets were fluidized with an air flow rate of $0.0707 \mathrm{~m}^{3} / \mathrm{s}$ and $0.0684 \mathrm{~m}^{3} / \mathrm{s}$ for No-Deflector and Modified-Deflector cases, respectively. After a few minutes, when the air reached the required temperature of $115^{\circ} \mathrm{F}$, the pre-pulse solution was pumped into the spray nozzle at a flow rate of 10 $\mathrm{ml} / \mathrm{min}$ with $35 \mathrm{psi}$ atomizing air. In order to simulate an actual coating run, and to ensure the spray nozzle was running under steady state conditions, the bed was allowed to run for 5 minutes before the pulse of blue solution (for No-Deflector case) or red solution (for Modified-Deflector case) was injected via the spray nozzle. Once the dye 
was seen coming out from the spray nozzle, a stopwatch was started. After 9 seconds (refer to Appendix IV for particle circulation time calculation), the peristaltic pump and atomizing air were switched off simultaneously and the bed continued to run without the coating solution for another 5 minutes in order to dry the coated particles. Finally, 100 particles from each run were randomly sampled and used in the coating analysis.

\subsection{Tablet Coating Analysis}

In both cases, No-Deflector and Modified-Deflector, each tablet was soaked in 2 $\mathrm{ml}$ of distilled water in a test tube for 10 minutes. After the tablet was completely dissolved, the mixture was filtered with filter paper (Fisher Q5, Porosity: Medium). In order speed up the filtration process, vacuum filtration was used. Another $1 \mathrm{ml}$ of distilled water was used to wash the remaining dye in the test tube and on the filter paper. Then, the clear colored liquid was analyzed for dye (blue or red) content using a Lambda 2 UV/VIS Spectrophotometer (Perkin-Elmer corp., Norwalk, CT) equipped with data acquisition software package PECSS version 4.0 (refer to Appendix V for the blue and red dye wavelength characterization, spectrophotometer calibration and detail calculation of dye content).

The results of the analysis were plotted in a histogram and were compared with the simulation results. 


\section{CHAPTER 4: MODEL DEVELOPMENT AND}

\section{CALCULATION METHOD}

A Monte Carlo simulation model of the particle movement and coating efficiency occuring in a semicircular fluidized bed column is developed in this chapter. For versatility purposes, the model is developed in such a way that it can predict the coefficient of variation (cv) of the coating-per-particle-per-pass distribution for various fluidized bed operating conditions. The basis of the model is the data of Subramanian, 2001. These data show, for various bed conditions and operating parameters, that the particle velocity and voidage profiles in the draft tube region of a fluidized bed are different. Therefore, the raw data of velocity and voidage of the particles at each operating condition are used as input data for the model. In addition, the predictions of the model developed in this work are compared with experimental pulse test data obtained at conditions similar to those used by Subramanian and described in Chapter 3.

In Subramanian's (2001) experiments, the front face of the semi-circular fluidized bed was divided into 70 equal sections as shown in Figures 4.1 and 4.2. In every section, a series of experimental values of local velocity in the x-direction $\left(u_{x}\right)$, local velocity in the y-direction $\left(u_{y}\right)$ and the local voidage $(\varepsilon)$ were obtained. The standard deviations and the average values of the velocity data in each section were calculated and used in the model. The average voidage values for each section were also used. It should be noted that each section is assumed to extend from the front face of the semicircular bed through $90^{\circ}$. Thus each section represents one quadrant of the bed, as shown in Figure 4.3. 


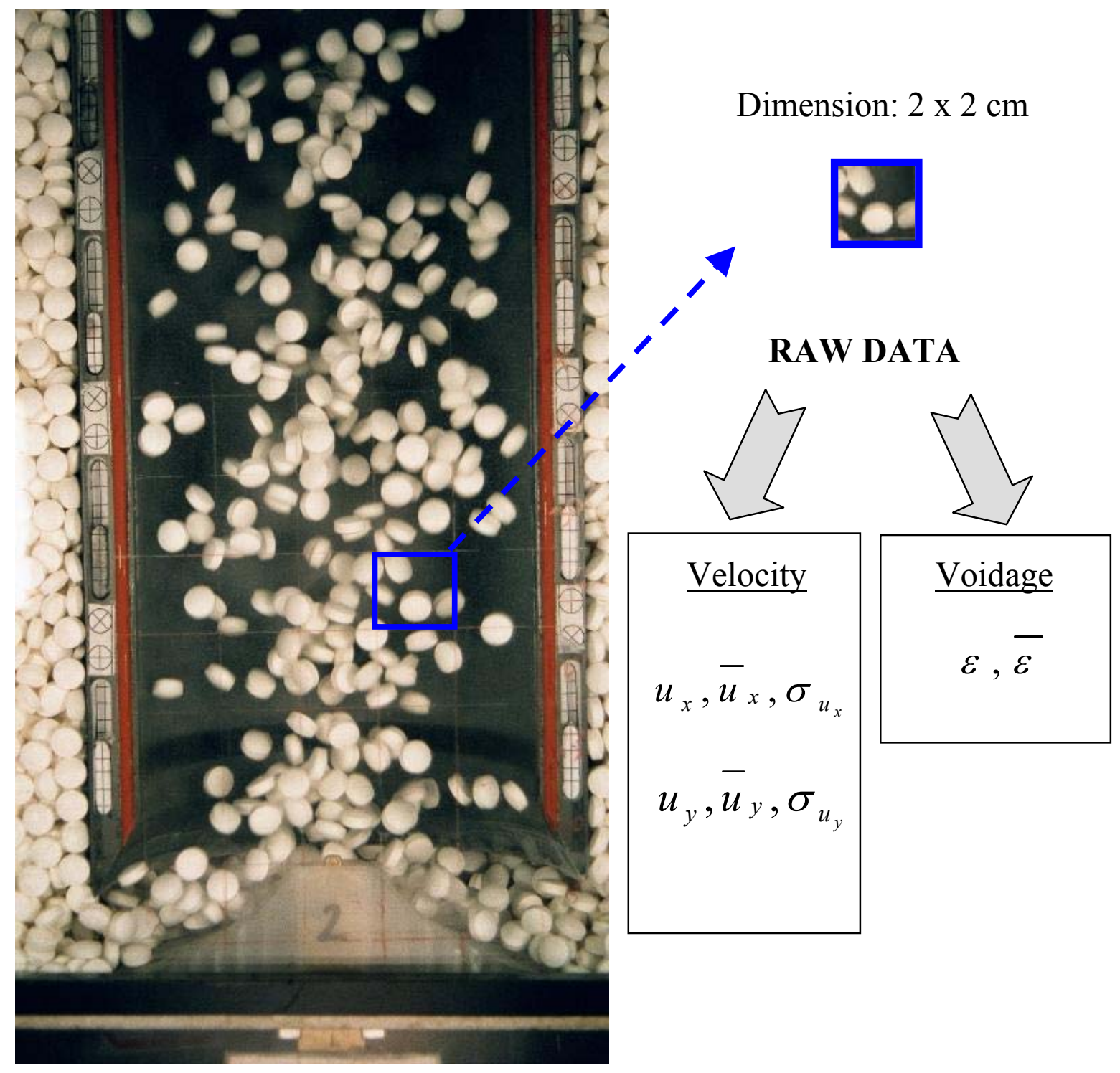

Figure 4.1: A photograph of the front view of semi-circular fluidized bed spouted region (Subramanian, 2001). 


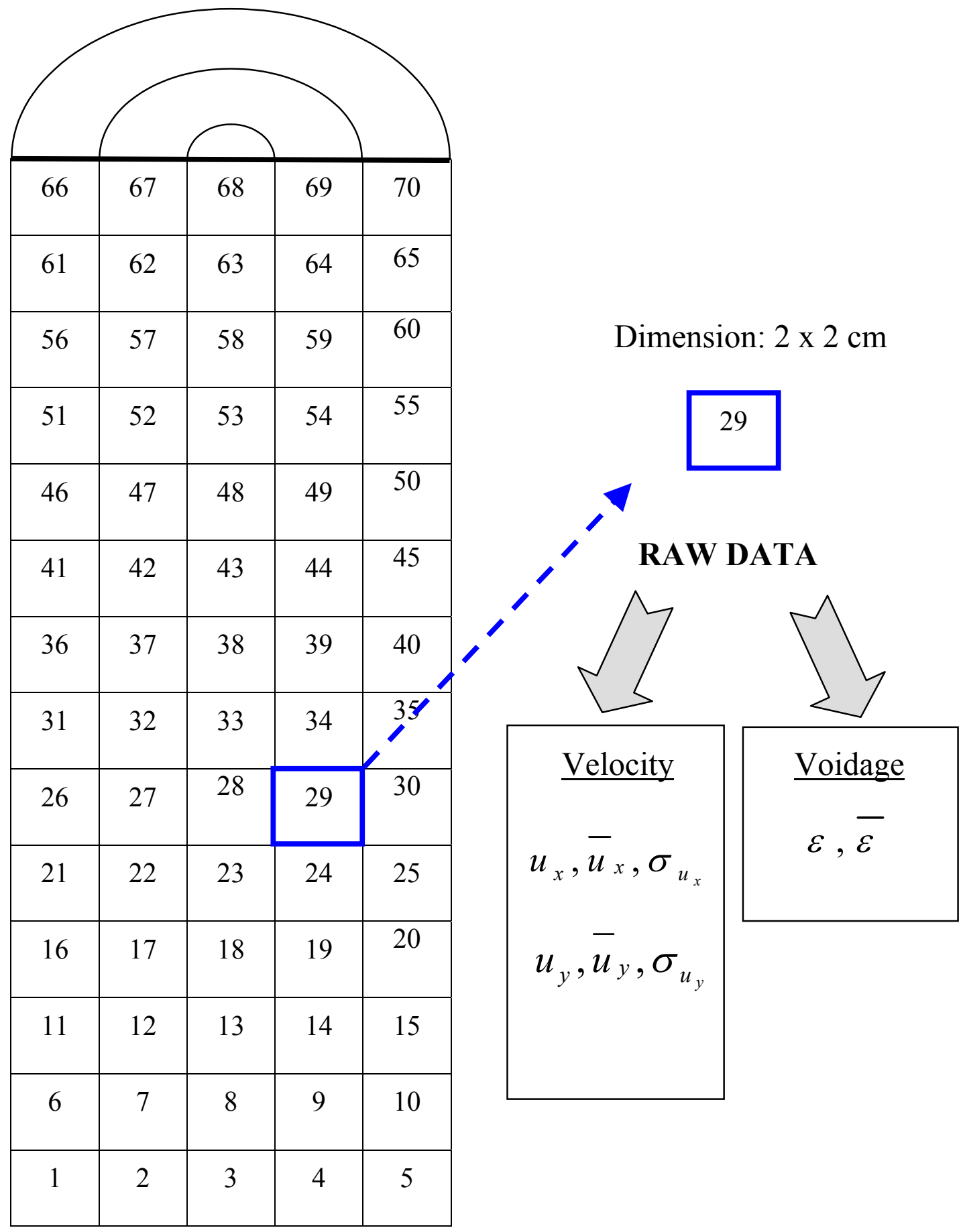

Figure 4.2: A schematic diagram of front view of semi-circular fluidized bed spouted region. 


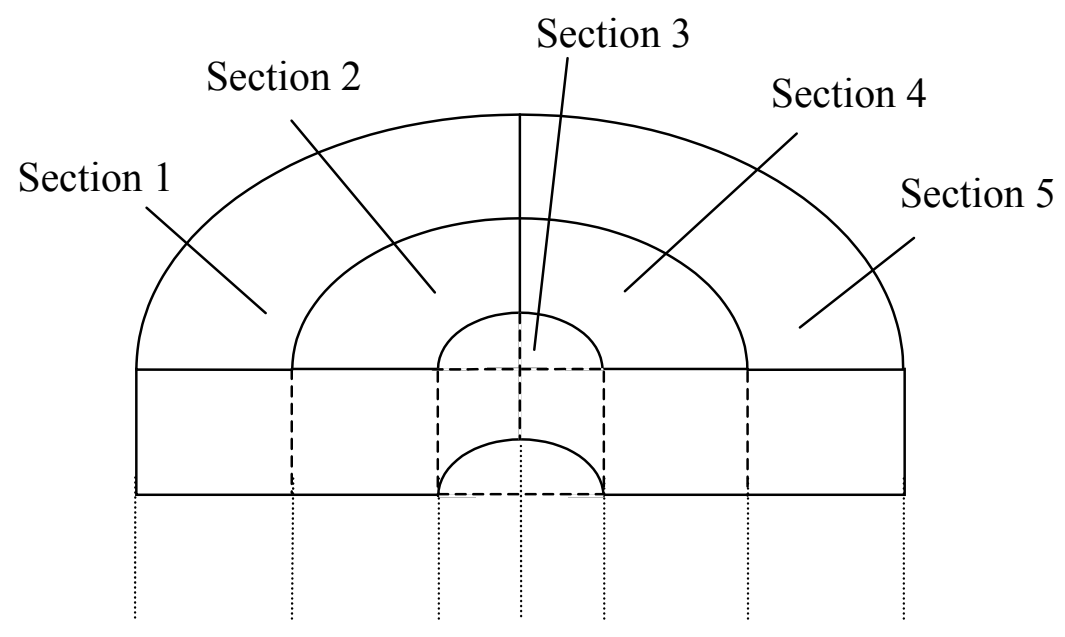

a) The first layer of the grids(sections): Section 1- 5

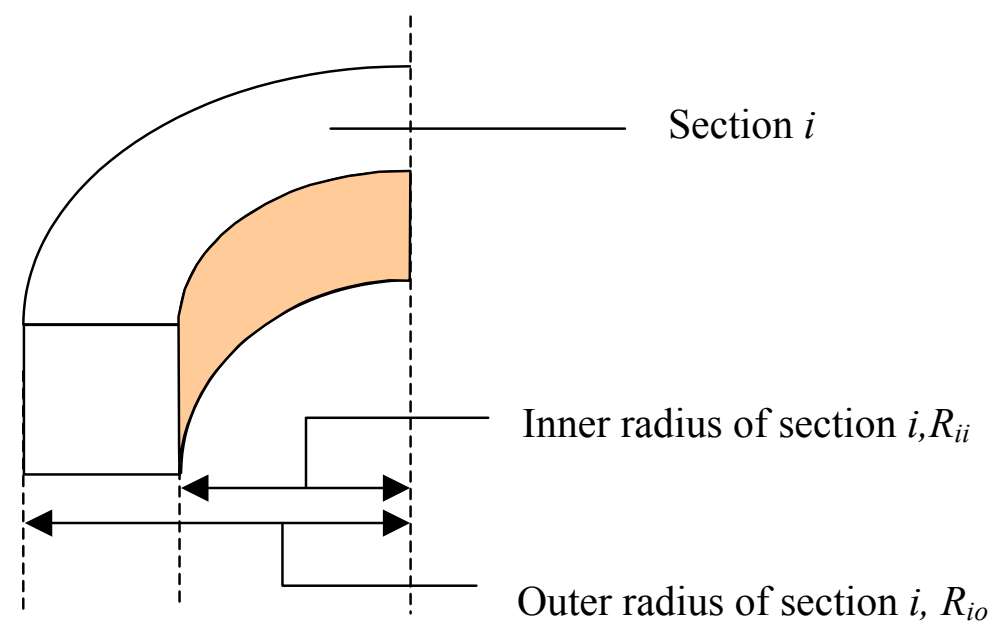

b) Section $i$

Figure 4.3: A schematic diagram of the top view of semicircular fluidized bed 


\subsection{Starting Location for Tablet Movement}

The movement of a particle in the draft tube region of a fluidized bed coater starts at the bottom of the bed as it moves horizontally through the gap between the distributor and the bottom of the draft tube. It is then entrained into the spouted region during which the spray material is deposited onto the particle. After traveling upward through the draft tube, the particle decelerates in the fountain region at the top of the bed and then falls into the annular region before reaching the bottom of the bed again. At steady state this particle circulation continues and the average particle circulation time becomes constant.

Assuming that the particle motion in a fluidized bed is at steady state, the starting point of the particle in the model is randomly determined using a probability function based on the distribution of mass flow into the bottom of the fluidized bed. The probability of the particle entering a given section is a function of volumetric flow rate at the bottom of the bed, which in turn is a function of voidage and velocity.

The volumetric flow rate of solids, through an annular section $i, Q_{s(i)}$, (at the bottom) of a semi-circular fluidized bed is given by:

$$
Q_{s(i)}=\frac{1}{2} \int_{R_{i i}}^{R_{i o}} \pi u_{y(i)}\left(1-\varepsilon_{(i)}\right) r d r
$$

where

$$
\begin{array}{ll}
u_{y(i)}= & \text { local velocity of the particle in upward direction } \\
& \text { (y-direction) in section } i \text { (from Subramanian, 2001). } \\
\varepsilon_{(i)}= & \text { voidage in section } i(\text { from Subramanian, 2001). } \\
R_{i i}= & \text { inner radius in section } i \text { (refer to Figure 4.3(b)) } \\
R_{i o} \quad= & \text { outer radius in section } i(\text { refer to Figure 4.3(b)) }
\end{array}
$$


The simulation region was defined as the inner area of the draft tube starting from the bottom of the bed up to the expanded region. However, the bottom of the bed of the simulation region was assumed to start from the layer of sections where the tip of the spray nozzle is located. The reason for this was to avoid the idle region occupied by the spray nozzle. Therefore, the active area of simulation would start from section 6 through section 70, see Figure 4.2.

Therefore, the volumetric flow rate, $Q_{s}$ in each section at the bottom of the simulation region, which are sections $6-10$, are given by:

$$
\begin{aligned}
& Q_{s(6)}=\frac{\pi}{4}\left(R_{6 o}{ }^{2}-R_{6 i}{ }^{2}\right)\left(u_{y(6)}\right)\left(1-\varepsilon_{(6)}\right) \\
& Q_{s(7)}=\frac{\pi}{4}\left(R_{7 o}{ }^{2}-R_{7 i}{ }^{2}\right)\left(u_{y(7)}\right)\left(1-\varepsilon_{(7)}\right) \\
& Q_{s(8)}=\frac{\pi}{2}\left(R_{8 o}{ }^{2}\right)\left(u_{y(8)}\right)\left(1-\varepsilon_{(8)}\right) \\
& Q_{s(9)}=\frac{\pi}{4}\left({R_{9 o}}^{2}-R_{9 i}{ }^{2}\right)\left(u_{y(9)}\right)\left(1-\varepsilon_{(9)}\right) \\
& Q_{s(10)}=\frac{\pi}{4}\left(R_{10 o}{ }^{2}-R_{10 i}{ }^{2}\right)\left(u_{y(10)}\right)\left(1-\varepsilon_{(10)}\right) \\
& Q_{s(b o t t o m)}=\sum_{i=6}^{10} Q_{s(i)}
\end{aligned}
$$

The fractional volumetric flow rate for each section at the bottom of the bed (sections 6 to 10) was plotted as a cumulative probability function as shown in Figure 4.4, and details are given in Appendix I. To determine the starting point of the particle, the computer generates a uniform random number between 0 to1. For example, if a 
random number of 0.6 is generated, then the starting point is set to a position $1.4 \mathrm{~cm}$ from the spray nozzle, as shown in Figure 4.4.

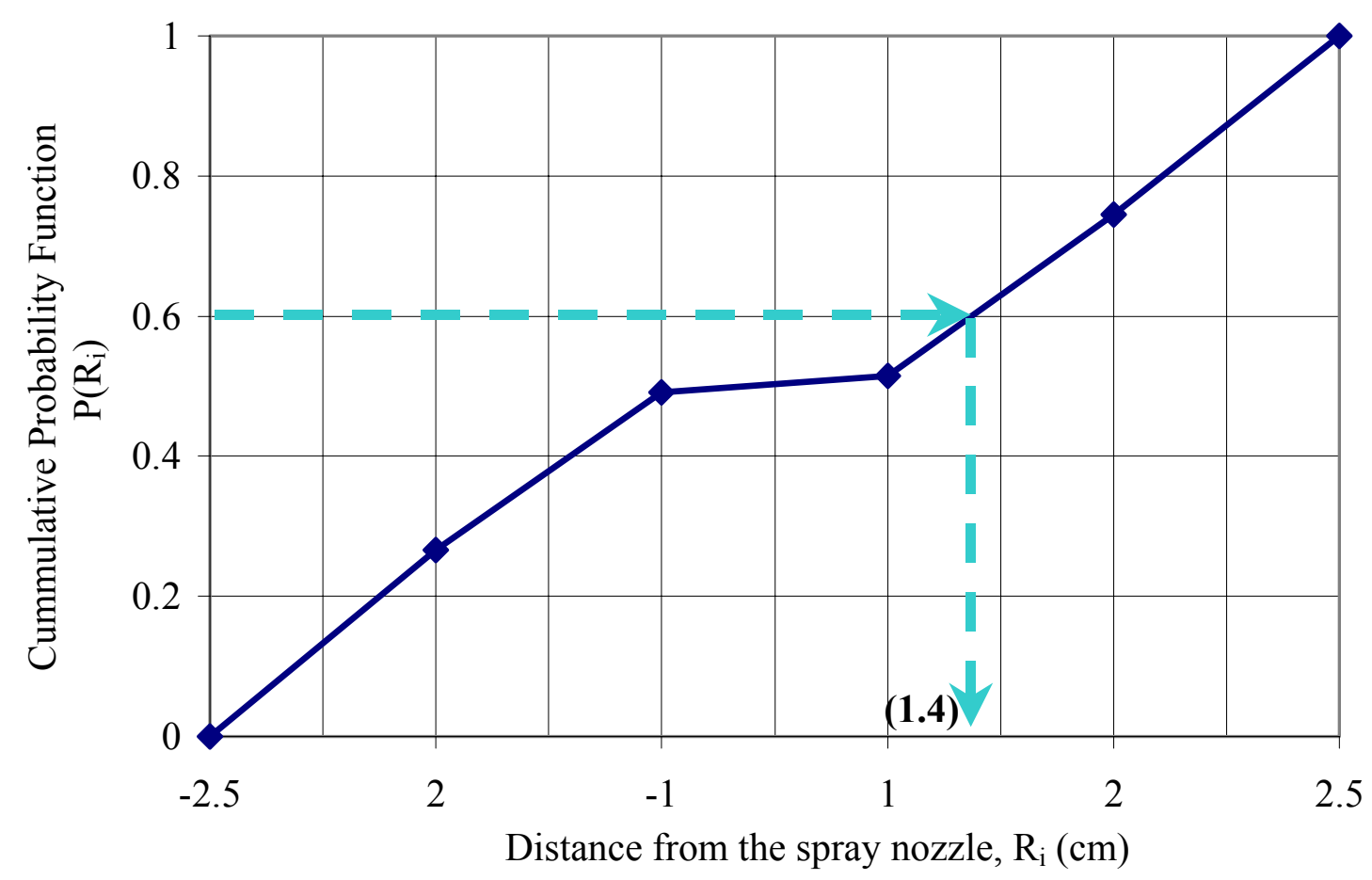

Figure 4.4: A sample of a cumulative probability function used to determine the starting point of a particle for the simulation. 


\subsection{Particle Movement}

Once the starting point (section) has been assigned to the particle, a Monte Carlo simulation is performed to model the particle motion. Based on the assumption of random walk behavior of the particle, the particle may move in both the $\mathrm{x}$-direction, with velocity $v_{x(i)}$, and the $y$-direction with velocity $v_{y(i)}$. For a particular section (section $i$ ), the velocity in the $\mathrm{x}$-direction of particle $n$ in section $i$ is given by:

$$
v_{x(i)}^{n}=\left(\sigma_{u_{x(i)}}\right)\left(R N_{1(i)}\right)+\bar{u}_{x(i)}
$$

where

$$
\begin{aligned}
\sigma_{u_{x(i)}}= & \text { standard deviation of x-component of velocity in section } \\
& i \text { (from Subramanian, 2001) } \\
\bar{u}_{x(i)}= & \text { average velocity in x-direction in section } i \text { (from } \\
& \text { Subramanian, 2001) } \\
R N_{l(i)}= & \text { random number from unit normal distribution } \mathrm{N}(0,1), \\
& \text { given by Equation (4.12). }
\end{aligned}
$$

Similarly, the velocity in the y-direction of particle $n$ in section $i$ is given by:

$$
v_{y_{(i)}}^{n}=\left(\sigma_{u_{y(i)}}\right)\left(R N_{1(i)}\right)+\bar{u}_{y(i)}
$$

where

$$
\begin{aligned}
\sigma_{u_{y(i)}}= & \text { standard deviation of y-component of velocity in section } \\
& i \text { (from Subramanian, 2001) } \\
\bar{u}_{y(i)}= & \text { average velocity in y-direction in section } i \text { (from }
\end{aligned}
$$


Subramanian, 2001)

$$
\begin{aligned}
R N_{2(i)}= & \text { random number from unit normal distribution } \mathrm{N}(0,1), \\
& \text { refer to Equation (4.12). }
\end{aligned}
$$

From these velocity data, the distance traveled by particle $n$ in both $\mathrm{x}-$ and $\mathrm{y}-$ directions are determined by:

$$
\begin{aligned}
& \Delta x^{n}=\left(v_{x^{n}}{ }^{(i)}\right) \Delta t \\
& v_{x}{ }^{n}(i)=\text { velocity in the } \mathrm{x} \text {-direction of particle } n \text { in section } i \\
& \Delta t \quad=\quad \text { duration between successive particle simulations. }
\end{aligned}
$$

and

$$
\begin{array}{ll}
\Delta y^{n}=\left(v_{y}{ }^{n}(i)\right) \Delta t & \text { distance traveled in the y-direction by particle } n \text { in } \\
v_{y}{ }^{n}(i)= & \text { section } i \\
\Delta t \quad=\quad & \text { duration between successive particle simulations. }
\end{array}
$$

In choosing the value of $\Delta t$, it is important to avoid large values as these give rise to large distance steps and the simulated particle movement would be uncharacteristic of the true motion. On the other hand, very small values of $\Delta \mathrm{t}$ would take long simulation times. Referring to Subramanian's experimental data (2001), the images of particle movement were collected at 0.002 seconds time intervals in sections of dimension 2 by 2 $\mathrm{cm}$. Taking an average velocity of $1 \mathrm{~m} / \mathrm{s}$, we can say that a reasonable value of $\Delta \mathrm{t}$ is 
between 0.01 to 0.002 seconds, therefore, the number of particle steps in any section is between 2 and 10.

The movement of a particle is simulated by the repeated application of Equations (4.7) and (4.8). Two random numbers are generated for each particle move. These random numbers are then used to generate samples from the unit normal distribution according to the following equation:

$$
R N_{1}=X_{11}\left(-2 \log \left(r_{1}\right) / r_{1}\right)^{1 / 2} \quad\left(\text { for } r_{1} \leq 1\right)
$$

where

$$
\begin{array}{lll}
X_{11} & = & \left(R N D_{11}\right)(2)-1 \\
X_{21} & = & \left(R N D_{21}\right)(2)-1 \\
r_{1} & X_{11}{ }^{2}+X_{21}{ }^{2} \\
R N D_{11} \text { and } R N D_{21}= & \text { computer generated random number } \\
& \text { of the uniform distribution from } 0 \text { to } \\
& 1, \text { shown in Figure } 4.5(\mathrm{~b}) .
\end{array}
$$

and

$$
R N_{2}=X_{12}\left(-2 \log \left(r_{2}\right) / r_{2}\right)^{1 / 2}\left(\text { for } r_{2} \leq 1\right)
$$

where

$$
\begin{array}{lll}
X_{12} & = & \left(R N D_{12}\right)(2)-1 \\
X_{22} & = & \left(R N D_{22}\right)(2)-1 \\
r_{2} & = & X_{12}{ }^{2}+X_{22}{ }^{2}
\end{array}
$$




$$
\begin{aligned}
& R N D_{12} \text { and } R N D_{22}=\quad \text { computer generated random number } \\
& \text { from the uniform distribution from } 0 \\
& \text { to 1, shown in Figure 4.5(b). }
\end{aligned}
$$

These two values $\left(R N_{1}\right.$ and $\left.R N_{2}\right)$ are used in Equations (4.7) and (4.8) as the random number multipliers. Figure 4.5(a) and (b) show the difference between the unit normal distribution random numbers (calculated from Equation (4.12)) $R N$, and the uniform random number (computer generated) $R N D$. Figure 4.6 shows the distribution of 10,000 random numbers calculated from Equation (4.12) with mean close to zero and standard deviation close to 1 . The linear relationship between the $\mathrm{z}$ values of $R N$ and the $\mathrm{z}$ values of uniform distribution is shown in Figure 4.7. These verify that $R N \mathrm{~s}$ are random numbers from the unit normal distribution.

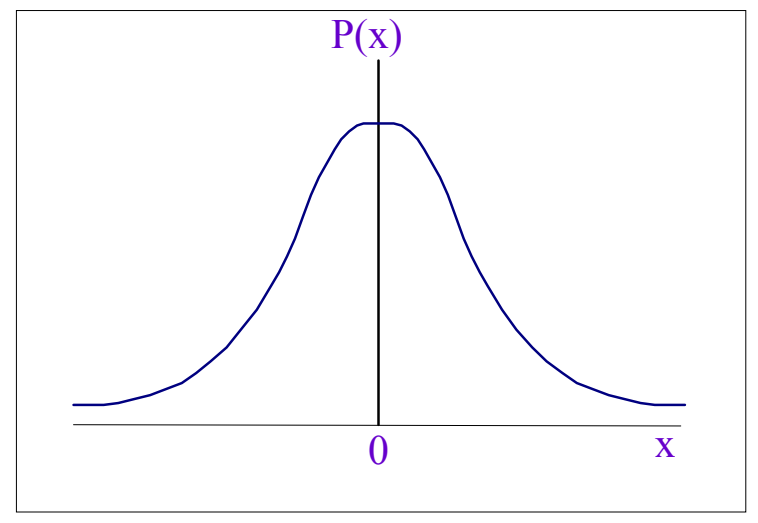

(a)

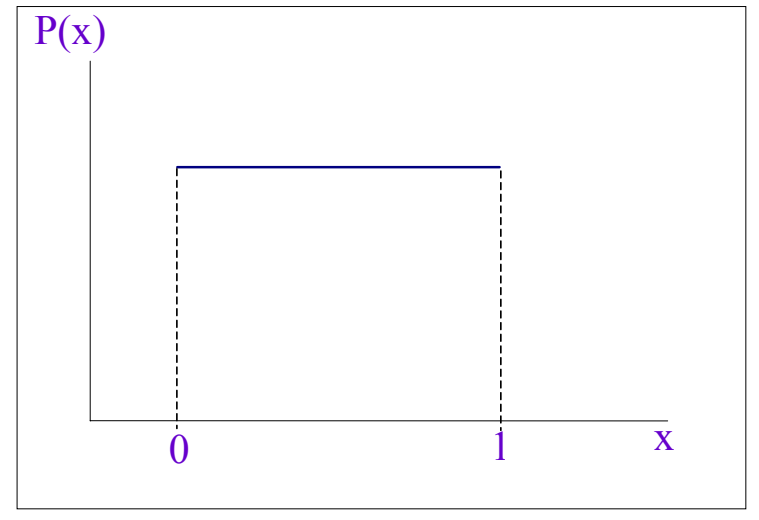

(b)

Figure 4.5: (a) $R N$, random numbers of unit normal distribution calculated from Equation (4.12). (b) $R N D$, uniform distribution of computer generated random numbers. 


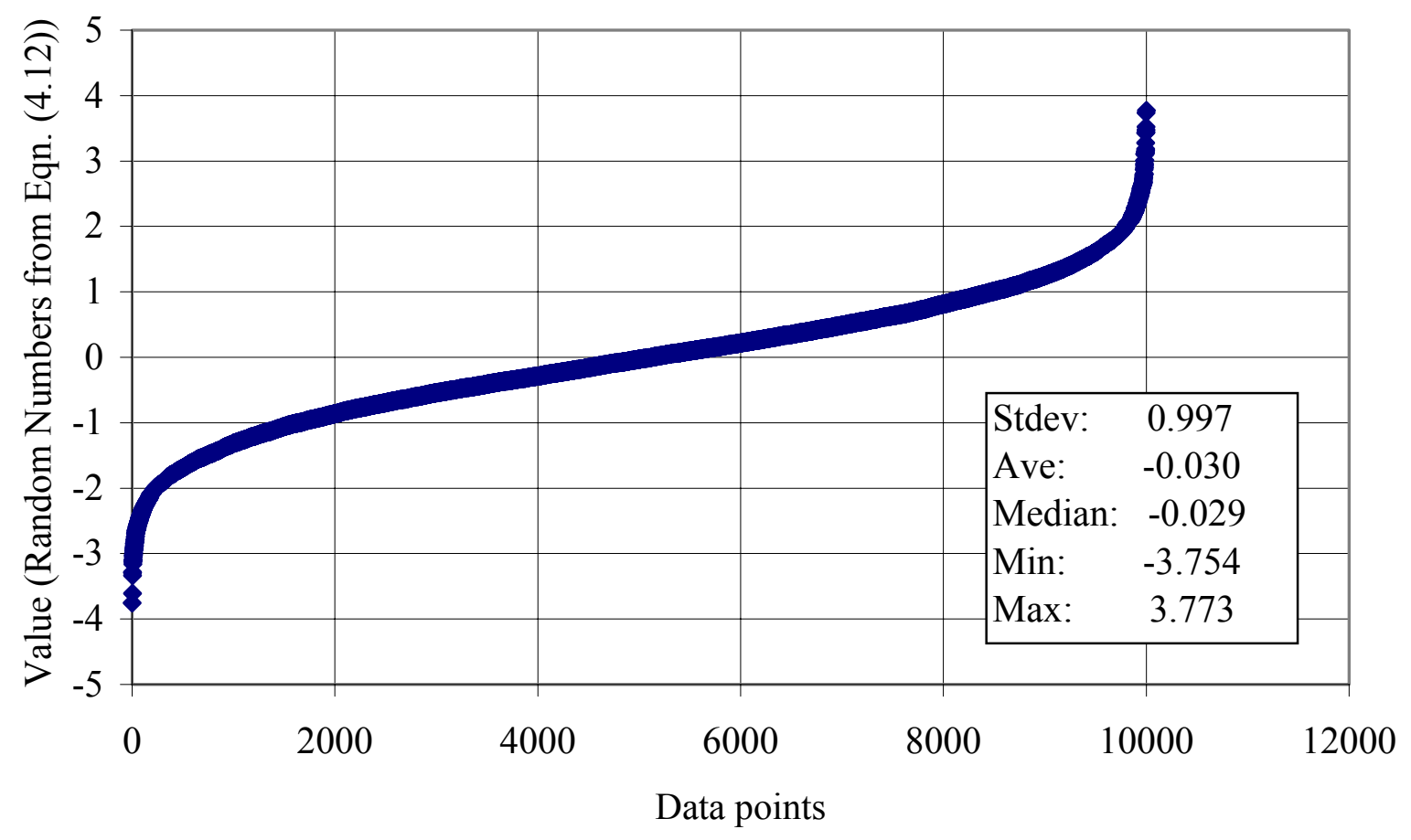

Figure 4.6: Graph shows the cumulative distribution of 10,000 data points generated from random numbers, $R N$ (using Equation 4.12).

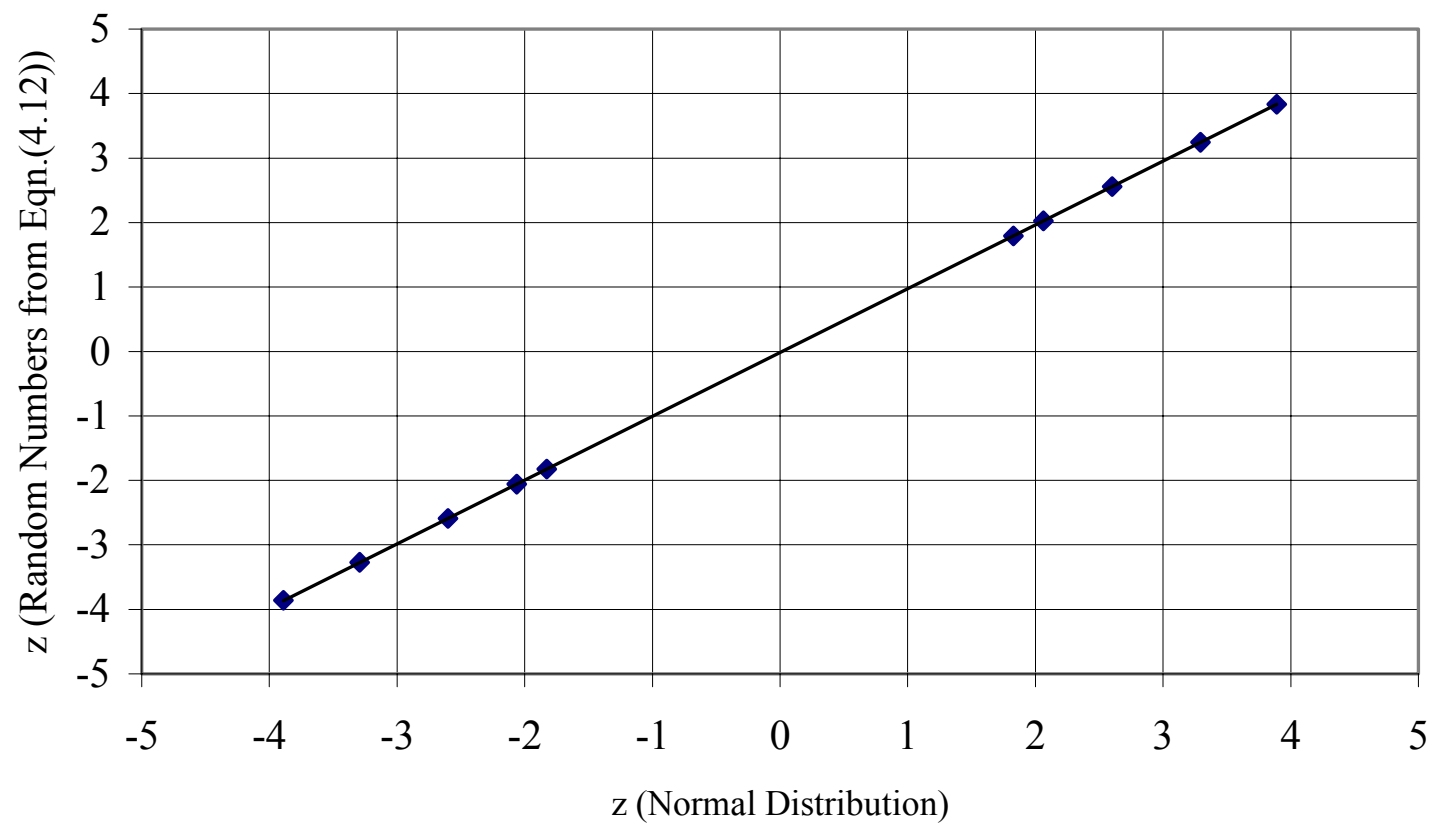

Figure 4.7: A comparison between the unit normal variable (z-value) generated from Equation (4.12) and the true unit normal distribution, $\mathrm{N}(0,1)$. 


\subsection{Particle Collisions}

Two basic collisions occur in the fluidized bed, namely particle-particle collisions and particle-wall collisions. During the movement in the fluidized bed, particles collide with other particles that are close to them (refer to Figure 3.8). These collisions cause momentum transfer from one particle to another, that result in changes in the particle velocity vector. In Subramanian's experiments, the velocity of a particle was determined by analyzing two successive images of the particle taken at a specific time interval. The position of the particle taken in the second image, may be the result of particle movement due to a collision with other particles. Therefore, it is assumed that particle-particle collisions were taken into account correctly in the experimentally determined velocity (in both $\mathrm{x}$ and $\mathrm{y}$ directions) data.

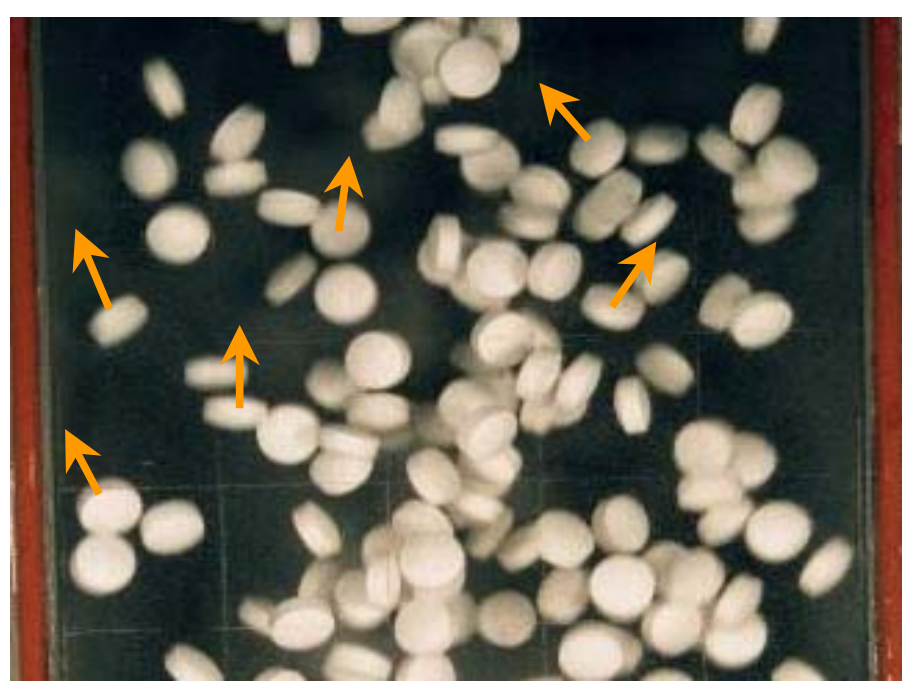

Figure 4.8: Image of tablets in fluidized bed - spouted region, (Subramanian, 2000), arrows show possible directions of particle movement. 
For the case when a particle moves towards and hits the wall of the column, a perfectly elastic collision is assumed. The new location of the particle is calculated based on the mirror image of the particle assuming that the wall is not there, as shown in Figure 4.9.

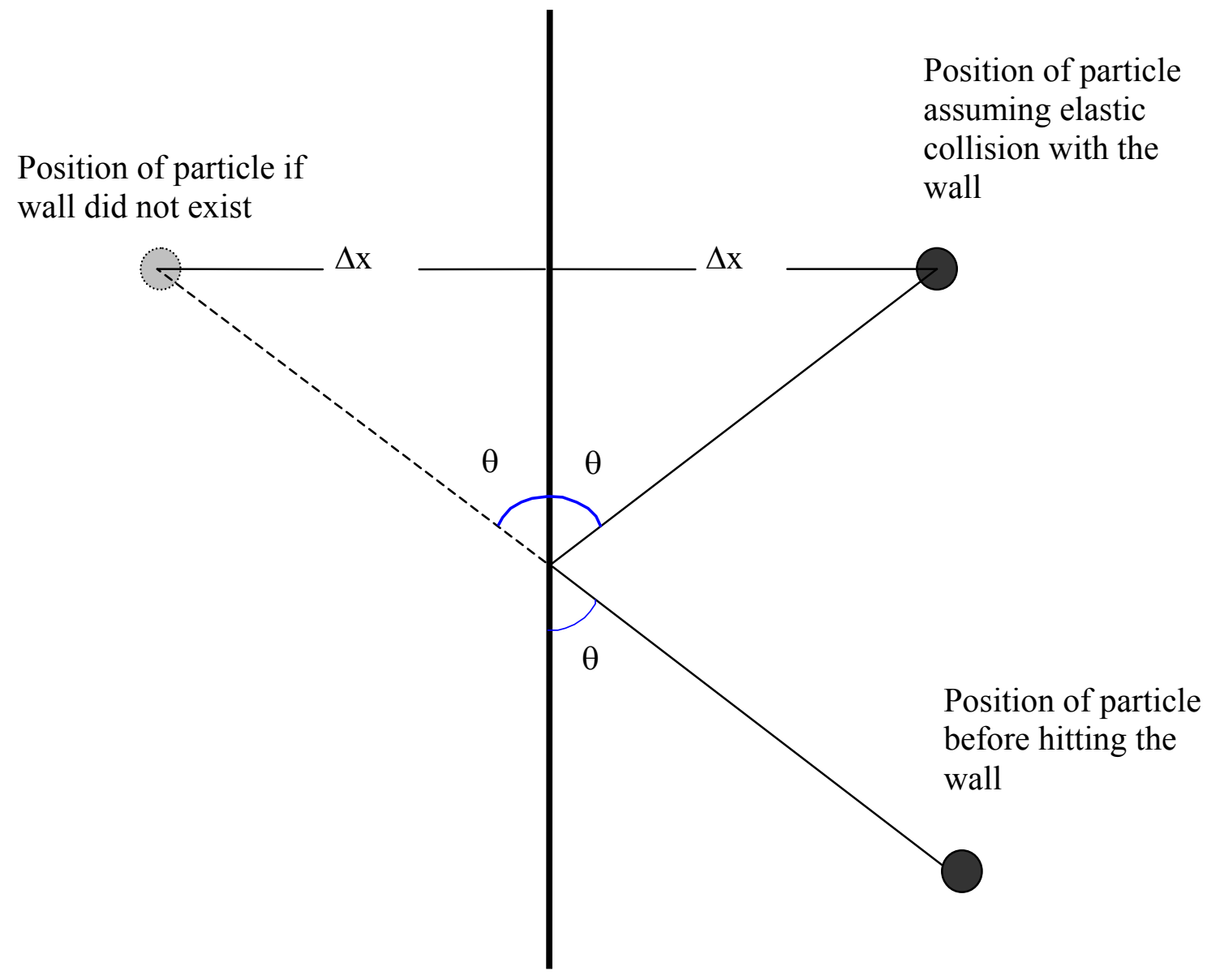

Wall

Figure 4.9: Illustration of an elastic collision with the wall. 


\subsection{Modeling the Spray and Coating of Particles}

To simulate spray material deposited onto the particles, a spray zone was defined in the model. The model performs a test to check whether the particle is in the spray zone. If the particle is not in the spray zone, the model only calculates the particle's next move. If the particle is in the spray zone, the model calculates both the amount of spray material that hits the particle at that position and the particle's next move. The method of calculating the amount of material that a given particle receives when it is in the spray zone is explained in the following sections.

\subsubsection{Particle Shape}

In order to determine the amount of particle surface area that can receive coating material, and that is not blocked by other particles, the shape of the particle needs to be specified. The particles used in Subramanian's work were pharmaceutical tablets, as shown in Figure 4.10. It was observed that as the particles moved and collided with each other they also rotated. Therefore, from Figure 4.11, the particle surface area facing the spray nozzle can be as big as the area of surface A or as small as the area of surface B. 


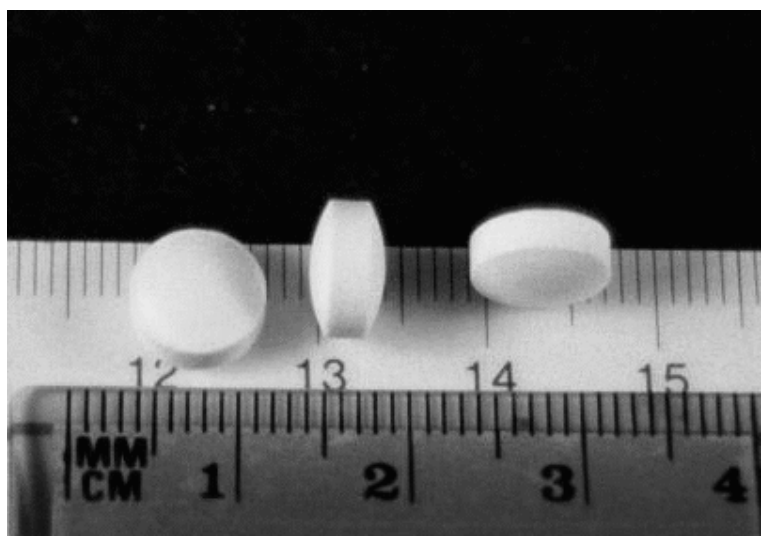

Figure 4.10: The shape of pharmaceutical tablet used in the experiment (Subramanian, 2000).

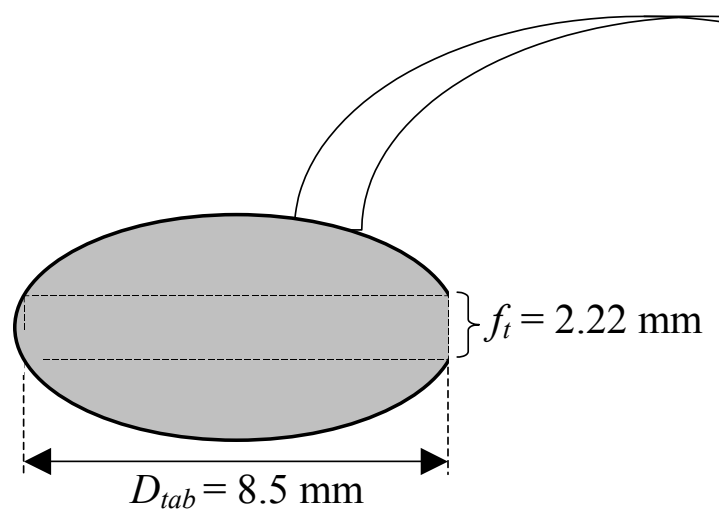

$\underline{\text { Surface A }}$

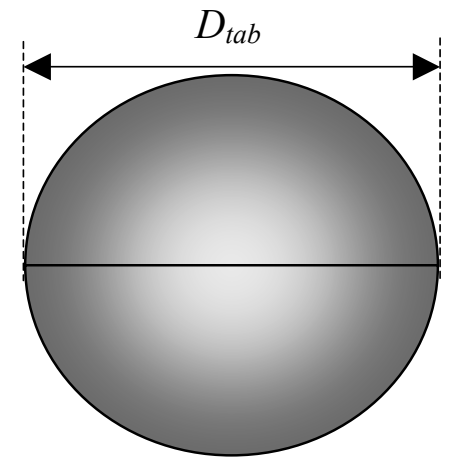

$\underline{\text { Surface B }}$

Figure 4.11: Figure illustrates the minimum (A) and maximum (B) surface areas that tablets expose to the spray. 
Essentially, the area of the tablet exposed to the spray may vary anywhere from A to B, Figure 4.11. In order to simplify the analysis, the particle shape used in the model is assumed to be a spherical particle with the same surface area as the tablet.

$$
A_{t a b}=A_{s p}
$$

where $A_{t a b}$ and $A_{s p}$ are the surface area of the tablet and the sphere respectively.

The surface area of the tablet is equal to the sum of the surface area of two spherical caps and the area of a cylinder, which is given by:

$$
A_{\text {tab }}=2(2 \pi J H)+D_{\text {tab }} f_{t}
$$

Therefore, the diameter of the sphere, $D_{s p}$ is given by:

$$
\begin{aligned}
& \pi D_{s p}^{2}=(2 \pi J H) 2+\pi D_{t a b} f_{t} \\
& D_{s p}=\sqrt{4 J H+D_{t a b} f_{t}}=2\left(J H+D_{t a b} f_{t}\right)^{1 / 2}
\end{aligned}
$$

In the simulation, the particle surface area receiving coating material, with no other particles blocking the spray, is equal to the projected surface area of the sphere of diameter $D_{s p}$.

\subsubsection{Spray Shape and Evaluation of Coating Coverage}

In order to determine the available fraction of spray that impinges on the surface of a particle at any instant, the amount of spray captured by particles in the path of the spray must be determined. To do this, the spray shape, as well as the spray density or 
spray distribution must be defined. In this work, two types of models with different spray shapes and flow directions of spray material were developed and studied.

\section{Solid Cone Spray Model}

In the initial work, the shape of the spray zone was assumed to be a solid cone and the spray density was assumed to be radially uniform with respect to the spray nozzle, as shown in Figure 4.12.

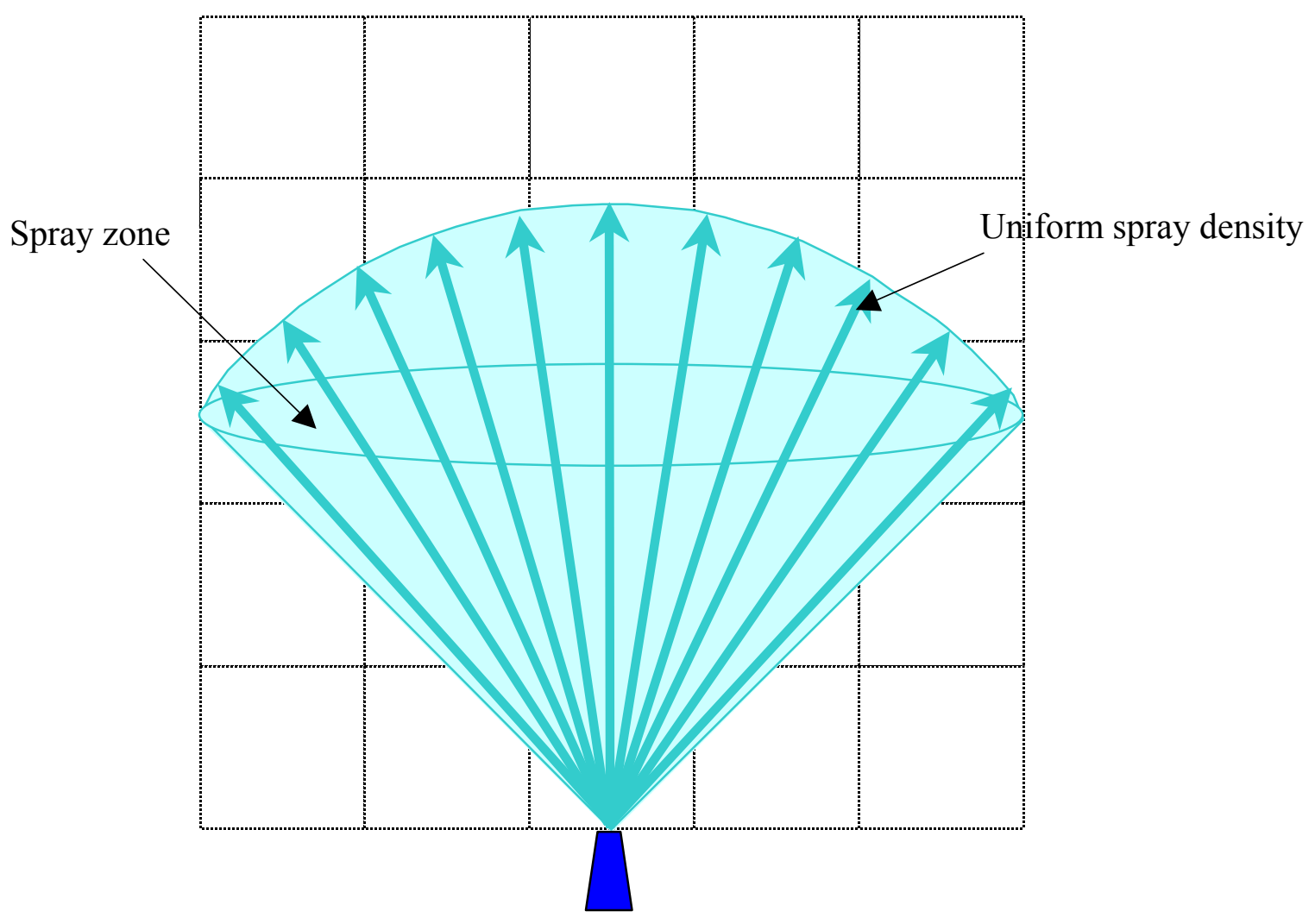

Figure 4.12: A schematic diagram illustrates a solid cone spray zone. 
The fraction of spray that hits a particle at any given position was calculated by dividing the projected spray area of the particle into $m$ elements of equal length $l$, as shown in Figure 4.13. The length $l$ is fixed for all particle positions. Therefore, the number of elements $m$, is determined by the distance of the particle from the spray nozzle.

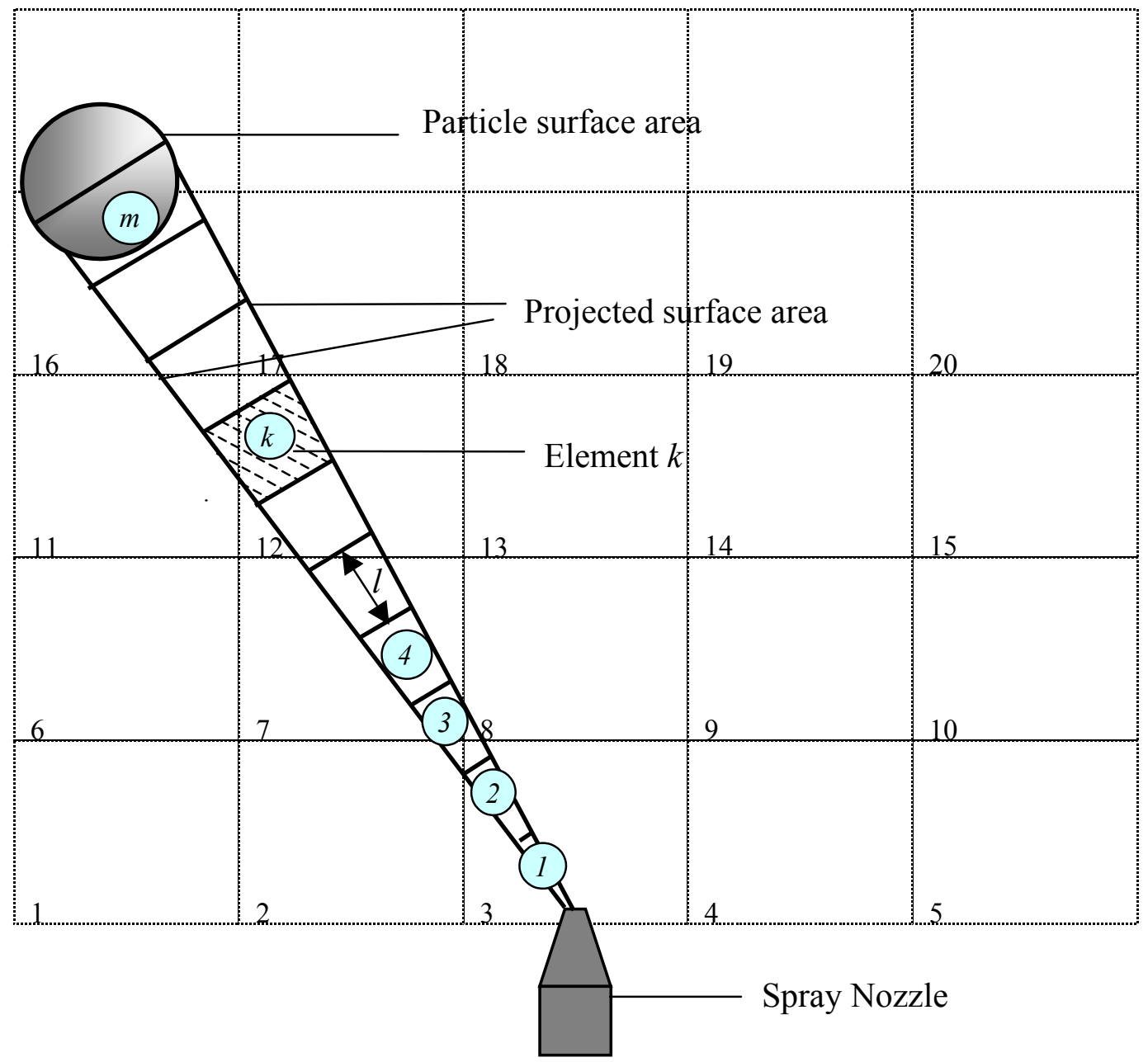

Figure 4.13: A schematic diagram illustrates the discretization of a particle's projected surface area assuming a solid cone spray shape. 
Suppose $V_{(k)}$ and $\varepsilon_{(k)}$ are the volume and voidage for element $k$, respectively, where $k$ is between 1 and $m$. The volume of all particles in element $k, V_{p(k)}$ is given by:

$$
V_{p(k)}=V_{(k)}\left(1-\varepsilon_{(k)}\right)
$$

The voidage $\varepsilon_{(k)}$ in element $k$ is equal to the voidage of the section in which the central point of the volume of element $k$ is located, see Figure 4.14.

Cross sectional area $=A_{(k+1)}$

Voidage of element, $\varepsilon_{(k)}$ depends on the voidage value at this point.

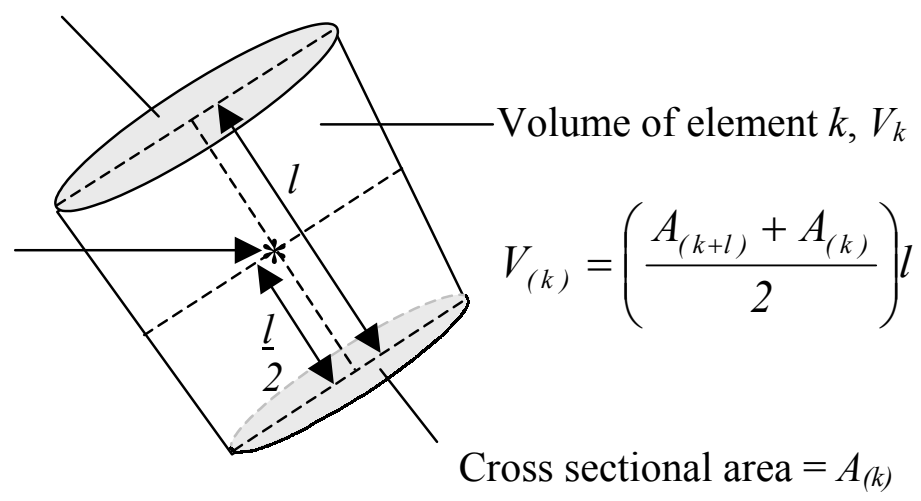

Figure 4.14: Illustration of the geometry of element $k$.

The number of particles in element $k, N_{p(k)}$, is calculated from the volume of particles in element $k, V_{(k)}$, divided by the volume of a single particle:

$$
N_{p(k)}=\frac{V_{p(k)}}{\frac{\pi}{6} D_{s p}^{3}}
$$

which is also equal to: 


$$
N_{p(k)}=\frac{V_{(k)}\left(1-\varepsilon_{(k)}\right)}{\frac{\pi}{6} D_{s p}{ }^{3}}
$$

The projected surface area of particles in element $k$ is:

$$
A_{p(k)}=\left(\frac{V_{(k)}\left(1-\varepsilon_{(k)}\right)}{\frac{\pi}{6} D_{s p}{ }^{3}}\right) \frac{\pi}{4} D_{s p}{ }^{2}
$$

which can be simplified to:

$$
A_{p(k)}=\frac{3}{2} \frac{V_{(k)}\left(1-\varepsilon_{(k)}\right)}{D_{s p}}
$$

The fraction of spray, $f_{(k)}$, entering the surface of the element at $k$ and leaving at $k+1$ is given by:

$$
f_{(k)}=1-\left(\frac{\frac{3}{2} \frac{V_{(k)}\left(1-\varepsilon_{(k)}\right)}{D_{s p}}}{\bar{A}_{(k)}}\right)
$$

where $\bar{A}_{(k)}$ is the average cross sectional area through which the spray passed into element $k$ which is calculated by (refer to Figure 4.14):

$$
\bar{A}_{(k)}=\frac{A_{(k)}+A_{(k+1)}}{2}
$$

The fraction of spray, $f_{(k)}$ is:

$$
f_{(k)}=1-3\left(\frac{V_{(k)}\left(1-\varepsilon_{(k)}\right)}{D_{s p}\left(A_{(k)}+A_{(k+1)}\right)}\right)
$$


Finally, the total fraction of spray, $F_{m}$, hitting the particle at location $m$ is given by:

$$
F_{m}=f_{(1)} f_{(2)} f_{(3)} \ldots f_{(m)} .
$$

By assuming the spray shape to be spherically symmetric, the amount of spray material deposited onto a particle at location $m$ is calculated as:

$$
S_{m}=F_{m} m_{s} \frac{A_{s p}}{A_{c a p}} \Delta t
$$

where $m_{s}$ is the mass flow rate of the spray material, $A_{s p}$ is the particle surface area and $A_{\text {cap }}$ is the area of the spherical shell of the spray material passing through the tablet. The area of this semi-circular spherical cap $A_{c a p}$, is equal to (refer to Figure 4.15):

$$
A_{\text {cap }}=2 \pi J H
$$

where $J$ and $H$ are the radius and the height of the spherical cap, respectively.
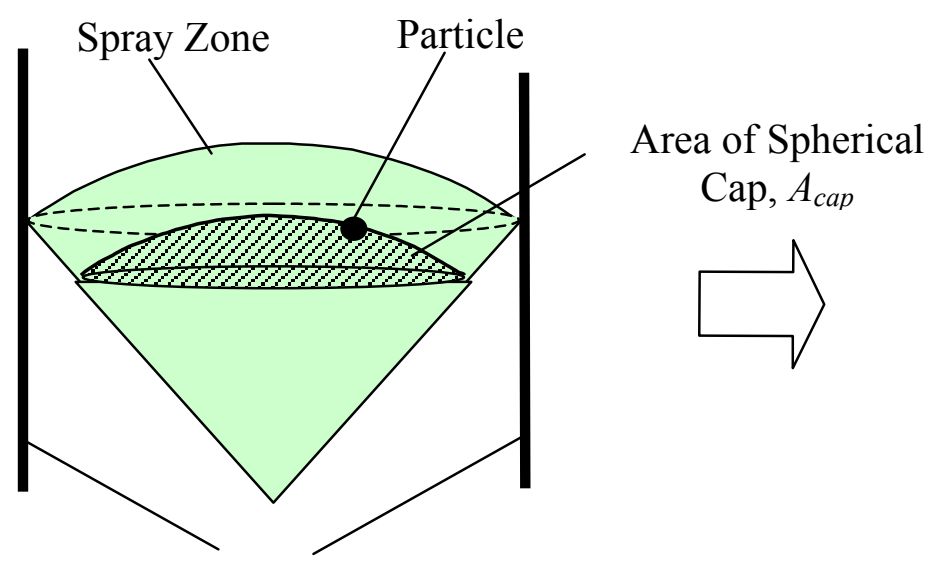

Draft Tube

Figure 4.15: A schematic diagram of a spherical cap in the spray zone 
However, if the particle is very close to the spray nozzle, the area of the particle, $A_{s p}$ may be bigger that the area of the spherical cap of the spray material $A_{c a p}$. For this case, $A_{s p}$ is set equal to $A_{c a p}$. For this condition, all of the spray material is deposited on the particle, refer to Figure 4.16.

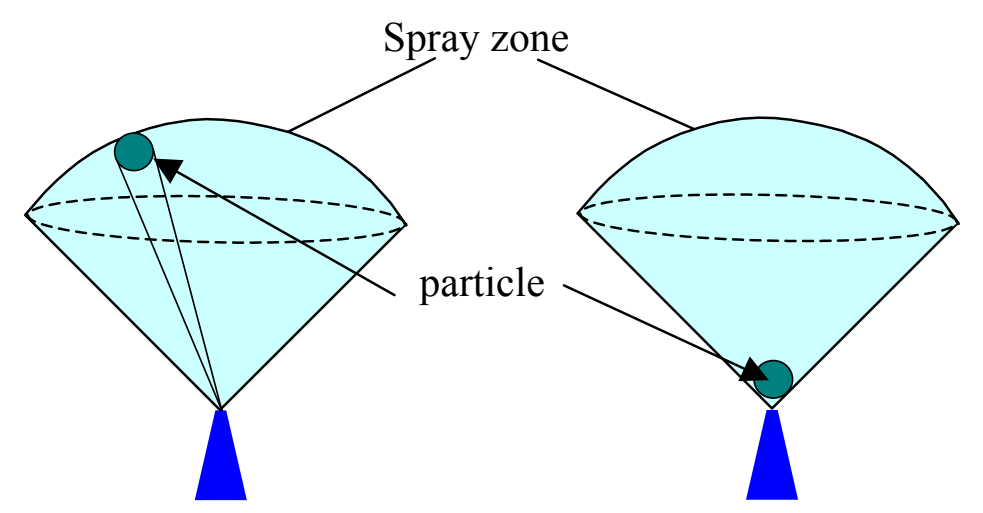

\begin{abstract}
A fraction $=A_{\text {sp }} / A_{\text {cap }}$ of spray material may hit the particle
\end{abstract}
All of spray material may hit the particle

Figure 4.16: A schematic diagram shows the effect of particle position in the spray zone on the fraction of spray material received by the particle.

As the particle moves from one point to another in the spray zone, it will collect different amounts of spray material. The amount of spray collected by the particle during its movement in the spray zone is equal to the sum of the amounts of spray material collected by the particle for each move. Assuming that the particle enters the spray zone after taking $j$ steps and starts to receive the spray material at step $j+1$ and leaves the spray 
zone after step $j+n$, the total amount of spray collected by the particle during its movement through the spray zone is given by:

$$
S_{\text {Total }}=\sum_{i=j+1}^{j+n}\left(\frac{S_{m_{i}}+S_{m_{i+1}}}{2}\right)
$$

\section{Uniform Upward Spray Model}

A simple experiment (refer to Appendix IV for details) was carried out to investigate the flow direction of the spray nozzle. A piece of white blotting paper with the same dimensions as the draft tube was pasted to the draft tube wall. The fluidized bed (without particles) and the spray nozzle with spraying material were allowed to run for a few minutes. Based on the observation, the spray material was found after a certain distance to move vertically upward from the bottom of the bed as shown in Figure 4.17. The spray droplets were found to travel in the y-direction (upward direction) together with the fluidizing air, consistent with this observation, the blotting paper was found to be uniformly wet and stained all the way to the top of the draft tube.

The conclusion from the observation is that without tablets present, the spray density is uniform in the y-direction as illustrated in Figure 4.18. Therefore, the projected surface area of the tablet that intersects with the spray is simply a cylinder with diameter equal to the particle diameter $D_{s}$ and height equal to the distance of the particle from the bottom of the bed. In this case, the number of elements, $m$ is determined by the distance of the particle from the bottom of the bed (refer to Figure 4.19). However, the spray density was found to vary in the radial position with all operating conditions. Details of the spray density at different atomizing air flow rate are given in Appendix V. 


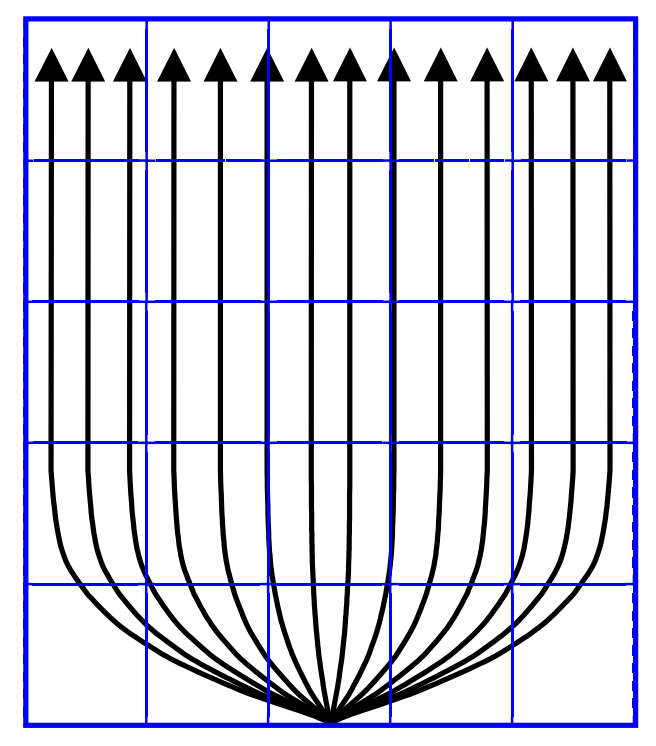

Figure 4.17: A schematic diagram illustrates the flow direction of spray material when running in a fluidized bed (with fluidizing air) without particles. Arrows show the flow direction of the spray material along the draft tube.

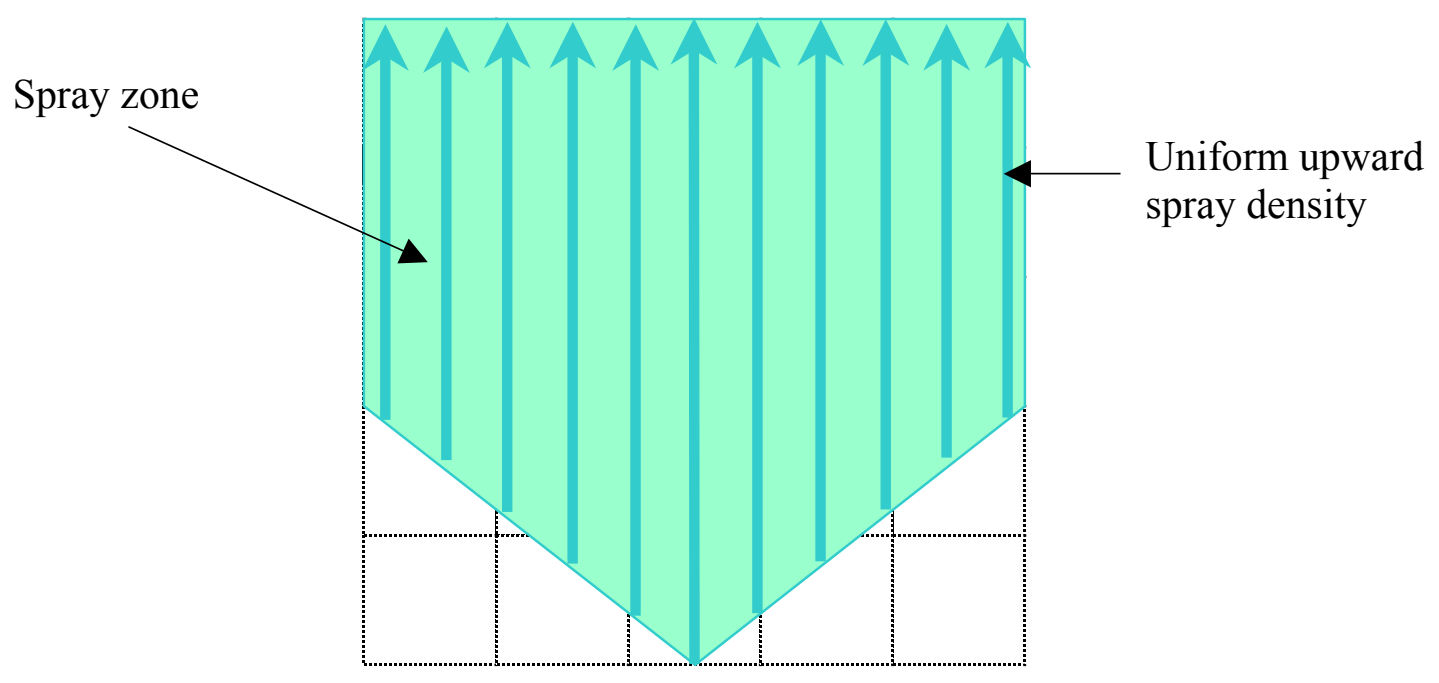

Figure 4.18: A schematic diagram of the shape of a uniform, upward moving spray. 
As defined in the previous section, $V_{(k)}$ and $\varepsilon_{(k)}$ are the volume and voidage for element $k$ respectively, where $k$ is between 1 and $m$. Similarly, the volume of particles in element $k, V_{p(k)}$ is given by Equation (4.17).

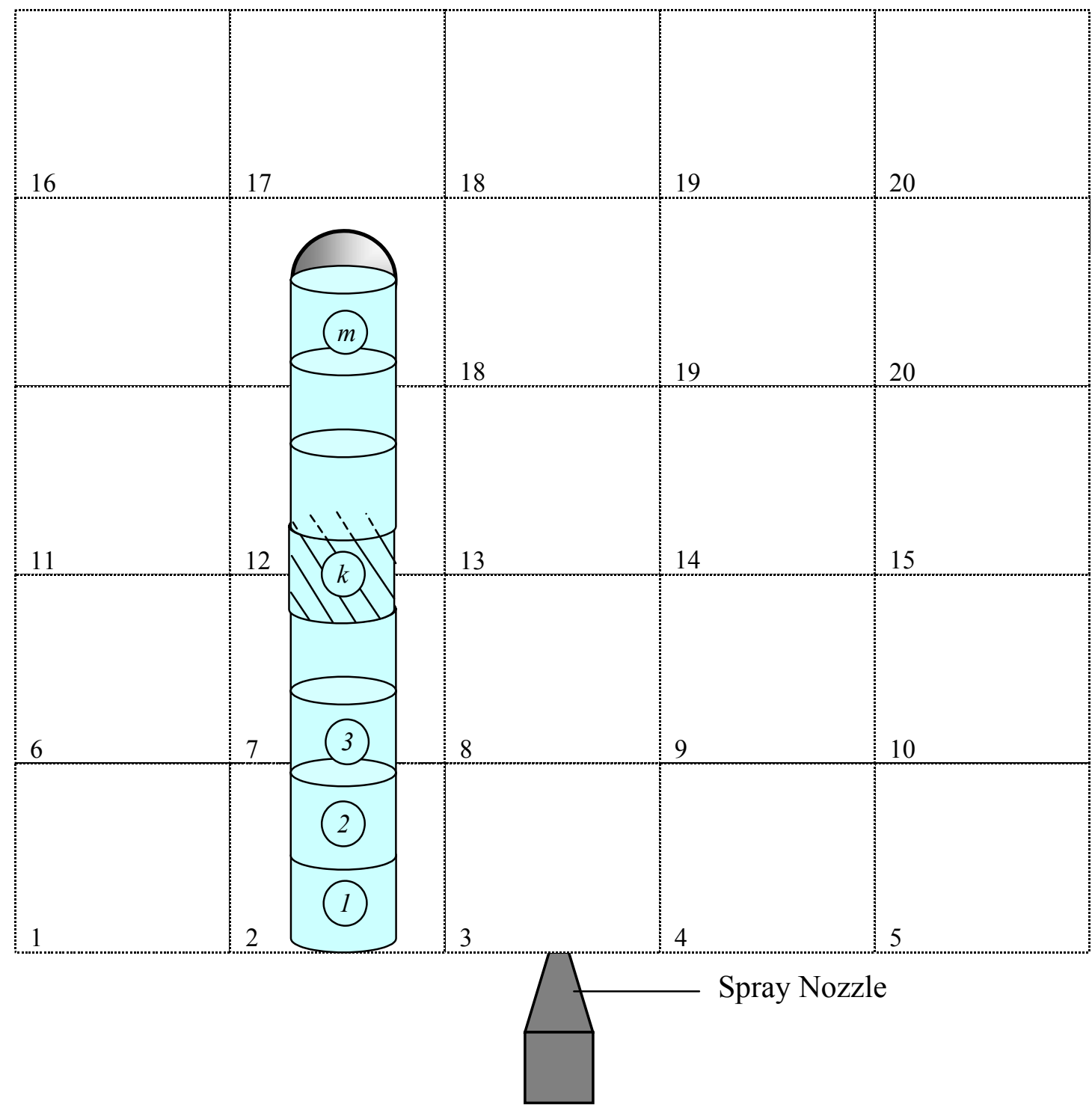

Figure 4.19: A schematic diagram illustrates the discretization of the particle projected surface area with the uniform, upward spray shape assumption. 
The voidage $\varepsilon_{(k)}$ in element $k$ is equal to the voidage of the section in which the central point of the volume of element $k$ is located, shown in Figure 4.20.

The number of particles in element $k, N_{p(k)}$, is given by Equations (4.18) and (4.19). The projected surface area of particles in element $k$ is given by Equations (4.20) and (4.21). The fraction of spray, $f_{(k)}$, entering $k$ and leaving at $k+1$, which is given by Equation (4.22), is simplified to the following equation:

$$
f_{(k)}=1-3\left(\frac{V_{(k)}\left(1-\varepsilon_{(k)}\right)}{2 D_{s p} A_{(k)}}\right)
$$

This simplification can be made because the cross sectional area of the element is constant

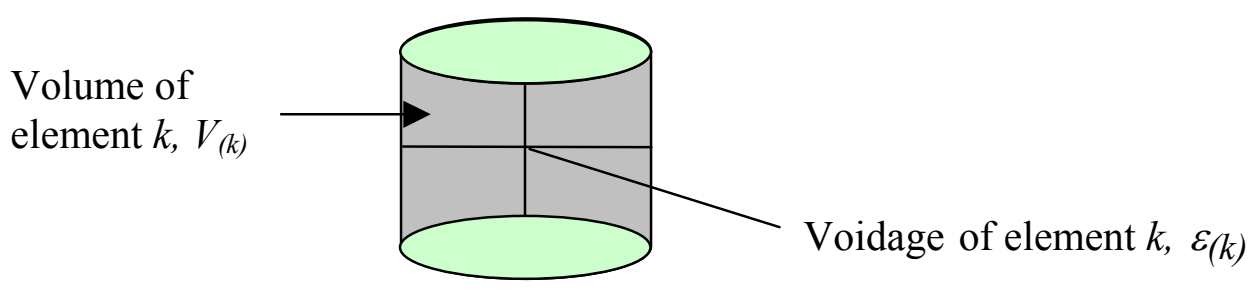

Figure 4.20: Schematic diagram illustrates a cylindrical volume of element, $k$

The total fraction of spray, $F_{m}$, hitting the particle at location $m$ is similar to the previous case, which wass given by Equation (4.25). However, the total available fraction of spray is a function of the fraction of spray $F_{m}$, the ratio of area of the tablet or particle, to the area of the segment, and the spray distribution fraction for the segment, 
$S_{\text {dist. }}$ A segment is referred to as half of a semi-circular fluidized bed section (for example, section 1 consists of segment $1 \mathrm{a}$ and segment $1 \mathrm{~b}$ ).

Therefore, the amount of spray material deposited on to a particle at location $m$, $S_{m}$ is calculated by using the following equation:

$$
S_{m}=F_{m} m_{s} \frac{A_{s p}}{A_{s e g}} S_{\text {dist }} \Delta t
$$

Consider the spray distribution (details are discussed in Section 5.2.6) in Figure 4.21 and suppose the particle is located $1.4 \mathrm{~cm}$ horizontally from the spray nozzle. Therefore, the area of the segment $A_{\text {seg, }}$, is equal:

$$
A_{\operatorname{Seg} 4(a)}=\frac{1}{4} \pi\left(R_{1.5}^{2}-R_{1.0}^{2}\right)
$$

where $R_{1.0}$ and $R_{1.5}$ are equal to $1.0 \mathrm{~cm}$ and $1.5 \mathrm{~cm}$ respectively. The corresponding fraction of the spray distribution $S_{\text {dist }}$ would be 0.0748 .

Similarly, as explained in the case of solid cone spray shape, the total amount of spray collected by the particle during its movement through the spray zone is calculated using Equation (4.28). 


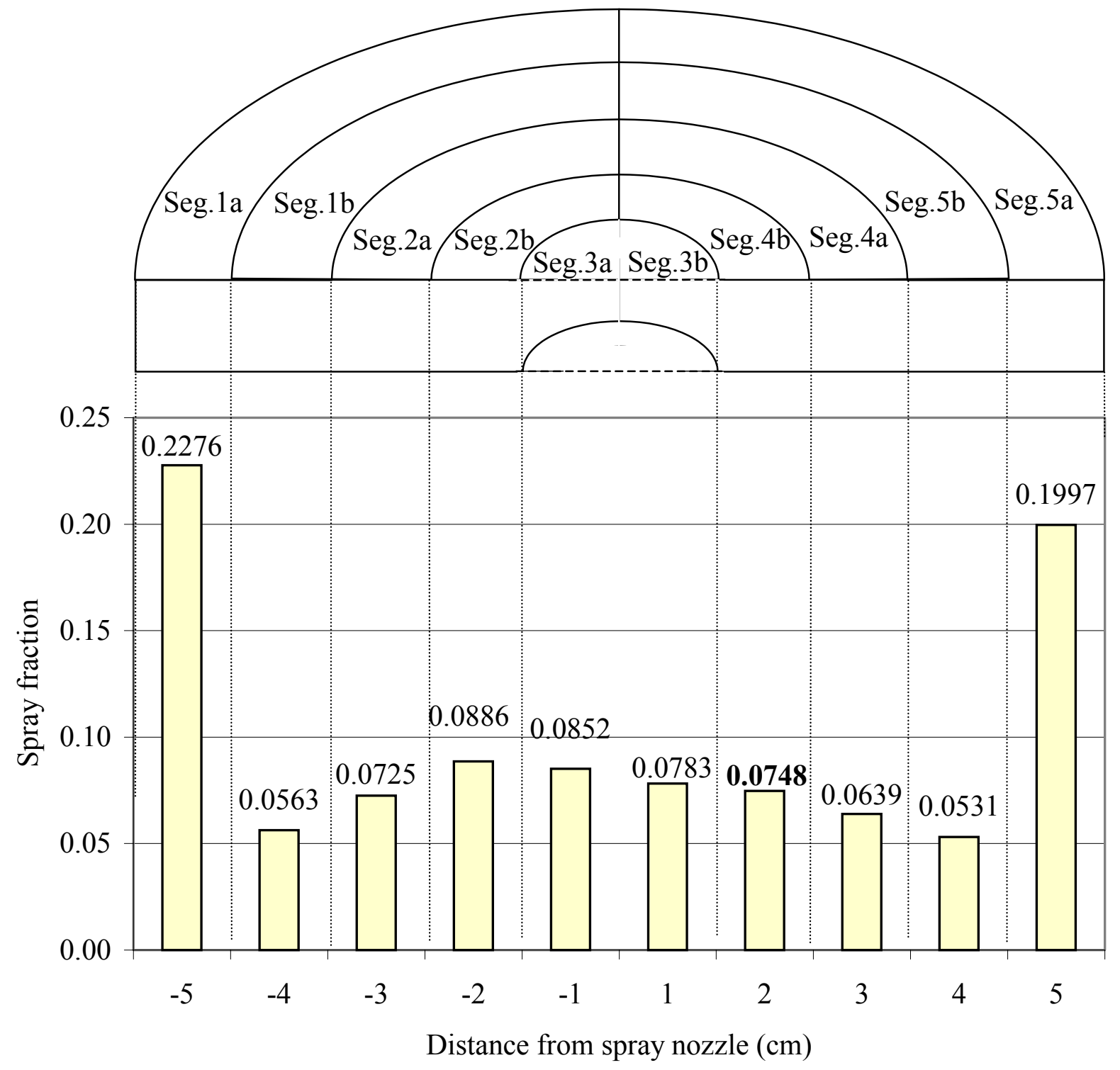

Figure 4.21: A schematic diagram illustrates a spray distribution as a function of radial position in the spouted region. The details of this spray distribution are given in Section 5.2.6. 


\section{CHAPTER 5: RESULTS}

\subsection{EXPERIMENTAL RESULTS FROM PULSE TESTS}

Experimental pulse tests were done under two different bed conditions; without a particle deflector and with a modified deflector, as explained in Chapter 3. The operating conditions for the No-Deflector case and the Modified-Deflector case were similar to Run 6 and Run 5 from Subramanian's experiments, respectively. Refer to Appendix VII for Subramanian's experimental matrix. The coating distributions obtained from pulse test experiments for these two cases are compared with the simulation results using the input data taken from Runs 6 and 5, respectively.

\subsubsection{Results for Experiments without a Particle Deflector (No-Deflector Case)}

A pulse test experiment was performed following the procedure described in Chapter 3. At the end of the experiment, 100 coated-tablets were sampled and analyzed. In order to confirm the results, the sampling was repeated three times. Thus, a total of 300 tablets were analyzed. The results of the experiments are summarized in Table 5.1.

The summary of the results for the tablet analysis are given in Figure 5.1. The binning was determined from the maximum and minimum values of the 300 tablets. The bin range was calculated by the Equation (5.1):

$$
x_{1+i}=x_{i}+\frac{(\max -\min )}{10}
$$

where $i$ ranging from zero to nine. 
Figure 5.1 shows the summary of the experimental results for each 100-tablet analysis run as well as the overall analysis (referred to as 'All runs'). For comparison purposes, the frequency data for the overall results was normalized to 100 tablets.

From the result of Analysis of Variance (ANOVA), the differences between Run 1 and 2 as well as between Run 2 and 3, are not statistically significant, with the pvalues* of 0.007813 and 0.4267 , respectively. Therefore, the results for the pulse test of the No-Deflector case can be represented by the overall analysis ('All Runs'). This result, which represents the coating distribution for No-Deflector case, is compared with the simulation results (at the same bed operating conditions) from the coating model developed in this study.

Table 5.1: $\quad$ Summary of No-Deflector pulse test experimental results.

\begin{tabular}{|l|l|l|l|l|}
\hline Data & Run 1 & Run 2 & Run 3 & All runs \\
\hline Min & 0.00070 & 0.00158 & 0.00137 & 0.00070 \\
\hline Max & 0.02170 & 0.01440 & 0.01275 & 0.02170 \\
\hline Mean & 0.00520 & 0.00414 & 0.00390 & 0.00441 \\
\hline Std Dev & 0.00321 & 0.00227 & 0.00216 & 0.00264 \\
\hline
\end{tabular}

*P-values is a smallest value of the significant level for the calculated test statistics. 


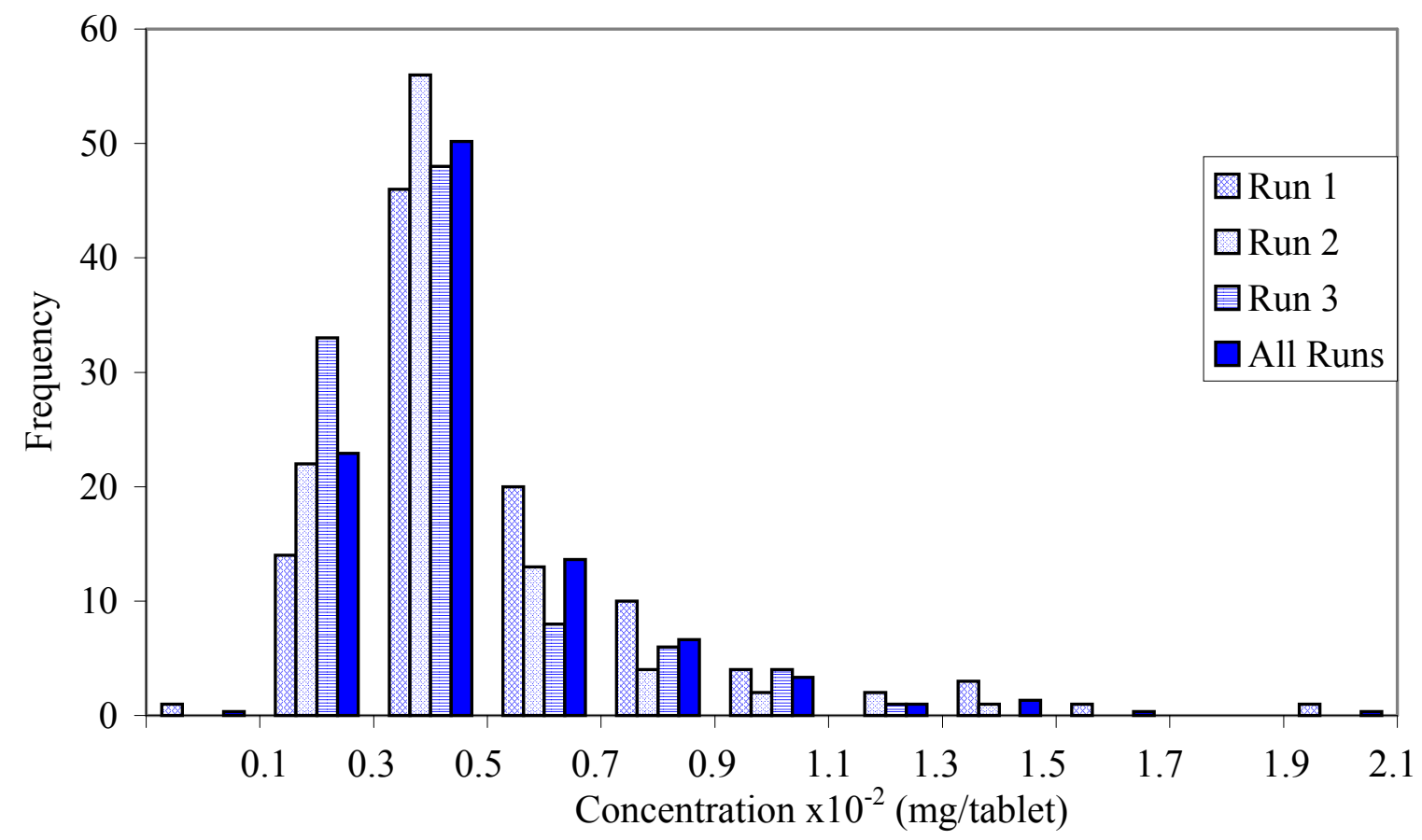

Figure 5.1: The results of the pulse test experiments for the No-Deflector case.

\subsubsection{Results for Experiments with the "Optimized" Particle Deflector (Modified-Deflector Case).}

Pulse test experiments were also performed using the modified deflector and 100 of coated tablets were sampled for analysis. Since the data from each sample of the NoDeflector run were consistent, the sampling for this run was done only twice, which meant a total of 200 tablets was analyzed. The ANOVA result between these two runs gave a p-value of 0.9998 , which means the difference is not statistically significant. The same method was used to determine the binning of the histogram plot. The results of the analysis are summarized in Table 5.2 and the data are plotted in Figure 5.2. 
Table 5.2: $\quad$ Summary of Modified-Deflector pulse test experimental results.

\begin{tabular}{|l|l|l|l|}
\hline Data & Run 1 & Run 2 & All runs \\
\hline Min & 0.00097 & 0.00223 & 0.00097 \\
\hline Max & 0.01278 & 0.00817 & 0.01278 \\
\hline Mean & 0.00417 & 0.00419 & 0.00418 \\
\hline Std Deviation & 0.00162 & 0.00123 & 0.00144 \\
\hline
\end{tabular}

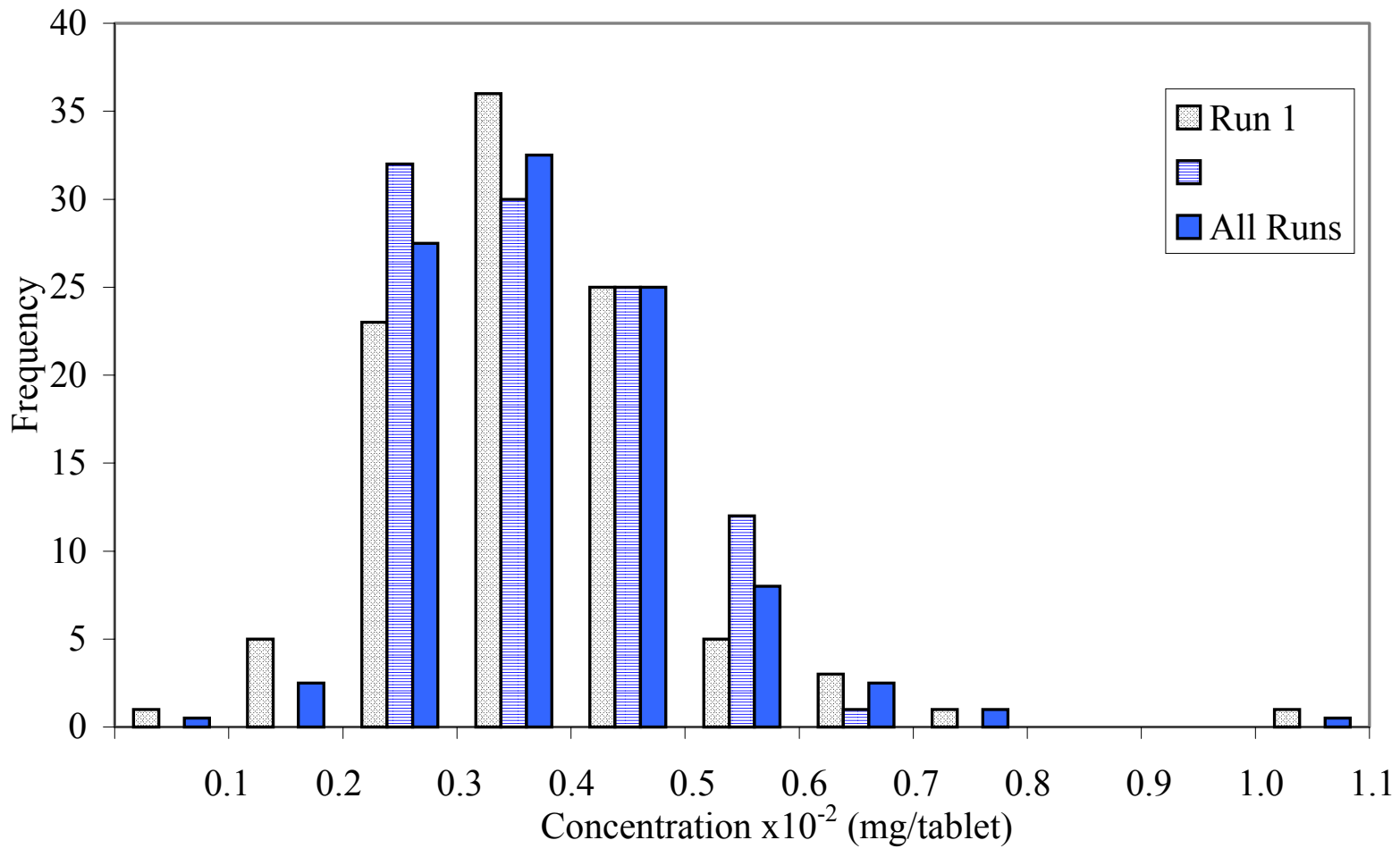

Figure 5.2: The results of the pulse test experiments for the Modified-Deflector case. 


\subsection{SIMULATION RESULTS}

A Visual Basic ${ }^{\circledR}$ program, based on the theoretical development of the coating model given in Chapter 4, was developed to simulate a fluidized bed coating equipment. This model was developed to predict the amount of coating material deposited onto each particle during a single pass through the spray zone. The calculation method and assumptions used in the model are explained in Chapter 4. In this section, the validation of the model, as well as the results, are discussed.

\subsubsection{Validation of the Model for Particle Movement}

Before the spray concept was introduced into the model, the ability of the model to simulate the 'correct' particle movement was validated. This was done, by simulating the model using Subramanian's experimental data of velocity (in the $\mathrm{x}$ and $\mathrm{y}$ directions) and voidage. The results of the simulation were compared with the voidage and velocity profiles from Subramanian's experimental data obtained at the same bed operating condition.

The results of the simulation of 150 particles, are shown in Figure 5.3. Each shaded line represents the movement of a particle. It is seen that the directions of the particle movement and the bed voidage are similar to the experimental profiles shown in Figures 5.4 and 5.5 respectively. For example, both simulation and experiment have low voidage at the areas surrounded by circles and high voidage at the area surrounded by rectangles. However, in the region close to the right side of the draft tube wall the simulation result indicates low voidage region instead of high voidage as shown in the experimental profile. This could be the effect from the raw data at the bottom of the bed 
where the bed voidage is low and the velocity of the particle in the y-directions is almost straight up, thus results in the low voidage region at the draft tube wall.

THE FIGURE IS SHOWING EXPERIMENT \#: 2

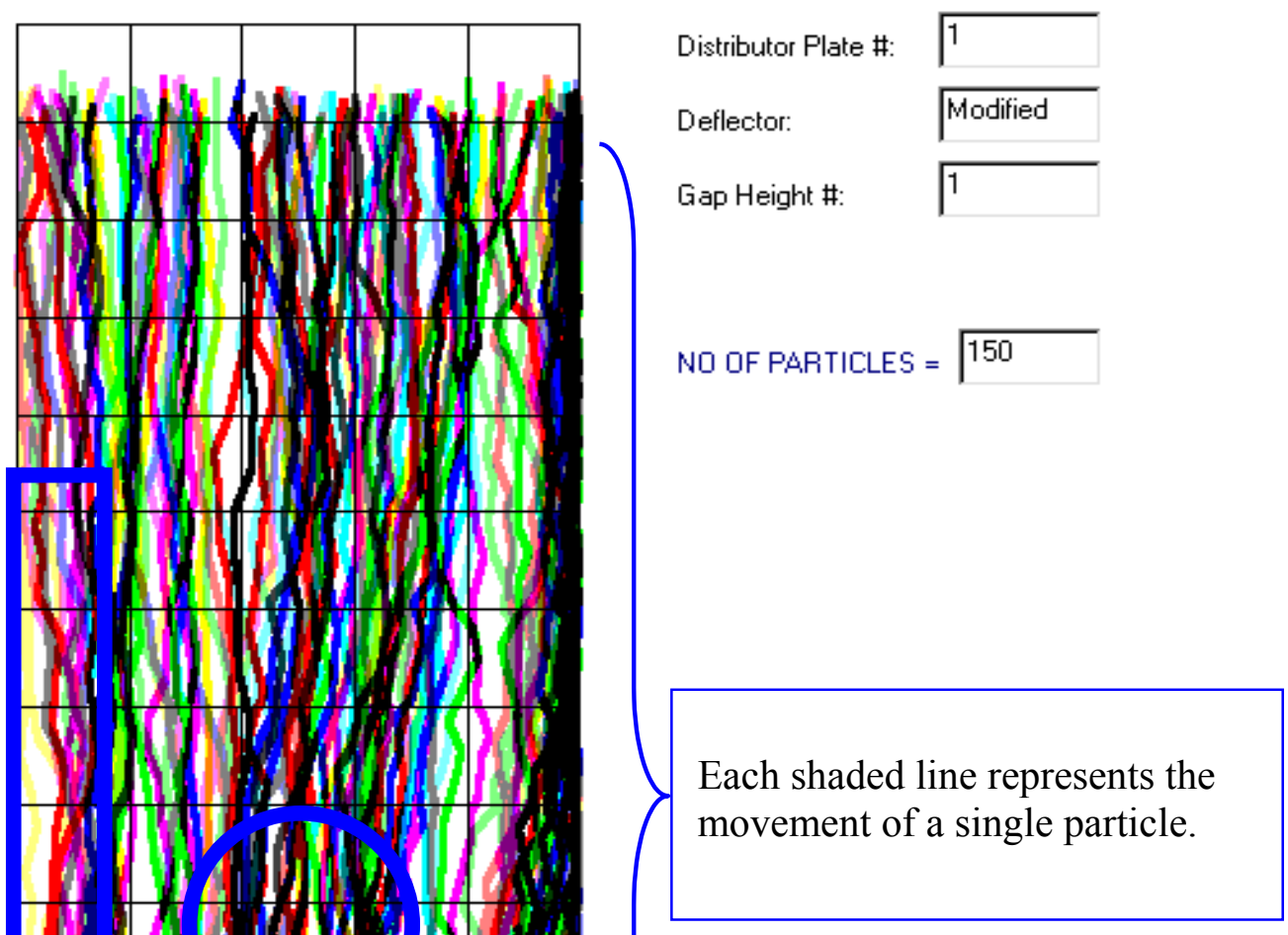

Figure 5.3: Simulation of particle movement using data from Run 2 of Subramanian, 2001. 


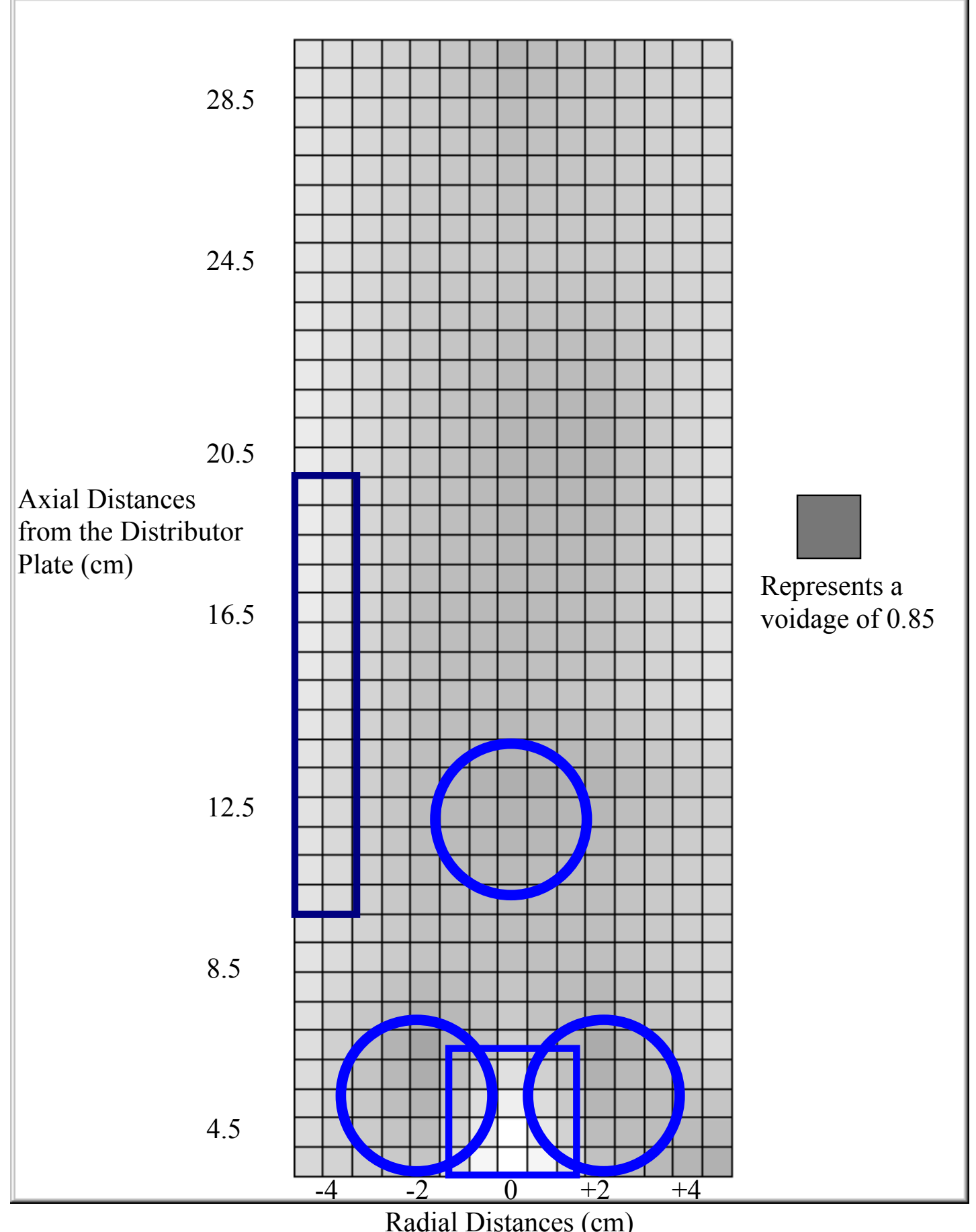

Figure 5.4: Voidage map in the draft-tube at different axial locations for experimental Run 2 (Subramanian, 2001). 


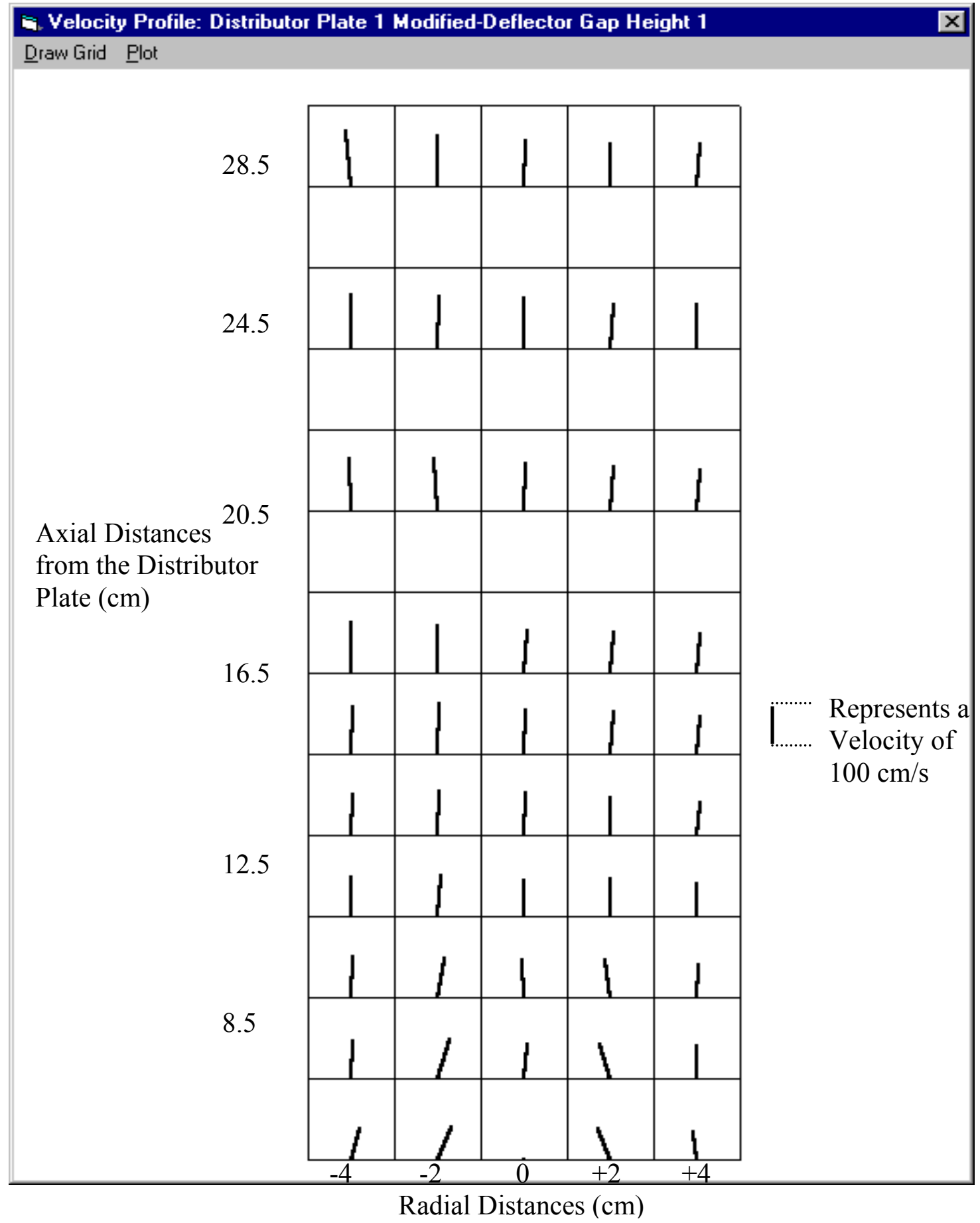

Figure 5.5: Particle velocity map in the draft-tube at different axial locations, for experimental Run 2 (Subramanian, 2001). 


\subsubsection{Validation of Particle Coating Model using Uniform Velocity and Voidage Model (Cheng 1993)}

Before the coating model can be employed to predict the coating variation, the functionality of the fundamental concepts used in the model were verified. This was done by comparing the simulation results from the model with the analytical model developed by Cheng (1993). In Cheng's Model, the amount of coating material deposited per particle per pass, was predicted by assuming the following operating conditions, which are illustrated in Figure 5.6:

- Particles moved with uniform velocity in the y-direction (vertically) and zero horizontal velocity.

- Voidage of the bed was uniform throughout the spray zone.

- The shape of the spray zone was a hollow cone with uniform spray density.

- The coating material that failed to hit the particles was assumed to be lost from the system.

- The shape of a particle was spherical

In order to verify the coating model using Cheng's assumption, the orientation of the discretization used in the simulation had to be adjusted to be identical to the orientation of the integrated segments used in Cheng's Model, as illustrated in Figure 5.7. Instead of discretizing the projected surface area of the coating model into several sections parallel to the particle surface area with respect to the spray nozzle (as shown in Figure 4.4), the projected surface area is discretized vertically, as shown in Figure 5.8. Using these assumptions, the fraction of spray passing through each of the discretized segments in both models are calculated using the equations listed in Table 5.3. 


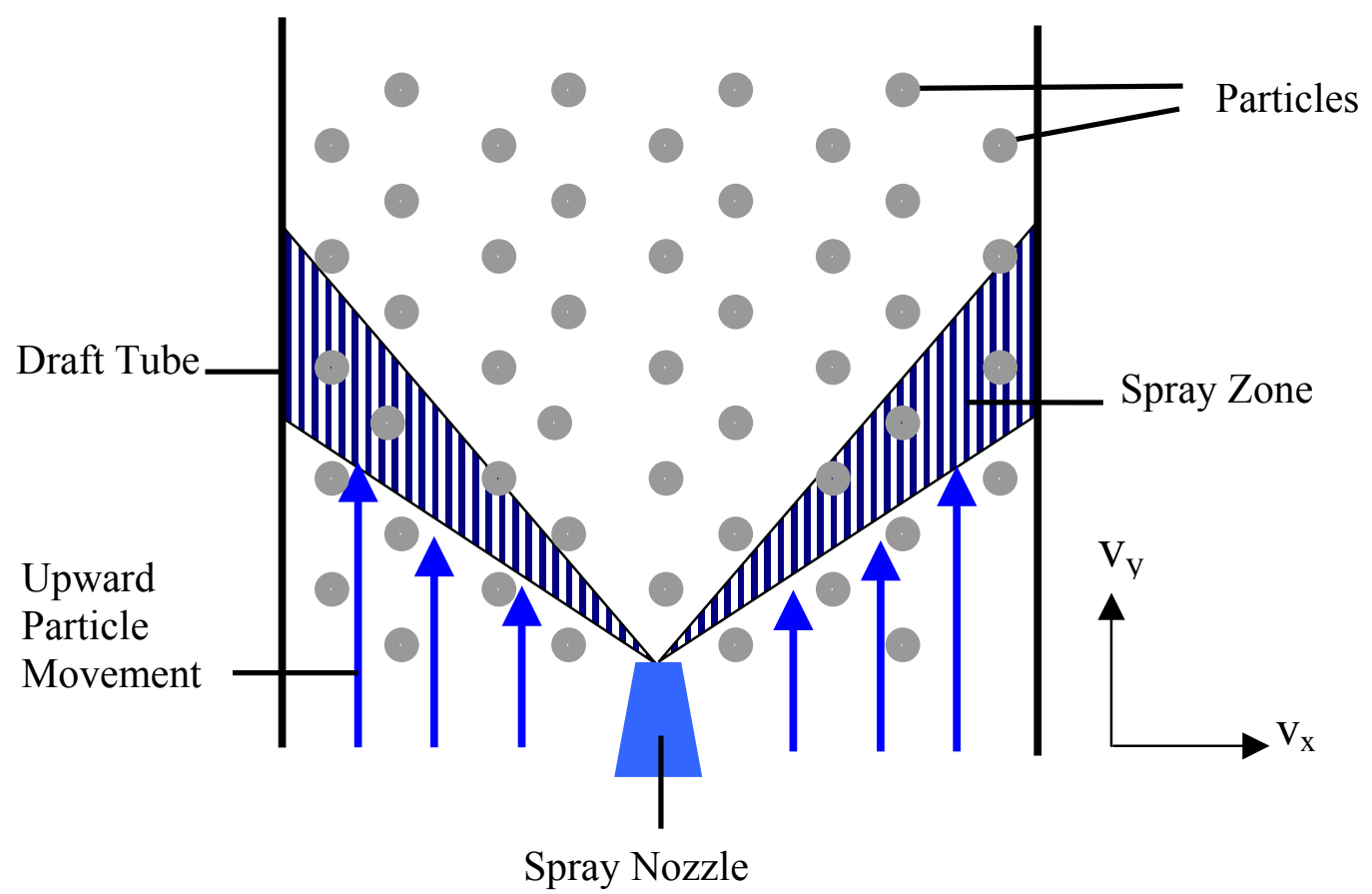

Figure 5.6: Illustration of the assumptions used in Cheng's Model.

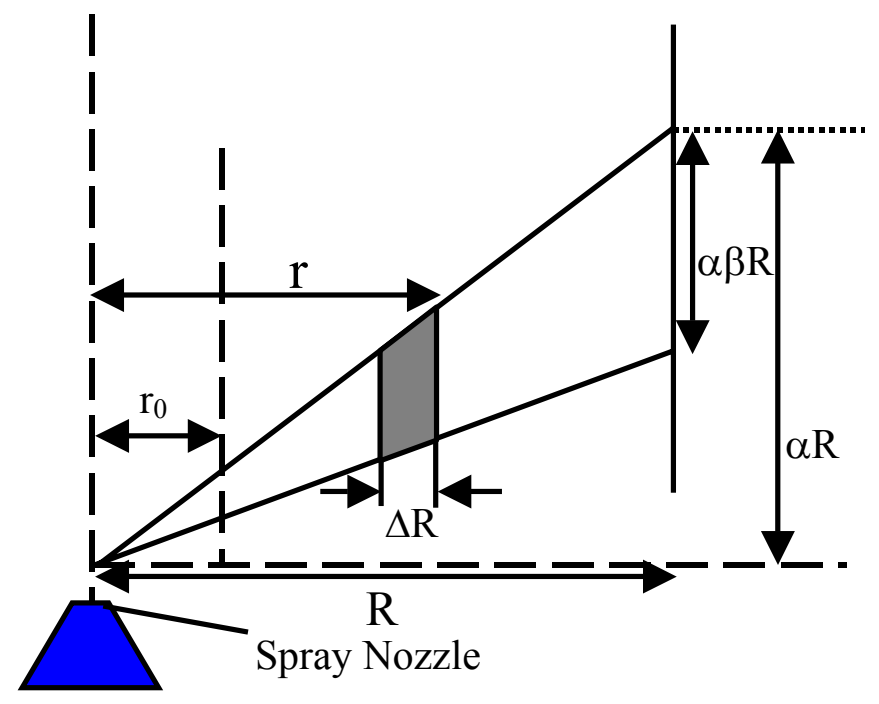

Figure 5.7: A schematic diagram illustrates the technique of discretizing the projected surface area in Cheng's Model. 


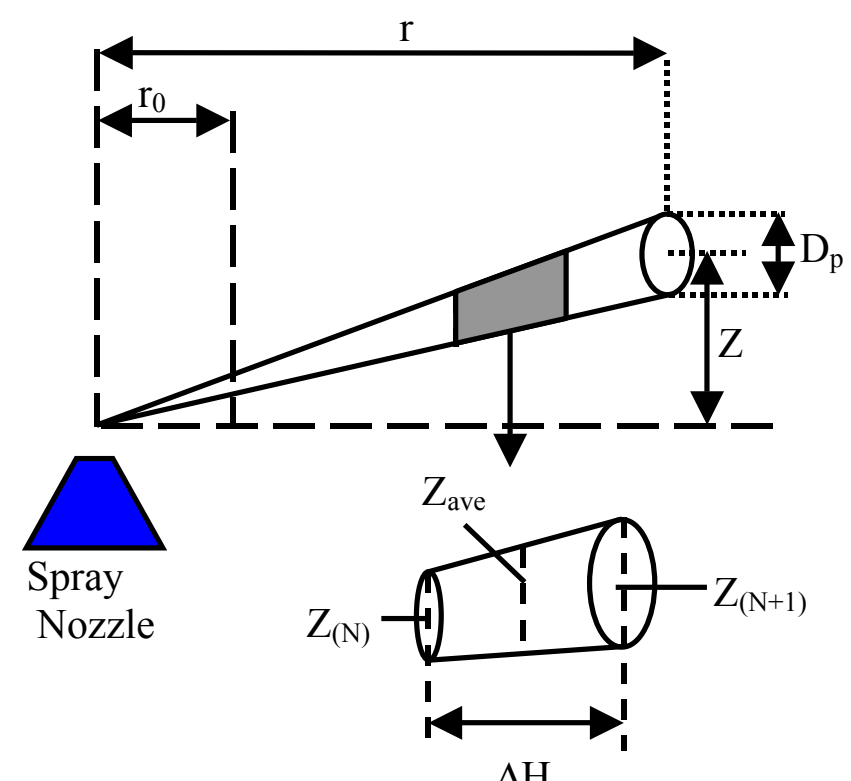

$\Delta \mathrm{H}$

Figure 5.8: A schematic diagram illustrates the technique for discretizing the projected surface area in the coating model used to compare Cheng's Model.

A series of simulations was run at different conditions based on the same assumptions used by Cheng (Cheng, 2000). The simulation shows similar results compared to those of Cheng, as shown in Figures 5.9 and 5.10. Based on the same assumptions for the sheltering effect, both models show a strong decrease in relative variation with an increase in voidage (Figure 5.9). Figure 5.10 shows that for a given voidage, the variation will increase with an increase in the diameter of the insert.

These results show that when the voidage is increased, with decreasing insert radius, the coefficient of variation of coating received per particle will decrease, since the tendency of spray material to impinge on particles far away from the spray nozzle is lower. However, if the voidage is too high, the coating efficiency decreases, due to the 
fact that more spray material will be lost in the system. These results show that the assumptions and equations used in simulating the coating model are valid and capable of predicting the coating variation in a fluidized bed coater.

Table 5.3: List of equations used in the coating model from this work and Cheng's model.

\begin{tabular}{|l|c|c|}
\hline \multicolumn{1}{|c|}{ Variables } & Coating Model & Cheng's Model \\
\hline Vol (element) & $\operatorname{Vol}_{(k)}=\frac{\pi \Delta H\left(Z_{a v e}\right)^{2}}{4}$ & $V o l=2 \pi \alpha \beta^{2} \Delta r$ \\
\hline $\begin{array}{l}\text { Number of particle } \\
\text { (in element) }\end{array}$ & $N_{u m_{p(k)}=\frac{V o l_{(k)}}{\frac{\pi}{6} D_{s p}^{3}}}$ & Num ${ }_{p}=\frac{V o l}{\frac{\pi}{6} D_{s p}^{3}}$ \\
\hline $\begin{array}{l}\text { Proj. surface area of } \\
\text { particle (in element) }\end{array}$ & $A_{p(k)}=N u m_{p(k)}\left[\frac{\pi}{4} D_{s p}^{2}\right]$ & $A_{p}=N u m_{p}\left[\frac{\pi}{4} D_{s p}^{2}\right]$ \\
\hline $\begin{array}{l}\text { Fraction of spray } \\
\text { (in element) }\end{array}$ & $f_{(k)}=1-\left[\frac{A_{p(k)}}{A_{(k)}}\right]$ & $\frac{d F}{d r}=K_{1} e^{-\left[\left(r-r_{0}\right) K_{1}\right]}$ \\
\hline $\begin{array}{l}\text { Total fraction of } \\
\text { spray }\end{array}$ & $F=f_{(1)} \cdot f_{(2)} \ldots . f_{(m)}$ & $K_{1}=\frac{3(1-\varepsilon)}{2 D_{s p}}$ \\
\hline $\begin{array}{l}\text { Amount of spray } \\
\text { particle) }\end{array}$ & $X=M_{s} t_{s} \frac{A_{t a b}}{A_{c a p}} F$ & $\left.\left.X=\frac{d F}{N u m_{p}}\right] \frac{\Delta r}{d r}\right] \Delta r$ \\
\hline
\end{tabular}




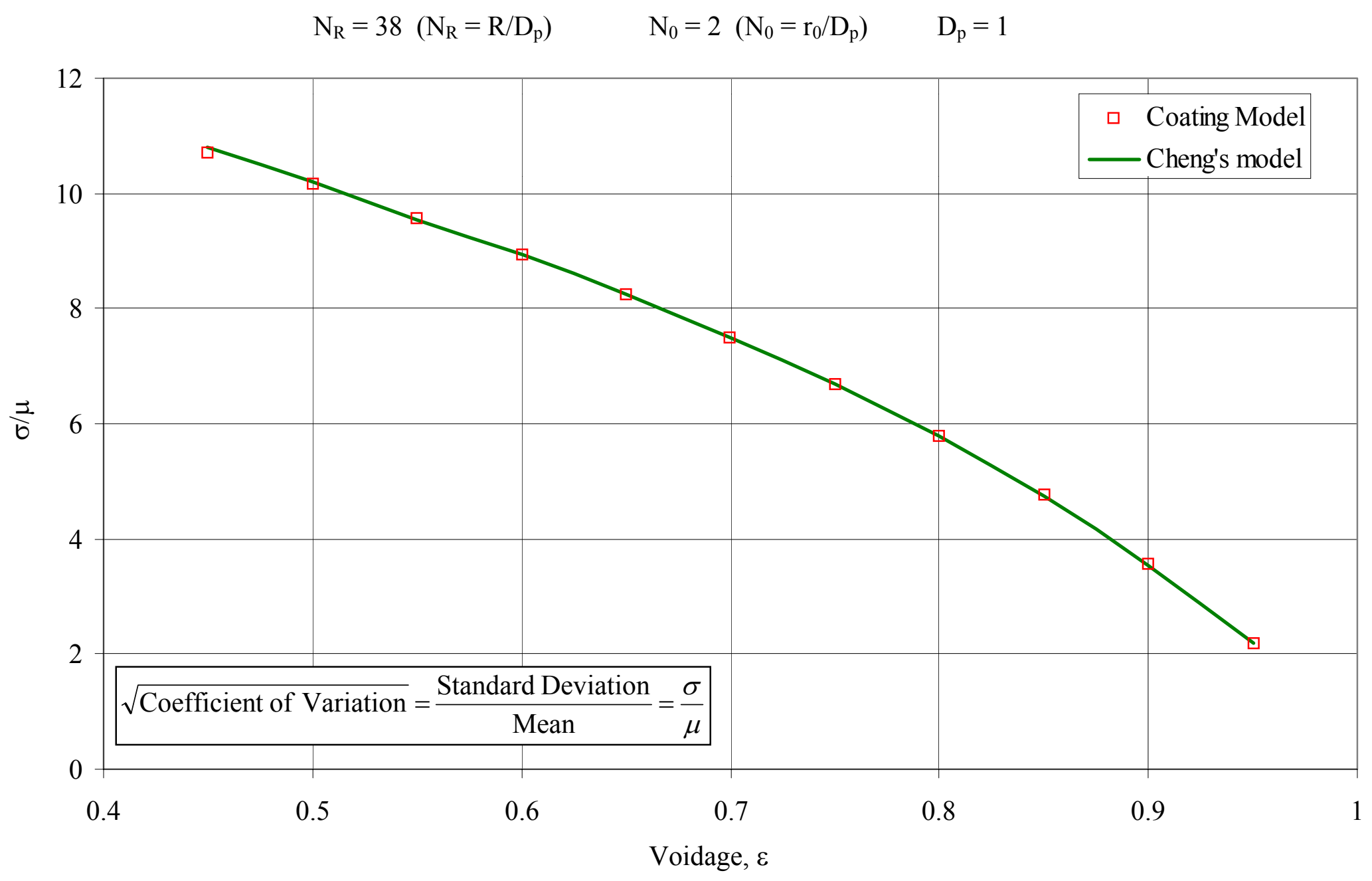

Figure 5.9: Effect of voidage on coefficient of variation of coating per particle for Cheng's Model and the coating model from this work. 


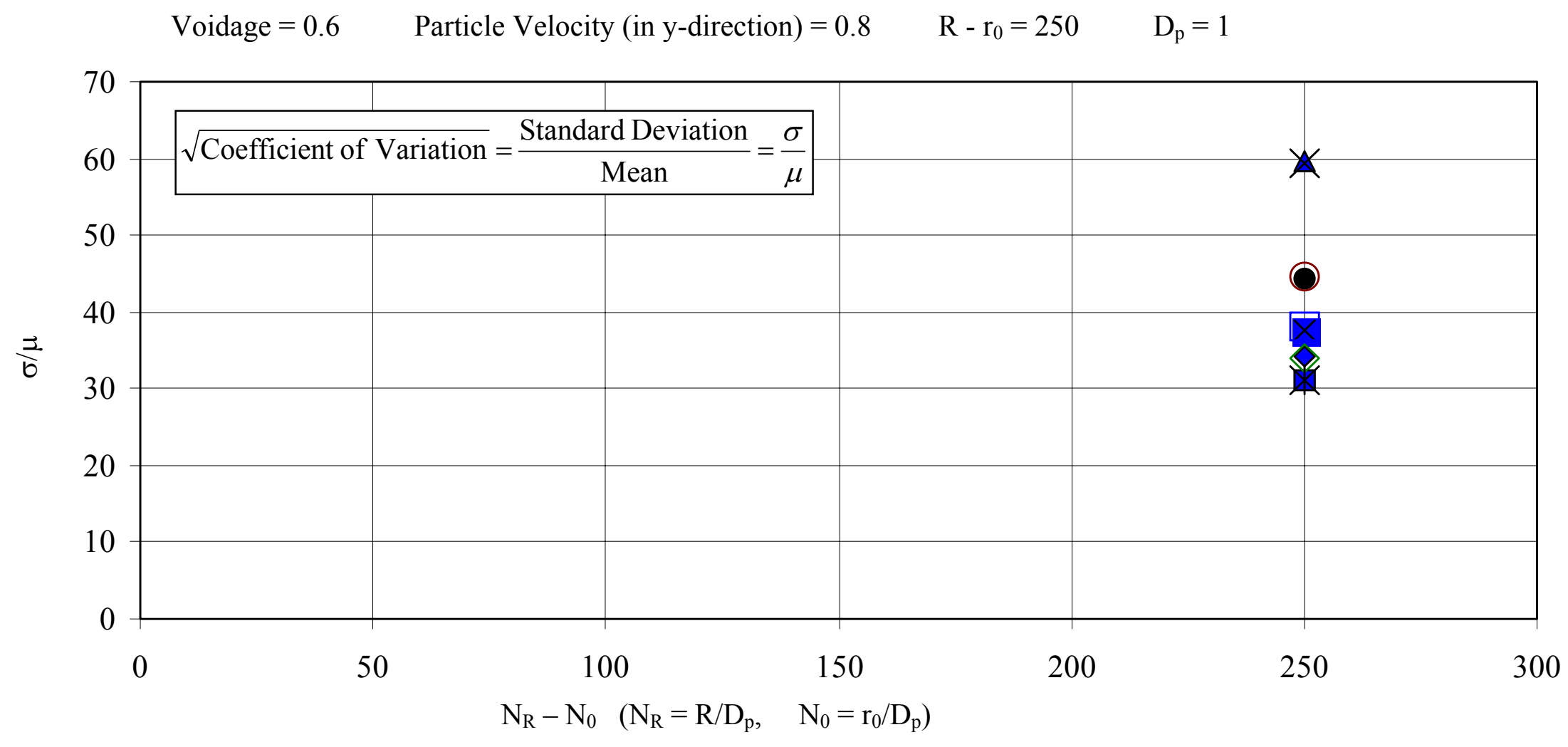

\begin{tabular}{|c|c|c|c|c|c|c|c|c|c|}
\hline \multicolumn{4}{|c|}{ Cheng's Model } & & \multicolumn{5}{|c|}{ Coating Model } \\
\hline$\Delta$ & - & $\mathrm{X}$ & $\diamond$ & $\square$ & $\times$ & 0 & $\square$ & $\diamond$ & * \\
\hline $\mathrm{N}_{0}=2$ & $\mathrm{~N}_{n}=4$ & $\mathrm{~N}_{n}=6$ & $\mathrm{~N}_{n}=8$ & $\mathrm{~N}_{0}=10$ & $\mathrm{~N}_{0}=2$ & $\mathrm{~N}_{0}=4$ & $\mathrm{~N}_{0}=6$ & $\mathrm{~N}_{0}=8$ & $\mathrm{~N}_{0}=10$ \\
\hline
\end{tabular}

Figure 5.10: The effect of insert (draft tube) diameter and particle size on the coefficient of variation of coating per particle. 
Since the predicted values from the model are strongly dependent on the fraction of the spray that hits the particle, which was determined by discretizing the projected surface area, it is important to determine the minimum number of discretized elements needed to agree with the predictions from Cheng's analytical model. To do this, the model was simulated using different numbers of discretized elements and the results are plotted and compared with the calculated value from Cheng's Model in Figure 5.11. From the figure it shows that in order to achieve the same result as predicted by Cheng (2000), the projected surface area has to be discreatized into 3,000 or more sections.

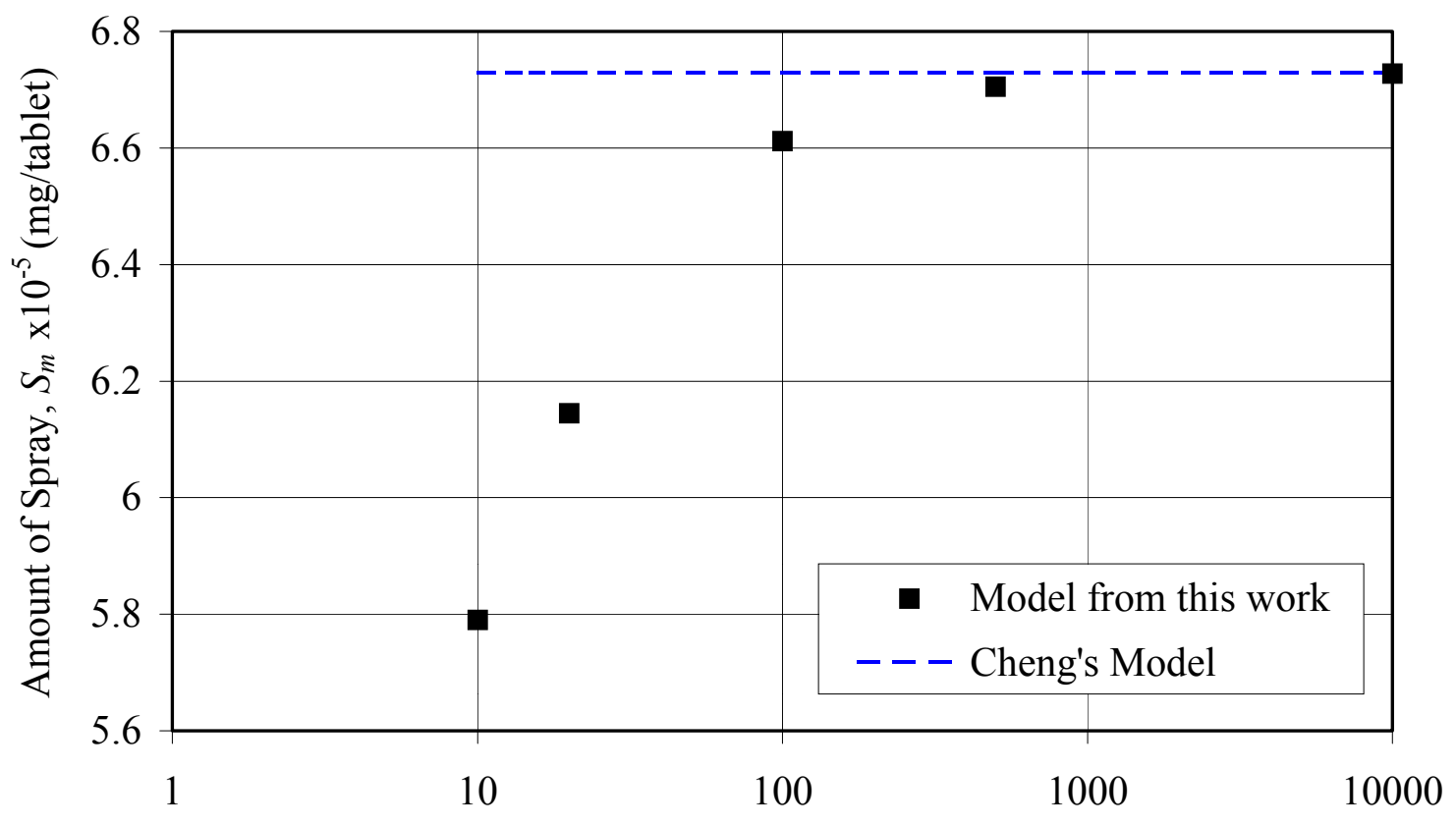

Figure 5.11: The effect of number of discretized sections on the predicted value from simulation. 


\subsubsection{Validation of Particle Coating Model with Experimental Data}

In this section, the functionality and the ability of a fully developed coating model to process the input data and to calculate the amount of spray material received by particles are verified. The validation was done using a solid cone spray model in which the projected surface area is discretized with respect to the spray zone. Initially, the model was simulated using uniform input data taken from Runs 6 and 5 for the NoDeflector and the Modified-Deflector cases, respectively. The uniform data for the velocity in the y-direction and the voidage were determined as the average values from the data. Refer to Appendix VII for the calculation method. The movement of the particles was only simulated in the y-direction with a given uniform velocity and uniform bed voidage.

The results shown in Figures 5.12 and 5.13, indicate that the model is able to recognize and process the input data and transform the result into the desired graphical output. Each shaded line represents a particle movement from the bottom to the top of the column. When the particle is in the spray zone, the amount of spray material received is represented by the intensity of the line's 'color'. The darker the line the more spray material was received. Since the time increment used in the simulation, $\Delta t$, is relatively small, each individual step of movement appears as a dot or a point. From the figure, it is seen that as the particle travels from the bottom of the bed, the intensity of the line becomes darker, and particles that started at a radial location away from the spray nozzle have lighter line intensities. This agrees with the expected result that as a particle travels from the bottom to the top of the bed in the spray zone, the spray material accumulates on 
the particle surfaces and that particles far away from the spray nozzle receive less spray material than those closer to the center.

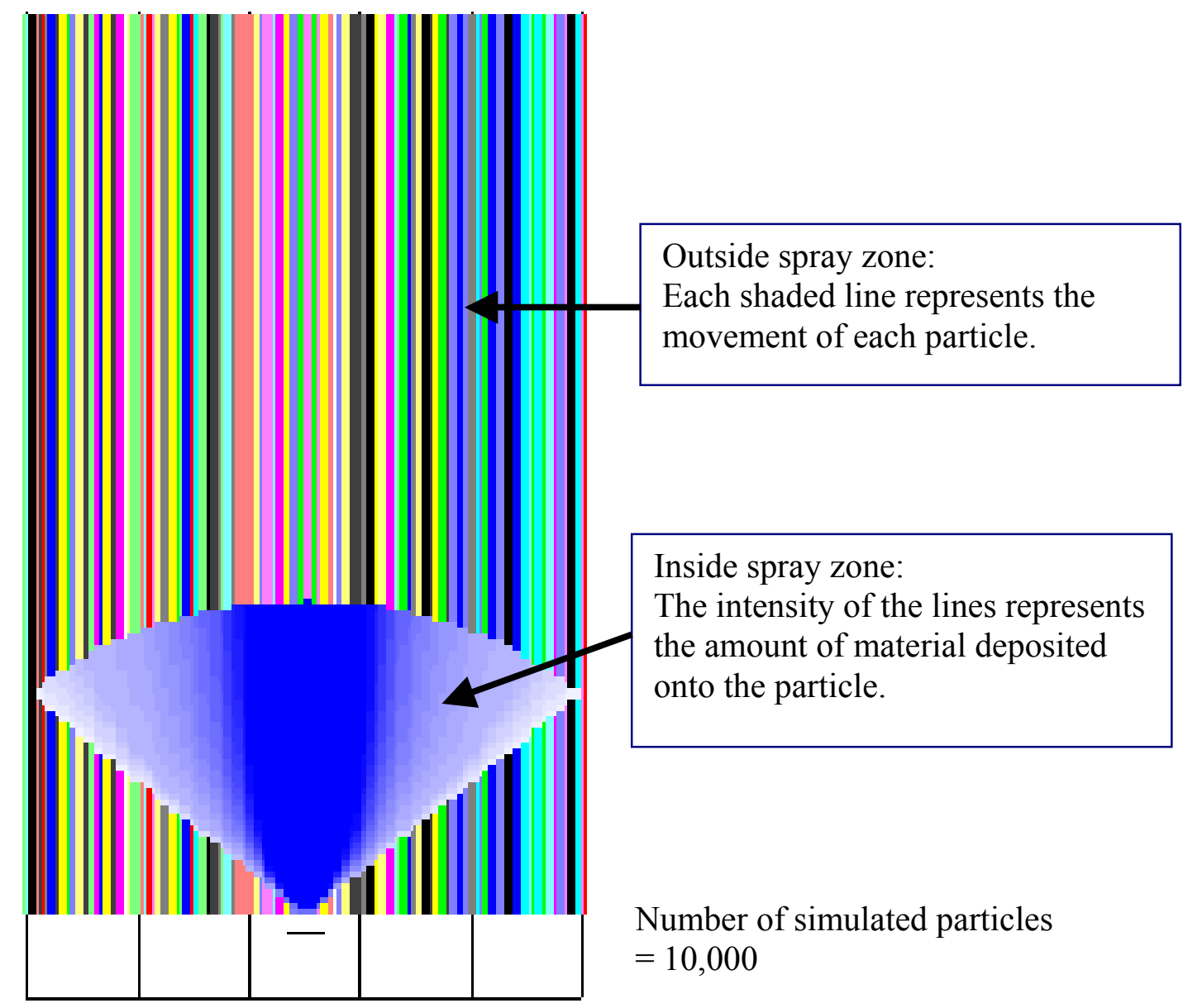

Figure 5.12: Sample output of the simulation using uniform velocity (only in the ydirection) and uniform voidage. Input data taken from experimental Run 6. 


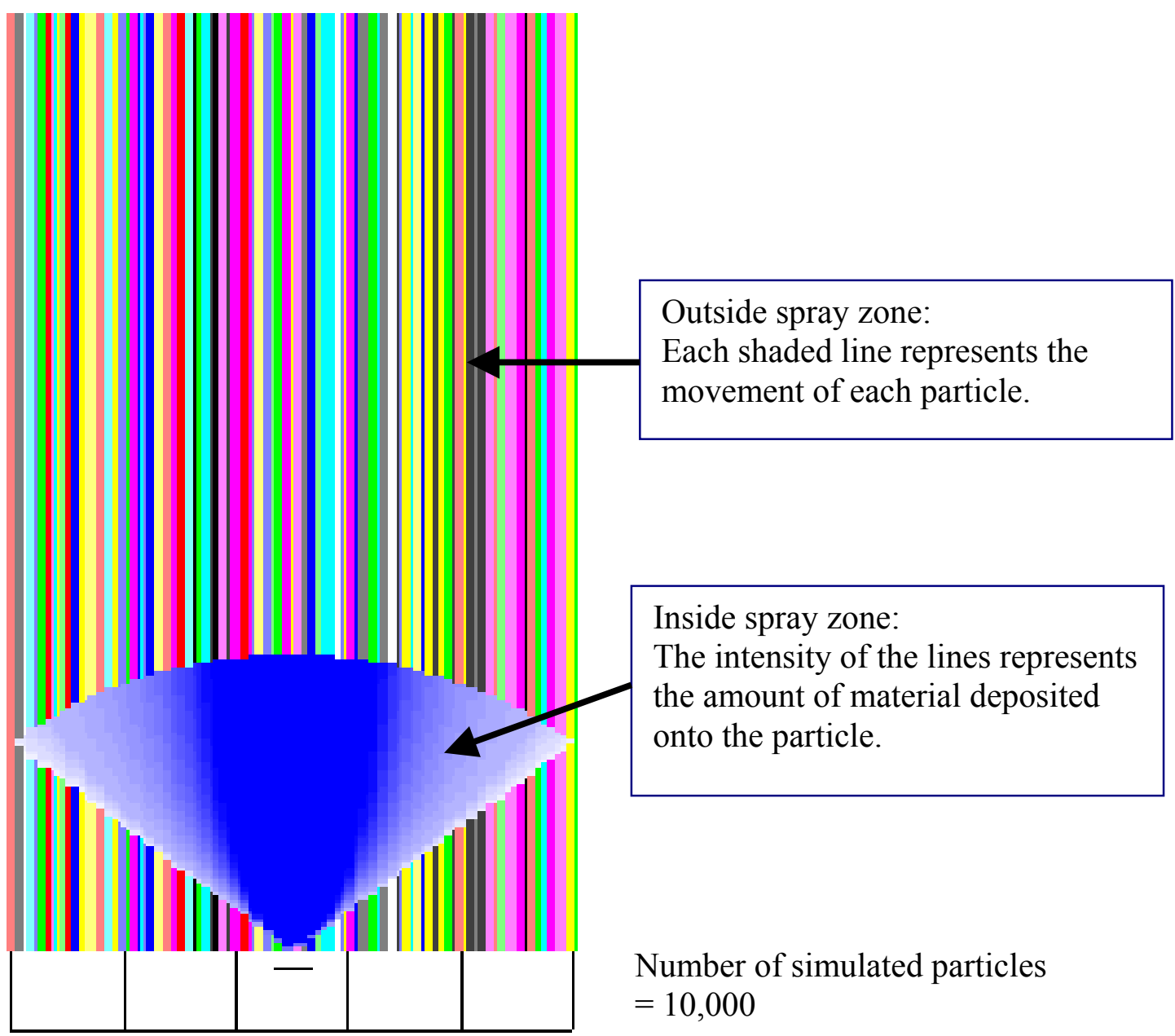

Figure 5.13: Sample output of the simulation using uniform velocity (only in the ydirection) and uniform voidage. Input data taken from experimental Run 8.

The next step was to verify the effect of using actual experimental voidage data, in the simulation. The results shown in Figures 5.14 and 5.15 show that the lines' intensity in the spray zone differs only slightly from Figures 5.12 and 5.13, respectively. This means that the variation in the voidage of the bed has a small effect on the amount 
of spray material received by the particles traveling through the spray zone. This is due to the slightly different sheltering that occurs due to the non-uniform voidage in the bed.

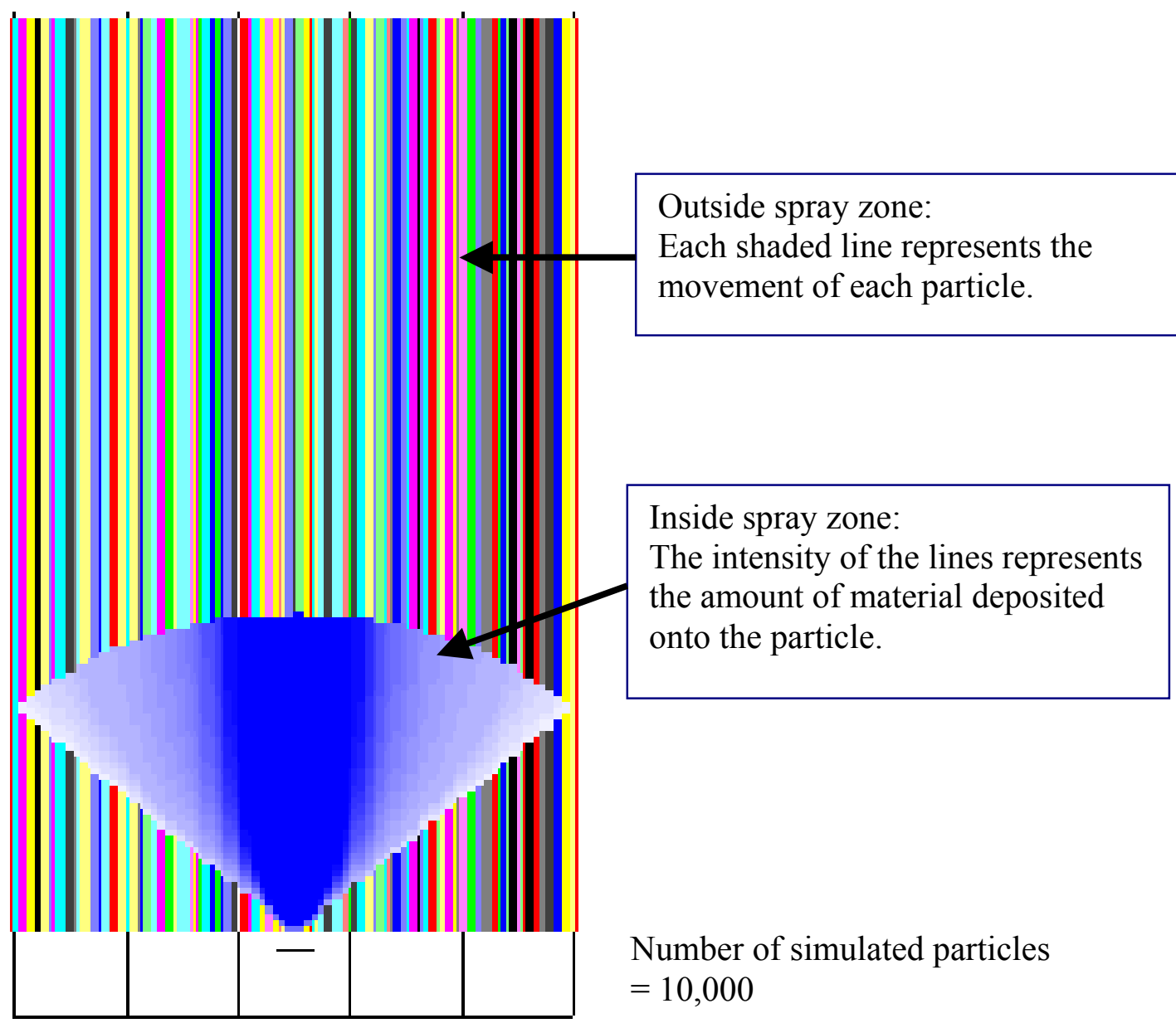

Figure 5.14: Sample output of the simulation using uniform velocity (only in the ydirection) and experimental voidage data from experiment Run 6. 


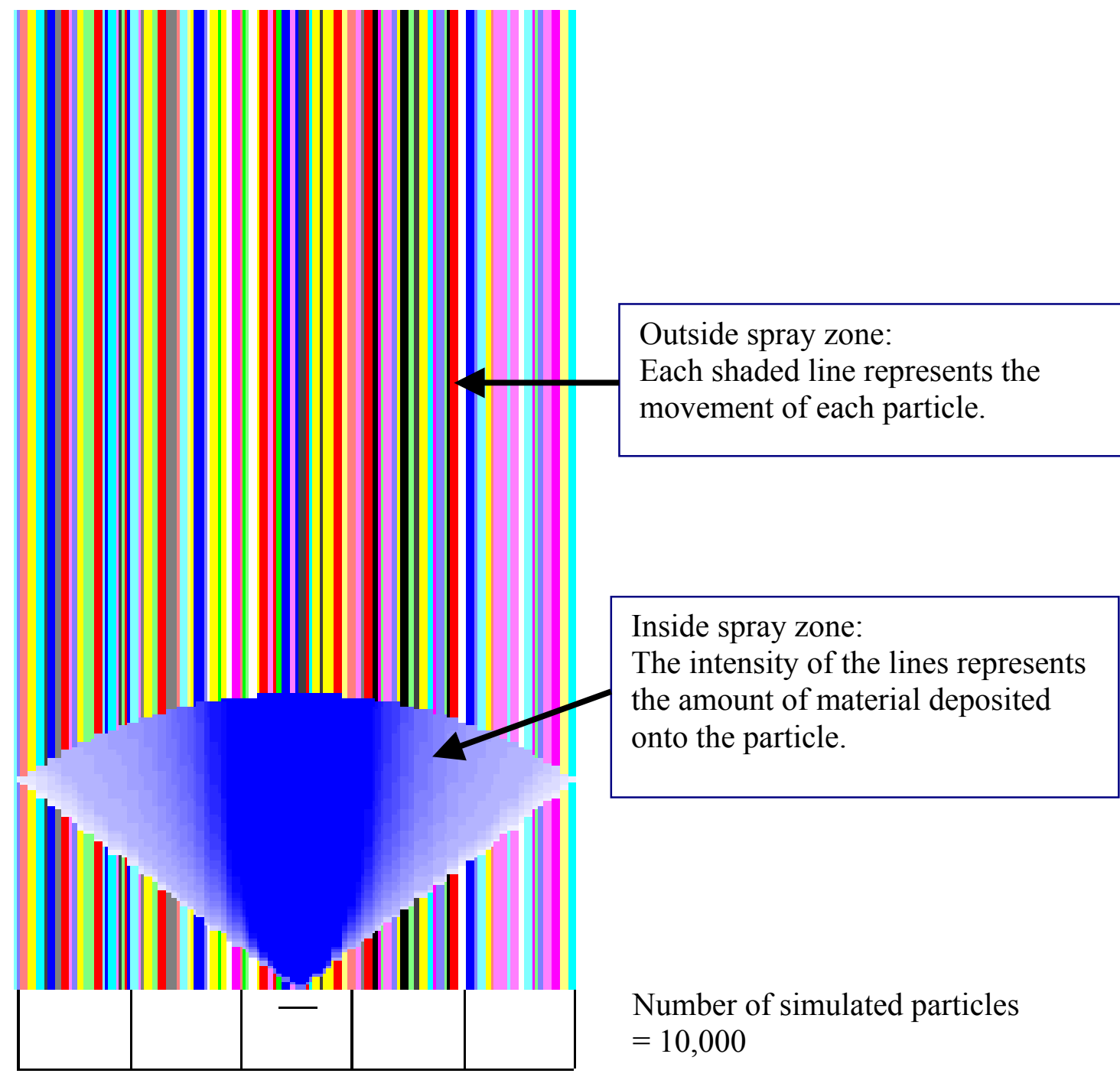

Figure 5.15: Sample output of the simulation using uniform velocity (only in the ydirection) and experimental voidage data from experiment Run 8. 
Finally, the simulation was run using the experimental data from Subramanian (2001) as input. In this case, the particles do not move in straight lines, but in the direction similar to the velocity profile obtained in Subaramanian's experiments under the same operating condition, refer to Figures 5.16 and 5.18 for experiment Run 6 and Figures 5.17 and 5.19 for experiment Run 8 .

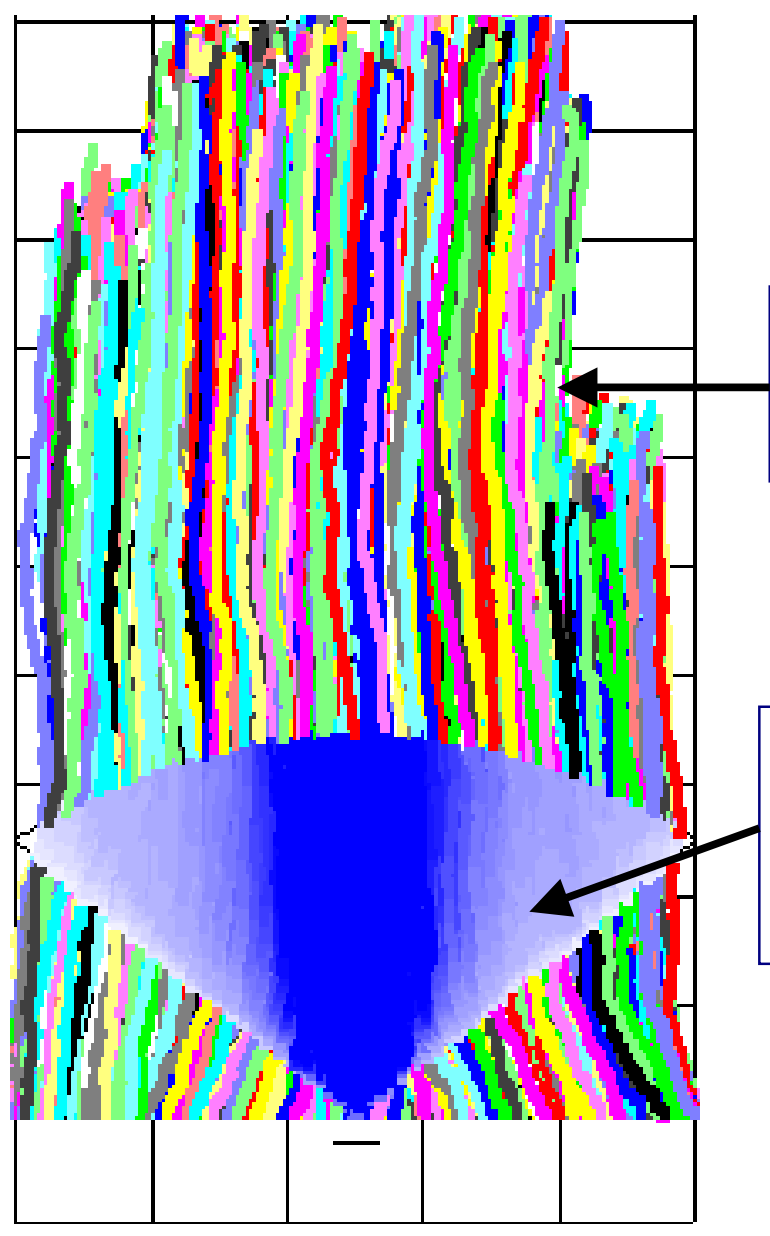

Outside spray zone:

Each shaded line represents the movement of each particle.

Inside spray zone:

The intensity of the lines represents the amount of material deposited onto the particle.

Number of simulated particles

$=10,000$

Figure 5.16: Sample output of simulation with all input data taken from experiment Run 6. The profile of the velocity used in this simulation is shown in Figure 5.18. 


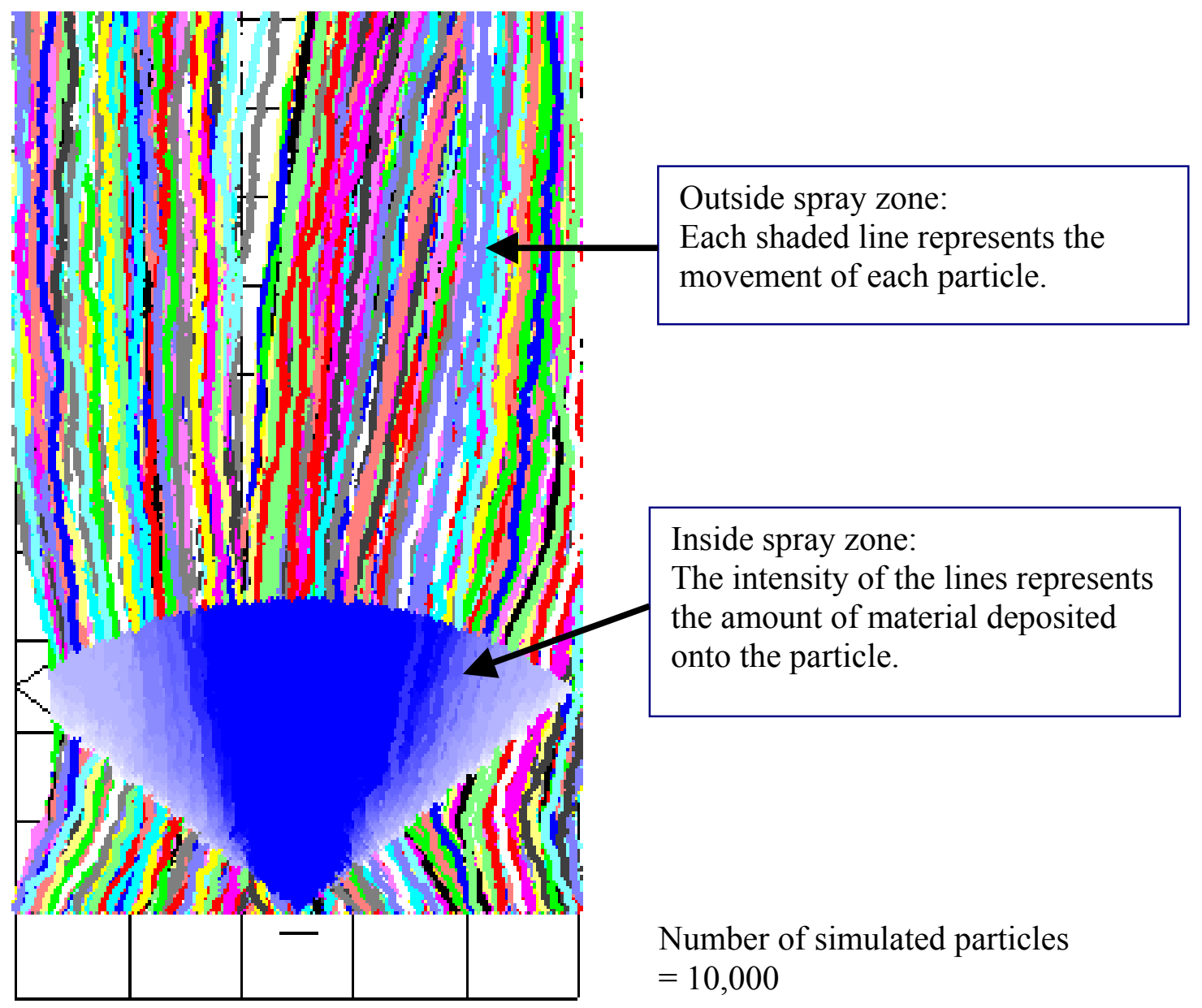

Figure 5.17: Sample output of simulation with all input data taken from experiment Run 8. The profile of the velocity used in this simulation is shown in Figure 5.19. 


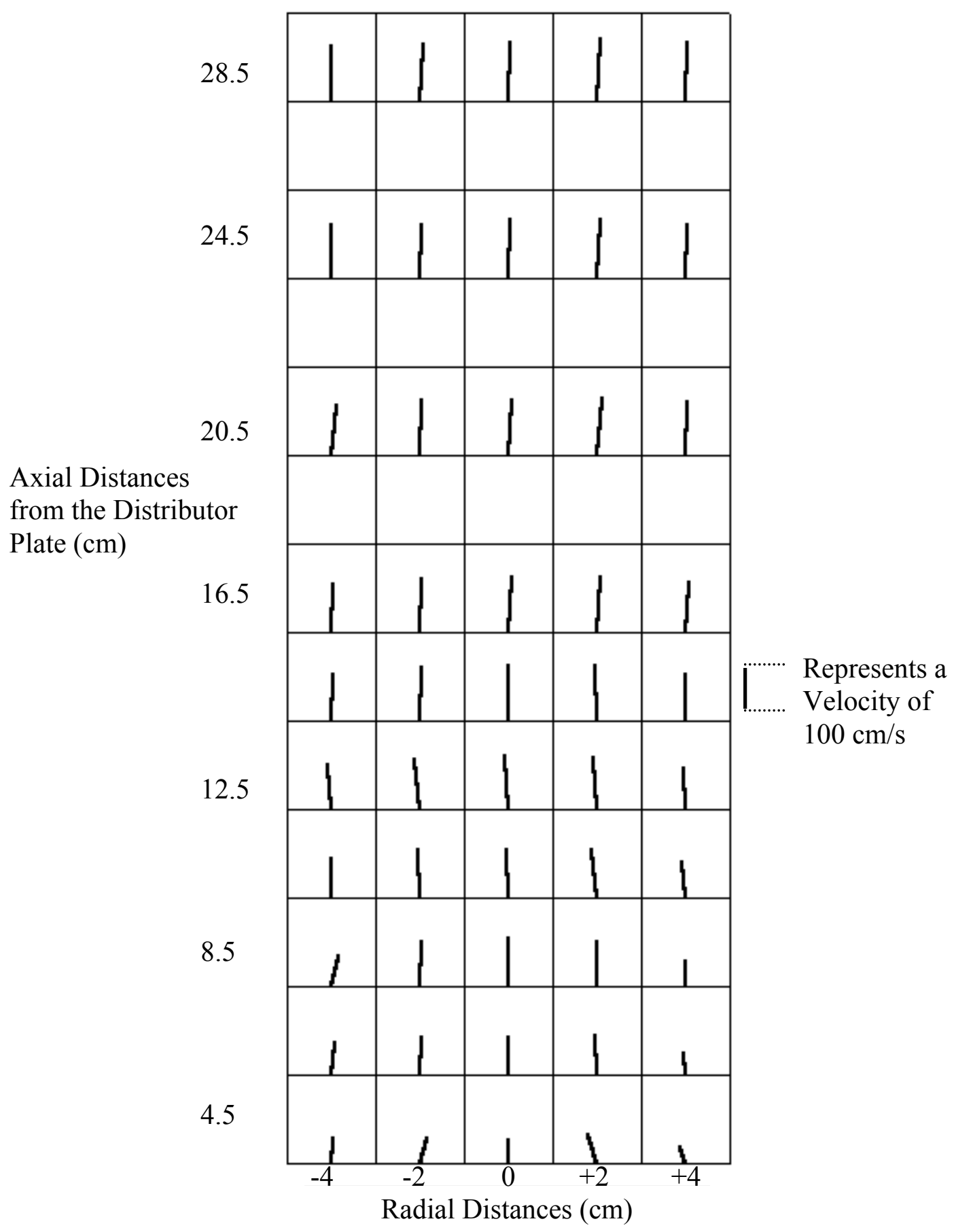

Figure 5.18: Particle velocity map in the draft-tube at different axial location for experimental Run 6 (Subramanian, 2001). 


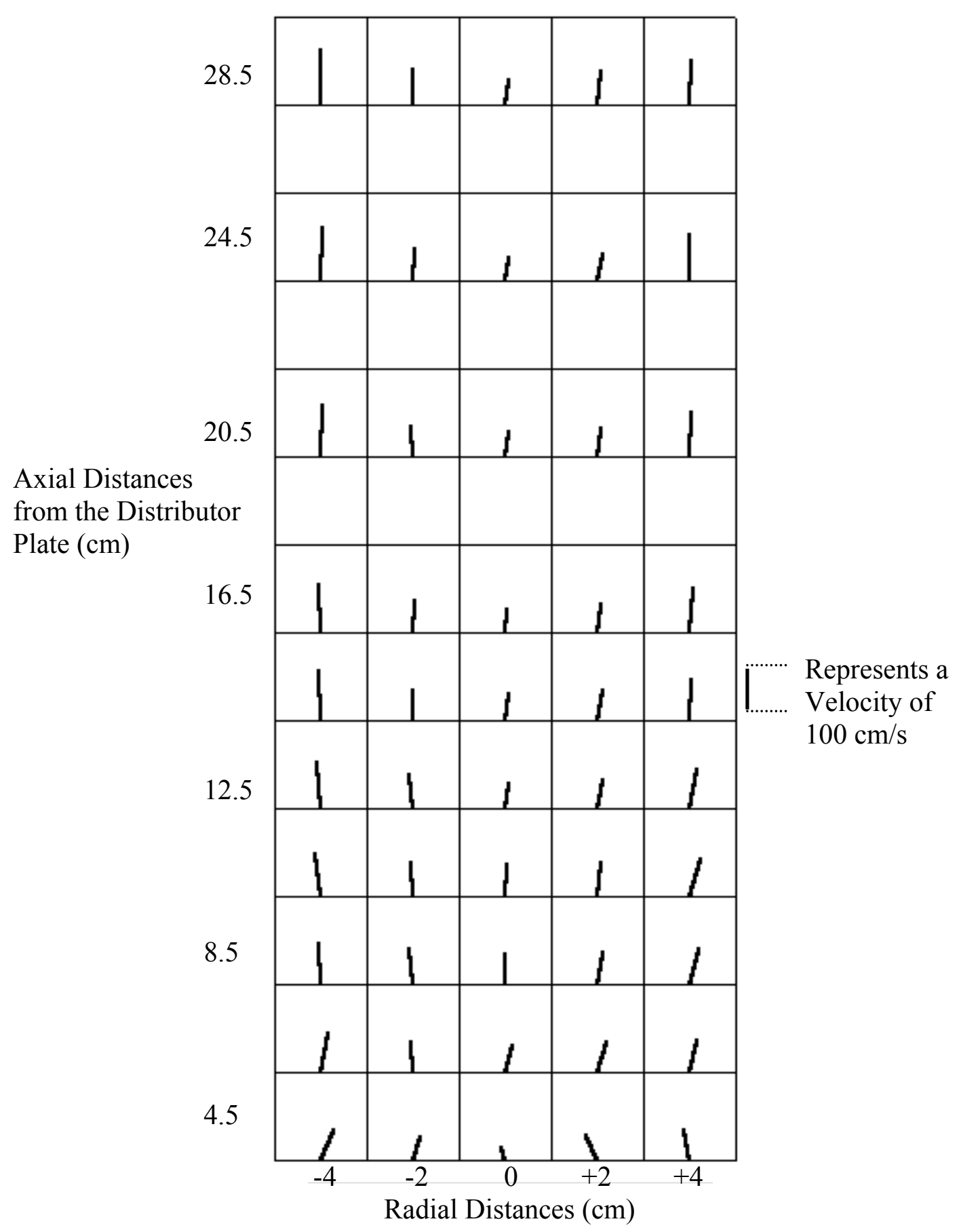

Figure 5.19: Particle velocity map in the draft-tube at different axial location for experimental Run 8 (Subramanian, 2001). 


\subsubsection{The Effect of Spray Shape and Discretization Method on the Predicted Coating Distribution}

\section{Discretization with respect to the spray nozzle}

As mention earlier, the first attempt to simulate the coating model was done by assuming the spray material moves in a radial direction from the spray nozzle in a so called "solid cone" spray pattern. The projected surface area is discretized with respect to the spray nozzle or perpendicular to the spray direction as described in the Chapter 4 and the schematic diagram of the discretization of the projected surface area is shown in Figure 4.4.

Using this orientation, a particle that is radially far from the nozzle receives the least amount of sprayed material and the particle that is at the center of the bed receives the most spray. Referring to the probability function used in the model to determine the starting point of the particle, about $65 \%$ of the particles enter the bottom of the bed at a

distance of more than $3.5 \mathrm{~cm}$ from the spray nozzle, $33 \%$ enter in the region between 1.5 $-3.5 \mathrm{~cm}$, and $2 \%$ enter in the region less than $1.5 \mathrm{~cm}$ from the nozzle, as shown in Figure 5.20. This means that about $2 \%$ of the particles receive a very large amount of spray material, while the remaining $98 \%$ of the particles receive only a very small amount. This results in a wide coating distribution with a very long tail as shown in Figure 5.21. 


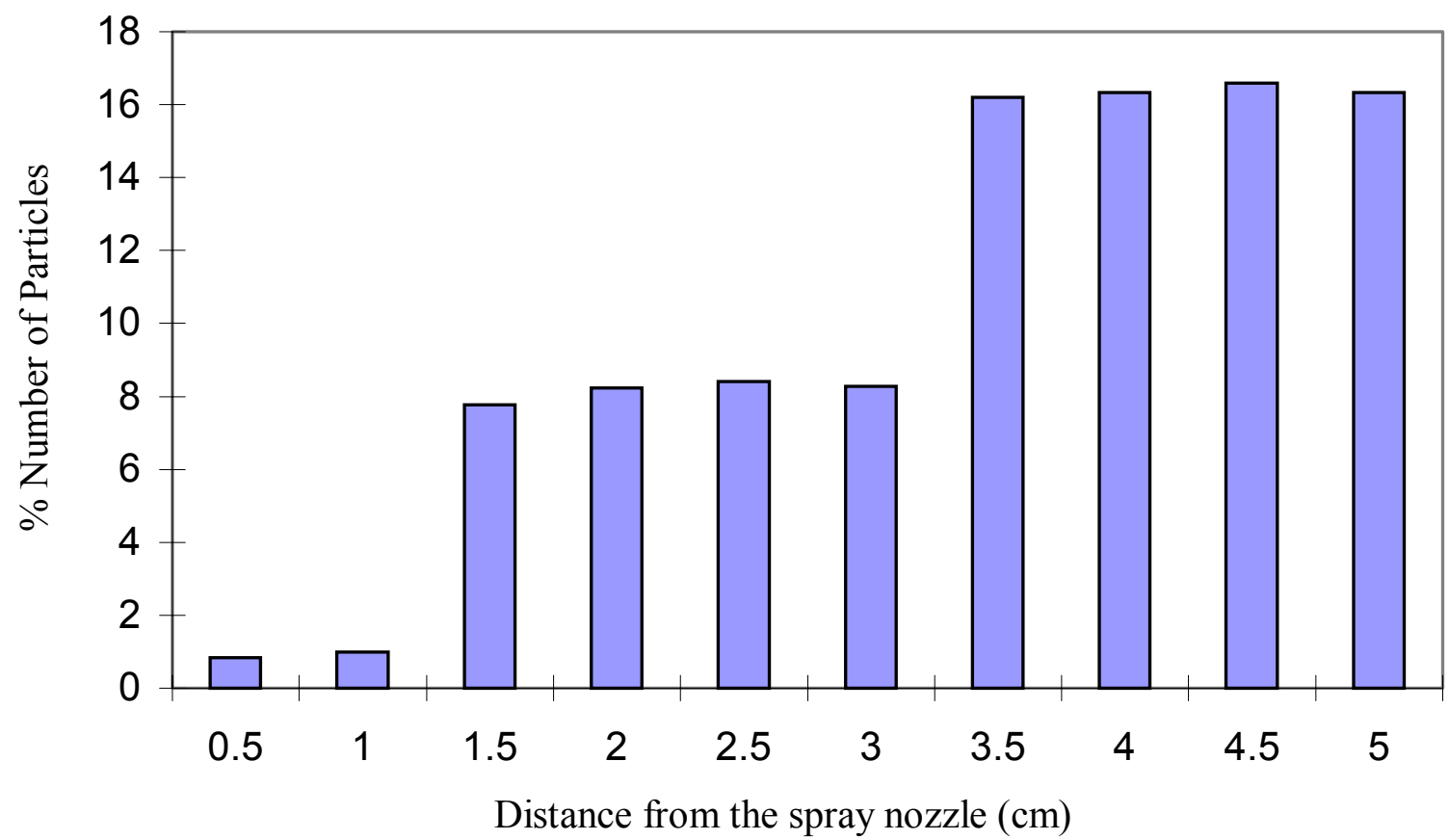

Figure 5.20: The relationship between the particle starting points and the distance from the spray nozzle for No-Deflector case.

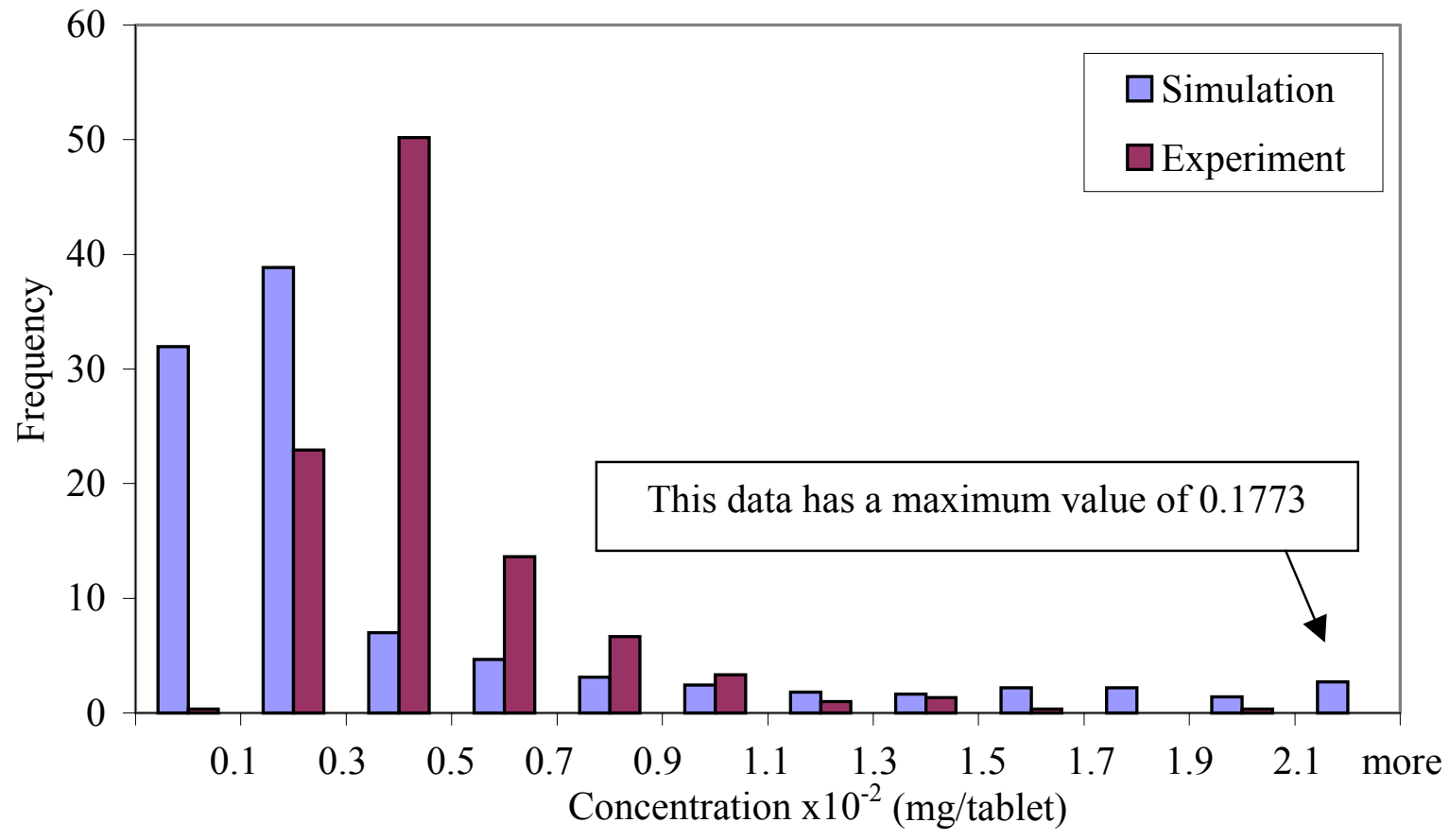

Figure 5.21: Coating distribution for No-Deflector case (discretized with respect to the spray nozzle) compared with experimental pulse test distribution. 


\section{Discretize vertically from the bottom of the bed.}

Based on the observation of the spray shape from the experiment given in Section 3.3, the spray material was found to move vertically upward after a certain distance from the bottom of the bed, as shown in Figure 4.17. With this observation, it is more reasonable to discretize the projected surface area in the vertical direction as shown in Figure 4.17. Therefore the flow direction of the spray material used in the model will be similar to the one shown in Figure 5.22.

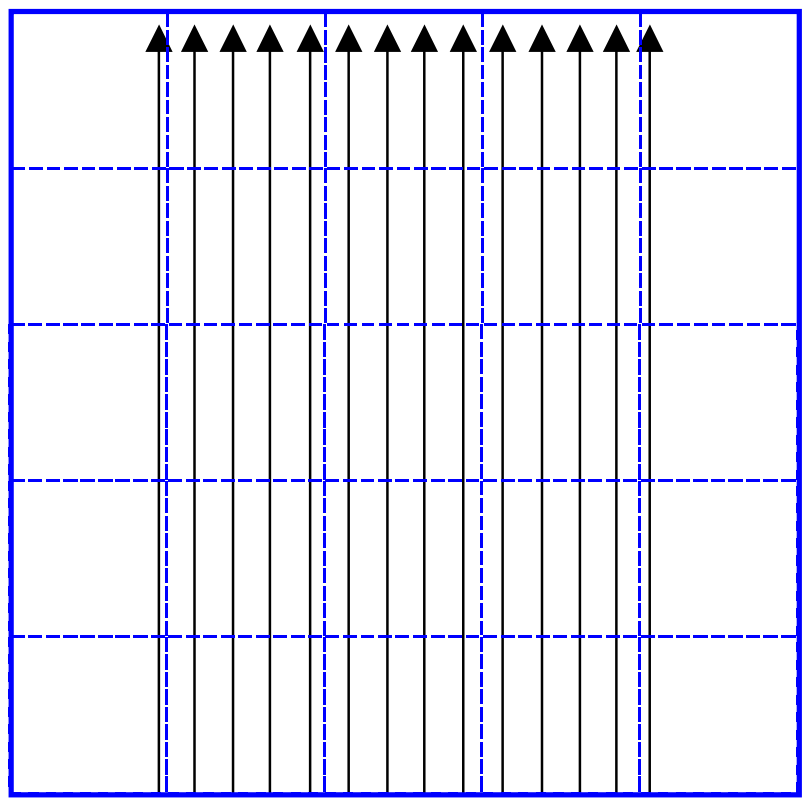

Figure 5.22: Direction of spray used in subsequent coating simulations. 
In this case, the amount of spray material received by the particle does not depend on the particle distance from the spray nozzle but will be a function of the spray density at a given radial position. In the case of uniform spray distribution and uniform voidage, the fraction of spray material that will hit a particle is the same at any radial position from the spray nozzle, and this should give rise to a much narrower coating distribution.

\subsubsection{The Effect of Spray Shape on the Coating Uniformity Predicted by the Model}

The initial work of this research used the assumption of a solid cone spray shape, shown in Figure 5.23. This is consistence with the picture suggested by Cheng (Cheng, 1993), used to derived an analytical solution for the spray distribution on a batch of particles. However, with this assumption, the distribution of spray material does not match well with the experimental data. This is due to the extreme condition caused by the shape of the spray where the particle in the outer zone of the spray nozzle would spend very little time in the spray zone. On the other hand, a particle in the middle of the draft tube would spend the most available time in the spray zone and would receive a large spray fraction due to the low sheltering effect at the center of the spray.

To investigate further the effect of spray shape on the coating distribution, a rectangular spray shape, as shown in Figure 5.24, was used in the model. This reduces the effect of spending less time in the spray zone. The only factor that affects the amount of spray material picked up by the particles is the distance from the nozzle. 


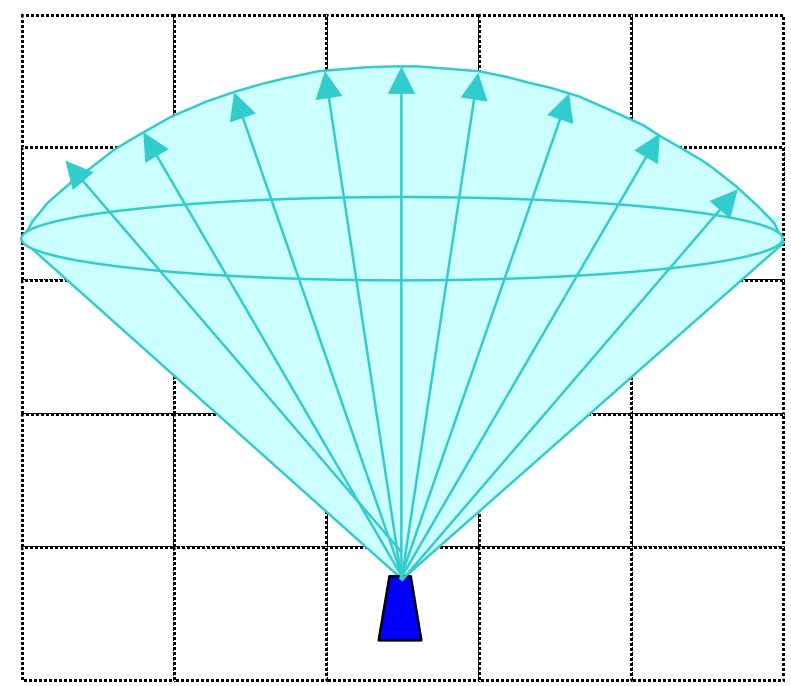

Figure 5.23: Illustration of the solid cone spray shape used in the model.

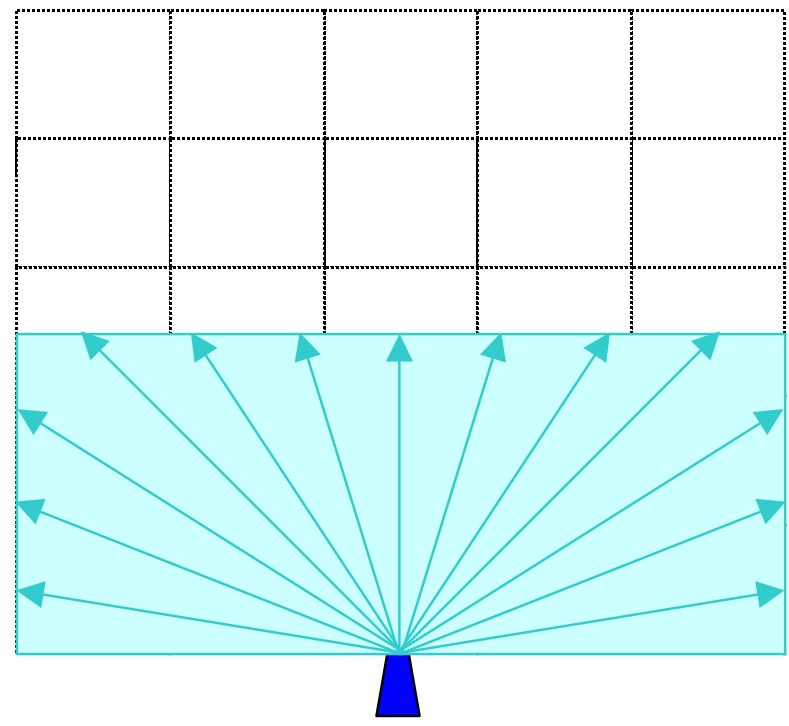

Figure 5.24: Illustration of the rectangular spray shape used in the model. 
Figure 5.25 compares the results of the simulation using a solid cone spray shape, using a rectangular spray shape, and the experimental pulse test results. The simulation is done using uniform input data in order to eliminate the effect of the velocity and voidage variations on the coating distribution. The graph shows that the results of both simulations have long tails and wide distributions. In the case of the solid cone spray shape, about $78 \%$ of the data are concentrated in the first two bins but this is reduced to $58 \%$ for the case of rectangular spray shape. This shows that the solid cone shape promotes a very wide coating distribution, which in turn increases the coating variance. Figure 5.26 illustrates the results for both solid cone and rectangular spray shapes.

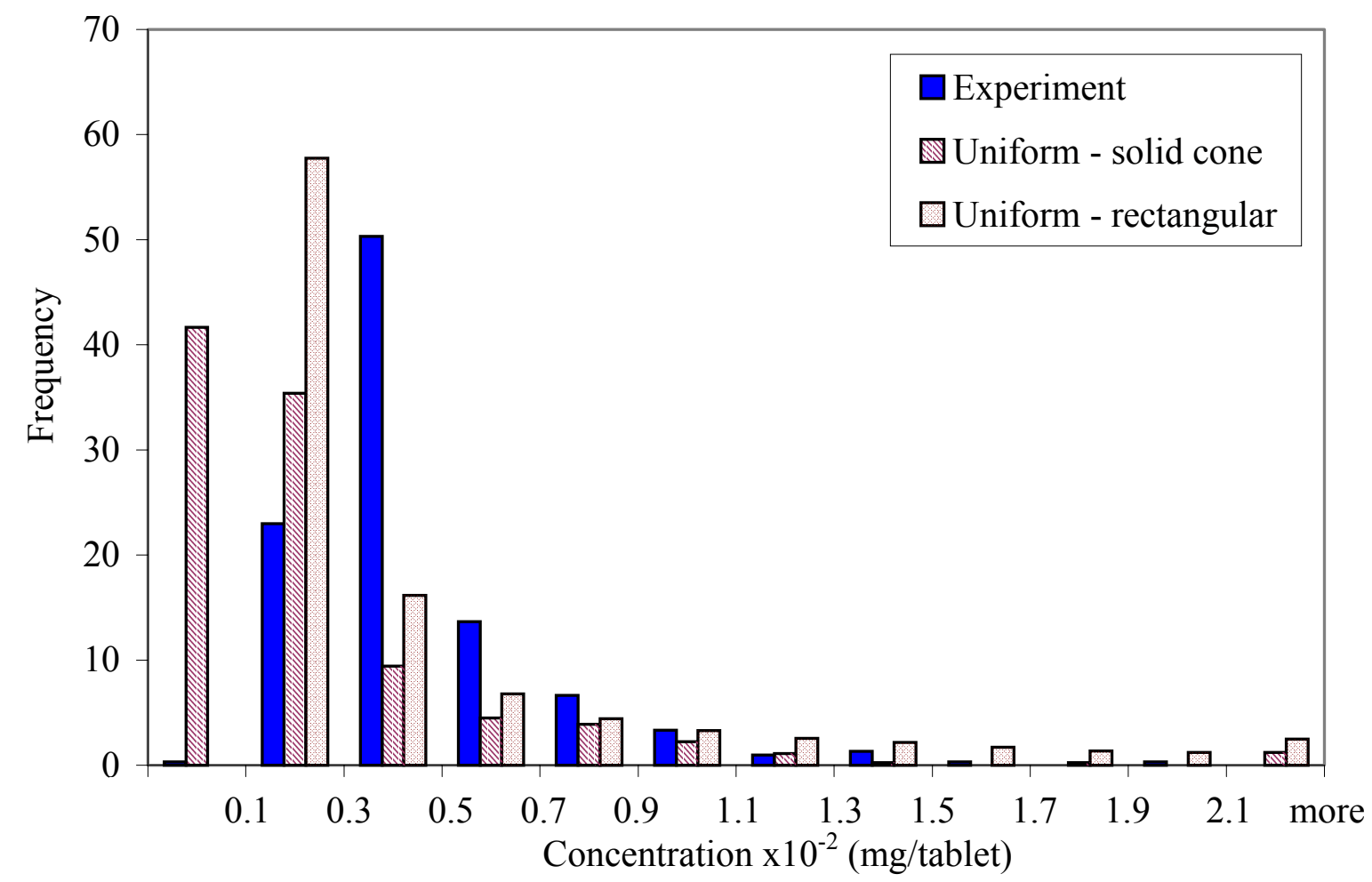

Figure 5.25: Coating distribution for No-Deflector case simulated with uniform input data, uniforms spray density, but different spray shapes compared with experimental results. 


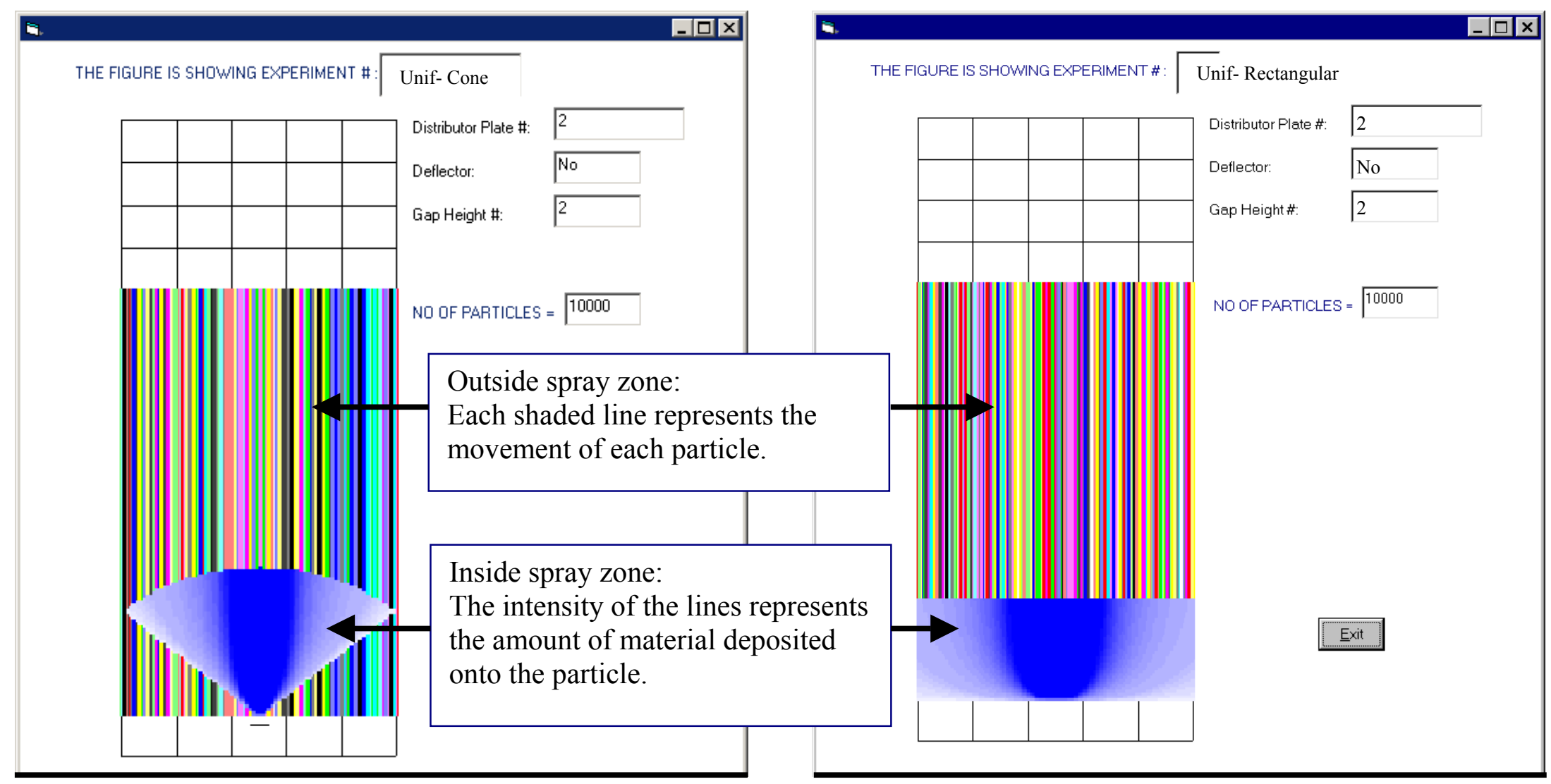

Figure 5.26: The output of simulation for the No-Deflector case simulated with uniform input data and solid cone and rectangular spray shapes. 
The results of the experiments using blotting paper in the draft tube (Section 3.3) suggested that the spray material moves vertically upward rather than having a specific shape. This leads to the idea of having no boundary at the top of the spray zone as shown in Figure 5.27. For this case, material would stop receiving the spray material only when there is enough sheltering effect to prevent the spray material hitting the particle. In addition, it suggests that the flow direction of the spray material is vertical from the bottom of the bed rather than from the spray nozzle. The coating distributions resulting from this assumptions are presented and discussed in the following section.

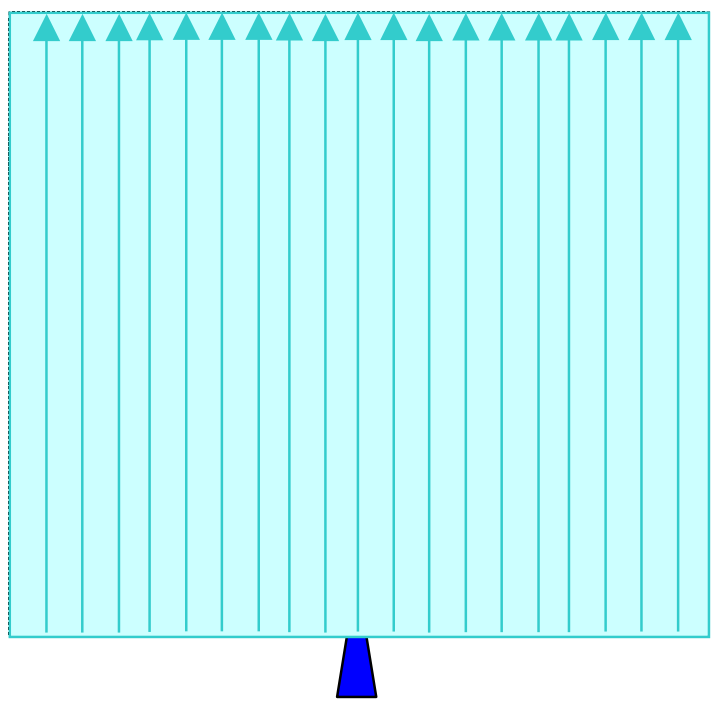

Figure 5.27: Rectangular spray shape without a top boundary having vertical direction of spray material. 


\subsubsection{The Effect of Spray Distribution to the Coating Uniformity Predicted by the Model}

Based on the results discussed previously, it is found that the direction of the spray material is vertical all over the draft tube region. This requires that the projected surface area must be discretized in the vertical direction as shown in Figure 4.19. Therefore, the amount of spray material deposited onto the particle at any location depends on the voidage of the projected surface area (discretized elements) and the spray distribution.

In order to obtain accurate information on the radial distribution of spray, a series of tests were performed by Spraying Systems Co. using a traditional single dimension patternator and laser beam doppler velocity meter for the semi-circular nozzle used in this work. The nozzle was placed in the center directly above a channel divider at a distance of 5.5 in. The details of this test are given in Appendix V. Figure 5.28 shows the spray distribution for the nozzle operating at $30 \mathrm{psi}$ atomizing air pressure at which the pulse test experiments were operated. Note that the original data of the spray distribution are reported in $2 \mathrm{~cm}$ range value as shown in Appendix V. A smaller range of values, $1 \mathrm{~cm}$, was obtained by linear interpolation.

\section{Overall distribution}

The 30 psi overall distribution ranging from $-10 \mathrm{~cm}$ to $14 \mathrm{~cm}$ from the spray nozzle was regressed in Excel ${ }^{\circledR}$ to get the polynomial equation, shown in Figure 5.28. The equation is then used in the model to calculate the fraction of available spray material at any instance in the spray nozzle. The result of the simulation with the overall distribution was plotted in Figure 5.29 and 5.30 for No Deflector and Modified Deflector 
respectively. From both graphs, it is obvious that the coating distributions of the particles are not identical with the experimental pulse test coating distribution. This is explained by the phenomena described in Section 4.4.2.2 where at certain distance from the spray nozzle, the spray material travels vertically upward. Therefore, it is assumed that when the bed is fluidizing, the spray material does not hold its original distribution shape.

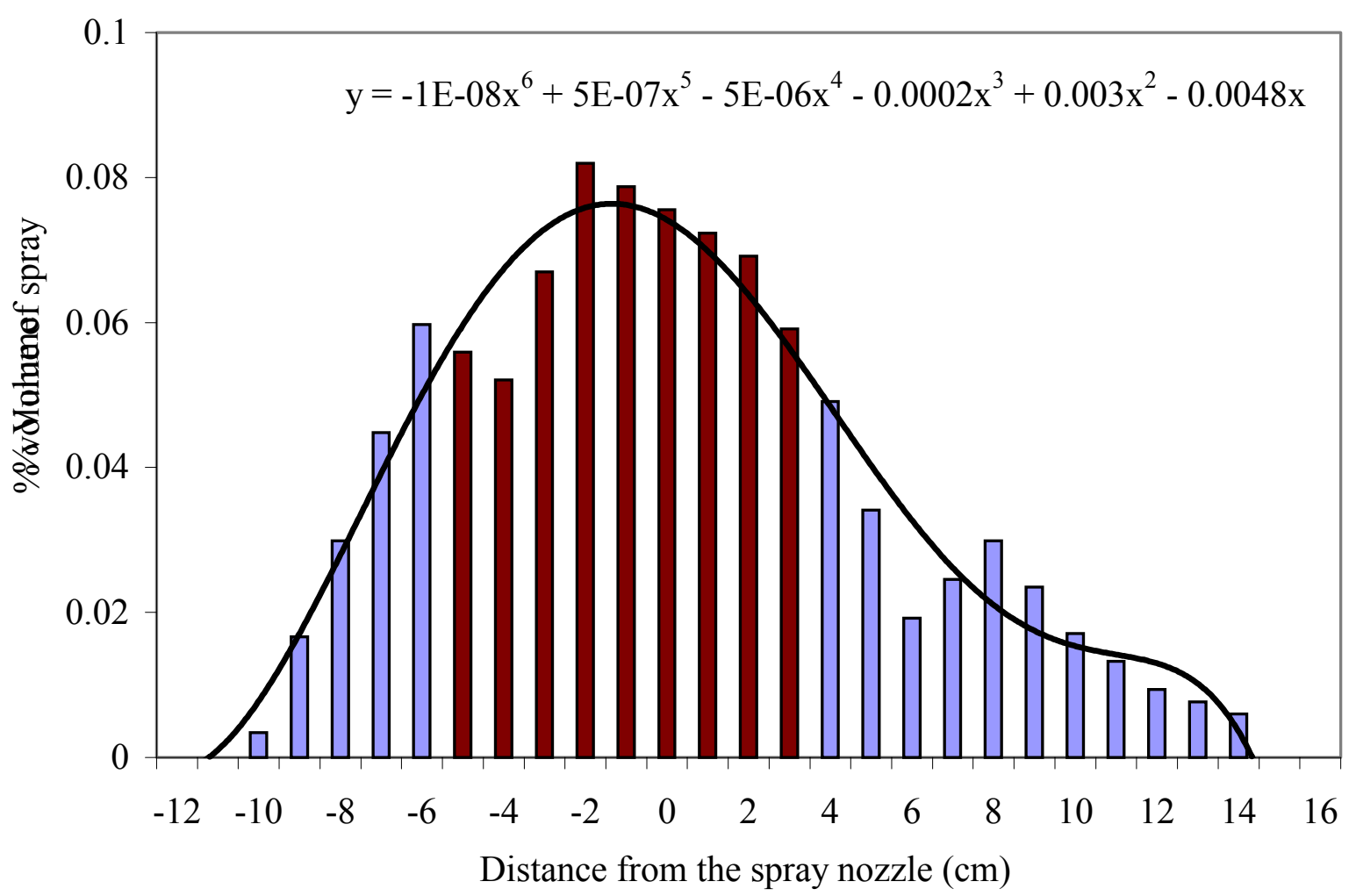

Figure 5.28: Overall spray distribution for 30 psi atomizing air. The darker bars indicate the region in the draft tube. 


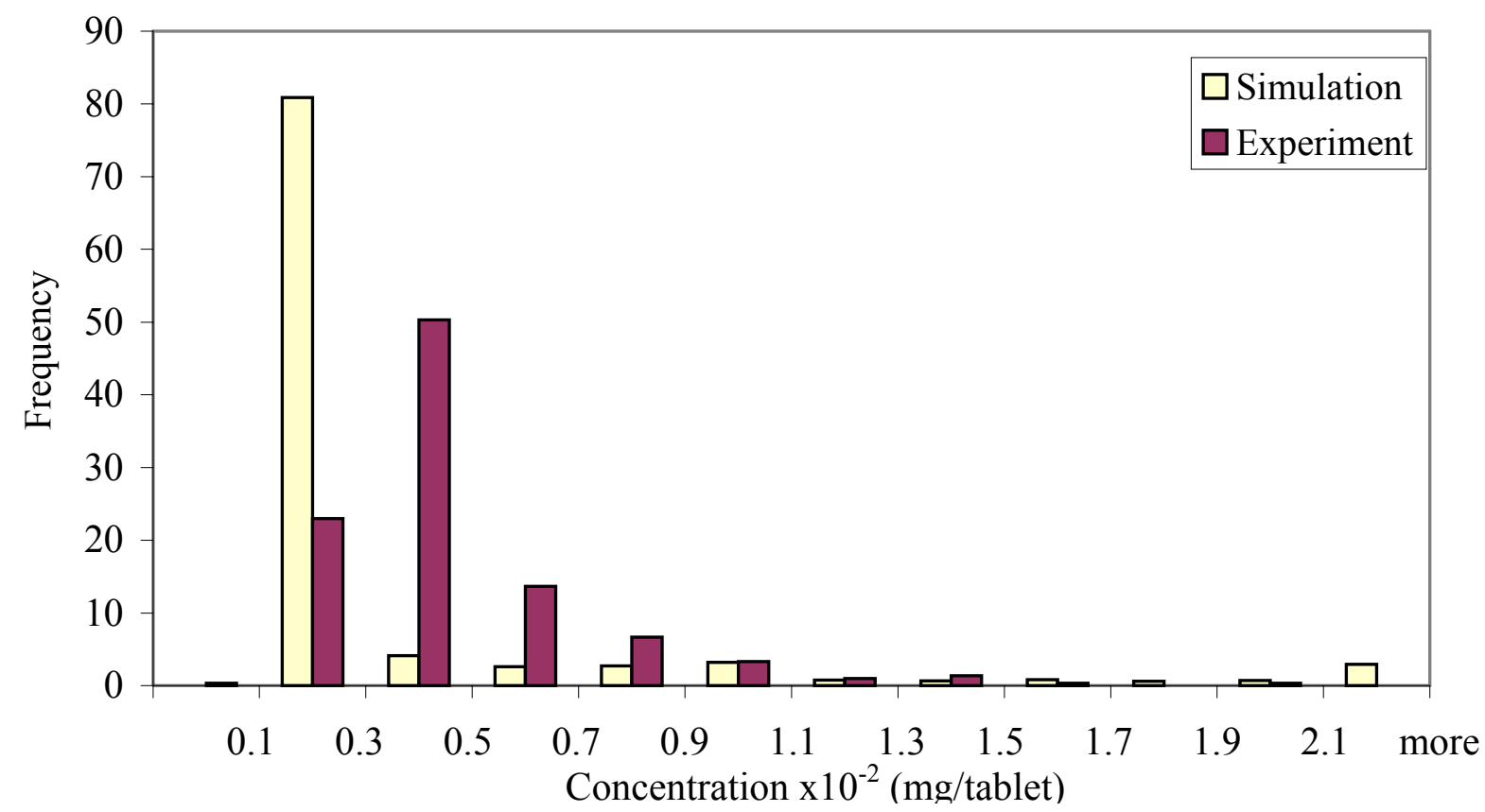

Figure 5.29: Coating distribution for No-Deflector case simulated using overall spray distribution compared with the experimental pulse test distribution.

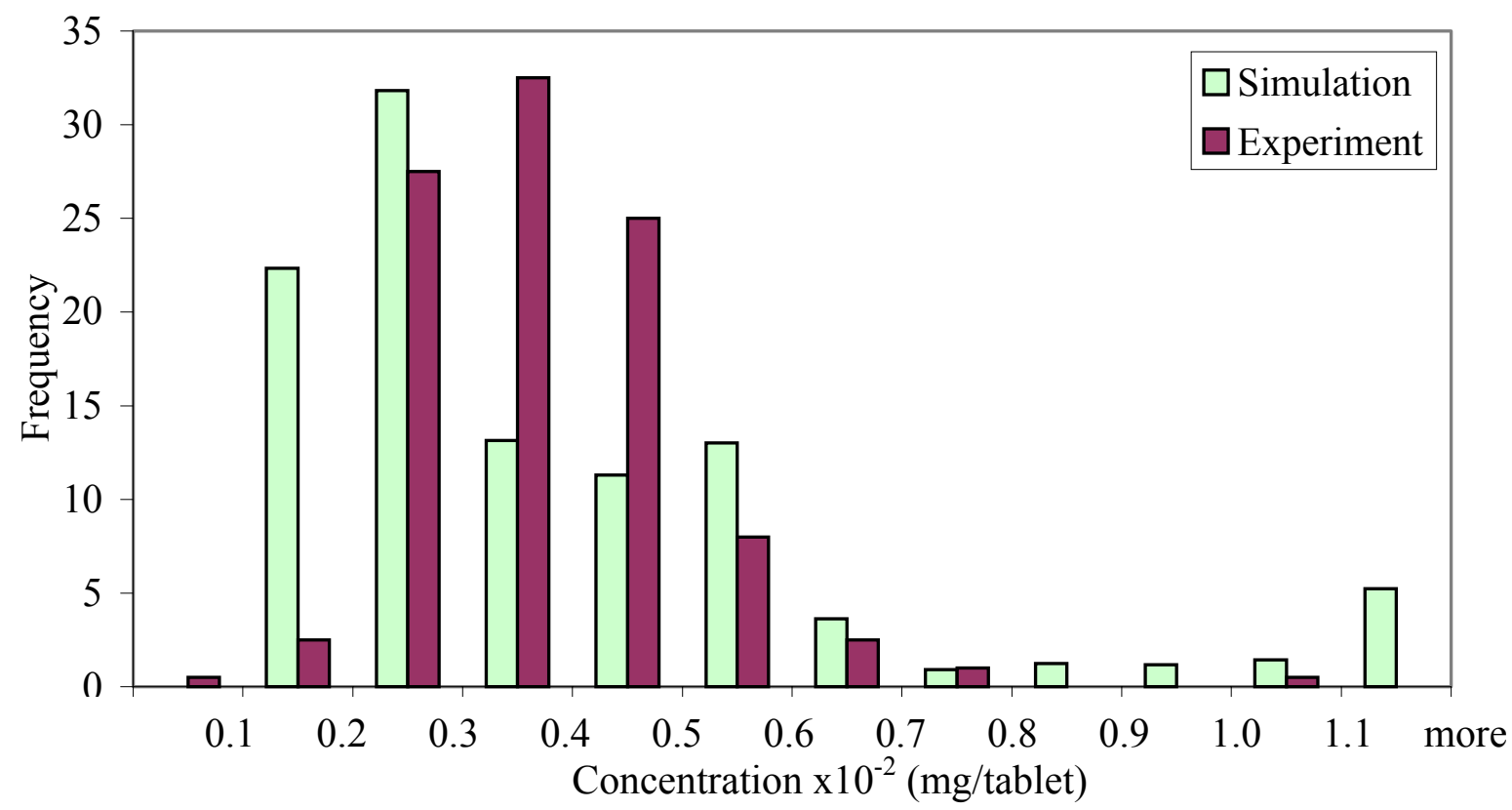

Figure 5.30: Coating distribution for Modified-Deflector case simulated using overall spray distribution compared with the experimental pulse test distribution. 


\section{Spray distribution - Case I}

At a distance far from the spray nozzle and near to the draft tube wall, the velocity of the fluidizing air is much greater than the velocity of the atomizing air, and this causes the spray material to be dragged vertically upward. The data in Appendix V, show the spray pattern covers a region of $-10 \mathrm{~cm}$ to $14 \mathrm{~cm}$ from the spray nozzle, but the width of the draft tube is approximately $10 \mathrm{~cm}$. Therefore, it is assumed that the 'excess' spray material at the outer edges greater than a radial distance of $5 \mathrm{~cm}$ from the spray nozzle is swept upwards at the sides of the draft tube. This modifies the spray distribution to that shown in Figure 5.31.

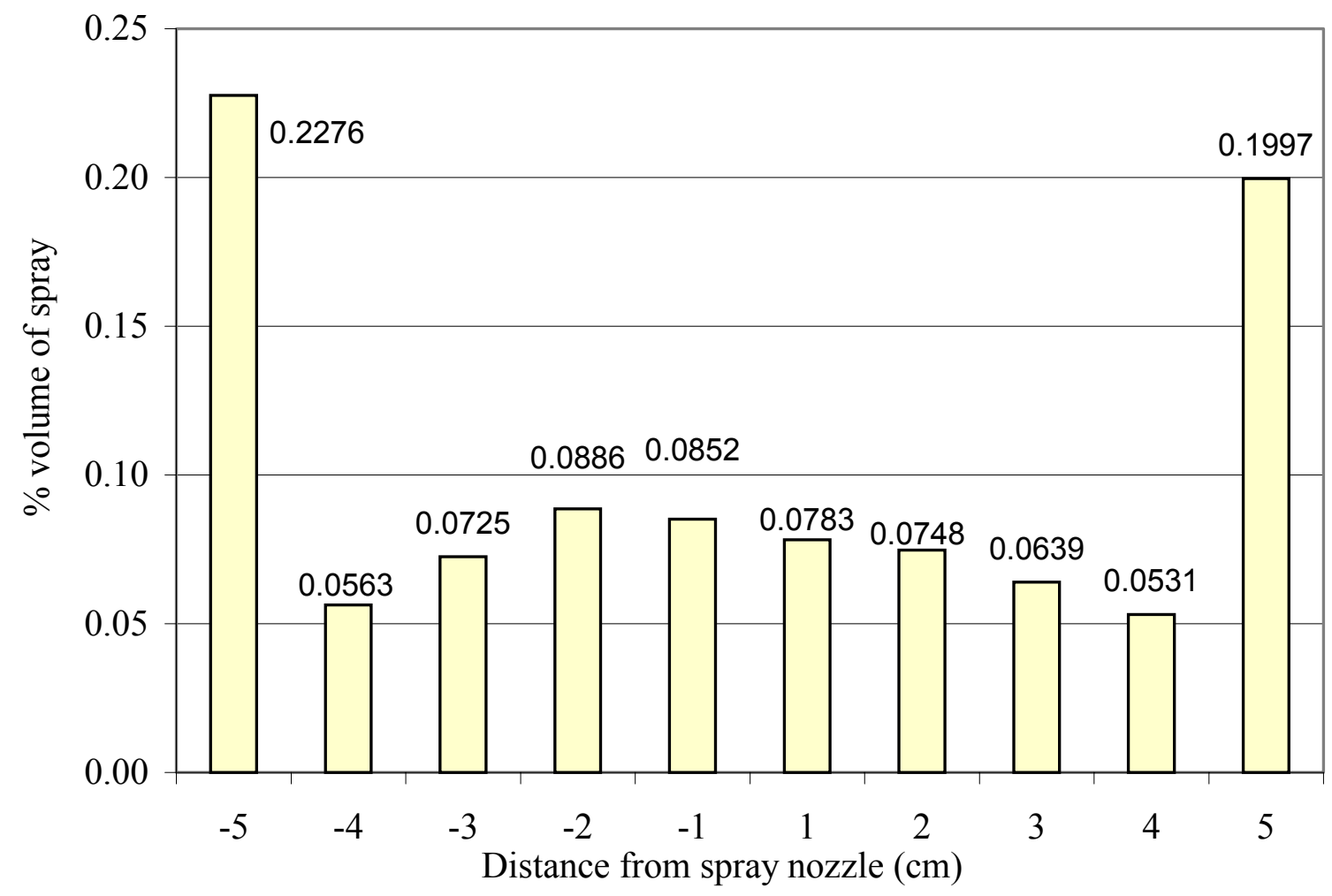

Figure 5.31: $\quad$ Spray distribution of Case I for 30 psi atomizing air 
Figure 5.32 and 5.33 show the simulation results for the No-Deflector and the Modified-Deflector cases using the spray distribution from Figure 5.31, respectively. For No-Deflector case, the result shows very good agreement with the pulse test experimental data. The Chi-Square analysis shows that those results are not statistically significant. (Refer to Appendix VIII).

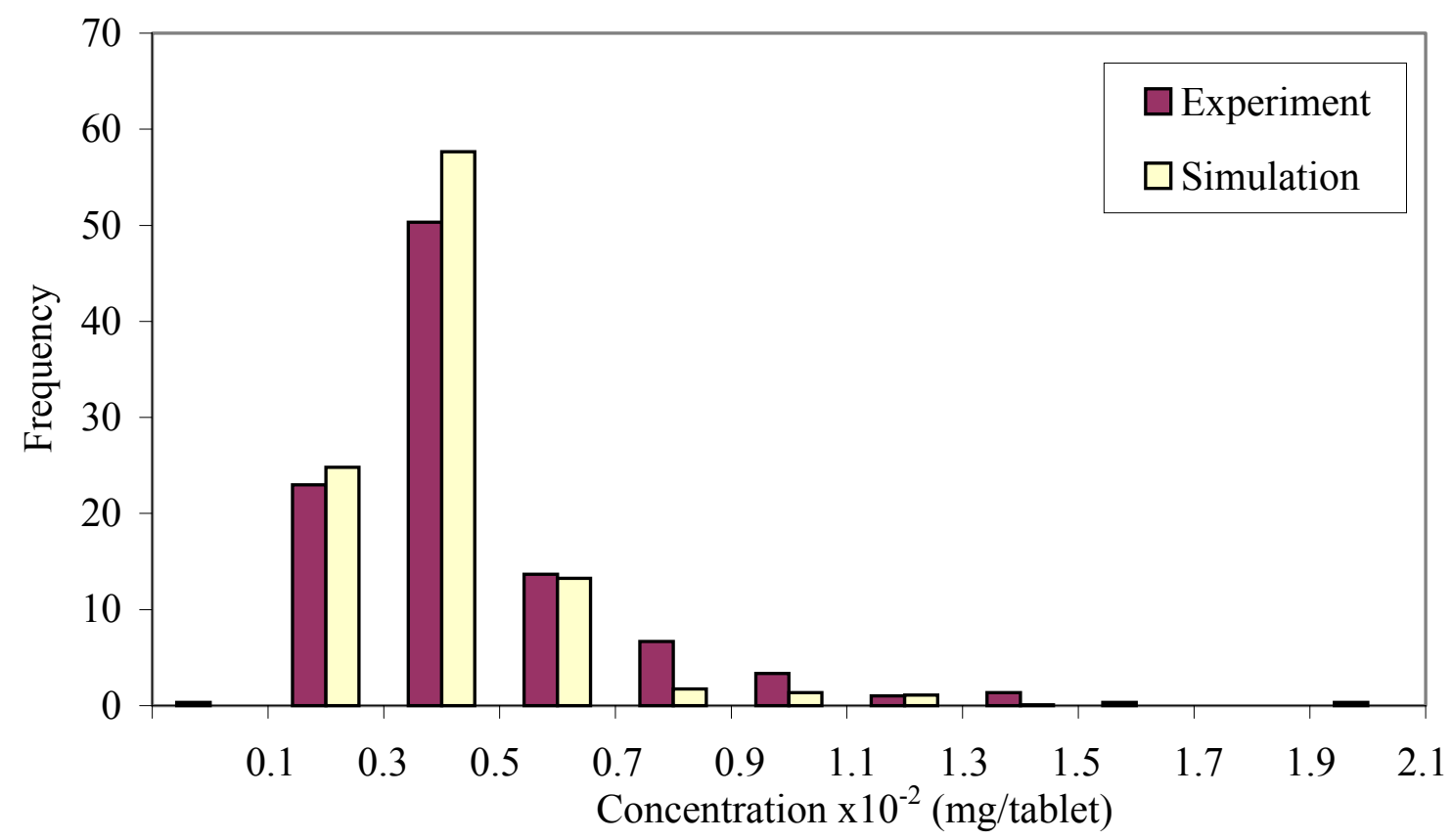

Figure 5.32: Coating distribution for No-Deflector case simulated using Case I spray distribution compared with the experimental pulse test distribution.

However, the result for the Modified Deflector simulation suggests that the spray distribution may vary with the presence of the deflector. This can be explained by the function of the deflector, which is to draw the particles (at the bottom of the bed) away from the spray nozzle. Thus results in having more particles in the region close to the draft tube wall compared to those in the No-Deflector case. With Case I spray 
distribution, the spray fractions at the regions next to the draft tube walls are almost three times higher than at other regions. This explains why the coating distribution of the simulation in Figure 5.33 has more particles that receive high amounts of spray.

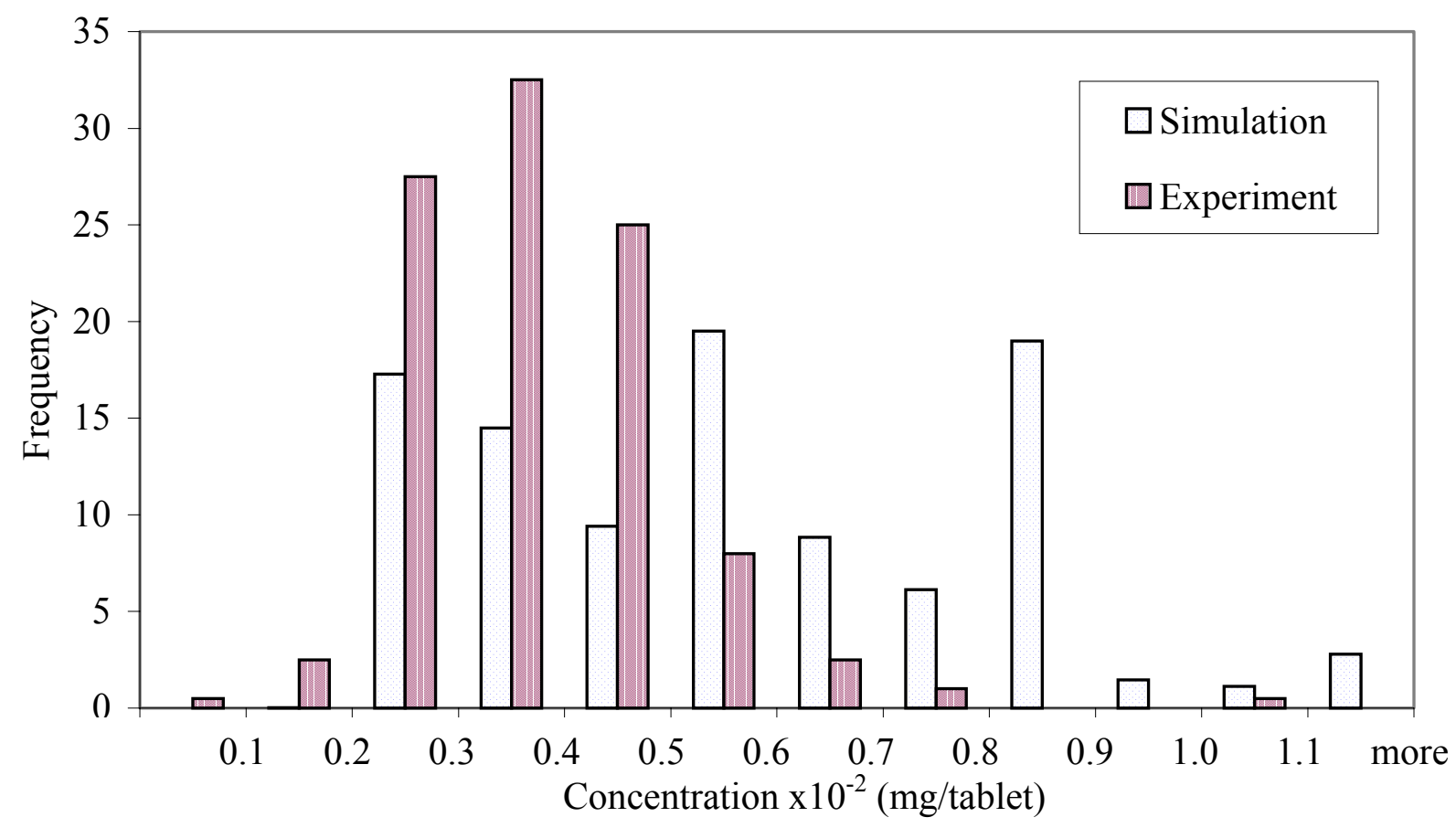

Figure 5.33: Coating distribution for Modified-Deflector case simulated using Case I spray distribution compared with the experimental pulse test distribution.

\section{Spray Distribution - Case II}

For the case of the Modified-Deflector, the particles that enter the spray zone are directed away from the spray nozzle. This means that more particles are present close to the draft tube wall to block the fluidizing air, thus decreasing the air velocity. Therefore, 
it is postulated that the amount of spray material dragged by the fluidizing air at the draft tube wall would also decreased. Based on this explanation, it is assumed that half of the 'excess' spray material passes to the outer radial segment of the spray zone and the another half goes to the segment next to it. Figure 5.34 shows this type of spray distribution.

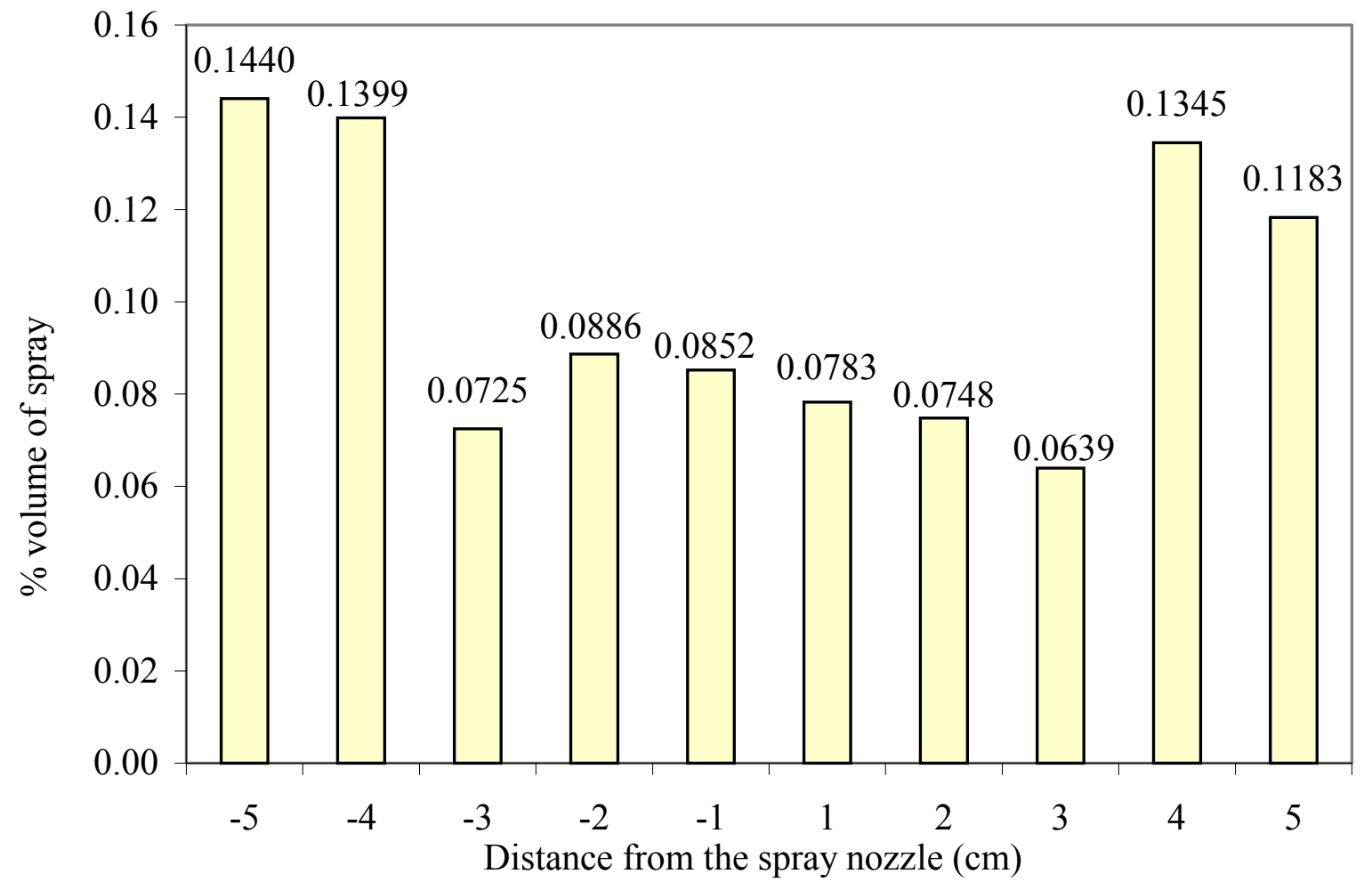

Figure 5.34: Spray distribution of Case II for $30 \mathrm{psi}$ atomizing air. 
Figure 5.35 and 5.36 show the results of the simulation for No-Deflector and Modified-Deflector using the spray distribution of Case II. For this type of spray distribution, the Modified-Deflector case show better agreement compared to those for the No-Deflector case. In order to make the distribution to shift to the left, the bottom part of spray zone is modeled as a region where the spray angle is 45 degree at the bottom of the bed (as shown in Figure 5.37), the Modified-Deflector simulation result gives very similar results as the coating distribution to the experimental pulse test results, as shown in Figure 5.38.

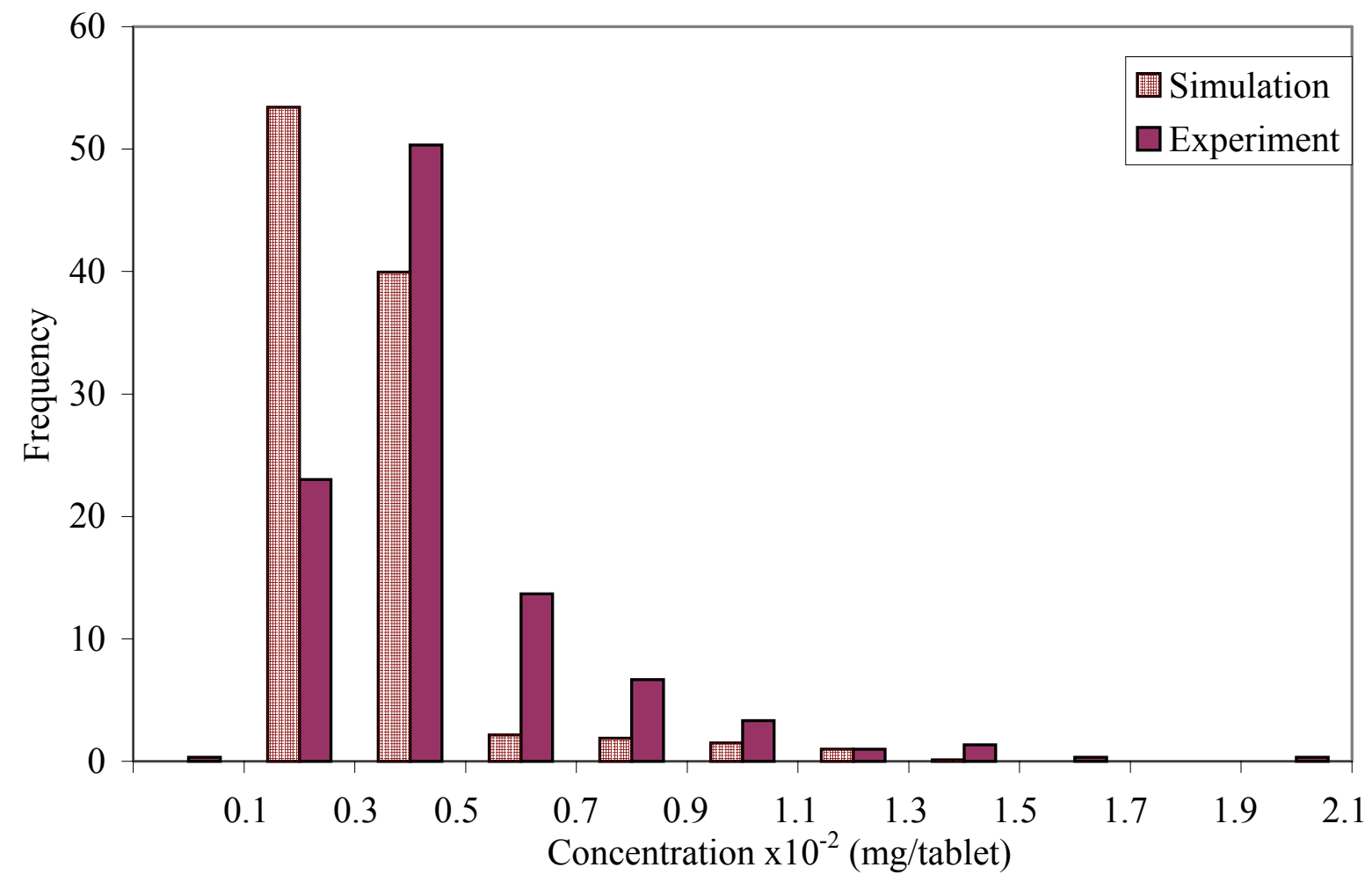

Figure 5.35: Coating distribution for No-Deflector case simulated using Case II spray distribution compared with the experimental pulse test distribution. 


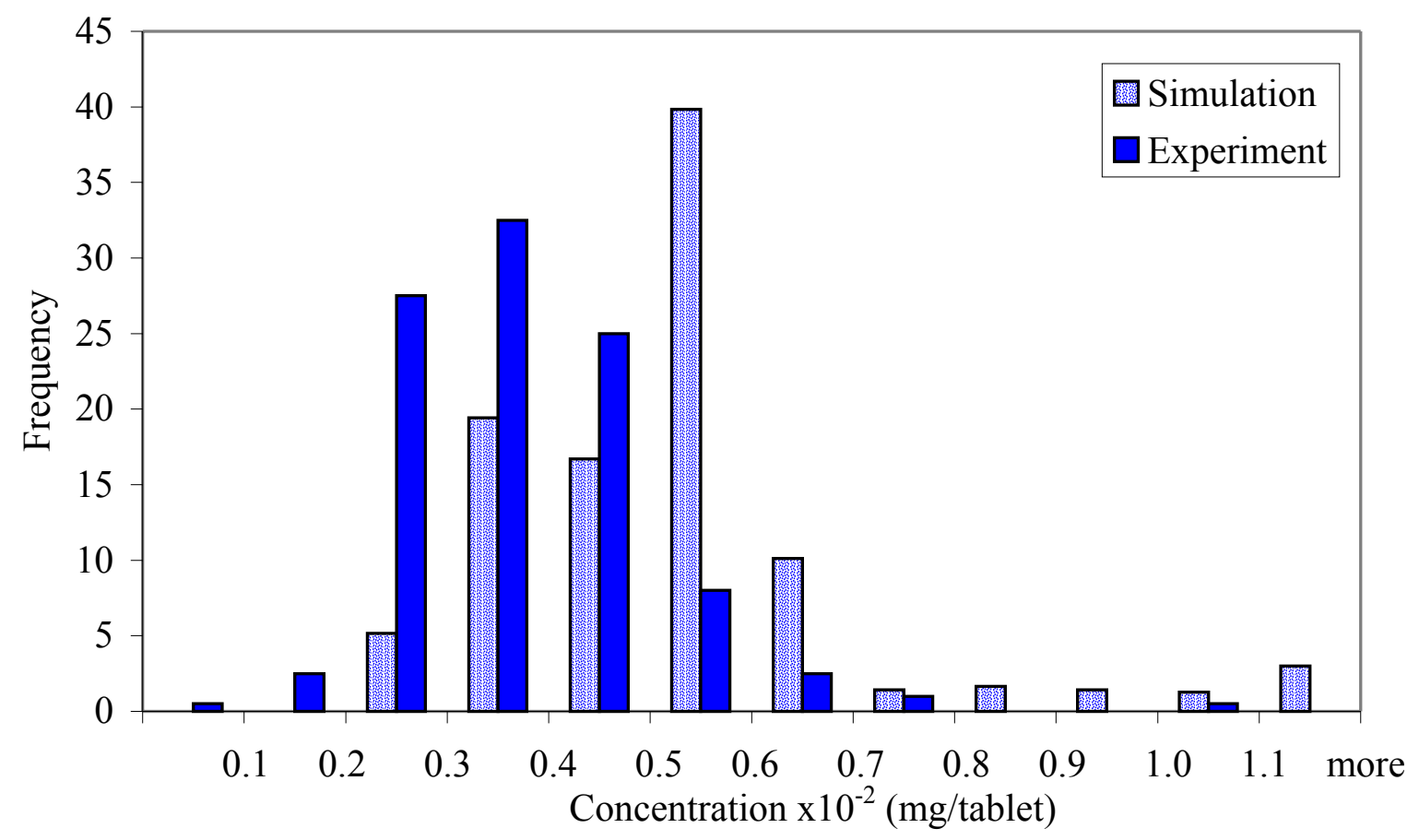

Figure 5.36: Coating distribution for Modified-Deflector case simulated using Case II spray distribution compared with the experimental pulse test distribution.

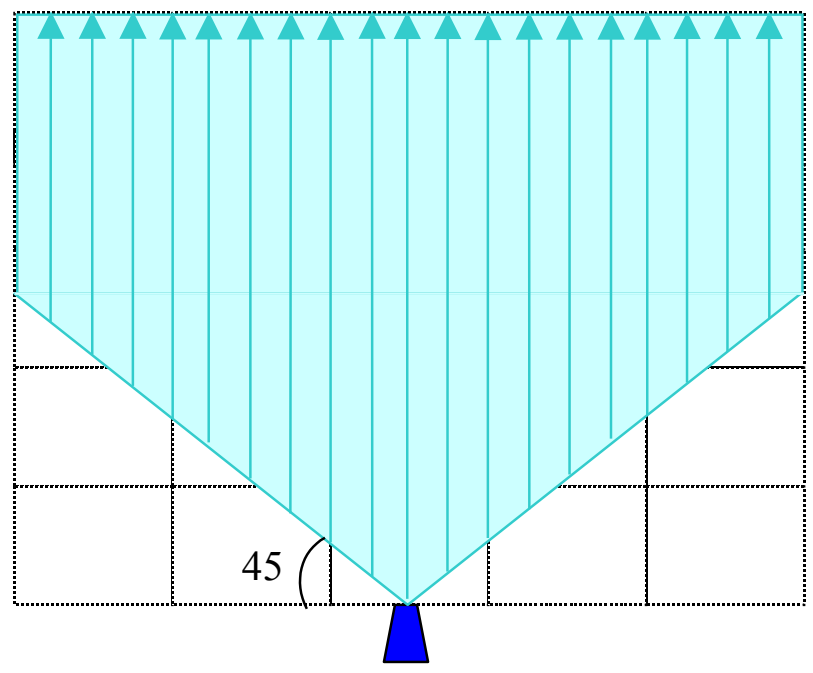

Figure 5.37: The rectangular spray shape having 45 degree angle at the bottom of the spray zone. 


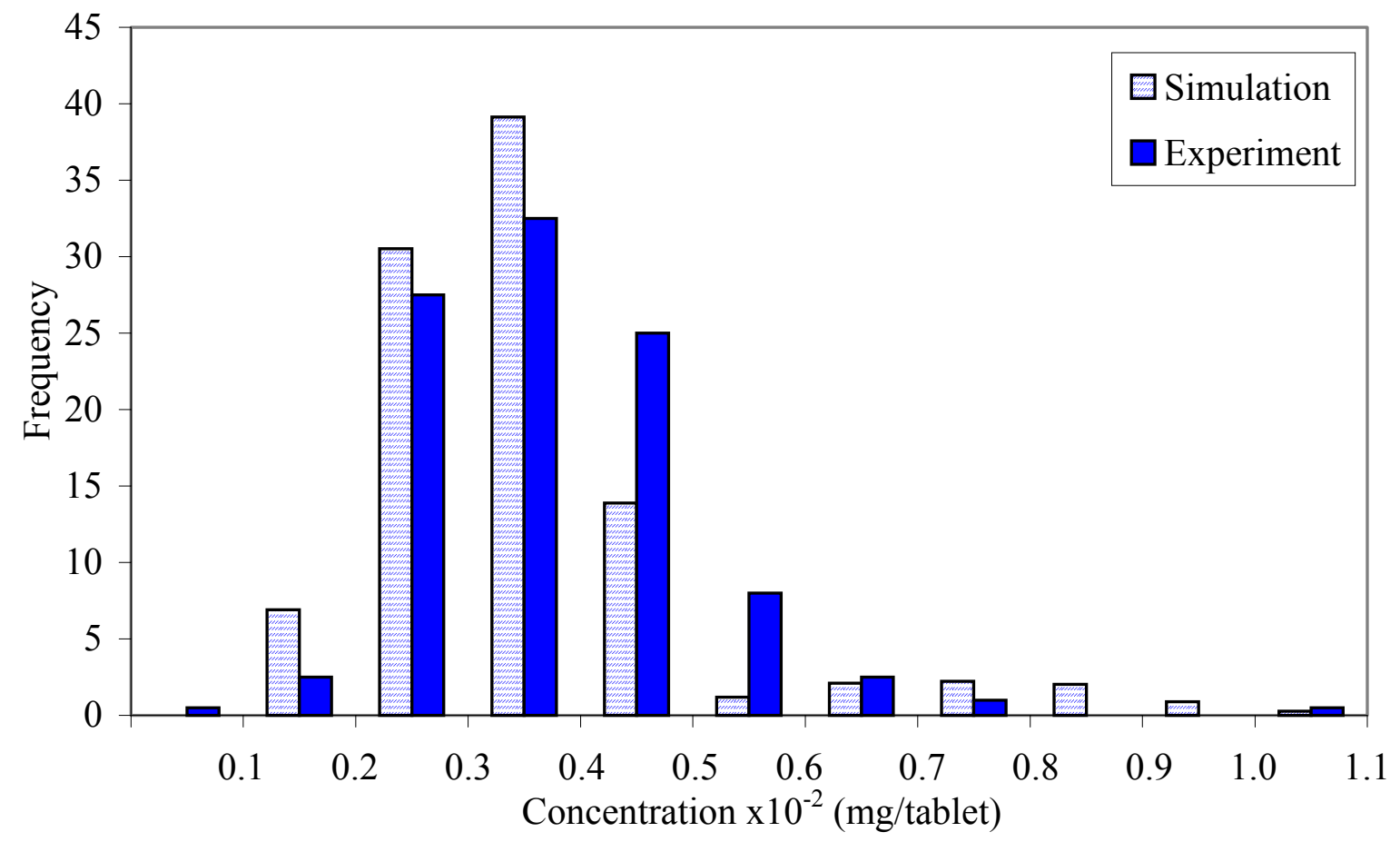

Figure 5.38: Coating distribution for Modified-Deflector case simulated using Case II spray distribution having $45^{\circ}$ angle at the bottom of the spray zone, compared with the experimental pulse test distribution.

When the 45-degree angle at the bottom of spray zone was applied to NoDeflector simulation with Case II spray distributions, the result does not agree well with the experimental coating distribution as shown in Figures 5.39. Comparing Figures 5.35 and 5.39, the No-Deflector simulation results using Case II spray distribution, one can see that in Figure 5.39 the amount of particles that receive less spray material has increased. This may due to the fact particles close to the wall start receiving spray material after a certain height from the bottom of the bed at which point the fraction of spray that hits the 
particles is reduced due to sheltering effect. This results in an increase in the amount of particles that receive less coating, thus making the distribution shift to the left.

The overall results suggest that, the spray distribution, as well as the spray zone shape, vary with different bed operating condition. However, further work has to be done to investigate these phenomena.

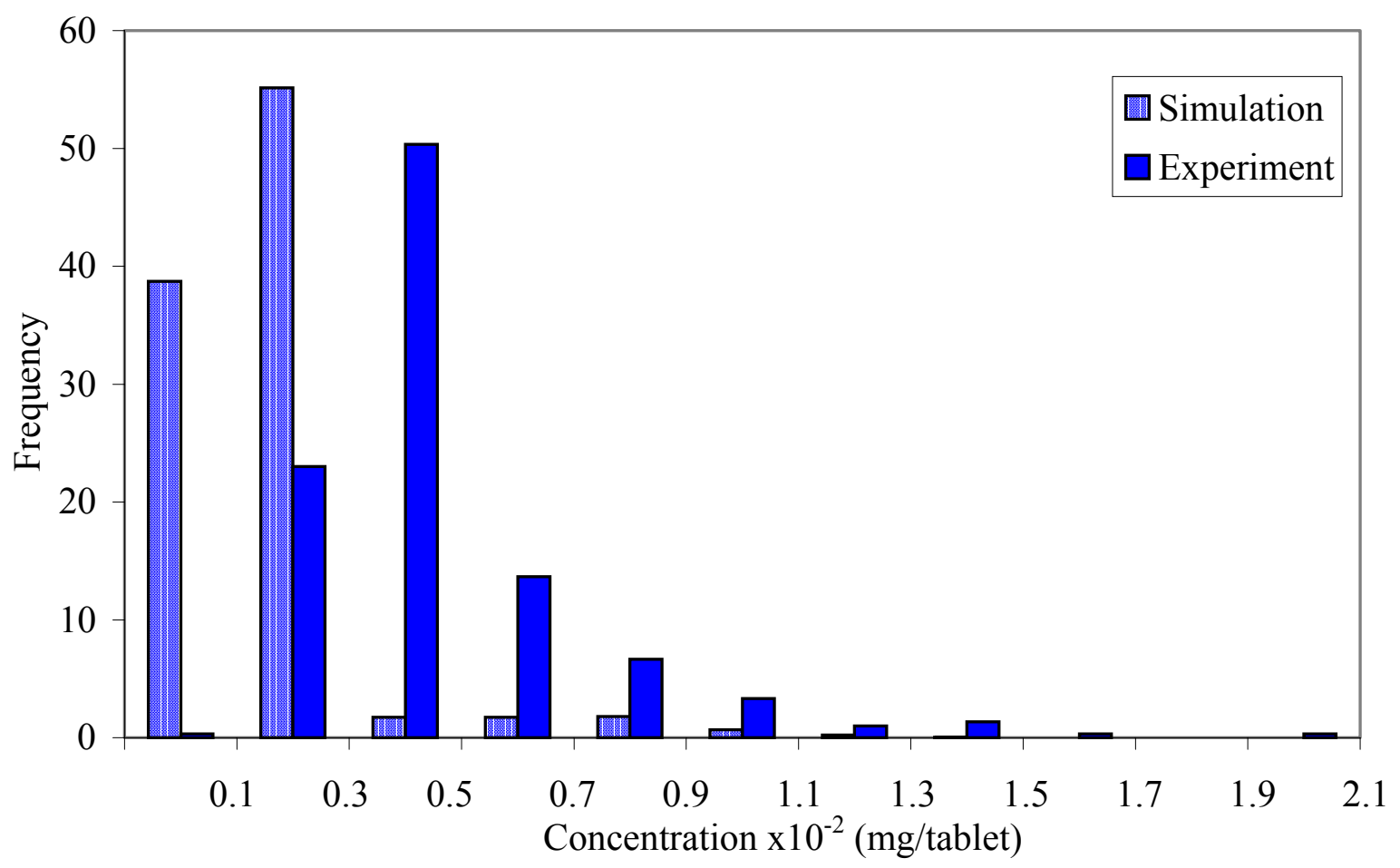

Figure 5. 39: Coating distribution for No-Deflector case simulated using Case II spray distribution having $45^{\circ}$ angle at the bottom of the spray zone. 


\section{CHAPTER 6: CONCLUSIONS}

A Monte Carlo coating model was developed to predict the coating variation in a semi-circular Wurster fluidized bed at different operating conditions. The input data used in the model was based on the experimental velocity and voidage data taken by Subramanian (2001). The results of the particle movement from the simulation were analyzed and compared with the experimental voidage and velicty profiles. The comparison confirmed the ability of the model to simulate the correct particle movement in a semi-circular fluidized bed. The equations and calculation methods used in the coating model were verified using Cheng's uniform velocity and voidage model (2000). Finally, the results of the simulations were compared with the experimental pulse test data.

Pulse test experiments were carried out to determine the coating variation obtained both with and without particles deflectors. The results were analyzed and the coating distributions were compared with the predictions from the simulations from the coating model developed in this work.

The conclusions that can be drawn from the experiments and simulations are summarized as follows:

- The results of the simulation show that the directions of the particle movement, as well as the bed voidage, are similar to the experimental profile. This proved that the model was capable of using the input data and to give realistic velocity and voidage profile in the equipment. 
- The coating model developed in this work gave similar results to Cheng's uniform velocity and voidage model when the projected surface area was discretized using the same orientation as Cheng's work.

- The number of discretized elements of the projected surface area plays a very important role in the simulation. In order to achieve the same result as predicted by Cheng (2000), the projected surface area have to be discreatized into 3,000 or more sections.

- When the model was simulated with uniform velocity and voidage and compared with a model simulated with uniform velocity but with experimental voidage, the intensities of the lines in both cases were almost identical. This suggested that for the experimental conditions used in the current work, the variation in bed voidage has only a small effect on the amount of material received by the particles.

- The results from experimental work in a particle-free bed showed that the direction of spray material is vertically upward (from the bottom of the bed). This required that the projected surface area be discretized normal to the bottom of the bed.

- When the projected surface area was discretized with respect to the spray nozzle, using a solid cone spray shape, the coating distribution of the particles was found to have a very long tail. This was due to the fact that the closer the particle to the spray zone received more spray material and vice versa. This effect is reinforced by the effect of the conical shape of the spray zone, where 
particles close to the draft tube (far from the spray zone) spend less time in the spray zone, thus receiving less spray material.

- The results of the spray characterization experiments carried out by Spraying System Co. (Wheaton, IL) showed a radial variation in the spray density. When this spray distribution is introduced into the model, the simulation results do not agree with the experimental pulse test results. However, in NoDeflector case, the best results were obtained when the spray was directed vertically upwards and the "excess spray fraction" was added to the outer region of the spray pattern. In the case of the Modified-Deflector, the best results were obtained when the "excess spray fraction" was divided and added to the first two outer regions of the spray pattern. Based on the above assumptions and results, it suggests that the shape of the spray is a very important parameter in modeling the distribution of coating material received per-particle-per-pass.

- The blotting paper experiment suggests that there is no specific spray shape for the spray zone as per predicted earlier. Instead, the spray material was found to be distributed over whole region of the draft tube in the absence of particles. In addition, the flow direction of the spray material was found to be vertically upward. In the No-Deflector case, the best result was obtained when the spray material was assumed to flow vertically upwards. However, in the case of Modified-Deflector, the best simulation results were obtained by assuming that there is a no-spray zone, which is at the region below the line of 45 degree from the bottom of the bed to the draft tube wall. This may suggest 
that the spray shape at the bottom of the bed is different with different bed condition particularly with or without the presence of a particle deflector. However, more work has to be done to investigate this theory.

- Finally, it can be concluded that, with adequate experimental input data, Monte Carlo simulation can be used to predict the coating variation at different operating condition in semi-circular Wurster fluidized bed coating equipment. 


\section{CHAPTER 7: RECOMMENDATIONS FOR FUTURE WORK}

The recommendations for future work are as follows:

- The results from the blotting paper experiment have shown that the direction of the spray material is vertically upward. However, the experiment was done without the particles present in the fluidized bed. The observation of the flow direction of the spray material was based on the trace of the spray material on the blotting paper. Despite spraying with a colored spray solution, the flow of the spray is very fast and the spray droplet is so small that it is difficult to visually observe the direction of the spray material flow as well as the spray coverage. An experiment with an ultra violet content of spray material could be conducted so that flow and the coverage of the spray material can be easily seen.

- Based on the test report provided by Spraying System Co., the spray density varies in the axial position from the spray nozzle. This spray distribution was used as the input data in the simulation. A modification to the spray distribution was made based on an assumption that the spray material was swept away by the fluidizing air. In order to obtain better prediction from the simulation, a study should be conducted to measure and investigate how the spray distribution varies with different bed operating conditions when particles are present. 


\title{
NOMENCLATURE
}

\author{
$A_{(k)} \quad$ cross sectional area of element $\mathrm{k}, \mathrm{m}^{2}$ \\ $\bar{A}_{(k)} \quad$ average cross sectional area of element $\mathrm{k}, \mathrm{m}^{2}$ \\ $A_{\text {cap }} \quad$ area of the spherical cap, $\mathrm{m}^{2}$

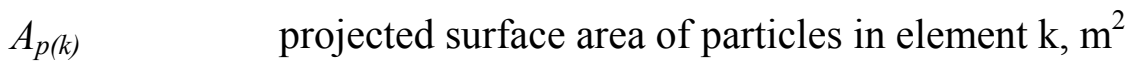 \\ $A_{\text {sec }} \quad$ area of the section of semi-circular fluidized bed, $\mathrm{m}^{2}$ \\ $A_{\text {seg }} \quad$ area of the segment of semi-circular fluidized bed, $\mathrm{m}^{2}$ \\ $A_{s p} \quad$ surface area (projected) of the sphere particle used in the simulation, $\mathrm{m}^{2}$ \\ $A_{\text {tab }} \quad$ surface area of the tablet used in the experiment, $\mathrm{m}^{2}$ \\ $c v \quad$ coefficient of variation \\ $C_{t} \quad$ particle circulation time, $\mathrm{s}$ \\ $D_{s p} \quad$ diameter of the sphere particle used in the simulation, $\mathrm{m}$ \\ $D_{t a b} \quad$ diameter of the tablet used in the experiment, $\mathrm{m}$ \\ $f_{(k)} \quad$ fraction of spray passing through element $\mathrm{k}$ \\ $f_{t} \quad$ function used in equation $3.14, \mathrm{~m}$ \\ $F_{m} \quad$ total fraction of spray passing through all elements \\ $J \quad$ radius of the sphere of the spherical cap, $\mathrm{m}$ \\ $l \quad$ length of element, $\mathrm{m}$ \\ $m \quad$ number of elements, \\ $\dot{m} \quad$ mass flowrate, $\mathrm{kg} / \mathrm{s}$ \\ $n_{p} \quad$ number of spray droplets per second, $\mathrm{s}^{-1}$.
}




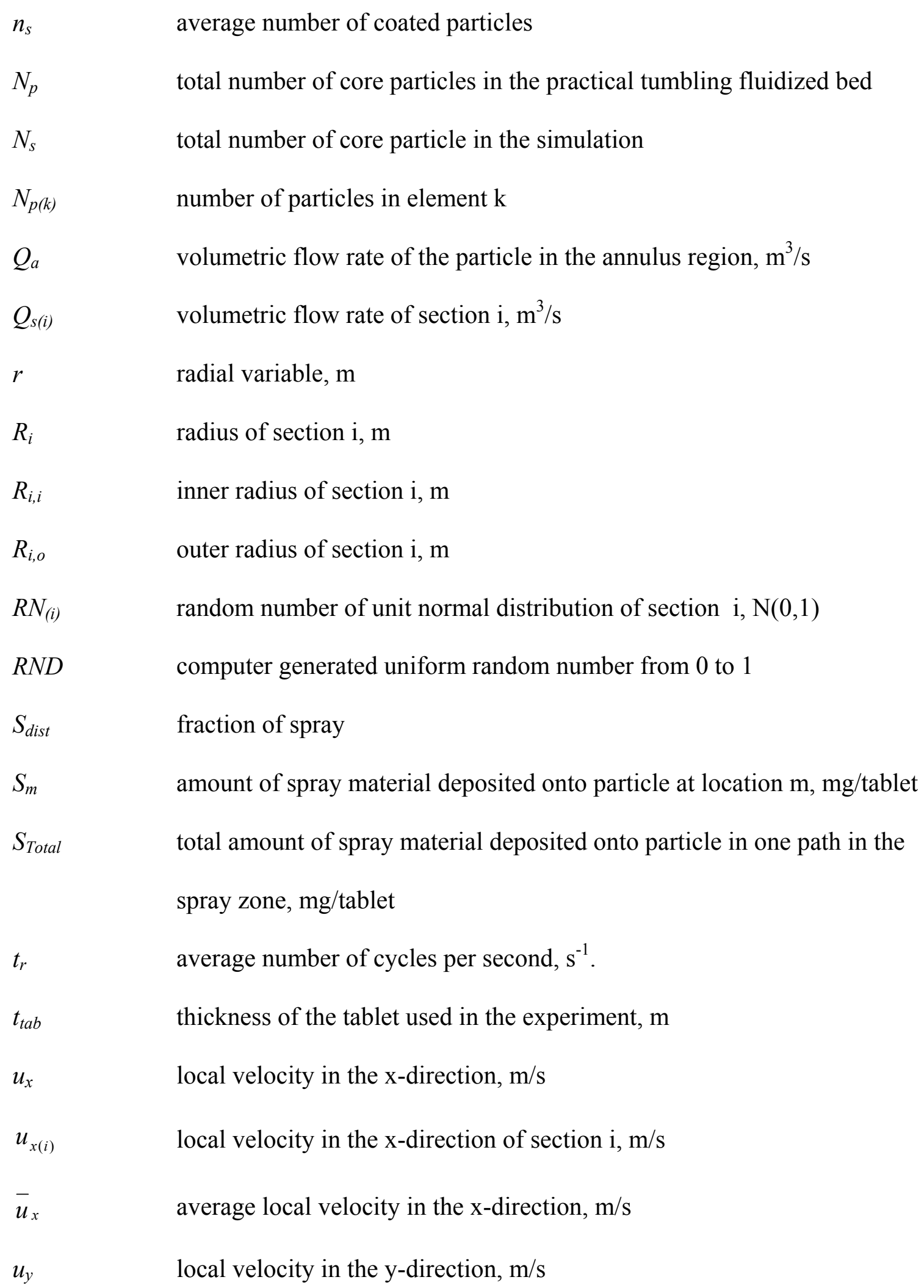


$u_{y(i)} \quad$ local velocity in the $y$-direction of section $\mathrm{i}, \mathrm{m} / \mathrm{s}$

$\bar{u}_{y(i)} \quad$ average local velocity in the y-direction, $\mathrm{m} / \mathrm{s}$

$\bar{u}_{y(i)} \quad$ average local velocity in the $\mathrm{y}$-direction of section $\mathrm{i}, \mathrm{m} / \mathrm{s}$

$v_{a} \quad$ particle velocity in the annulus region, $\mathrm{m} / \mathrm{s}$

$V_{(k)} \quad$ volume of section $\mathrm{k}, \mathrm{m}^{3}$

$V_{p(k)} \quad$ volume of particles in section $\mathrm{k}, \mathrm{m}^{3}$

$v_{x}^{n}{ }^{n}(i) \quad$ velocity in $\mathrm{x}$-direction of particle $\mathrm{n}$ in section $\mathrm{i}, \mathrm{m} / \mathrm{s}$

$v_{y}{ }^{n}{ }^{(i)} \quad$ velocity in $\mathrm{y}$-direction of particle $\mathrm{n}$ in section $\mathrm{i}, \mathrm{m} / \mathrm{s}$

$\Delta t \quad$ duration between successive particle simulations, $\mathrm{s}$

$\Delta x^{n} \quad$ distance traveled in X-direction of particle $n, \mathrm{~m}$

$\Delta y^{n} \quad$ distance traveled in y-direction of particle $n, \mathrm{~m}$

$\varepsilon \quad$ local voidage

$\bar{\varepsilon} \quad$ average local voidage

$\varepsilon_{(k)} \quad$ voidage of section $k$

$\sigma_{u_{x(i)}} \quad$ standard deviation of local velocity in the x-direction

$\sigma_{u_{y(i)}} \quad$ standard deviation of local velocity in the y-direction 


\section{BIBLIOGRAPHY}

Abe, E., Yamada, N., Hirosue, H., Nakamura, H., "Coating Mass Distributions of Seed Particles in a Tumbling Fluidized Bed Coater", Powder Technology, 99, 2, 85-90 (1998).

Britannica Encyclopedia (britannica.com), "Pharmaceutical Industry-Preparation of Dosage Forms", http://www.britannica.com/eb/article?eu=115137\&tocid=82355, 2001.

Cheng, X.X. and R. Turton, "The Study of Uniformity of Particle Coating", Ph.D. Dissertation, West Virginia University (1993).

Cheng, X.X. and R. Turton, "The Uniformity of Coating Occurring in Fluidized Bed", AIChE Symp. Sep. 90 (301), 142-151 (1994).

Cheng, X.X. and R. Turton, "The Prediction of Variability Occuring in Fluidized Bed Coating Equipment. I. The Measurement of Particle Circulation Rates in a Bottom-Spray Fluidized Bed Coater", Pharmaceutical Development and Technology, 5, 3, 311-322 (2000).

Cheng, X.X. and R. Turton, "The Prediction of Variability Occuring in Fluidized Bed Coating Equipment. II. The Role of Nonuniform Particle Coverage as Particle Pass Through the Spray Zone”, Pharmaceutical Development and Technology, 5, 3, 323-332 (2000).

Choi, M. S. and Meisen, A., "Sulfur Coating of Urea in Shallow Spouted Beds", (1996) He, Y.L., C.J. Lim, J.R. Grace, J.X.Zhu and S.Z. Qin, "Measurement of Voidage Profiles in Spouted Beds”, Can. J. Chem. Engr., 72, 229-234 (1994a).

He, Y.L., C.J. Lim, J.R. Grace, J.X.Zhu and S.Z. Qin, "Particle Velocity Profiles and Solids Flow Patterns in Spouted Beds", Can. J. Chem. Engr., 72, 561-568 (1994b). Iley, 
W.J., "Effect of Partile Size and Porosity on Particle Film Coatings", Powder Technology , 65, 1-3, 441-445 (1991).

Kucharski, J., Kmiec, A., "Hydrodynamics, Heat and Mass Transfer during Coating of Tablets in Spouted Bed", Can. J. Chem. Eng., 61, 435-439 (1983).

Lefroy G.A. and J.F. Davidson, “ The mechanics of Spouted Beds”, Trans. Instn. Chem. Engrs., 47, T120-T128 (1969)

Mann U. and Crosby E.J., "Cycle Time Distribution Measurements in Spouted Beds", Chemical Engineering Science, 28, 2, 623-627 (1973).

Mann Uzi, Crosby E.J., Robinovitch M., "Number of Cycle Distribution in Circulating Systems", Chemical Engineering Science, 29, 3, 761-765 (1974).

Maronga, S.J., Wnukowski, P., "Modelling of the Three-domain Fluidized Bed Particulate Coating Process", Chemical Engineering Science, 52, 17, 2915-2925 (1997).

Massilla, L., J.W. Westwater, "Photographic Study of Solids-Gas Fluidization", AICHE $J ., 6,1,132-138(1959)$.

Nakamura, H., Abe, E., Yamada, N., "Coating Mass Distributions of Seed Particles in a Tumbling Fluidized Bed Coater. Part II. A Monte Carlo Simulation of Particle Coating”, Powder Technology, 99, 2, 140-146 (1998).

Oliveira, W.P., Freire, J.T., Coury, J.R., "Analysis of Particle Coating by Spouted Bed Process", International of Pharmaceutics, 158, 1-9 (1997).

Porter, Stuart C., "Coating of Pharmaceutical Dosage Forms", Chapter 90, Remington's Pharmaceutical Sciences, 17, 1666-1675 (1985). 
Saadevandi, B. A., "The Use of Imaging Techniques to Study the Hydrodynamics of Particle Motion in a Fluidized Bed Coating Device in the Region of the Liquid Spray", Dissertation (1996).

Saleh, K., Cherif, R., Hemati, M., "Experimental Study of Fluidized Bed Coating: Influence of Operating Conditions on Growth Rate and Mechanism”, Advanced Powder Technology, 10, 3, 255-277 (1999).

Shelukar, S., Ho, J., Zega, J., Roland, E., Yeh N., Quiram D, Nole A., Katdare A., and Reynolds, S., "Identification and Characterization of Factors Controlling Tablet Coating Uniformity in a Wurster Coating Process", Powder Technology, 110, 29-36 (2000).

Singiser, R.E., Heiser, A. L., and Prillig, E. B., "Air-suspension Tablet Coating", Chemical Engineering Progress, 62, 6, 107-111 (1966).

Subramanian, G., "Video Imaging of the Flow Patterns of Tablets in a Semi-Circular Fluidized Bed", Master Thesis (2001).

Sudsakorn, K. and R. Turton, "Non-uniformity of Particle Coating on a Size Distribution of Particles in a Fluidized Bed Coater", Powder Technology, 110, 37-43, (2000)

Terashita. K., Susumu, N., Takehiko, N., Hiroshi, S., "Design for Fluidized Bed with Draft Tube by DEM analysis", Journal of Japan Society of Powder and Powder Metallurgy, 47, 12, 1306-1311 (2000).

Toomey, R.D., And H.F. Johnson, Chemical Engineering Progr. Symposium Ser. No. 5, 49, 51, (1953)

Van Velzen, D., H. J. Flamm, H. Langenkamp and A. Casile," "Motion of Solids in Spouted Beds", Can. J. Chem. Eng., 52, 156-161 (1974) 
Weiss, P. J. and Meisen A., "Laboratory Studies on Sulphur-Coating Urea by the Spouted Bed Process", The Canadian Journal of Chemical Engineering, 61, 440-447 (1983).

Wurster, D.E., “U.S. Patent, 2,648,609,” (1953).

Xu M., "A Theoretical and Experimental Investigation of Spouted Beds With Draft Tube", Ph.D. Dissertation, West Virginia University, (1994).

Xu M. and R. Turton, “A New Data Processing Technique for Noisy Signals Application to Measuring Particle Circulation Times in a Draft Tube Equipped Fluidized Bed", Powder Technology, 92, 111-117, (1997). 


\section{Appendix I}

\section{Calculation of Particle Circulation Time}

The particle circulation time was calculated from the mass flowrate of the particles through the annular packed bed region. The velocity of a marked particle in the annulus region was measured using a stopwatch to record the time taken for the particle to move from the top to the bottom of the annulus region in a distance of $20 \mathrm{~cm}$. The results are shown in Table A-1.1.

Table A-1.1: Measurement of time taken for the particle to move $20 \mathrm{~cm}$ distance from the top to the bottom of the bed in the annulus region.

\begin{tabular}{|c|c|}
\hline Trial & Time $(\mathbf{s})$ \\
\hline 1 & 5.24 \\
\hline 2 & 3.90 \\
\hline 3 & 3.99 \\
\hline 4 & 5.27 \\
\hline 5 & 7.10 \\
\hline 6 & 3.84 \\
\hline 7 & 5.58 \\
\hline 8 & 4.74 \\
\hline 9 & 6.18 \\
\hline 10 & 4.66 \\
\hline 11 & 3.60 \\
\hline 12 & 4.85 \\
\hline 13 & 4.87 \\
\hline 14 & 4.42 \\
\hline 15 & 4.06 \\
\hline Average & 4.82 \\
\hline \multicolumn{2}{|c}{} \\
\hline
\end{tabular}


Therefore the velocity of the particle in the annulus is:

$$
v_{a}=\frac{1}{\left(\frac{4.82 \mathrm{~s}}{20 \mathrm{~cm}}\right)}=4.15 \mathrm{~cm} / \mathrm{s}
$$

Given that the outer and the inner radii of the annulus region are $11.45 \mathrm{~cm}$ and $6.35 \mathrm{~cm}$ respectively, and the voidage is 0.435 . The mass flowrate for the annulus region is equal to:

$$
\begin{aligned}
& \dot{m}=\frac{1}{2}(3.14)\left(11.45^{2} \mathrm{~cm}^{2}-6.35^{2} \mathrm{~cm}^{2}\right)(1-0.435)\left(1.215 \times 10^{-3} \mathrm{~kg} / \mathrm{cm}^{3}\right)(4.15 \mathrm{~cm} / \mathrm{s}) \\
& \dot{m}=0.406 \mathrm{~kg} / \mathrm{s}
\end{aligned}
$$

Particle circulation time is equal to:

$$
\begin{aligned}
C_{t} & =\frac{\text { Total Bed Weight }}{\text { Mass flowrate }} \\
C_{t} & =\frac{3.6 \mathrm{~kg}}{0.406 \mathrm{~kg} / \mathrm{s}} \\
C_{t} & =8.87 \mathrm{~s}
\end{aligned}
$$




\section{Appendix II}

\section{Scanning Spectra of Blue Dye \#1 and Red Dye \#3 in water}

A Lambda 2 UV/VIS Spectrophotometer (Perkin-Elmer corp., Norwalk, CT) with data acquisition software package PECSS version 4.0 was used to analyze FD\&C Blue Dye \#1 and Red Dye \#3.

First, the wavelength at which the maximum absorbance for each dye was obtained by using the 'scan' function in the PECSS software. Figure A-2.1 and A-2.2 show the scanning results for blue and red dye respectively.

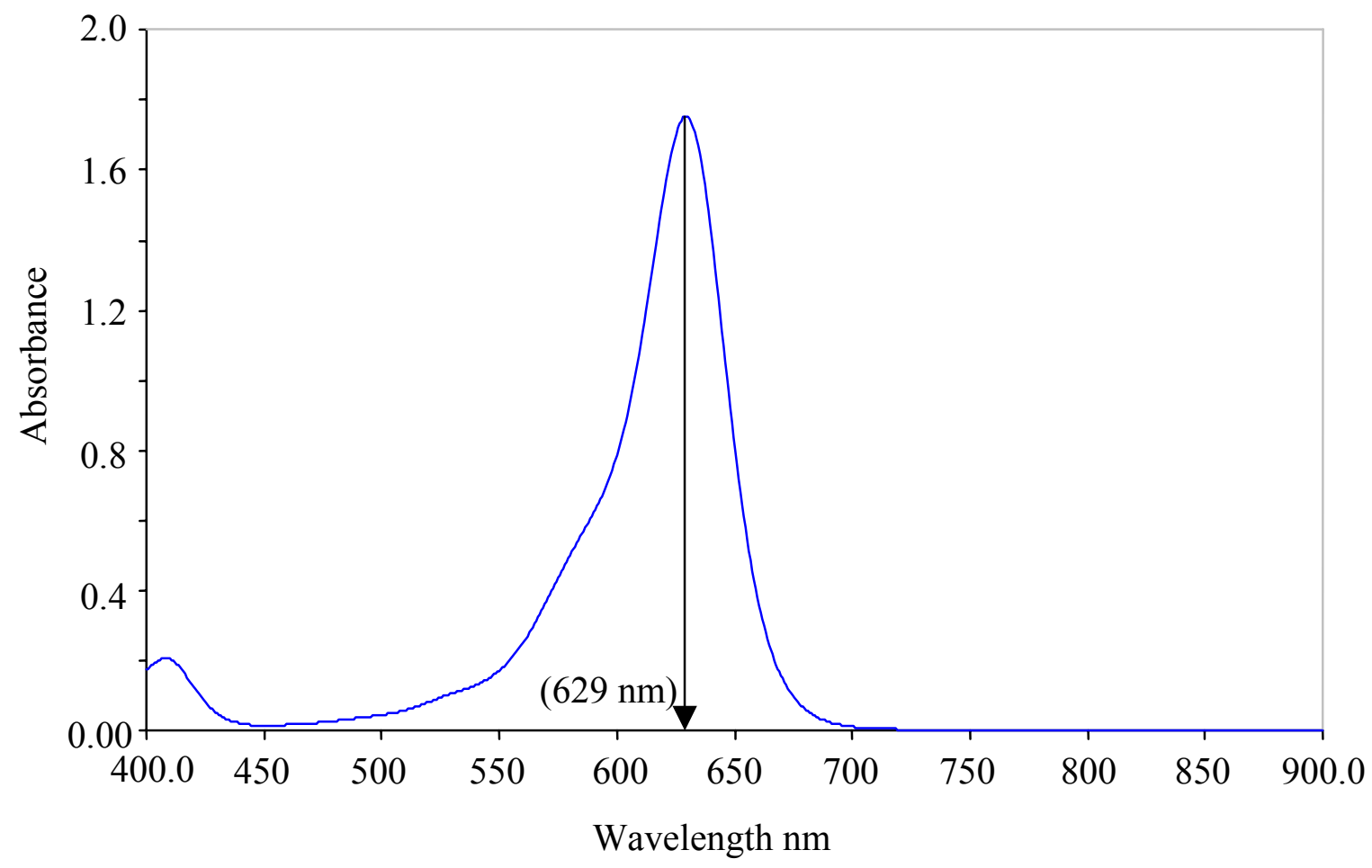

Figure A-2.1: Spectra of Blue Dye \#1 in water. 


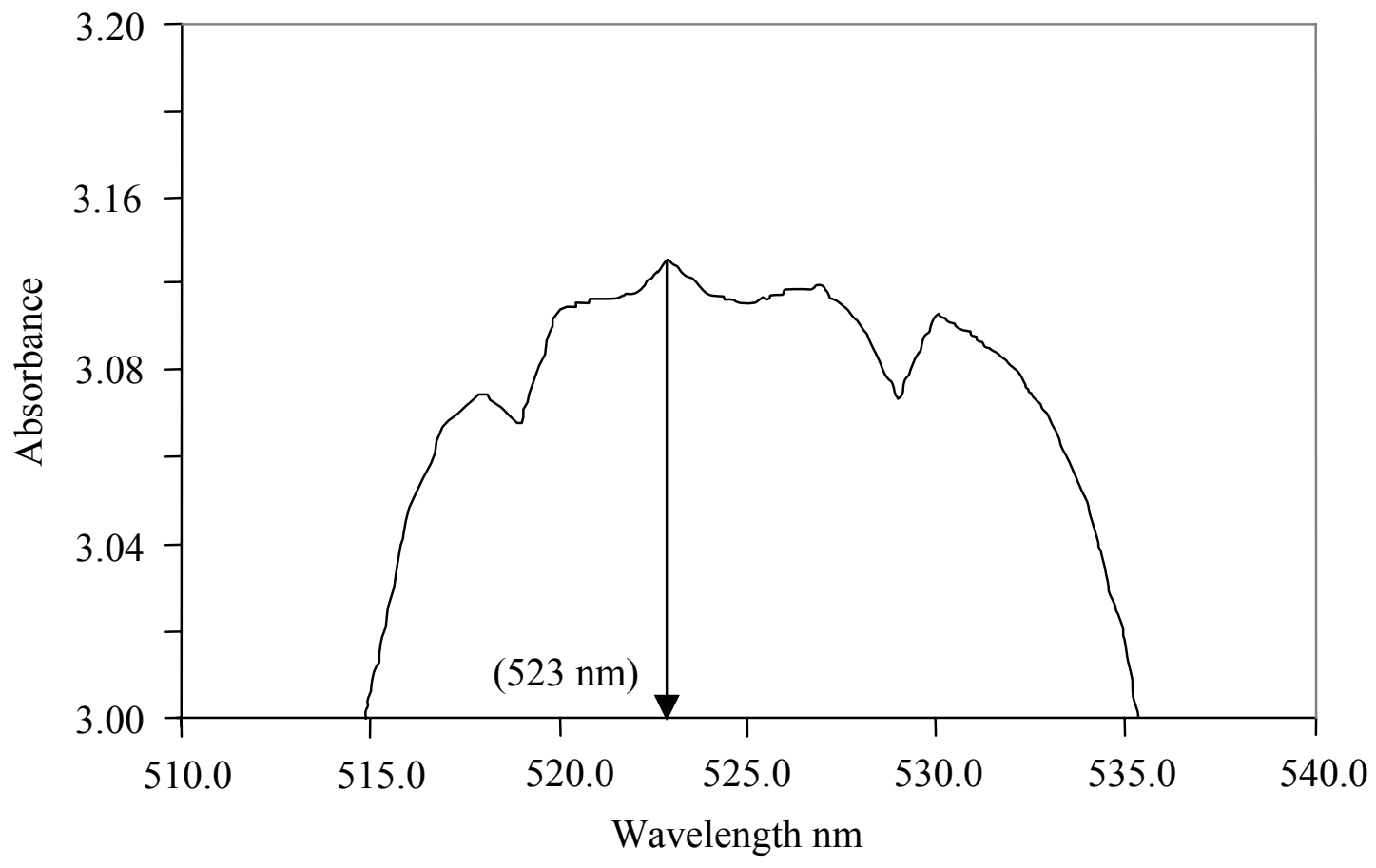

Figure A-2.2: Spectra of Red Dye \#3 in water.

\section{Calibration of spectrophotometer}

Since low concentration of blue and red dye deposited on to each tablet from the pulse test run was expected, the calibration of the spectrometer was performed at low blue or red dye concentrations. Below are the calibration data and calibration curves for both blue and red dyes. 
Table A-2.1: Data for calibration of the spectrophotometer for Blue Dye \#1

\begin{tabular}{|c|c|c|c|}
\hline $\begin{array}{c}\text { Wavelength } \\
(\mathrm{s})\end{array}$ & $\begin{array}{c}\text { Sample } \\
\text { ID }\end{array}$ & $\begin{array}{c}\text { Concentration } \\
(\mathrm{mg} / \mathrm{ml})\end{array}$ & Absorbance \\
\hline 629.0 & BLU01 & 0.000500 & 0.0726 \\
\hline 629.0 & BLU02 & 0.000300 & 0.0452 \\
\hline 629.0 & BLU03 & 0.000100 & 0.0169 \\
\hline 629.0 & BLU04 & 0.000090 & 0.0135 \\
\hline 629.0 & BLU05 & 0.000070 & 0.0118 \\
\hline 629.0 & BLU06 & 0.000050 & 0.0084 \\
\hline 629.0 & BLU07 & 0.000001 & 0.0001 \\
\hline
\end{tabular}

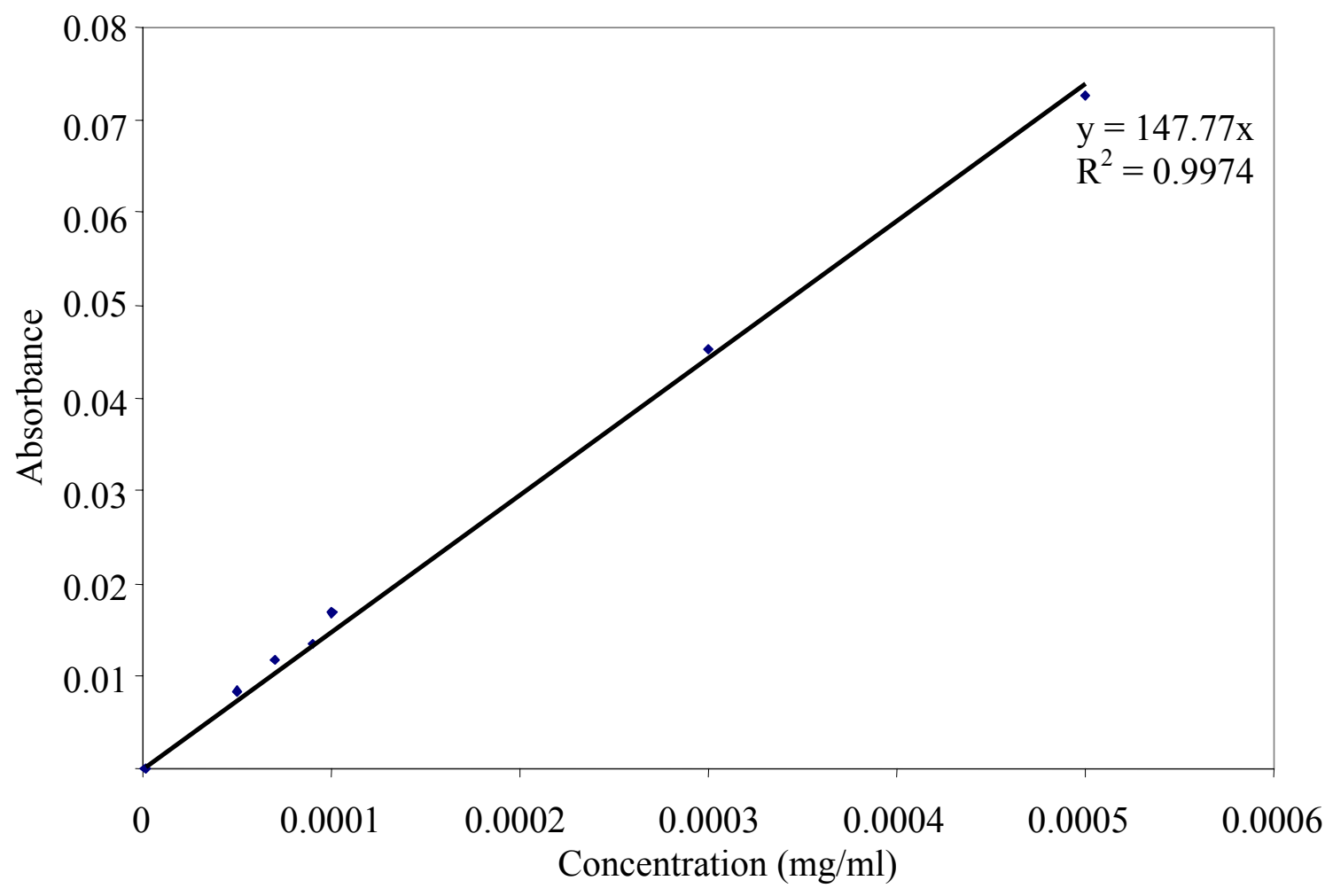

Figure A-2.3: Calibration curve for spectrophotometer of Blue Dye \#1. 
Table A-2.2: Data for calibration of the spectrophotometer for Red Dye \#3

\begin{tabular}{|c|c|c|c|}
\hline $\begin{array}{c}\text { Wavelength } \\
(\mathrm{s})\end{array}$ & $\begin{array}{c}\text { Sample } \\
\text { ID }\end{array}$ & $\begin{array}{c}\text { Concentration } \\
(\mathrm{mg} / \mathrm{ml})\end{array}$ & Absorbance \\
\hline 523.0 & RED01 & 0.0000 & 0.0000 \\
\hline 523.0 & RED02 & 0.0005 & 0.0481 \\
\hline 523.0 & RED03 & 0.0010 & 0.0955 \\
\hline 523.0 & RED04 & 0.0050 & 0.4968 \\
\hline 523.0 & RED05 & 0.0100 & 0.9977 \\
\hline 523.0 & RED06 & 0.0125 & 1.2418 \\
\hline 523.0 & RED07 & 0.0200 & 1.9615 \\
\hline 523.0 & RED08 & 0.0250 & 2.4150 \\
\hline
\end{tabular}

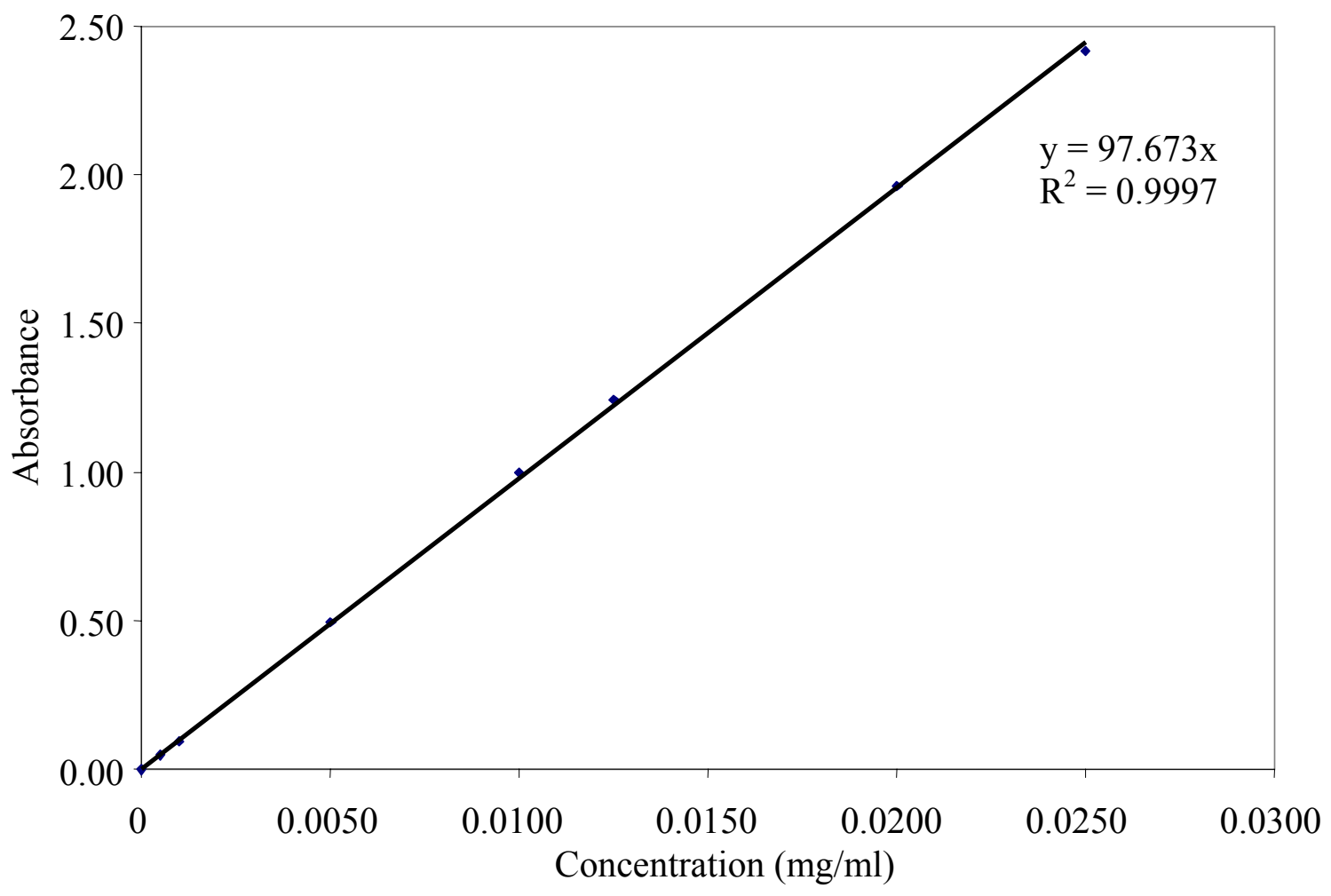

Figure A-2.4: Calibration curve for spectrophotometer of Red Dye \#3. 


\section{Appendix III}

\section{Probability Function}

The starting points of the particles were determined by the probability function obtained from the volumetric flow rate at the bottom of the bed. The volumetric flow rate of the particle in a given section is given by equation (4.1).

$$
Q_{s(i)}=\frac{1}{2} \int_{R i i}^{R i o} \pi u_{y(i)}(1-\varepsilon(i)) r d r
$$

Table A-3.1: Probability function of the volumetric flow rate for No-Deflector.

\begin{tabular}{|c|c|c|c|c|c|c|}
\hline \multicolumn{7}{|c|}{ No deflector } \\
\hline Section $i$ & $\begin{array}{c}\text { Velocity, } \mathrm{u}_{\mathrm{y}} \\
(\mathrm{m} / \mathrm{s})\end{array}$ & Voidage, $\varepsilon$ & Radius, $R_{i}(\mathrm{~m})$ & $\begin{array}{c}\text { Vol. flowrate, } Q_{s} \\
\left(\mathrm{~m}^{3} / \mathrm{s}\right)\end{array}$ & Probability & Cum. Prob. \\
\hline 6 & 0.72258437 & 0.91133333 & 0.05 & 8.04708E-05 & 0.25680947 & 0.256809467 \\
\hline 7 & 0.71094084 & 0.82033333 & 0.03 & 8.02159E-05 & 0.25599593 & 0.512805398 \\
\hline 8 & 0.65831084 & 0.79758333 & 0.01 & 1.04604E-05 & 0.03338254 & 0.546187937 \\
\hline 9 & 0.79894847 & 0.81858333 & 0.03 & 9.10239E-05 & 0.29048789 & 0.836675831 \\
\hline \multirow[t]{2}{*}{10} & 0.47196508 & 0.91366667 & 0.05 & 5.11774E-05 & 0.16332417 & 1 \\
\hline & & & Total $Q_{\mathrm{s}}$ & 0.000313348 & 1 & \\
\hline
\end{tabular}

Table A-3.2: Probability function of the volumetric flow rate for Modified-Deflector.

\begin{tabular}{|c|c|c|c|c|c|c|}
\hline \multicolumn{7}{|l|}{ Modified deflector } \\
\cline { 1 - 7 } Section $i$ & $\begin{array}{c}\text { Velocity, } \mathrm{u}_{\mathrm{y}}(\mathrm{m} / \mathrm{s}) \\
\text { Voidage, } \varepsilon\end{array}$ & Radius, $R_{i}(\mathrm{~m})$ & $\begin{array}{c}\text { Vol. flowrate, } \mathrm{Q}_{\mathrm{s}} \\
\left(\mathrm{m}^{3} / \mathrm{s}\right)\end{array}$ & Probability & Cum.Prob. \\
\hline 6 & 0.84106122 & 0.91133333 & 0.05 & $9.36651 \mathrm{E}-05$ & 0.267574343 & 0.267574343 \\
\hline 7 & 0.67081388 & 0.82033333 & 0.03 & $7.56884 \mathrm{E}-05$ & 0.216220081 & 0.483794423 \\
\hline 8 & 0.35794363 & 0.79758333 & 0.01 & $5.68762 \mathrm{E}-06$ & 0.016247906 & 0.500042329 \\
\hline 9 & 0.70400984 & 0.81858333 & 0.03 & $8.02076 \mathrm{E}-05$ & 0.22913023 & 0.729172559 \\
\hline 10 & 0.87429438 & 0.91366667 & 0.05 & $9.48038 \mathrm{E}-05$ & 0.270827441 & 1 \\
\hline
\end{tabular}




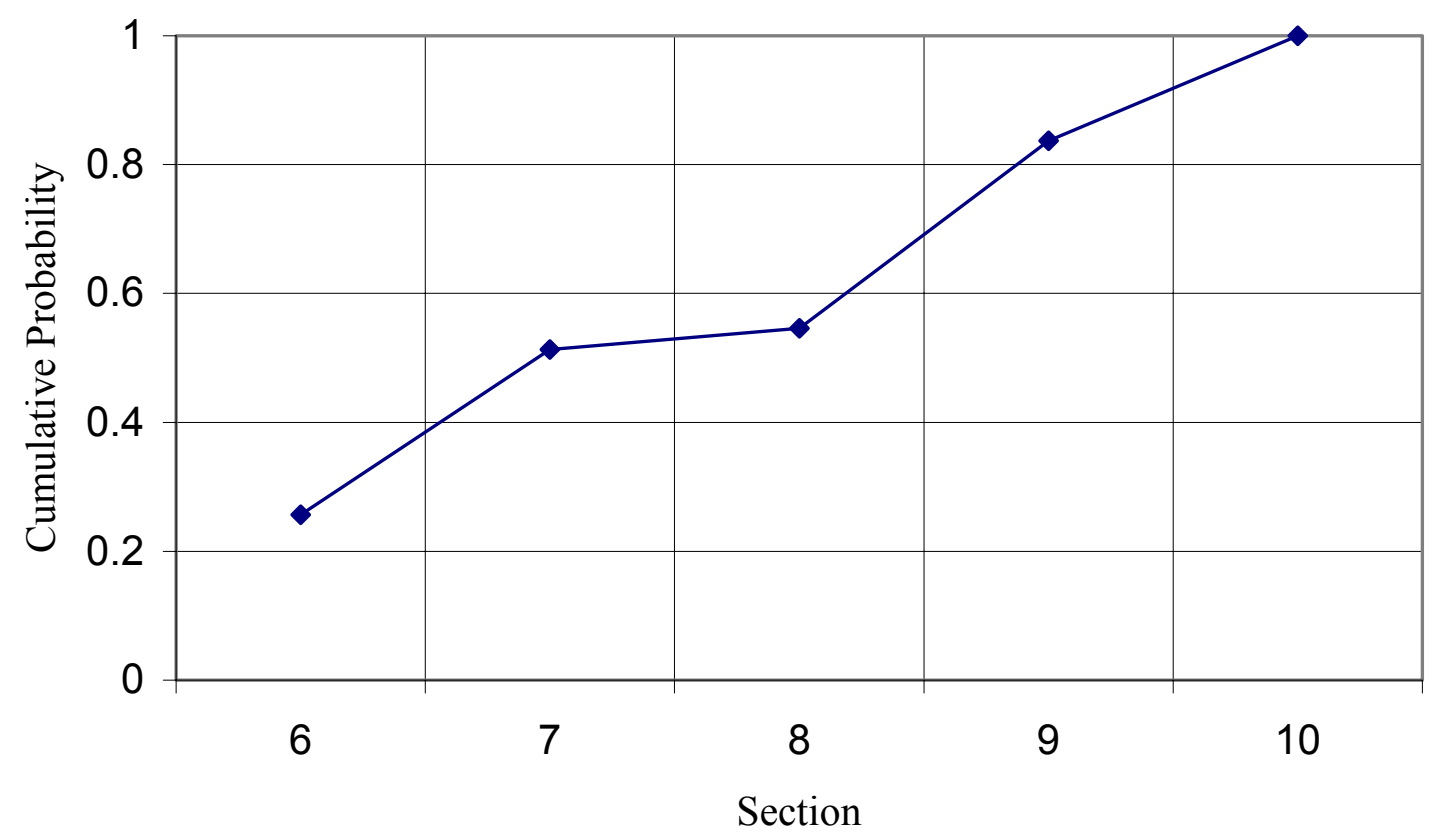

Figure A-3.1: Probability function for No-Deflector case

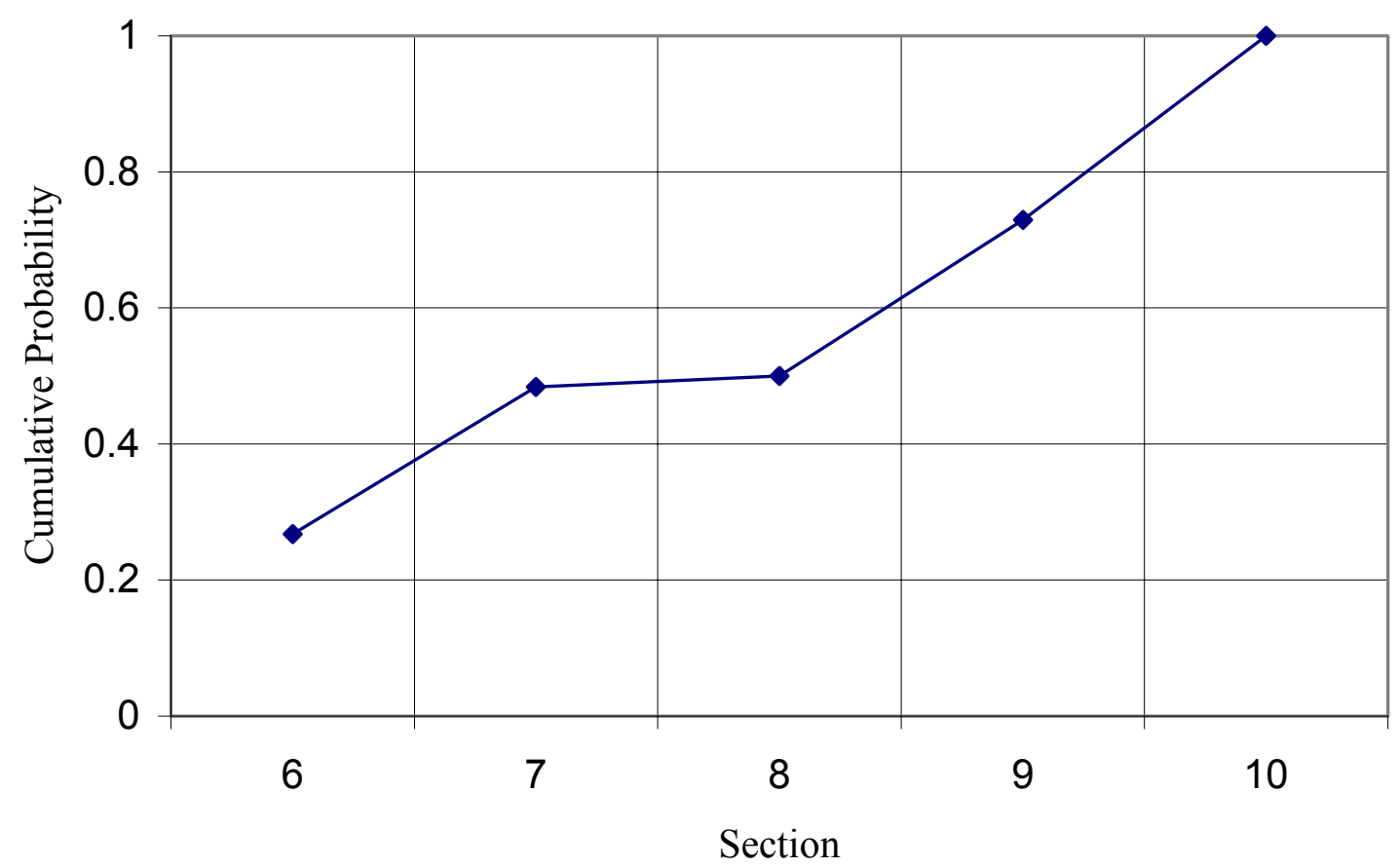

Figure A-3.2: Probability function for Modified-Deflector case. 


\section{Appendix IV}

\section{Blotting paper Experiment}

The objective of this experiment was to examine the spray shape and the direction of the spray material in the fluidizing bed. A piece of white blotting paper, big enough to cover the whole area of the draft tube wall as shown in Figure A-4.1, was glued to the inner draft tube wall.

The fluidized bed, without any particles, was run at a fluidizing air velocity rate equal to that used in the pulse test. Then the colored solution was sprayed into the fluidizing bed for a few minutes, during which the direction of the spray material and the spray shape were carefully observed.

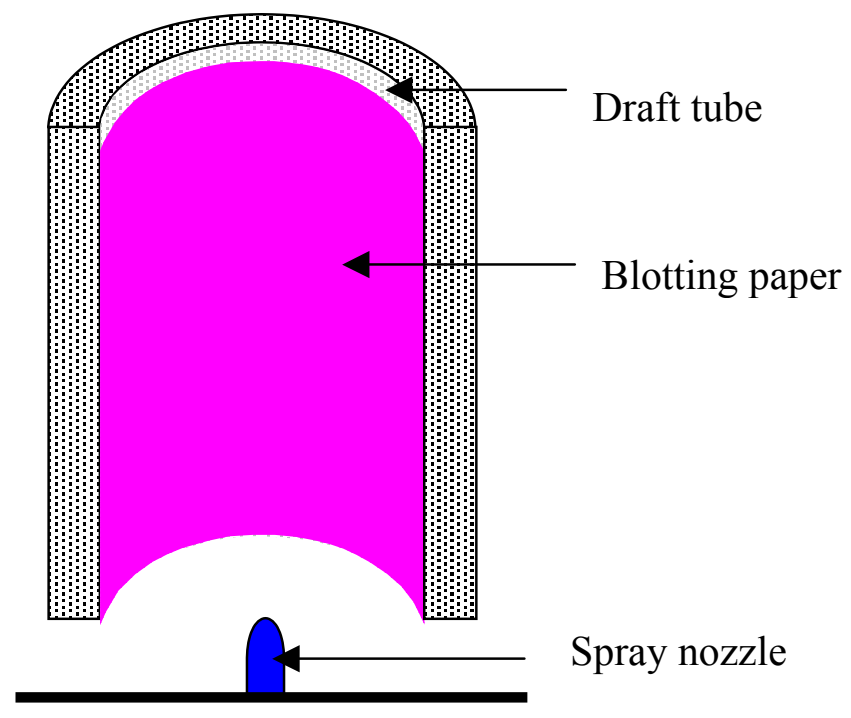

Figure A-4.1: Schematic diagram shows blotting paper on the draft tube wall.

The results are as follows: 
- The blotting paper was wet and stained by the colored solution all over the draft tube region. This shows that there was no specific area or spot concentrated with spray material.

- The traces of colored solution on the blotting paper indicated that spray flowed vertically from the bottom to the top of the bed, as shown in Figure A-4.2.

- From visual observation at the front face of the glass wall of the semi-circular fluidized bed, the cloud of spray material close to the spray nozzle formed a cone shape. The spray material flowed at a certain angle axially from the spray nozzle. The angle of the spray material flow slowly changed until it reached a certain distance from the bottom of the bed, the direction of the flow was then vertically upward as shown in Figure A-4.3. This demonstrated that, the fluidizing air flow rate, which is greater than the flow rate of the atomizing air (through the spray nozzle) dragged the spray material upwards. 


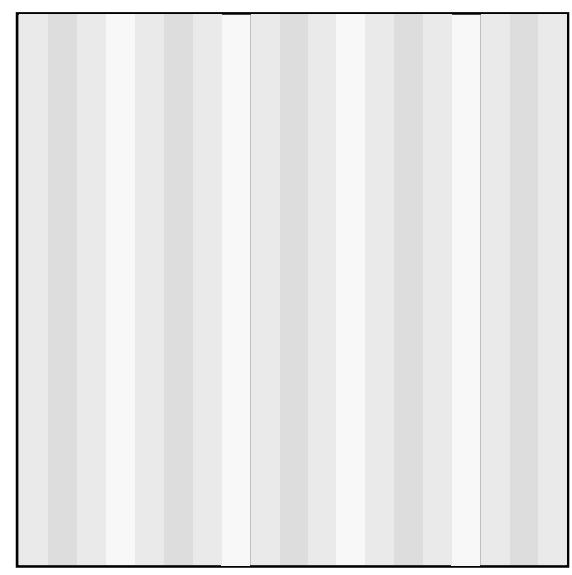

Figure A-4.2: Schematic diagram illustrates the trace of spray material on the blotting paper.

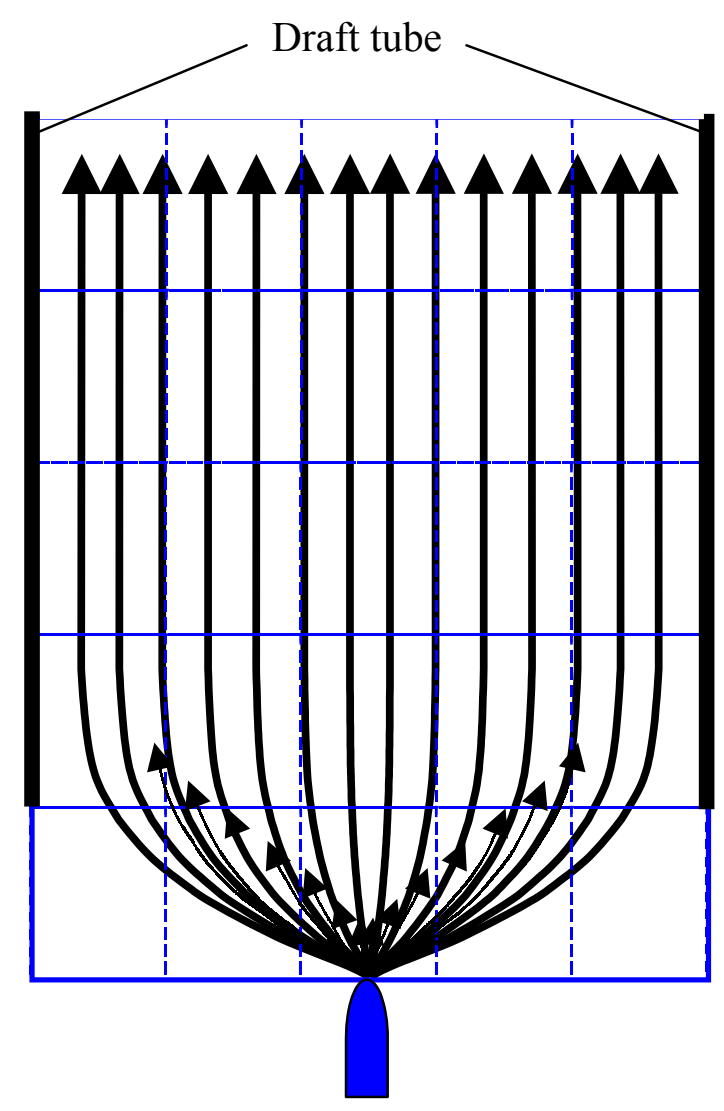

Figure A-4. 3: The arrows indicate the flow direction of the spray material in the vicinity of the spray zone during the bed was fluidizing. 


\section{Appendix V}

\section{Spray Test Report}

A semi-circular two-fluid nozzle was sent to Spraying System Co. to determine the spray characteristics when spraying a 1:1 ratio of Aquacoat ECD-ethyl cellulose solution and water. The objectives of the test were:

- To evaluate the spray pattern of the spray nozzle configuration as used in the coating process.

- To determine the effect of experimental operating parameters: coating solution flow rate and atomizing pressure on spray-pattern uniformity and drop size.

The tests consisted of two parts; droplet size analysis and volume flux measurement. However, only the volume flux data were used in the present work. A traditional single dimension patternator was used to measure the volumetric distribution using 1 in. $^{2}$ x 7.5 in. collection channel. The nozzle was centered directly above a channel divider at a distance of $5.5 \mathrm{in}$. In order to provide a wide enough collection area to ensure that the entire spray was captured, the volumetric collection tubes were positioned to $12 \mathrm{in}$. on both sides of the nozzle. The nozzle was spraying from the zero position along the axis of measurement for 5 minutes.

The results of the test can be summarized as follows:

- The spray density varies axially from the spray nozzle and does not have a symmetric spray pattern. 
- The spray density varies at different atomizing air pressure. Figure A-5.1, A-5.2, and A-5.3 show the overall spray distribution obtained by the experiment for 30 , 40 and 50 psi atomizing air respectively.

- The spray angle decreases as the air pressure is increased.

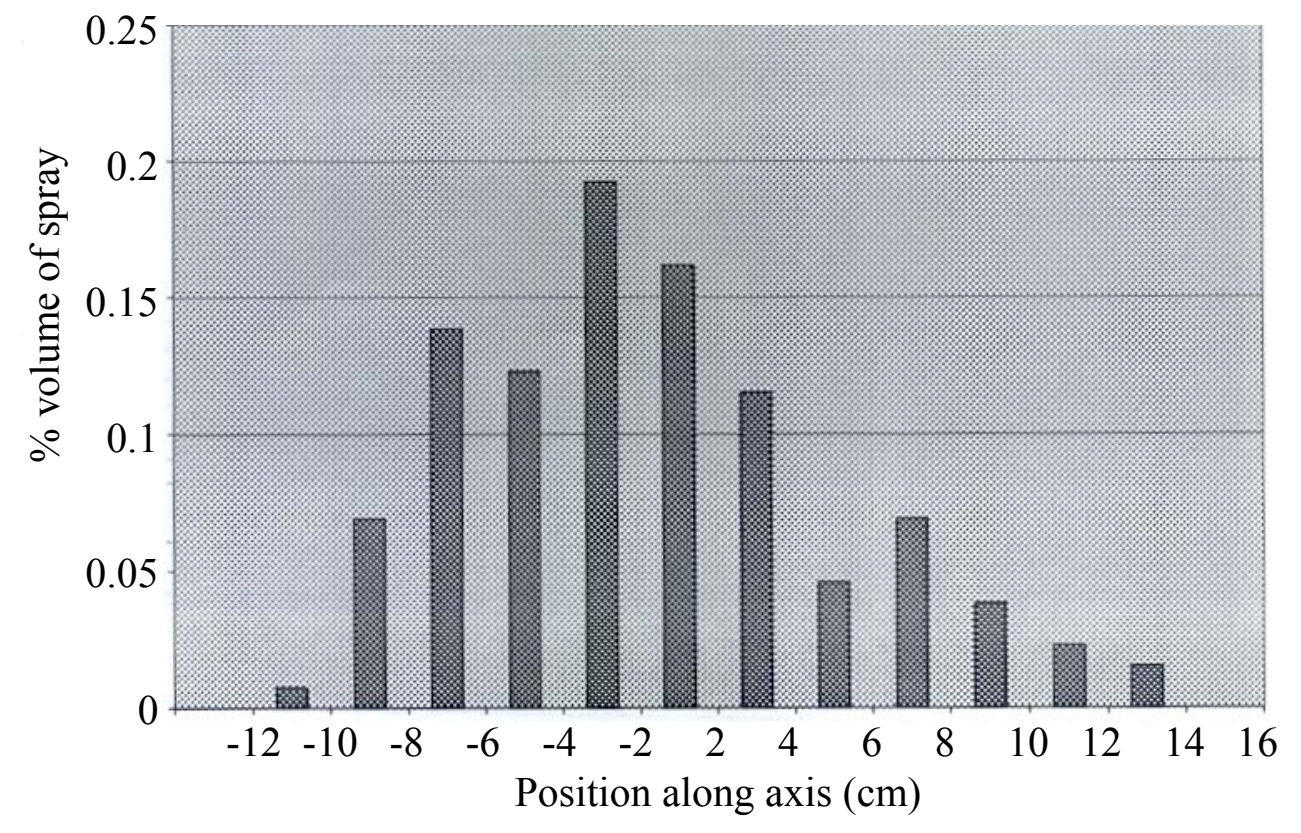

Figure A-5.1: The spray distribution for $30 \mathrm{psi}$ atomizing air pressure. 


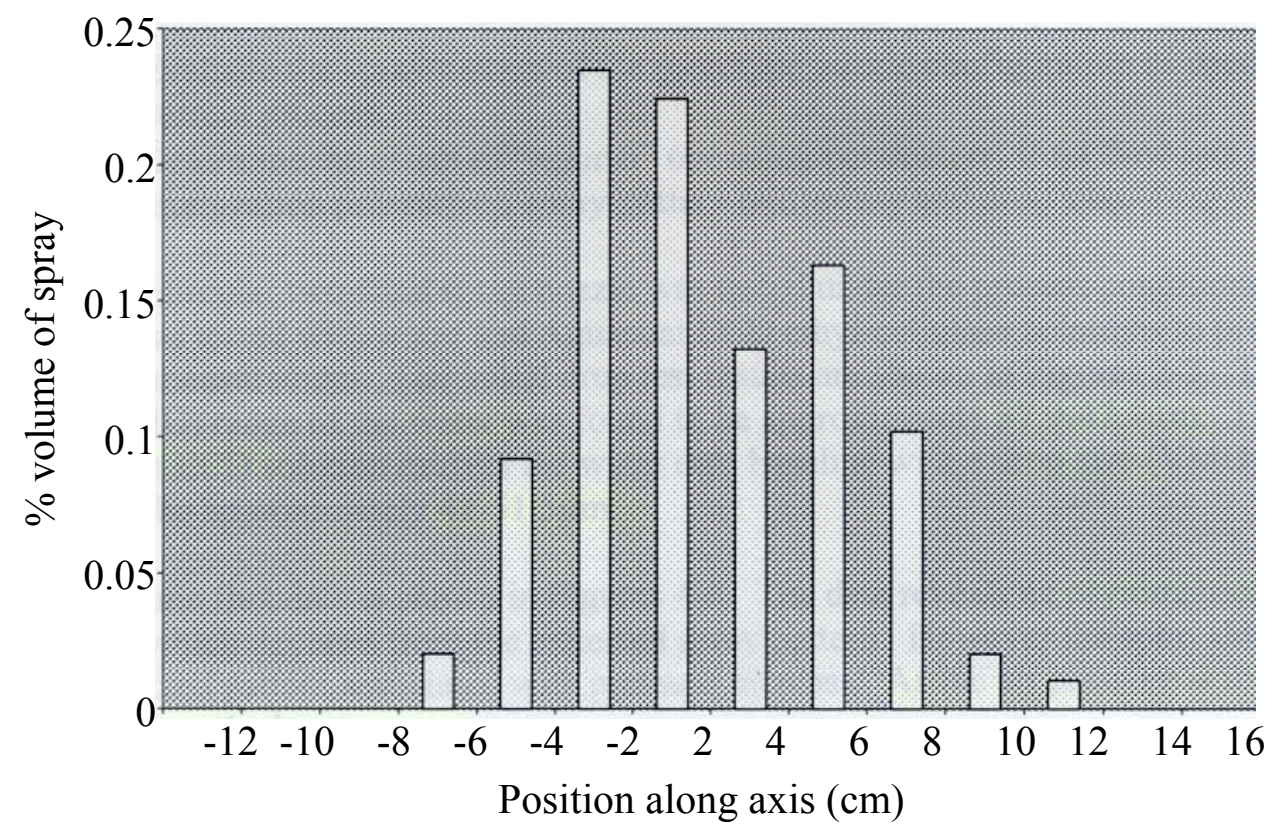

Figure A-5.2: The spray distribution of $40 \mathrm{psi}$ atomizing air pressure

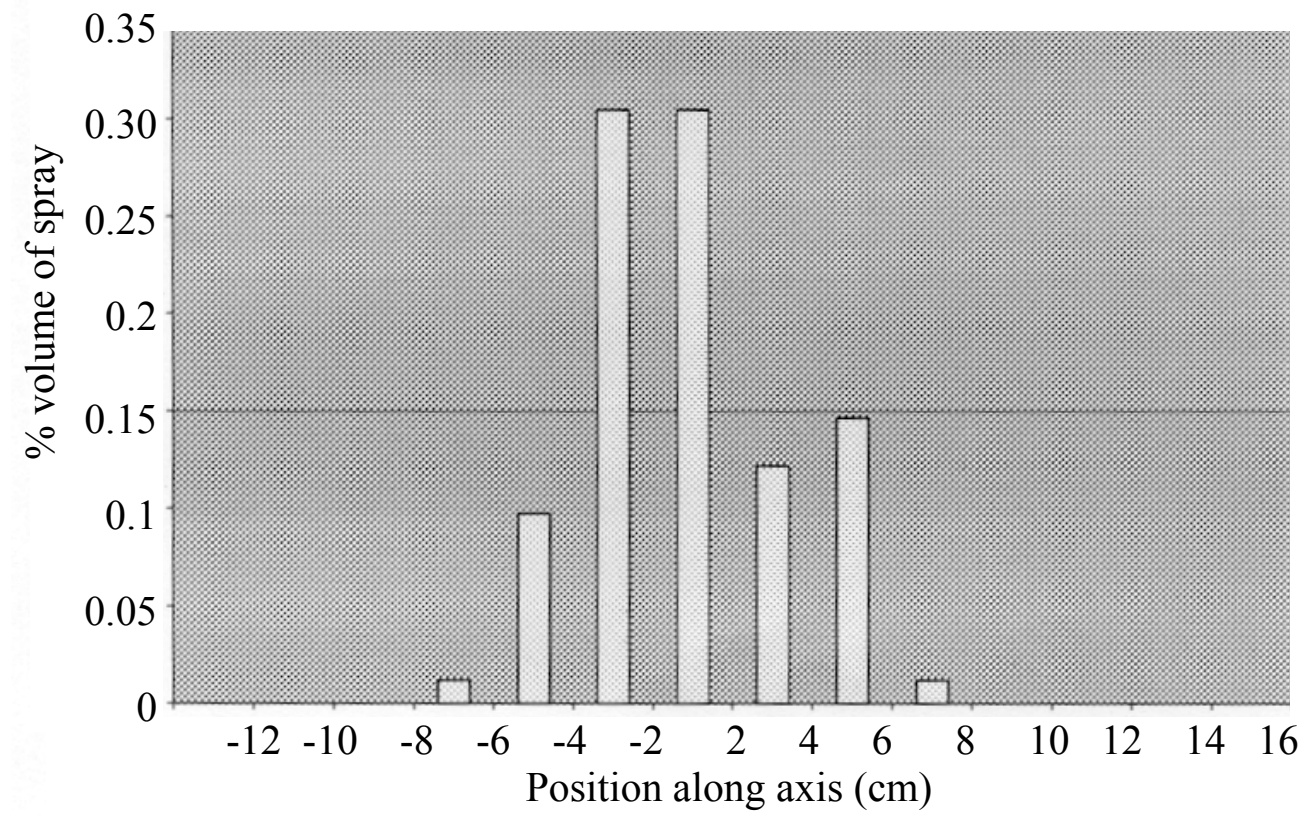

Figure A-5.3: The spray distribution of $50 \mathrm{psi}$ atomizing air pressure. 


\section{Appendix VI}

\section{Subramanian's Experimental Matrix}

Table A-6.1: Experimental matrix for the velocity and voidage profile study (Subramanian, 2001).

\begin{tabular}{|c|c|c|c|c|c|c|}
\hline \multirow{2}{*}{ Run } & \multirow{2}{*}{$\begin{array}{c}\text { Distributor } \\
\text { Plate }\end{array}$} & \multirow{2}{*}{$\begin{array}{c}\text { Gas Flow } \\
\left(\mathrm{m}^{3} / \mathrm{s}\right)\end{array}$} & \multirow{2}{*}{$\begin{array}{l}\text { Gap } \\
\text { Height } \\
(\mathrm{m})\end{array}$} & \multicolumn{3}{|c|}{ Deflector Type } \\
\hline & & & & Deflector & $\begin{array}{l}\text { Modified } \\
\text { Deflector }\end{array}$ & $\begin{array}{c}\text { No } \\
\text { Deflector }\end{array}$ \\
\hline 1 & 1 & 0.0649 & $\begin{array}{l}0.027 \\
\text { (“1”) }\end{array}$ & Y & - & - \\
\hline 2 & 1 & 0.0684 & $\begin{array}{l}0.027 \\
\text { ("1") }\end{array}$ & - & $\mathrm{Y}$ & - \\
\hline 3 & 1 & 0.0686 & $\begin{array}{l}0.027 \\
\text { (“1”) }\end{array}$ & - & - & $\mathrm{Y}$ \\
\hline 4 & 1 & 0.0695 & $\begin{array}{l}0.074 \\
\text { (“2") }\end{array}$ & Y & - & - \\
\hline 5 & 1 & 0.0684 & $\begin{array}{l}0.074 \\
\text { (“2”) }\end{array}$ & - & $\mathrm{Y}$ & - \\
\hline 6 & 1 & 0.0707 & $\begin{array}{l}0.074 \\
\text { (“2”) }\end{array}$ & - & - & Y \\
\hline 7 & 2 & 0.0684 & $\begin{array}{l}0.074 \\
\text { ("2") }\end{array}$ & - & - & $\mathrm{Y}$ \\
\hline 8 & 1 & 0.0766 & $\begin{array}{l}0.074 \\
\text { (“2”) }\end{array}$ & - & $\mathrm{Y}$ & - \\
\hline
\end{tabular}




\section{Appendix VII}

\section{Sample Calculation for the Uniform Voidage/Velocity Data}

Original voidage data in each section

\begin{tabular}{|l|l|l|l|l|l|}
\hline 66 & 67 & 68 & 69 & 70 & \\
$\varepsilon_{66}$ & $\varepsilon_{67}$ & $\varepsilon_{68}$ & $\varepsilon_{69}$ & $\varepsilon_{70}$ & \\
\hline$\ldots$ & $\ldots$ & $\ldots$ & $\ldots$ & $\ldots$ & \\
\hline 11 & 12 & 13 & 14 & 15 \\
$\varepsilon_{11}$ & $\varepsilon_{12}$ & $\varepsilon_{13}$ & $\varepsilon_{14}$ & $\varepsilon_{15}$ & \\
\hline 6 & 7 & 8 & 9 & 10 & \\
$\varepsilon_{6}$ & $\varepsilon_{7}$ & $\varepsilon_{8}$ & $\varepsilon_{9}$ & $\varepsilon_{10}$ & \\
\hline
\end{tabular}

$\varepsilon_{\text {ave }}=\frac{\varepsilon_{6}+\varepsilon_{7}+\ldots+\varepsilon_{70}}{65}$

Uniform voidage data in each section

\begin{tabular}{|c|c|c|c|c|}
\hline $\begin{array}{l}66 \\
\varepsilon_{\text {ave }}\end{array}$ & $\begin{array}{l}67 \\
\varepsilon_{\text {ave }}\end{array}$ & $\begin{array}{l}68 \\
\varepsilon_{\text {ave }}\end{array}$ & $\begin{array}{l}69 \\
\varepsilon_{\text {ave }}\end{array}$ & $\begin{array}{l}70 \\
\varepsilon_{\text {ave }}\end{array}$ \\
\hline$\ldots$ & $\ldots$ & $\ldots$ & $\ldots$ & $\ldots$ \\
\hline $\begin{array}{l}11 \\
\varepsilon_{\text {ave }}\end{array}$ & $\begin{array}{l}12 \\
\varepsilon_{\text {ave }}\end{array}$ & $\begin{array}{l}13 \\
\varepsilon_{\text {ave }}\end{array}$ & $\begin{array}{c}14 \\
\varepsilon_{\text {ave }}\end{array}$ & $\begin{array}{c}15 \\
\varepsilon_{\text {ave }}\end{array}$ \\
\hline $\begin{array}{l}6 \\
\varepsilon_{\text {ave }}\end{array}$ & $\begin{array}{l}7 \\
\varepsilon_{\text {ave }}\end{array}$ & $\begin{array}{l}8 \\
\varepsilon_{\text {ave }}\end{array}$ & $\begin{array}{l}9 \\
\varepsilon_{\text {ave }}\end{array}$ & $\begin{array}{l}10 \\
\varepsilon_{\text {ave }}\end{array}$ \\
\hline
\end{tabular}




\section{APPENDIX VIII}

\section{Chi-square Analysis}

Table A-8.1: Chi-square analysis between experimental pulse test data and simulation results for No-Deflector case using Case I spray distribution.

\begin{tabular}{|c|c|c|c|c|c|}
\hline Data & $\begin{array}{l}\text { Observed (O) } \\
\text { EXPERIMENT* }\end{array}$ & $\begin{array}{l}\text { Expected (E) } \\
\text { SIMULATION* }\end{array}$ & O-E & $(\mathrm{O}-\mathrm{E})^{2}$ & $\mathrm{X}^{2}\left[(\mathrm{O}-\mathrm{E})^{2}\right] / \mathrm{E}$ \\
\hline 1 & 25 & 23 & 2 & 4 & 0.17391304 \\
\hline 2 & 58 & 50 & 8 & 64 & 1.28 \\
\hline 3 & 13 & 14 & -1 & 1 & 0.07142857 \\
\hline 4 & 2 & 7 & -5 & 25 & 3.57142857 \\
\hline 5 & 1 & 3 & -2 & 4 & 1.33333333 \\
\hline 6 & 1 & 1 & 0 & 0 & 0 \\
\hline 7 & 0 & 1 & -1 & 1 & 1 \\
\hline
\end{tabular}

* Data in this table is taken from data used in Figure 5.28.

Degree of Freedom $(\mathrm{df}) \quad=\quad(\#$ rows -1$)(\#$ column -1$)$

$$
\begin{aligned}
& =\quad(7-1)(2-1) \\
& =6
\end{aligned}
$$

The critical values for Chi-square distribution with 6 degree of freedom at $\mathrm{P}<0.05$ is 12.592. Comparing this value with the calculated value of 7.4301 , therefore we can say that the results from those two groups of data namely 'simulation' and 'experiment' are not statistically significant. 


\section{Appendix IX}

\section{Visual Basic ${ }^{\circledR}$ Program}

Below are the code used in the program. Note that the declaration of the variables was made in the separate module, which is not shown here.

1. Code for the calculation of the particle movement as well as the amount of spray received by the particle.

'THIS PROGRAM IS TO CALCULATE THE SPRAY FRACTION RECEIVED BY PARTICLES IN ONE PATH THRU THE SPRAY ZONE

Private Sub cmdCalculate_Click()

Randomize

'To open the input data from the text file

counter $=$ Val(frmOpenData.txtRecNo)

frmOpenData.grdData.Col $=1$

For $\mathrm{e}=1$ To counter Step 1

frmOpenData.grdData.Row $=\mathrm{e}$

$\mathrm{v}(\mathrm{e})=\mathrm{Val}$ (frmOpenData.grdData.Text) 'local velocity in the $y$-direction

Next e

frmOpenData.grdData.Col $=2$

For $\mathrm{e}=1$ To counter Step 1

frmOpenData.grdData.Row $=\mathrm{e}$

sy(e) = Val(frmOpenData.grdData.Text) 'stdev. of the local velocity in the $y$-direction Next e

frmOpenData.grdData.Col $=3$

For $\mathrm{e}=1$ To counter Step 1

frmOpenData.grdData.Row $=\mathrm{e}$

$\mathrm{u}(\mathrm{e})=\mathrm{Val}($ frmOpenData.grdData.Text) 'local velocity in the $x$-direction

Next e

frmOpenData.grdData.Col $=4$

For $\mathrm{e}=1$ To counter Step 1

frmOpenData.grdData. Row $=\mathrm{e}$ 
$\operatorname{sx}(\mathrm{e})=\mathrm{Val}($ frmOpenData.grdData.Text) 'stdev of the local velocity in the $x$-direction

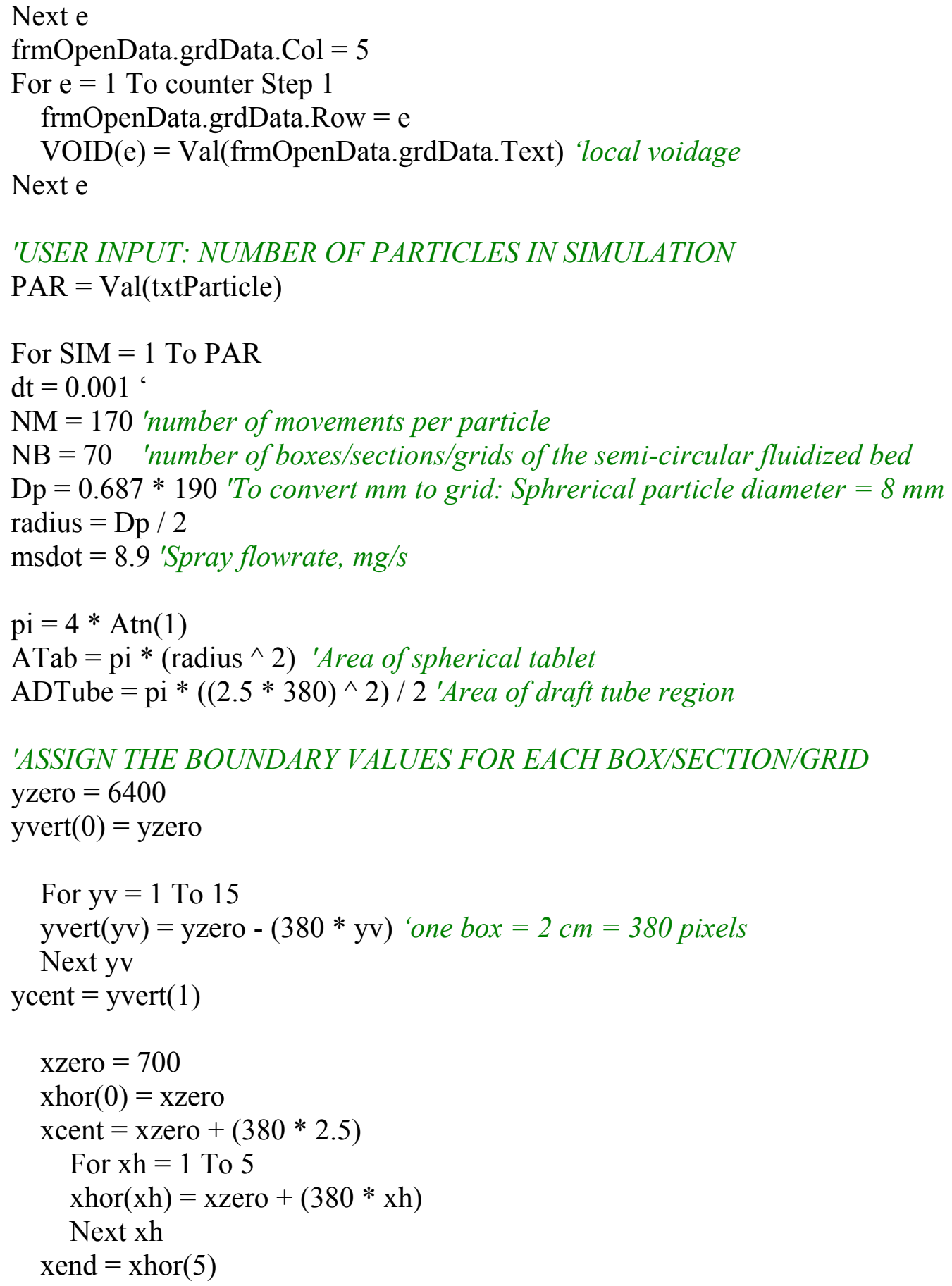


$\operatorname{rad} 2=3$ 'outer radius of section 2 in $\mathrm{cm}$ $\operatorname{rad} 3=1$ 'outer radius of section 3 in $\mathrm{cm}$ rad4 $=3$ 'outer radius of section 4 in $\mathrm{cm}$ $\operatorname{rad} 5=5$ 'outer radius of section 5 in $\mathrm{cm}$

$$
\begin{aligned}
& \text { Mass flowrate, unit=m3/s } \\
& \operatorname{mf}(1)=\mathrm{pi} / 4 *\left((\operatorname{rad} 1 \wedge 2)-\left(\operatorname{rad} 2^{\wedge} 2\right)\right) * \mathrm{v}(1+5) *(1-\operatorname{VOID}(1+5)) * 100 \\
& \operatorname{mf}(2)=\mathrm{pi} / 4 *((\operatorname{rad} 2 \wedge 2)-(\operatorname{rad} 3 \wedge 2)) * \mathrm{v}(2+5) *(1-\operatorname{VOID}(2+5)) * 100 \\
& \operatorname{mf}(3)=\mathrm{pi} / 4 *((\operatorname{rad} 3 \wedge 2)) * \mathrm{v}(3+5) *(1-\operatorname{VOID}(3+5)) * 100 \\
& \operatorname{mf}(4)=\mathrm{pi} / 4 *((\operatorname{rad} 4 \wedge 2)-(\operatorname{rad} 3 \wedge 2)) * \mathrm{v}(4+5) *(1-\operatorname{VOID}(4+5)) * 100 \\
& \operatorname{mf}(5)=\mathrm{pi} / 4 *((\operatorname{rad} 5 \wedge 2)-(\operatorname{rad} 4 \wedge 2)) * \mathrm{v}(5+5) *(1-\operatorname{VOID}(5+5)) * 100 \\
& \quad \mathrm{TM}=\operatorname{mf}(1)+\operatorname{mf}(2)+\operatorname{mf}(3)+\operatorname{mf}(4)+\operatorname{mf}(5)
\end{aligned}
$$

$$
\begin{aligned}
& \operatorname{PRB}(0)=0 \\
& \text { For bil }=1 \text { To } 5
\end{aligned}
$$$$
\mathrm{PRB}(\text { bil })=(\mathrm{mf}(\text { bil }) / \mathrm{TM})+\mathrm{PRB}(\text { bil }-1)
$$$$
\mathrm{S}(\mathrm{bil})=(\mathrm{PRB}(\mathrm{bil})-\mathrm{PRB}(\mathrm{bil}-1)) /(\text { bil }-(\text { bil - 1) }) \text { 'slope of the line }
$$$$
\mathrm{c}(\mathrm{bil})=\mathrm{PRB}(\text { bil })-(\mathrm{S}(\mathrm{bil}) * \text { bil) 'intersect at } y \text {-axiz: } c=y \text { - } m x
$$

Next bil

'2) Generate uniform random numbers $0<z<1$ to determine a starting point

\section{Randomize}

$100 \quad \mathrm{Z}=$ Rnd

'OPTION: Enable - Manually select a number between 0-1 to manually determine the starting point at equal distance

'For $\mathrm{ZS}=1$ To PAR

$' \mathrm{Z}(\mathrm{ZS})=\mathrm{ZS} / \mathrm{PAR}$

'Next ZS

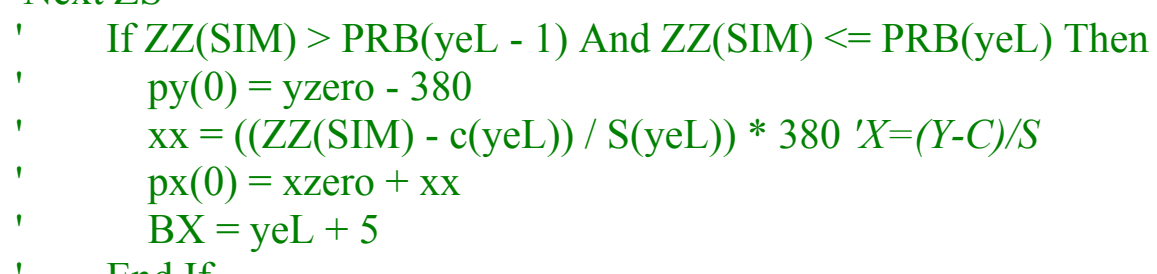

\section{End If}

For yeL $=1$ To 5

$$
\begin{aligned}
& \text { If } Z>P R B(y e L-1) \text { And } Z<=P R B(y e L) \text { Then } \\
& \text { py(0)=yzero }-380 \\
& \quad x x=((Z-c(y e L)) / S(y e L)) * 380^{\prime} X=(Y-C) / S \\
& \operatorname{px}(0)=x z e r o+x x \\
& B X=y e L+5 \\
& \text { End If }
\end{aligned}
$$

Next yeL 


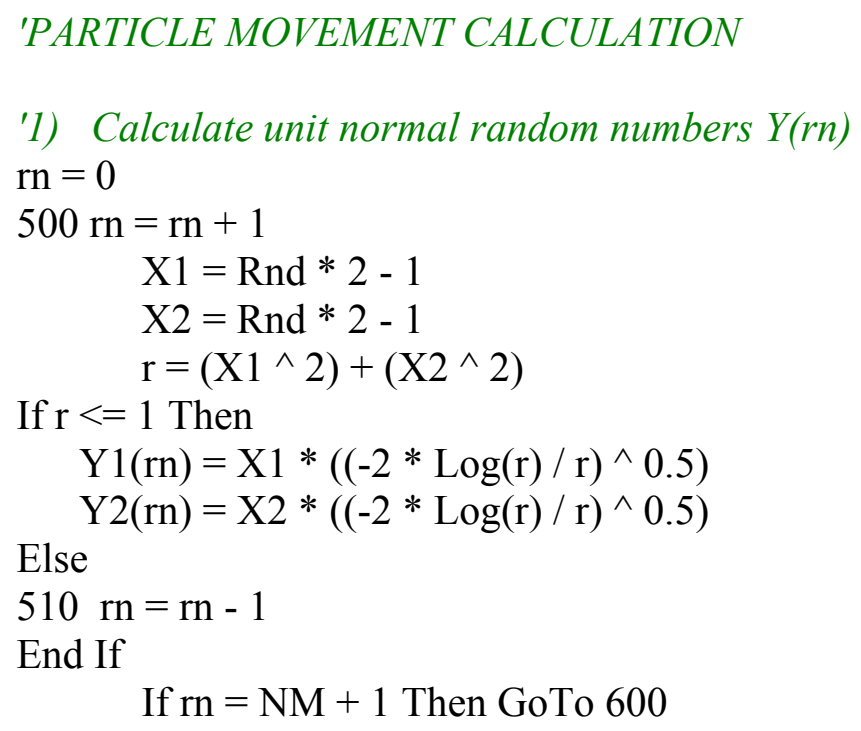

rin $=\mathrm{Rnd}$ 'to assign a random number so that can be used to randomly select the line color for each particle.

'Start a PARTICLE MOVEMENT loop

For $\mathrm{m}=1$ To NM

'Velocity

$\mathrm{Vy}(\mathrm{m})=(\operatorname{sy}(\mathrm{KOT}(\mathrm{m})) * \mathrm{Y} 2(\mathrm{~m}))+\mathrm{v}(\mathrm{KOT}(\mathrm{m}))$

$\mathrm{Vx}(\mathrm{m})=(\mathrm{sx}(\mathrm{KOT}(\mathrm{m})) * \mathrm{Y} 1(\mathrm{~m}))+\mathrm{u}(\mathrm{KOT}(\mathrm{m}))$

'Calc next point - Delta $X$

$\mathrm{px}(\mathrm{m})=\mathrm{px}(\mathrm{m}-1)+(\mathrm{Vx}(\mathrm{m}) * 100 * 190 * \mathrm{dt})$

$\operatorname{py}(\mathrm{m})=\operatorname{py}(\mathrm{m}-1)-(\mathrm{Vy}(\mathrm{m}) * 100 * 190 * \mathrm{dt})$

If py(m) $<700$ Then GoTo 5000

'Specify the particle location (which box/section/grid) - outside of the spray zone 'Horizontal test

For $\mathbf{J}=1$ To 5 
If $\mathrm{px}(\mathrm{m})>=\operatorname{xhor}(\mathrm{J}-1)$ And $\mathrm{px}(\mathrm{m})<\operatorname{xhor}(\mathrm{J})$ Then

$\mathrm{HL}=\mathrm{J}$

End If

Next J

'Vertical test

For $\mathrm{k}=1$ To 15

If $p y(m)<\operatorname{yvert}(k-1)$ And py $(m)>=\operatorname{yvert}(k)$ Then

$\mathrm{VL}=\mathrm{k}$

End If

Next k

$\operatorname{boox}(\mathrm{m})=((\mathrm{VL}-1) * 5)+\mathrm{HL}$

$\operatorname{KOT}(\mathrm{m}+1)=\operatorname{boox}(\mathrm{m})$ 'the box/section/grid number at which the particle is located

'Particle Collision with wall

If $\mathrm{px}(\mathrm{m})<700$ Then $\mathrm{px}(\mathrm{m})=700+(700-\mathrm{px}(\mathrm{m}))$

If $\mathrm{px}(\mathrm{m})>(700+(380 * 5))$ Then $\mathrm{px}(\mathrm{m})=(700+(380 * 5))-((\mathrm{px}(\mathrm{m})-(700+(380 *$

5))))

If $p y(m)>6020$ Then $p y(m)=6020$

'If py $(\mathrm{m})<6020-(380 * 15)$ Then py $(\mathrm{m})=6400-(380 * 15)$

2000 'SPRAY ZONE: CALCULATING SPRAY MATERIAL DEPOSITED ONTO THE PARTICLE

'To calc length of center line $\mathrm{CO}$

$\mathrm{CO}(\mathrm{m})=\mathrm{ycent}-\mathrm{py}(\mathrm{m})$ 'discretize normal to the bottom of the bed

'To specify each point of the divided section of spray

$2200 \operatorname{DIVV}(\mathrm{m})=\mathrm{CO}(\mathrm{m}) / 2$

$\mathrm{DIV}=\operatorname{DIVV}(\mathrm{m})$

'To discretize the projected spray area

DivLine $(0)=0$

For kt $=1$ To DIV

$\operatorname{DivLine}(\mathrm{kt})=(\mathrm{CO}(\mathrm{m}) / \mathrm{DIV} * \mathrm{kt})$

$\operatorname{DivCtrPt}(\mathrm{kt})=((\operatorname{DivLine}(\mathrm{kt})-\operatorname{DivLine}(\mathrm{kt}-1)) / 2)+\operatorname{DivLine}(\mathrm{kt}-1)$

$\operatorname{PtY}(k t)=$ ycent $-\operatorname{DivCtrPt}(k t)$

$\operatorname{PtX}(\mathrm{kt})=\operatorname{px}(\mathrm{m})$

'Specify the particle location (which box/section/grid) - in the spray zone

'Horizontal test

For JK $=1$ To 5 


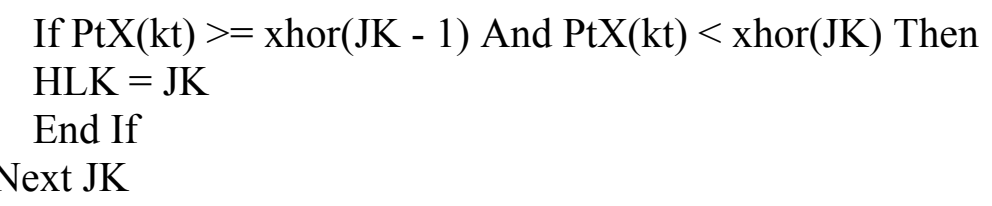

'Vertical test

For $\mathrm{kK}=1$ To 15

If $\mathrm{PtY}(\mathrm{kt})<\operatorname{yvert}(\mathrm{kK}-1)$ And $\mathrm{PtY}(\mathrm{kt})>=\operatorname{yvert}(\mathrm{kK})$ Then $\mathrm{VLK}=\mathrm{kK}$

End If

Next kK

particle is located

$\mathrm{bK}(\mathrm{kt})=((\mathrm{VLK}-1) * 5)+\mathrm{HLK}$ 'the box/section/grid number at which the

'To calculate volume of section $k$

$\operatorname{Area}(0)=0$

$\mathrm{rR}(\mathrm{kt})=$ radius

Area $(\mathrm{kt})=\mathrm{pi} * \mathrm{rR}(\mathrm{kt}) \wedge 2$ 'Cross sectional area of section $k$

$\operatorname{Vol}(\mathrm{kt})=\operatorname{Area}(\mathrm{kt}) * \operatorname{DivLine}(\mathrm{kt})$ 'Volume of all the section up to section $k$

$\operatorname{VolSec}(\mathrm{kt})=\operatorname{Vol}(\mathrm{kt})-\operatorname{Vol}(\mathrm{kt}-1)$ 'Volume of section $k$ only

'To calc fraction of spray passes thru section $k$

$\mathrm{Vp}(\mathrm{kt})=\operatorname{VolSec}(\mathrm{kt}) *(1-\operatorname{VOID}(\mathrm{bK}(\mathrm{kt})))$ 'Vp is the vol. of particle in sect. $k$ $\mathrm{Np}(\mathrm{kt})=\mathrm{Vp}(\mathrm{kt}) /\left(\left(\mathrm{pi} *\left((\mathrm{Dp})^{\wedge} 3\right)\right) / 6\right)$ 'Np is the \# of particles in section $k$ $\mathrm{Ap}(\mathrm{kt})=\mathrm{Np}(\mathrm{kt}) *\left(\mathrm{pi} / 4 *\left(\mathrm{Dp}^{\wedge} 2\right)\right)$ 'Projected Surface Area in section $k$ AveArea $(\mathrm{kt})=(\operatorname{Area}(\mathrm{kt})+\operatorname{Area}(\mathrm{kt}-1)) / 2$

$\mathrm{f}(\mathrm{kt})=1-(\mathrm{Ap}(\mathrm{kt}) /$ AveArea $(\mathrm{kt}))$ 'Fraction of spray in section $k$ $\mathrm{FS}(0)=1$

Next kt

$\mathrm{FS}(\mathrm{kt})=\mathrm{f}(\mathrm{kt}) * \mathrm{FS}(\mathrm{kt}-1)$ 'Total fraction of spray in section $k$

\footnotetext{
'Spray density is not uniform

If $\mathrm{px}(\mathrm{m})>700$ And $\mathrm{px}(\mathrm{m})<(700+(190 * 1))$ Then GoTo 2901

If $\mathrm{px}(\mathrm{m})>(700+(190 * 1))$ And $\mathrm{px}(\mathrm{m})<(700+(190 * 2))$ Then GoTo 2902

If $\mathrm{px}(\mathrm{m})>(700+(190 * 2))$ And px $(\mathrm{m})<(700+(190 * 3))$ Then GoTo 2903

If $\mathrm{px}(\mathrm{m})>(700+(190 * 3))$ And $\mathrm{px}(\mathrm{m})<(700+(190 * 4))$ Then GoTo 2904

If $\mathrm{px}(\mathrm{m})>(700+(190 * 4))$ And $\mathrm{px}(\mathrm{m})<(700+(190 * 5))$ Then GoTo 2905

If $\mathrm{px}(\mathrm{m})>(700+(190 * 5))$ And $\mathrm{px}(\mathrm{m})<(700+(190 * 6))$ Then GoTo 2906

If $\mathrm{px}(\mathrm{m})>(700+(190 * 6))$ And $\mathrm{px}(\mathrm{m})<(700+(190 * 7))$ Then GoTo 2907

If $\mathrm{px}(\mathrm{m})>(700+(190 * 7))$ And $\mathrm{px}(\mathrm{m})<(700+(190 * 8))$ Then GoTo 2908

If $\mathrm{px}(\mathrm{m})>(700+(190 * 8))$ And px $(\mathrm{m})<(700+(190 * 9))$ Then GoTo 2909

If $\mathrm{px}(\mathrm{m})>(700+(190 * 9))$ And $\mathrm{px}(\mathrm{m})<(700+(190 * 10))$ Then GoTo 2910
} 
'OPTION FOR SPRAY DISTRIBUTION TO BE USED

DIS $=$ Val(txtDistribution)

If DIS $=1$ Then GoTo 2800

IF DIS $=2$ Then GoTo 2900

'Spray fraction is given in each segment (segment=section/2)

2800 'Case I: Spray Distribution:

$2801 \quad$ SpDist $=0.2276$

radist $2=2.5 * 380$

radist $1=2 * 380$

GoTo 2990

$2802 \quad$ SpDist $=0.05632$

radist $2=2 * 380$

radist $1=1.5 * 380$

GoTo 2990

$2803 \quad$ SpDist $=0.0725$

radist $2=1.5 * 380$

radist $1=1 * 380$

GoTo 2990

$2804 \quad$ SpDist $=0.0886$

radist $2=1 * 380$

radist $1=0.5 * 380$

GoTo 2990

$2805 \quad$ SpDist $=0.0852$

radist $2=0.5 * 380$

radist $1=0 * 380$

GoTo 2990

$2806 \quad$ SpDist $=0.0782$

radist $2=0.5 * 380$

radist $1=0 * 380$

GoTo 2990

$2807 \quad$ SpDist $=0.0748$

radist $2=1 * 380$

radist $1=0.5 * 380$

GoTo 2990

$2808 \quad$ SpDist $=0.0639$ 
radist $2=1.5 * 380$

radist $1=1 * 380$

GoTo 2990

2809 SpDist $=0.0531$

radist $2=2 * 380$

radist $1=1.5 * 380$

GoTo 2990

$2810 \quad$ SpDist $=0.1996$

radist $2=2.5 * 380$

radist $1=2 * 380$

GoTo 2990

2900 'Case II Spray distribution

2901 SpDist $=0.0562$

radist $2=2.5 * 380$

radist $1=2 * 380$

GoTo 2990

2902 SpDist $=0.0651$

radist $2=2 * 380$

radist $1=1.5 * 380$

GoTo 2990

2903 SpDist $=0.163$

radist $2=1.5 * 380$

radist $1=1 * 380$

GoTo 2990

2904 SpDist $=0.2076$

radist $2=1 * 380$

radist $1=0.5 * 380$

GoTo 2990

2905 SpDist $=0.2178$

radist $2=0.5 * 380$

radist $1=0 * 380$

GoTo 2990

2906 SpDist $=0.0754$

radist $2=0.5 * 380$

radist $1=0 * 380$

GoTo 2990

2907 SpDist $=0.0708$ 


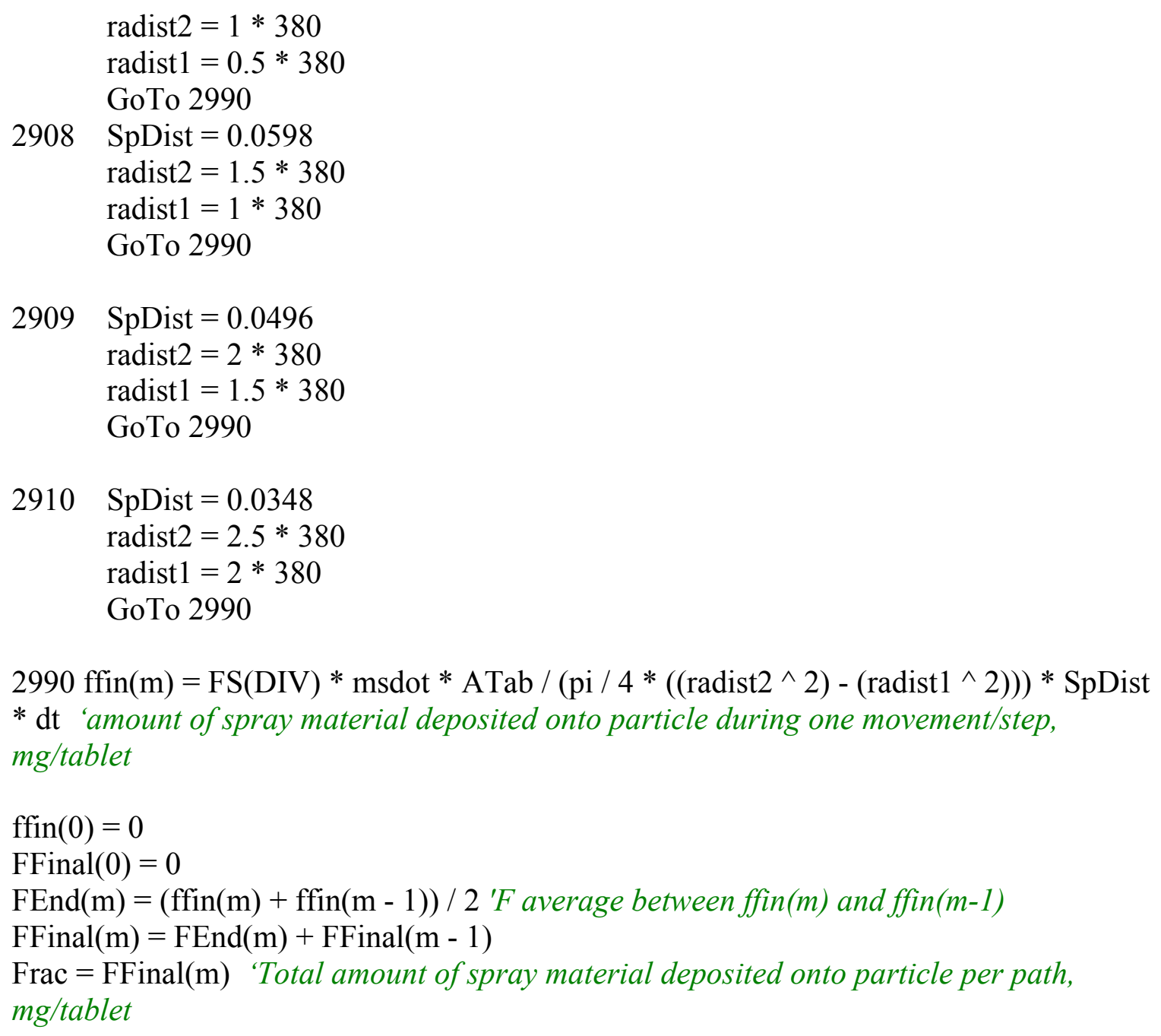

'TO PRINT SPRAY MATERIAL IN THE SPRAY ZONE: 255 is for blue color, whose intensities vary with different amount of spray material received.

If FFinal $(\mathrm{m})<0.9$ And FFinal $(\mathrm{m})>0.8$ Then $\mathrm{hh}=255$

If FFinal $(\mathrm{m})<0.79$ And FFinal $(\mathrm{m})>0.7$ Then $\mathrm{hh}=255-10$

If FFinal $(\mathrm{m})<0.69$ And FFinal $(\mathrm{m})>0.6$ Then $\mathrm{hh}=255-20$

If FFinal $(\mathrm{m})<0.59$ And FFinal $(\mathrm{m})>0.5$ Then $\mathrm{hh}=255-30$

If FFinal $(\mathrm{m})<0.49$ And FFinal $(\mathrm{m})>0.4$ Then $\mathrm{hh}=255-40$

If FFinal $(\mathrm{m})<0.39$ And FFinal $(\mathrm{m})>0.3$ Then $\mathrm{hh}=255-50$

If FFinal $(\mathrm{m})<0.29$ And FFinal $(\mathrm{m})>0.2$ Then $\mathrm{hh}=255-60$

If FFinal $(\mathrm{m})<0.19$ And FFinal $(\mathrm{m})>0.1$ Then $\mathrm{hh}=255-70$

If FFinal $(\mathrm{m})<0.099$ And FFinal $(\mathrm{m})>0.09$ Then $\mathrm{hh}=255-80$

If FFinal $(\mathrm{m})<0.089$ And FFinal $(\mathrm{m})>0.08$ Then $\mathrm{hh}=255-90$

If FFinal $(\mathrm{m})<0.079$ And FFinal $(\mathrm{m})>0.07$ Then $\mathrm{hh}=255-100$

If FFinal $(\mathrm{m})<0.069$ And FFinal $(\mathrm{m})>0.06$ Then $\mathrm{hh}=255-110$

If FFinal $(\mathrm{m})<0.059$ And FFinal $(\mathrm{m})>0.05$ Then $\mathrm{hh}=255-120$ 
If FFinal $(\mathrm{m})<0.049$ And FFinal $(\mathrm{m})>0.04$ Then $\mathrm{hh}=255-130$

If FFinal $(\mathrm{m})<0.039$ And FFinal $(\mathrm{m})>0.03$ Then $\mathrm{hh}=255-140$

If FFinal $(\mathrm{m})<0.029$ And FFinal $(\mathrm{m})>0.02$ Then $\mathrm{hh}=255-150$

If FFinal $(\mathrm{m})<0.019$ And FFinal $(\mathrm{m})>0.01$ Then $\mathrm{hh}=255-160$

If FFinal $(\mathrm{m})<0.0099$ And FFinal $(\mathrm{m})>0.009$ Then $\mathrm{hh}=255-170$

If FFinal $(\mathrm{m})<0.0089$ And FFinal $(\mathrm{m})>0.008$ Then $\mathrm{hh}=255-180$

If FFinal $(\mathrm{m})<0.0079$ And FFinal $(\mathrm{m})>0.007$ Then $\mathrm{hh}=255-190$

If FFinal $(\mathrm{m})<0.0069$ And FFinal $(\mathrm{m})>0.006$ Then $\mathrm{hh}=255-200$

If FFinal $(\mathrm{m})<0.0059$ And FFinal $(\mathrm{m})>0.005$ Then $\mathrm{hh}=255-210$

If FFinal $(\mathrm{m})<0.0049$ And FFinal $(\mathrm{m})>0.004$ Then $\mathrm{hh}=255-220$

If FFinal $(\mathrm{m})<0.0039$ And FFinal $(\mathrm{m})>0.003$ Then $\mathrm{hh}=255-230$

If FFinal $(\mathrm{m})<0.0029$ And FFinal $(\mathrm{m})>0.002$ Then $\mathrm{hh}=255-240$

If FFinal $(\mathrm{m})<0.0019$ And FFinal $(\mathrm{m})>0 \#$ Then $\mathrm{hh}=255-250$

frmLine. DrawMode $=4$ 'specify the style of the line of movements

frmLine.DrawWidth $=3$ specify size of the line of movements

frmLine.Line $(\mathrm{px}(\mathrm{m}), \mathrm{py}(\mathrm{m}))-(\mathrm{px}(\mathrm{m}-1), \mathrm{py}(\mathrm{m}-1)), \mathrm{RGB}(\mathrm{hh}, \mathrm{hh}, 0)$ 'specify the line and the(blue) line intensity depends on the amount of spray received.

GoTo 4000

3000 'Continue

'TO PRINT LINE OF PARTICLE MOVEMENT OUTSIDE OF SPRAY ZONE (FOR A MODEL WITH A CERTAIN SHAPE OF SPRAY ZONE)

'To print line of movement

frmLine.DrawMode $=4$ 'specify the style of the line of movements

frmLine.DrawWidth = 3 specify size of the line of movements

code $=15 *$ rin

frmLine.Line $(\mathrm{px}(\mathrm{m}), \mathrm{py}(\mathrm{m}))-(\mathrm{px}(\mathrm{m}-1), \mathrm{py}(\mathrm{m}-1))$, QBColor(ccode) 'specify the line and the line color randomly varies with particle.

4000 'Continue

Next $\mathrm{m}$ 'to simulate the next movement/step

'To write the calculated data in a form

FSIM $($ SIM $)=$ Frac

frmDistribution.grdFracSpray. Row $=$ SIM

frmDistribution.grdFracSpray.Col $=2$

frmDistribution.grdFracSpray.Text = Format(Frac, "\#\#0.\#000000000")

frmDistribution.grdFracSpray. $\mathrm{Col}=1$

frmDistribution.grdFracSpray.Text $=\operatorname{rr0}(\mathrm{SIM})$

frmDistribution.grdFracSpray. $\mathrm{Col}=0$ 
frmDistribution.grdFracSpray.Text $=$ LOC(SIM)

GoTo 5000

5000 Next SIM 'to simulate another particle

frmDistribution. Show

frmLine.txtnopart $=$ Val $($ txtParticle $)$

'AUTOMATICALLY SAVE CALC. DATA IN AN OUTPUT FILE

Open "d:Ifall02\UpwardSpray\ModDef-ATabADTubeOvDist-p10000-8.9" For Output

As \#500 'Open file for OUTPUT: Pls change to your desired destination file

For $\mathrm{i}=1$ To PAR Step 1

Write \#500, LOC(i), rr0(i); FSIM(i)

Next

Close \#500

End Sub 